\title{
Unravelling fatigue in the working population : course,consquences, and its association with burnout
}

Citation for published version (APA):

Leone, S. S. (2009). Unravelling fatigue in the working population : course,consquences, and its association with burnout. [Doctoral Thesis, Maastricht University]. Wilco.

https://doi.org/10.26481/dis.20090116sl

Document status and date:

Published: 01/01/2009

DOI:

10.26481/dis.20090116sl

Document Version:

Publisher's PDF, also known as Version of record

\section{Please check the document version of this publication:}

- A submitted manuscript is the version of the article upon submission and before peer-review. There can be important differences between the submitted version and the official published version of record.

People interested in the research are advised to contact the author for the final version of the publication, or visit the DOI to the publisher's website.

- The final author version and the galley proof are versions of the publication after peer review.

- The final published version features the final layout of the paper including the volume, issue and page numbers.

Link to publication

\footnotetext{
General rights rights.

- You may freely distribute the URL identifying the publication in the public portal. please follow below link for the End User Agreement:

www.umlib.nl/taverne-license

Take down policy

If you believe that this document breaches copyright please contact us at:

repository@maastrichtuniversity.nl

providing details and we will investigate your claim.
}

Copyright and moral rights for the publications made accessible in the public portal are retained by the authors and/or other copyright owners and it is a condition of accessing publications that users recognise and abide by the legal requirements associated with these

- Users may download and print one copy of any publication from the public portal for the purpose of private study or research.

- You may not further distribute the material or use it for any profit-making activity or commercial gain

If the publication is distributed under the terms of Article $25 \mathrm{fa}$ of the Dutch Copyright Act, indicated by the "Taverne" license above, 


\section{Unravelling fatigue in the working population:}

Course, consequences, and its association with burnout 
Unravelling fatigue in the working population: course, consequences, and its association with burnout

Stephanie Susanah Leone

ISBN:

$978-90-9023748-0$

Cover Milad Kavehzadeh

Lay-out Yvonne Leenders, Epidemiologie, Universiteit Maastricht

Milad Kavehzadeh

Printed by Wilco, Amersfoort

(C) 2008, Stephanie S. Leone

All rights reserved. No part of this thesis may be reproduced or transmitted in any form or by any means, electronic or mechanical, including photocopying, recording or any information storage or retrieval system, without permission in writing from the author, or, when appropriate, from the publishers of the publications. 


\title{
Unravelling fatigue in the working population:
}

Course, consequences, and its association with burnout

\author{
PROEFSCHRIFT
}

Ter verkrijging van de graad van doctor

aan de Universiteit Maastricht,

op gezag van de Rector Magnificus,

Prof. mr. G.P.M.F. Mols,

volgens het besluit van het College van Decanen,

in het openbaar te verdedigen

op vrijdag 16 januari 2009 om 12:00 uur

door

Stephanie Susanah Leone 


\section{Promotor}

Prof. dr. J.A. Knottnerus

\section{Co-promotores}

Dr. ing. IJ. Kant

Prof. dr. M.J.H. Huibers

\section{Beoordelingscommissie}

Prof. dr. M.H. Prins (voorzitter)

Prof. dr. S. Wessely (Institute of Psychiatry, King's College, London)

Prof. dr. M.L. Peters

Prof. dr. R. Vos

Prof. dr. F.R.H. Zijlstra

This project was funded by the Occupational Health Epidemiology programme of the Research Institute Caphri, Maastricht University, The Netherlands and by the Health Research and Development Council (ZorgOnderzoek Nederland), The Netherlands (grant no. 21000104). The Maastricht Cohort Study is part of the Netherlands concerted research action on Fatigue at Work, granted by The Netherlands Organisation for scientific Research (NWO).

The studies presented in this thesis were conducted at the Department of Epidemiology (Maastricht University) under the auspices of the Care and Public Health Research Institute (Caphri). Caphri is part of the Netherlands School of Primary Care Research (CaRe), which has been acknowledged since 1995 by the Royal Netherlands Academy of Arts and Sciences (KNAW).

Financial support for the printing of this thesis was kindly provided by the Department of Epidemiology (Maastricht University) and the Occupational Health Epidemiology programme (Maastricht University). 


\section{Contents}

1 Introduction 9

2 Long-term predictors of outcome in fatigued employees on sick leave: A 4-year follow-up study

3 Long-term efficacy of cognitive-behavioural therapy by general practitioners for fatigue: A 4-year follow-up study

4 Chronic fatigue syndrome-like caseness as a predictor of work status in fatigued employees on sick leave: A 4-year follow-up study

5 Two sides of the same coin? On the history and phenomenology of burnout and chronic fatigue

6 Similarities, overlap and differences between burnout and prolonged fatigue in the working population

7 A comparison of the course of burnout and prolonged fatigue: A 4-year prospective cohort study

8 The prognosis of burnout and prolonged fatigue in the working population: A comparison

9 The temporal relationship between burnout and prolonged fatigue: A 4-year prospective cohort study

10 Discussion

Summary

Samenvatting

Dankwoord

About the author 
Introduction

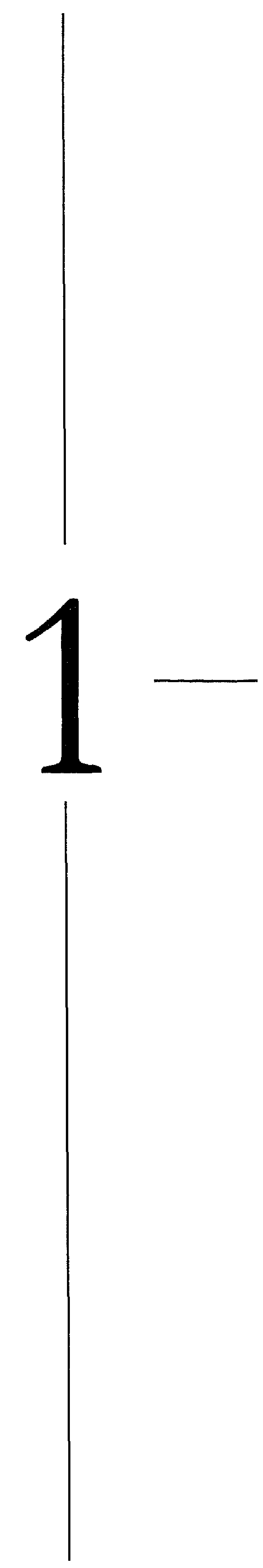




\section{Introduction}

Fatigue is a complex and pervasive concept. It can affect anyone, at any time. In fact, it has been argued that fatigue can be conceptualised along a continuum of severity and duration ${ }^{1}$. In this sense, fatigue can vary in duration and severity ranging from mild fleeting fatigue, which everybody experiences at some point in time, to chronic severe fatigue. Fatigue is also an elusive concept as it is difficult to measure and define ${ }^{2,3}$. Since interest in and study of fatigue began, issues such as its objective or subjective nature, somatic or psychological nature and one-dimensional or multidimensional nature have been the topic of debate ${ }^{3}$. Moreover, fatigue manifests itself in different ways, making it a difficult concept to grasp: it can occur as a symptom alongside another primary medical or psychiatric condition, it can be medically unexplained and it can be the main clinical phenomenon in medical or psychological conditions (e.g. chronic fatigue syndrome) ${ }^{1,4}$. This difficulty still manifests itself today in various measures and conceptualisations of fatigue ${ }^{2,5,6}$. An important historical impulse in the modern interest of fatigue came from the effect it had on employees and their productivity during the industrial revolution ${ }^{7}$. Fatigue was perceived to be a barrier to productivity which needed to be broken through. Therefore, insight into fatigue was deemed necessary and the quest to understand fatigue began ${ }^{7}$. One-hundred years later, fatigue is still an important health problem among employees and many questions remain unanswered. In the Netherlands, the presumed negative effects that fatigue has on employees such as diminished health, sickness absence and work disability, along with the impact it has on employers and society, led to the large scale national concerted research action "Fatigue at Work" ${ }^{8}$. Two studies carried out within the framework of the concerted research action form the basis for the current thesis. The first study is the Maastricht Cohort Study on Fatigue at Work (MCS) and the second, related, study was a randomised controlled trial (RCT) which aimed to assess the efficacy of cognitive behavioural therapy (CBT) for fatigued employees.

\section{Fatigue at work: important questions}

The Maastricht Cohort Study on Fatigue at Work is a prospective cohort study which aimed to gain insight into, among others, the prevalence, aetiology and course of fatigue and associated factors in the working population ${ }^{8,9}$. At baseline, this study included 12,140 employees from 45 different companies and organisations who did not necessarily suffer from (significant) fatigue. The MCS yielded a wealth of information on fatigue in the working population. However, to date the main emphasis in the MCS has been on the aetiology of fatigue and its course has been relatively understudied ${ }^{8}$. Moreover, the interrelatedness of different manifestations of fatigue such as the general fatigue in prolonged fatigue and chronic fatigue syndrome (CFS) and the work-related fatigue in burnout and the implications it could have in terms of course, prognosis and treatment has received relatively little attention. The RCT mentioned above, however, shed a little more 
light on these issues. The aim of the intervention (cognitive behavioural therapy) in the RCT was to reduce fatigue complaints and stimulate work resumption in a sample of 151 severely fatigued employees who were on sick leave for at least 6 weeks ${ }^{10}$. At 12 months of follow-up, it became clear that 1) prolonged fatigue is difficult to treat, 2) prolonged fatigue can be very persistent and 3) that different forms of fatigue, such as in prolonged unexplained fatigue, chronic fatigue syndrome and burnout, overlap to a certain extent ${ }^{11}$. Although these two studies (i.e. the MCS and the RCT) yielded a wealth of information, several important questions remained unanswered. Specifically, this concerns questions about the course of fatigue and the association and relationship of different manifestations of fatigue. What, for example, is the long-term course and prognosis of the relatively severe fatigue found in the trial sample and can a psychological intervention affect the course of this severe fatigue in the long term (i.e. after 12 months)? How does fatigue develop over time in the general working population (i.e. in the MCS sample) and which factors influence its outcome? Are there conceptual or theoretical differences between different fatigue conditions? Do different fatigue conditions also show a different course? Do they have different prognostic factors? How are they related to work status? How are they related in time? If there are differences, what consequences does this have for intervention? If there are no differences, do we still need to make a differential diagnosis?

\section{Research Aims}

Based on the questions outlined above, this thesis has two main aims. The first aim is to focus on and gain insight into the course of fatigue complaints. The second aim is to compare and unravel different manifestations of fatigue in the working population, especially with respect to burnout and prolonged fatigue and to a lesser degree CFS. It will become clear from the chapters of this thesis that these two aims are intertwined with each other as the course will also be examined when trying to unravel different manifestations of fatigue. The ultimate goal of this thesis is to contribute to the knowledge that may help to make informed decisions about treatment and prevention opportunities for (different manifestations of) fatigue complaints. The two aims of this thesis are discussed below in a little more detail. After this, an outline of the chapters of this thesis is presented.

\section{A focus on course}

Fatigue complaints are not either present or absent, but rather they are best understood as ranging on a continuum from mild complaints to severe and debilitating complaints ${ }^{1}$ (figure 1). Examining the course of fatigue and fatigue conditions is important to gain insight into the duration, severity and persistence of complaints. Moreover, examining factors associated with the course allows us to gain insight into possible leads for intervention and 
even prevention if we can prevent significant complaints from progressing to severe and debilitating complaints (figure 1).

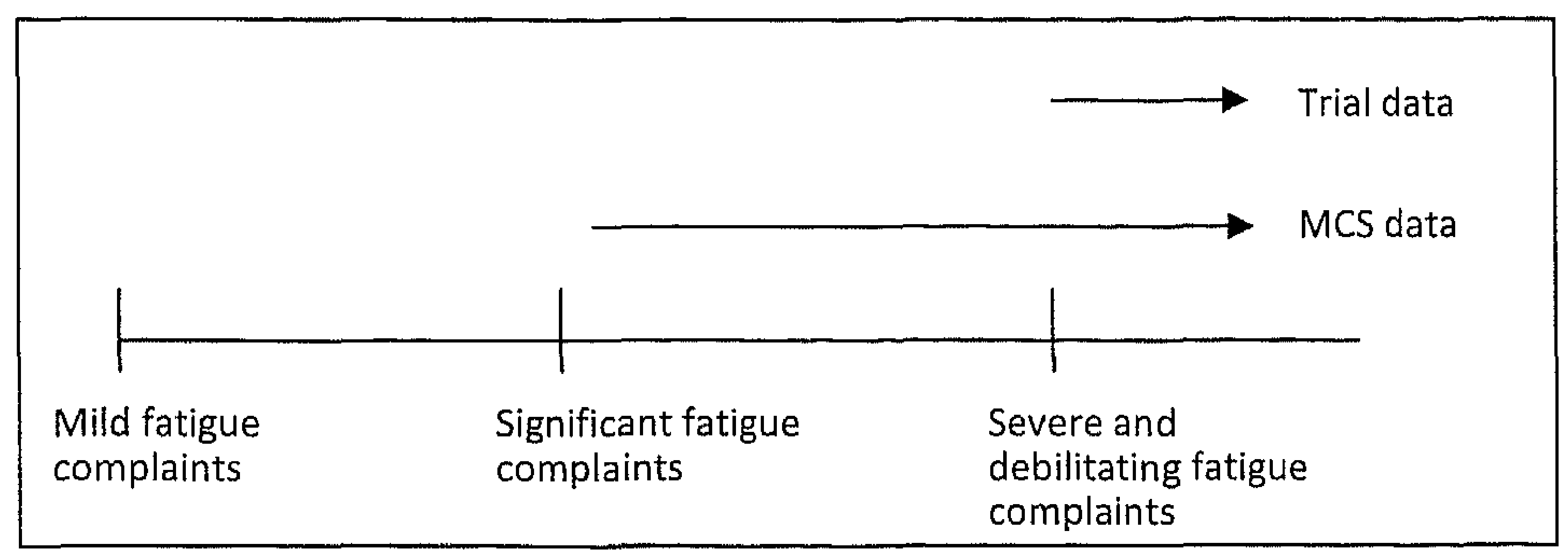

Figure 1 Severity of fatigue complaints and the sample frames under study

Although the course of the more 'medical' manifestations of fatigue such as, CFS, chronic fatigue and prolonged fatigue has received attention across different populations ${ }^{12-16}$, it has not been widely investigated in the working population ${ }^{17-19}$. Research on the work-related fatigue condition 'burnout' has typically focused on aetiology, correlates and consequences. Some studies have focused on the course of burnout ${ }^{20,21}$, but overall the course of burnout has not been widely examined, resulting in a lack of knowledge in this area. CFS, burnout and prolonged fatigue are assumed to be persistent yet, this has been substantiated more widely for CFS and prolonged fatigue than for burnout ${ }^{15,16,18,22-24}$.

An issue in studying the course of a condition is timing. At what stage in the development and severity of the condition do we choose to focus on the course? The two samples described above, the trial sample and the MCS sample, will be used in this thesis. This provides the opportunity to look at varying degrees of severity in the course of fatigue. The trial sample provides us with the opportunity to look at fatigue symptoms in a severe and debilitating form and examine how these symptoms develop and are influenced in the long term. The MCS sample allows us to take a step back in time and start at a less advanced level of fatigue, to see if we can gain insight into the course of fatigue in the period after fatigue complaints become significant, up until and including the severe end of the fatigue spectrum. This will give us a more complete picture of the course of fatigue complaints and may also provide clues for preventing fatigue complaints from moving to the end of the spectrum, thus becoming extremely severe and debilitating.

\section{Unravelling different manifestations of fatigue}

Over the years, many labels and diagnoses have appeared to denote conditions or syndromes in which the symptom of fatigue is the central problem ${ }^{1}$. Examples are: neurasthenia, CFS, ME, burnout, and chronic or prolonged fatigue. In practice, different 
manifestations of fatigue such as in conditions like burnout and CFS could cause confusion and create difficulty in making a differential diagnosis due to similarities between fatigue conditions ${ }^{25}$. As noted above, burnout, unexplained prolonged fatigue and CFS seem to overlap to some extent ${ }^{11}$, but the exact nature of their relationship is unclear. These conditions are relatively common in the working population with an estimated prevalence of $22 \%$ for prolonged fatigue ${ }^{9}, 3.6 \%$ for CFS ${ }^{26}, 4.2 \%$ for severe clinical burnout ${ }^{27}$ and $14 \%$ for mild "probable" burnout ${ }^{9}$. Moreover, they are associated with negative outcomes such as sickness absenteeism and work disability ${ }^{28-32}$.

This thesis aims to unravel different manifestations of fatigue in the working population by comparing and studying their course. This is important as it provides information on whether a (clear) differential diagnosis is necessary between fatigue states and conditions and whether the factors that need to be targeted in interventions, once fatigue complaints are present, need to be different for different manifestations of fatigue. From the point of view of unravelling fatigue conditions, it does not seem useful to start at the far end of the fatigue continuum and focus on severe and debilitating complaints (figure 1) such as in CFS and severe clinical burnout. Especially, as severe fatigue symptoms tend to become complicated and co-occur with other (psychological) health problems ${ }^{3,33-35}$, which could make discrimination very difficult. Rather, it seems more useful to look at the milder forms or precursors of these conditions. With that in mind, the starting point for comparison in this thesis will be at a less advanced, but still significant, level of fatigue complaints and focus on prolonged fatigue (as a precursor of CFS) ${ }^{19,36}$ and mild "probable" burnout (as a precursor of severe clinical burnout $)^{37}$. The former is conceptualised as a multidimensional condition in which subjective fatigue complaints are present for a prolonged period (for example more than two weeks) alongside problems with motivation, concentration and activity using the Checklist Individual Strength ${ }^{38}$. The latter is conceptualised, using the Dutch version of the Maslach Burnout Inventory-General Survey, as a multidimensional construct in which exhaustion symptoms are present along with a cynical attitude towards work and/or a decline of the sense of accomplishment or efficacy in the work situation ${ }^{37,39}$.

\section{Outline of thesis}

Using data from the previously carried out clinical $\mathrm{RCT}{ }^{10}$, the long-term course and prognosis of fatigue in this sample will be assessed in chapter 2 . The long-term efficacy of a psychological intervention (cognitive behavioural therapy) for fatigue complaints will be assessed in chapter 3 and the influence of CFS-like caseness on subsequent work status will be assessed in chapter 4 . In chapter 5 , the history and phenomenology of fatigue conditions such as burnout and CFS will be considered. Following this, data from the MCS $^{9}$ will be used to try to unravel the relationship between prolonged fatigue and burnout in terms of their overlap and characteristics (chapter 6), their course (chapter 7), their 
prognosis (chapter 8) and their temporal relationship (chapter 9). Finally, in chapter 10 , the main findings of this thesis will be summarised and integrated. In addition, practical implications and recommendations for future research will be discussed 


\section{References}

1 Lewis G, Wessely S. The epidemiology of fatigue: more questions than answers. Journal of Epidemiology and Community Health 1992; 46: 92-7.

2 Dittner AJ, Wessely SC, Brown RG. The assessment of fatigue: a practical guide for clinicians and researchers. Journal of Psychosomatic Research 2004; 56: 157-70.

3 Wessely $S$, Hotopf $M$, Sharpe M. Chronic fatigue and its syndromes. Oxford: Oxford University Press, 1998.

4 Sharpe M, Wilks D. Fatigue. British Medical Journal 2002; 325: 480-3.

5 De Vries J, Michielsen HJ, Van Heck GL. Assessment of fatigue among working people: a comparison of six questionnaires. Occupational and Environmental Medicine 2003; 60 Suppl 1: i10-5.

6 Schaufeli WB, Taris TW. The conceptualization and measurement of burnout: Common ground and worlds apart. Work and Stress 2005; 19: 256-62.

7 Rabinbach $A$. The human motor: energy, fatigue, and the origins of modernity. New York: Basic Books, Inc, 1990.

8 Mohren D, Jansen N, Van Amelsvoort L, Kant I. An epidemiological approach of fatigue and work. Experiences from the Maastricht Cohort Study. Maastricht: Programma Epidemiologie van Arbeid en Gezondheid, 2007.

9 Kant IJ, Bultmann U, Schroer KA, Beurskens AJ, Van Amelsvoort LG, Swaen GM. An epidemiological approach to study fatigue in the working population: the Maastricht Cohort Study. Occupational and Environmental Medicine 2003; 60 Suppl 1: i32-9.

10 Huibers MJ, Beurskens AJ, Van Schayck CP, Bazelmans E, Metsemakers JF, Knottnerus JA, Bleijenberg G. Efficacy of cognitive-behavioural therapy by general practitioners for unexplained fatigue among employees: Randomised controlled trial. British Journal of Psychiatry 2004; 184: 240-6.

11 Huibers $M J H$, Beurskens AJHM, Prins JB, Kant IJ, Bazelmans E, van Schayck CP, Knottnerus $J A$, Bleijenberg $G$. Fatigue, burnout, and chronic fatigue syndrome among employees on sick leave: do attributions make the difference? Occupational and Environmental Medicine 2003; 60: 26-31.

12 Taylor RR, Jason LA, Curie CJ. Prognosis of chronic fatigue in a community-based sample. Psychosomatic Medicine 2002; 64: 319-27.

13 Hickie I, Koschera A, Hadzi-Pavlovic D, Bennett B, Lloyd A. The temporal stability and comorbidity of prolonged fatigue: a longitudinal study in primary care. Psychological Medicine 1999; 29: 855-61.

14 Van der Werf SP, de Vree B, Alberts M, van der Meer JW, Bleijenberg G. Natural course and predicting self-reported improvement in patients with chronic fatigue syndrome with a relatively short illness duration. Journal of Psychosomatic Research 2002; 53: 749-53.

15 Cairns $R$, Hotopf $M$. A systematic review describing the prognosis of chronic fatigue syndrome. Occupational Medicine 2005; 55: 20-31.

16 Joyce J, Hotopf $M$, Wessely $S$. The prognosis of chronic fatigue and chronic fatigue syndrome: a systematic review. Quarterly Journal of Medicine 1997; 90: 223-33.

17 Janssen $\mathrm{N}$. The natural course of fatigue in a working population. Maastricht: Maastricht University Press, 2004. 
18 Huibers MJ, Bultmann U, Kasl SV, Kant I, van Amelsvoort LG, van Schayck CP, Swaen GM. Predicting the two-year course of unexplained fatigue and the onset of long-term sickness absence in fatigued employees: results from the Maastricht Cohort Study. Journal of Occupational and Environmental Medicine 2004; 46: 1041-7.

19 Huibers MJ, Kant IJ, Knottnerus JA, Bleijenberg G, Swaen GM, KasI SV. Development of the chronic fatigue syndrome in severely fatigued employees: predictors of outcome in the Maastricht cohort study. Journal of Epidemiology and Community Health 2004; 58: 877-82.

20 Mommersteeg PM, Heijnen CJ, Verbraak MJ, van Doornen U. A longitudinal study on cortisol and complaint reduction in burnout. Psychoneuroendocrinology 2006; 31: 793-804.

21 Sonnenschein M. Sick with burnout clarified through electronic diaries. Utrecht University: PhD thesis, 2007

22 Taris T, Schaufeli W, Schreurs PJ, Caljé D. Opgebrand in het onderwijs: stress, psychische vermoeidheid en ziekteverzuim onder leraren [Burnout in education: stress, psychological fatigue and sickness absence among teachers]. In: Houtman I, Schaufeli WB, Taris TW, eds. Psychische vermoeidheid en werk: cijfers, trends en analyses. Alphen aan den Rijn: NWO/Samson, 2000; 97-106.

23 Schaufeli $W$. Past performance and future perspectives of burnout research. South African Journal of Industrial Psychology 2003; 29: 1-15.

24 Prins JB, van der Meer JW, Bleijenberg G. Chronic fatigue syndrome. Lancet 2006; 367: 34655.

25 Weber A, Jaekel-Reinhard A. Burnout syndrome: a disease of modern societies? Occupational Medicine 2000; 50: 512-7.

26 Huibers MJ, Kant IJ, Swaen GM, KasI SV. Prevalence of chronic fatigue syndrome-like caseness in the working population: results from the Maastricht cohort study. Occupational and Environmental Medicine 2004; 61: 464-6.

27 Bakker A, Schaufeli WB, van Dierendonck D. Burnout: prevalentie, risicogroepen en risicofactoren. In: Houtman I, Schaufeli WB, Taris TW, eds. Psychische vermoeidheid en werk: cijfers, trends en analyses. Alphen aan den Rijn: NWO/Samson, 2000; 65-82.

28 Janssen N, Kant IJ, Swaen GMH, Janssen PPM, Schroer CAP. Fatigue as a predictor of sickness absence: results from the Maastricht cohort study on fatigue at work. Occupational and Environmental Medicine 2003; 60 Suppl 1: i71-6.

29 Van Amelsvoort LG, Kant IJ, Beurskens AJ, Schroer CA, Swaen GM. Fatigue as a predictor of work disability. Occupational and Environmental Medicine 2002; 59: 712-3.

30 Schaufeli WB, Enzman D. The burnout companion to study and practice: a critical analysis. London: Taylor \& Francis, 1998.

31 Borritz M, Rugulies R, Christensen KB, Villadsen E, Kristensen TS. Burnout as a predictor of self-reported sickness absence among human service workers: prospective findings from three year follow up of the PUMA study. Occupational and Environmental Medicine 2006; 63: 98-106.

32 Toppinen-Tanner S, Ojajarvi A, Vaananen A, Kalimo R, Jappinen P. Burnout as a predictor of medically certified sick-leave absences and their diagnosed causes. Behavioral Medicine 2005; 31: 18-27.

33 Schaufeli W, Van Dierendonck D. Burnout, een begrip gemeten. De Nederlandse versie van de Maslach Burnout Inventory (MBI-NL). / Burnout--The measurement of a concept: The Dutch version of the Maslach Burnout Inventory (MBI--NL). Gedrag and Gezondheid Tijdschrift voor Psychologie en Gezondheid 1994; 22: 153-72 
34 Ahola K, Honkonen T, Isometsa E, Kalimo R, Nykyri E, Aromaa A, Lonnqvist J. The relationship between job-related burnout and depressive disorders-results from the Finnish Health 2000 Study. Journal of Affective Disorders 2005; 88: 55-62.

35 Pawlikowska T, Chalder T, Hirsch SR, Wallace P, Wright DJ, Wessely SC. Population based study of fatigue and psychological distress. British Medical Journal 1994; 308: 763-6.

36 Huibers MJ, Bleijenberg G, van Amelsvoort LG, Beurskens AJ, van Schayck CP, Bazelmans E, Knottnerus JA. Predictors of outcome in fatigued employees on sick leave: results from a randomised trial. Journal of Psychosomatic Research 2004; 57: 443-9.

37 Schaufeli WB, Van Dierendonk D. UBOS, Utrechtse Burnout Schaal, Handleiding. Lisse: Swets Test Publishers, 2000

38 Vercoulen JHHM, Alberts M, Bleijenberg G. De Checklist Individuele Spankracht (CIS) [The Checklist Individual Strength (CIS)]. Gedragstherapie 1999; 32: 131-6.

39 Schaufeli WB, Leiter MP, Maslach C, Jackson SE. The Maslach Burnout Inventory- General Survey. In: Maslach C, Jackson SE, Leiter MP, eds. Maslach Burnout Inventory manual: 3rd Edition. Palo Alto, CA: Consulting Psychologists Press, 1996; 19-26. 
Long-term predictors of outcome in fatigued employees on sick leave:

\section{A 4-year follow-up study}

S.S. Leone ${ }^{1}$

M.J.H. Huibers ${ }^{2,3}$

is. Kant ${ }^{1}$

C.P. varl Schayck ${ }^{3}$

G. Bleijenberg ${ }^{4}$

J.A. Knottnerus ${ }^{3}$

${ }^{1}$ Department of Epidemiology, Maastricht University, Maastricht, The Netherlands

2 Department of Clinical Psychological Science, Maastricht University, Maastricht, The Netherlands

${ }^{3}$ Department of General Practice, Maastricht University, Maastricht, The Netherlands

${ }^{4}$ Expert Centre Chronic Fatigue, Radboud University Nijmegen Medical Centre, Nijmegen,

The Netherlands

Psychological Medicine 2006; 36:1293-1300

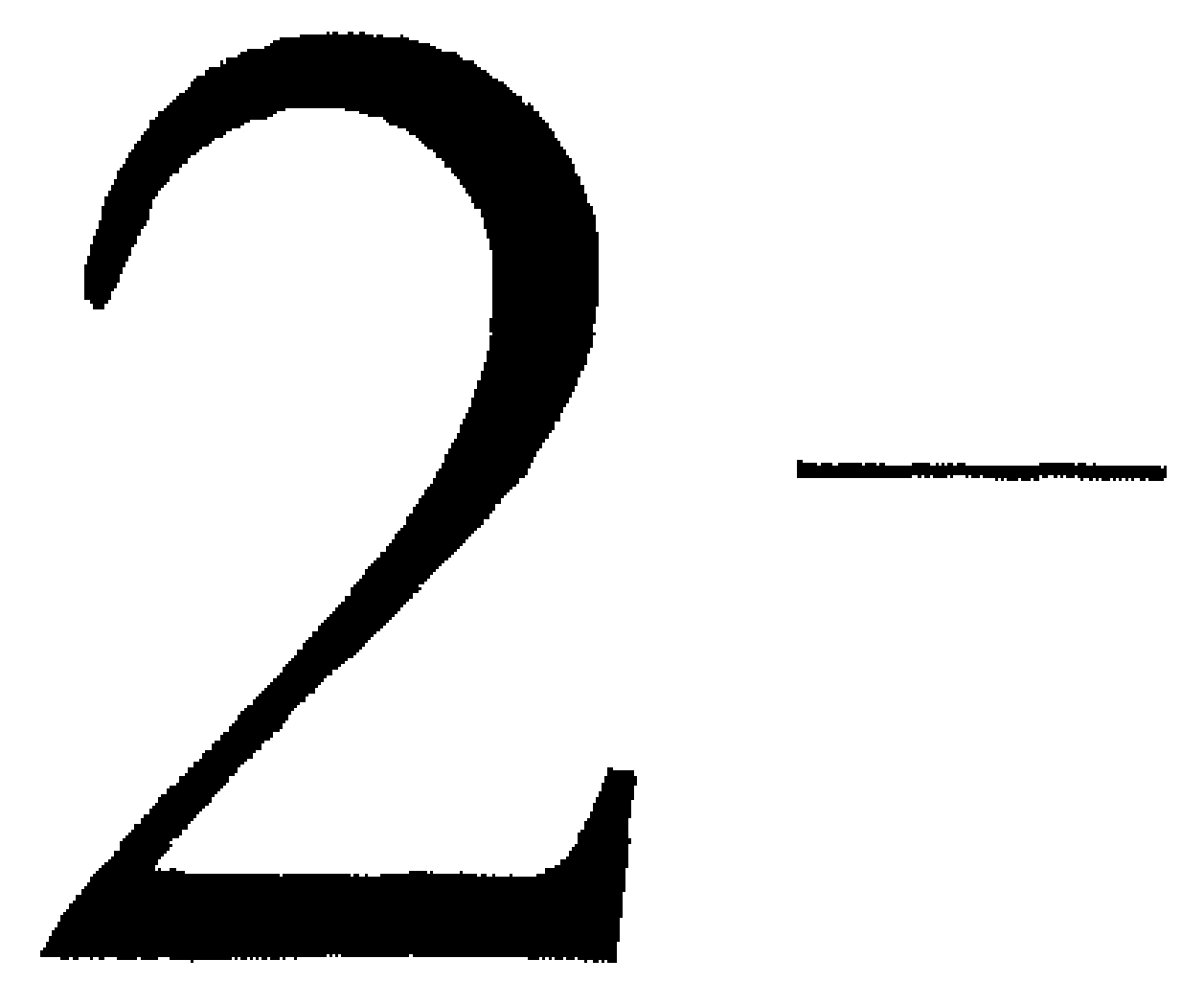




\section{Abstract}

\section{Background}

Persistent fatigue is strongly associated with functional status and can lead to absenteeism and work disability. Despite several prognostic studies on chronic fatigue, little attention has been paid to occupational outcomes.

\section{Methods}

A total of 127 fatigued employees on sick leave were followed-up after 4 years to determine long-term predictors of work disability, fatigue caseness and chronic fatigue syndrome (CFS)-like caseness. Measures included fatigue, physical functioning, iliness attributions, psychological problems and emotional exhaustion.

\section{Results}

Thirty-three participants (26\%) were receiving work disability benefits at the 4-year followup. Older age and lower levels of physical functioning predicted work disability. Weaker psychological attributions and lower levels of physical functioning were predictors of fatigue caseness. CFS-like caseness was predicted by female gender, and lower levels of physical functioning. Self-reported physical functioning remained a strong and statistically significant determinant of work disability (odds ratio (OR) $0.45,95 \%$ confidence interval (CI) $0.24-0.87$ ) and CFS-like caseness (OR $0.20,95 \% \mathrm{Cl} 0.09-0.43$ ) after controlling for confounders.

\section{Conclusions}

This study suggests that physical functioning plays an important role in the persistence of fatigue complaints and work disability in employees on sick leave. The course of fatigue is a complex process, and exploring temporal relationships between fatigue, functional status and work status in future research could provide valuable information for the improvement of fatigue management. 


\section{Introduction}

Fatigue conditions are poorly understood, difficult to treat and tend to have a poor prognosis ${ }^{1,2}$. To treat fatigue effectively, insight into factors associated with outcome in fatigued patients is necessary. Several prognostic studies have examined predictors of fatigue and have found illness attributions and psychological problems to be important and consistent predictors of outcome in fatigue ${ }^{3-6}$. Despite a considerable number of these prognostic studies, few data are available on occupational outcomes in studies of chronic fatigue and chronic fatigue syndrome (CFS) ${ }^{7,8}$. Knowledge of prognostic factors related to occupational outcomes is important because persistent fatigue is strongly associated with functional status and can lead to absenteeism and even full work incapacity ${ }^{8-10}$. These associations between fatigue, functional status and work status could grow stronger and become intertwined in the course of time, as a result of which the prognosis of fatigue could take a turn for the worse.

In this study, long-term predictors of outcome were examined in a population of persistently fatigued employees already on sick leave. Participants were initially recruited to take part in a randomised controlled trial, which aimed to assess the efficacy of cognitive behavioural therapy delivered by general practitioners (GPs) for fatigue and absenteeism ${ }^{11}$. The intervention did not prove to be effective at any of the measurements. To gain more insight into factors related to outcome in this group, we aimed to determine predictors of work disability, fatigue caseness and CFS-like caseness, at 4-years' follow-up.

\section{Methods}

\section{Design}

This was a prospective study conducted within the framework of a randomised controlled trial. More details on the design of the trial are described elsewhere ${ }^{11}$. Participants were initially followed-up at 4, 8, and 12 months. These measurements were fixed for each individual participant. A fifth measurement was conducted simultaneously for all participants, as a result of which the mean follow-up period was 3.8 years (range 3.1- 4.8 years).

\section{Participants}

In the original trial, 151 employees were recruited from an occupational health service. Inclusion criteria were the presence of severe fatigue [a score of 35 or more on the subjective fatigue subscale of the Dutch version of the Checklist Individual Strength ${ }^{12,13}$ for at least 4 months in combination with complete absenteeism from work for 6 to 26 weeks. Patients were excluded if they had a medical condition that explained fatigue, were receiving another intervention for fatigue, had a previously classified psychiatric disorder, 
were receiving current psychological treatment, were receiving a work disability benefit, and if their absenteeism was not health-related (e.g. work conflict). In total, 127 participants responded to the follow-up and were available for the present analyses. Nonresponders at 4 years' follow-up were significantly more fatigued and had significantly lower levels of physical functioning at baseline than responders.

\section{Study variables}

Fatigue severity was measured with the subjective fatigue subscale of the $\mathrm{CIS}^{12,{ }^{13}}$. This subscale consists of eight items, which are scored on a seven-point scale (range 8-56). Higher scores indicate higher levels of fatigue severity.

Psychological and somatic causal attributions were assessed with a modified version of the Causal Attribution List (CAL), which has been used in previous studies of fatigue ${ }^{14,15}$. The psychological attribution subscale consists of seven items (score range 7-28). The somatic attribution subscale consists of four items (range 4-16). Higher scores indicate respectively, higher levels of psychological attributions and somatic attributions.

Physical functioning was assessed with the physical functioning subscale of the Dutch version of the 36 -item Short Form Health Survey $\left(\right.$ SF-36, $\left.{ }^{16,17}\right)$. Scores can range from 0 to 100 , higher scores indicate higher levels of physical functioning.

Psychological distress was measured with the Dutch version of the Symptom CheckList-90 $\left(\mathrm{SCL}-90,{ }^{18},{ }^{19}\right)$. Scores can range from 90 to 450 , higher scores indicate higher levels of psychological distress.

The Dutch version of the Beck Depression Inventory (BDI) was used to measure depression 20,21 . Scores can range from 0 to 63 with higher scores indicating higher levels of depression.

Emotional exhaustion was measured with the emotional exhaustion subscale of the Dutch validated version of the Maslach Burnout Inventory-General Survey (MBI-GS, ${ }^{22}{ }^{23}$ ). Scores can range from 0 to 6 , higher scores indicating higher levels of emotional exhaustion.

Duration of fatigue complaints and duration of absenteeism (i.e. absenteeism due to sick leave) were measured by means of self-reports.

\section{Outcomes}

\section{Fatigue caseness}

Participants were classified as fatigue cases if they had a score of 35 or higher on the subjective fatigue subscale of the $\mathrm{CIS}^{13}$.

\section{Work disability}

In the Netherlands, employees on sick leave are eligible for a disability benefit (WAO) after being on sick leave for 2 years (previously after 1 year). After this 2-year period, a physician and a labour expert examine the employee and determine whether the employee is awarded either a full or partial disability benefit based on loss of earning capacity ${ }^{24}$. 
Participants indicated by means of self-report whether they were receiving a full work disability benefit at the time of follow-up. Work disability was only measured at the 4-year follow-up but we also asked patients to report on their work disability status in the 3 years prior to the current study (retrospectively).

\section{CFS-like caseness}

Participants were classified as potential chronic fatigue syndrome cases (CFS-like cases) if they met the following research criteria which were based on the criteria provided by the Centers for Disease Control and Prevention (CDC) for CFS ${ }^{25}$ : a CIS subjective fatigue subscale score of 40 or higher, a self reported duration of fatigue complaints of 6 months or more, an SF-36 score on physical functioning of 60 or lower, and the self-reported presence of four or more CFS symptoms during the past 6 months. It must be stressed that only a physician can make a true CFS diagnosis. None of the patients received a CFS diagnosis by a physician at the start of the study. The CFS status of patients was measured by self-reports only and therefore the term "CFS-like" was applied. CFS-like caseness is considered to be a good proxy for a true CFS diagnosis ${ }^{26,27}$.

\section{Statistical analysis}

Univariate and multiple logistic regression models were used to determine associations between the predictor variables and work disability $(0=$ no, $1=y e s)$, fatigue caseness $(0=$ no, $1=y e s)$, and CFS-like caseness ( $0=$ no, $1=y e s)$. In the first step of the multiple regression analyses, all of the variables that were significantly associated with the outcomes in the univariate analyses were entered in the model. Then in the second step demographic variables were entered. A backward stepwise procedure was used. In addition, multiple regression analyses were carried out with the change scores between baseline ( 0 ) and 12month follow-up ( $\mathrm{t} 3$ ) of the remaining significant predictors entered in the model. The change scores were calculated by subtracting the scores at the 12-month follow-up from the baseline scores. A backward stepwise procedure was also used in these analyses. Due to the results of the predictive analyses, additional explanatory analyses were performed in order to further explore the relationship between physical functioning and the outcome measures. Multiple logistic regression models were also used for these analyses. In the first step, physical functioning was entered in the model. Demographic variables were entered as potential confounders in the second step. In the third step, fatigue severity and duration of fatigue complaints were controlled for. In the final step, psychological attributions, somatic attributions, psychological problems and duration of absenteeism, allocated treatment group and follow-up period were entered as potential confounders. CFS status at baseline, allocated treatment in the original trial and follow-up period were controlled for in all the predictive analyses, but did not alter any of the findings and were therefore omitted from the analyses. All odds ratios (ORs) of continuous variables are expressed in 
change per standard deviation (S.D.) on the scale. All analyses were performed using SPSS (version 12.0).

\section{Results}

\section{Patient characteristics}

The patient characteristics at baseline and at the 4-year follow-up are summarised in table 1.

Table 1 Characteristics of participants at baseline and follow-up

\begin{tabular}{lcc}
\hline Variables $^{\text {a }}$ & $\begin{array}{c}\text { Baseline } \\
(n=127)\end{array}$ & $\begin{array}{l}4 \text {-year follow-up } \\
(n=127)\end{array}$ \\
\hline Age (years) & $44.1(8.2)$ & $47.7(8.4)$ \\
Gender, number male (\% m) & $56(44 \%)$ & $56(44 \%)$ \\
Education & & $35(28 \%)$ \\
$\quad$ High & $35(28 \%)$ & $64(50 \%)$ \\
$\quad$ Middle & $64(50 \%)$ & $28(22 \%)$ \\
$\quad$ Low & $28(22 \%)$ & $34.2(14.2)$ \\
Fatigue severity (CIS, scale 8-56) & $48.1(6.2)$ & n.a. \\
Duration of fatigue complaints (in months) & $27.7(29.0)$ & n.a. \\
Duration of absenteeism (in weeks) & $12.2(4.7)$ & $70.3(24.8)$ \\
Physical functioning (SF-36, scale 0-100) & $63.9(23.6)$ & $148.2(44.4)$ \\
Psychological problems (SCL-90, scale 90-450) & $179.7(49.4)$ & $2.6(1.5)$ \\
Emotional exhaustion (MBI-GS, scale 0-6) & $3.4(1.5)$ & $9.8(7.5)$ \\
Depression (BDI, scale 0-63) & $14.4(7.6)$ & n.a. \\
Psychological attribution (CAL, scale 7-28) & $19.0(4.4)$ & n.a. \\
Somatic attribution (CAL, scale 4-16) & $9.1(2.6)$ &
\end{tabular}

n.a.: data not available.

a Data are mean values (S.D.) or $n(\%)$.

\section{Work disability, fatigue and CFS-like cases}

Table 2 presents the course of outcome in our sample. Thirty-three participants (26\%) were claiming work disability benefits at the 4-year follow-up. The level of work disability was found to be similar over the 4 years, at approximately $30 \%$. At baseline, $41 \%$ of the participants met criteria for CFS-like caseness. Although there was an overall decrease in fatigue and CFS-like cases in the course of the 4 years, there was a slight increase in fatigue and CFS-like cases between the 12-month and the 4-year follow-up, which could indicate a relapse of complaints. 
Table 2 Number (\%) of work disability, fatigue cases and CFS-like cases in the course of 4 years

\begin{tabular}{|c|c|c|c|}
\hline & $\begin{array}{l}\text { Baseline } \\
(n=127)\end{array}$ & $\begin{array}{l}\text { 12-month follow-up } \\
(n=127)\end{array}$ & $\begin{array}{l}\text { 4-year follow-up } \\
(n=127)\end{array}$ \\
\hline Work disability & $0 \quad(0 \%)$ & n.a. & $33(26 \%)$ \\
\hline Fatigue cases & $127(100 \%)$ & $63(53 \%)$ & $72(57 \%)$ \\
\hline CFS-like cases & $52 \quad(41 \%)$ & $24(20 \%)$ & $33(27 \%)$ \\
\hline
\end{tabular}

n.a.: data not available

\section{Univariate associations}

Table 3 presents the univariate associations between the potential predictors and the outcomes at the 4-year follow-up. Older age, a lower level of physical functioning and a higher level of emotional exhaustion were significantly related to work disability at followup. Factors associated with fatigue were a longer duration of fatigue complaints, lower levels of physical functioning, a lower level of psychological attribution and a higher level of somatic attribution. Female gender, a higher level of fatigue, a lower level of physical functioning and a lower level of psychological attribution were associated with CFS-like caseness at follow-up.

Table 3 Crude associations between baseline predictors and outcome measures at 4-year follow-up

\begin{tabular}{|c|c|c|c|c|c|c|}
\hline \multirow[b]{2}{*}{ Age } & \multicolumn{2}{|c|}{$\begin{array}{l}\text { Work disability } \\
\text { OR }(95 \% \mathrm{Cl})\end{array}$} & \multicolumn{2}{|c|}{$\begin{array}{l}\text { Fatigue } \\
\text { OR }(95 \% \mathrm{Cl})\end{array}$} & \multicolumn{2}{|c|}{$\begin{array}{l}\text { CFS like caseness } \\
\text { OR }(95 \% \mathrm{Cl})\end{array}$} \\
\hline & 1.98 & $(1.24-3.13)$ & 0.89 & $(0.63-1.27)$ & 1.13 & $(0.75-1.69)$ \\
\hline Gender (male $=$ reference group) & 1.84 & $(0.80-4.21)$ & 1.63 & $(0.80-3.31)$ & 2.40 & $(1.02-5.83)$ \\
\hline \multicolumn{7}{|l|}{ Education } \\
\hline High (reference group) & 1.00 & & 1.00 & & 1.00 & \\
\hline Middle & 1.00 & $(0.33-3.00)$ & 4.50 & $(1.55-13.06)$ & 1.19 & $(0.38-3.70)$ \\
\hline Low & 0.77 & $(0.28-2.09)$ & 2.50 & $(0.98-6.18)$ & 0.99 & $(0.35-2.79)$ \\
\hline Fatigue severity & 1.06 & $(0.71-1.59)$ & 1.35 & $(0.94-1.92)$ & 1.69 & $(1.07-2.66)$ \\
\hline Duration of fatigue complaints & 1.26 & $(0.86-1.83)$ & 1.58 & $(1.03-2.36)$ & 1.30 & $(0.89-1.88)$ \\
\hline Duration of absenteeism & 0.91 & $(0.59-1.42)$ & 0.97 & $(0.68-1.38)$ & 0.82 & $(0.50-1.34)$ \\
\hline Physical functioning & 0.52 & $(0.34-0.81)$ & 0.46 & $(0.31-0.70)$ & 0.29 & $(0.17-0.51)$ \\
\hline Psychological problems & 1.00 & $(0.67-1.56)$ & 1.10 & $(0.78-1.63)$ & 1.16 & $(0.78-1.72)$ \\
\hline Emotional exhaustion & 1.56 & $(1.03-2.36)$ & 0.73 & $(0.51-1.05)$ & 1.21 & $(0.81-1.81)$ \\
\hline Depression & 0.90 & $(0.60-1.35)$ & 1.06 & $(0.75-1.52)$ & 1.16 & $(0.78-1.71)$ \\
\hline Psychological attribution & 0.73 & $(0.49-1.08)$ & 0.51 & $(0.34-0.76)$ & 0.61 & $(0.40-.92)$ \\
\hline Somatic attribution & 1.23 & $(0.82-1.85)$ & 1.66 & $(1.14-2.42)$ & 1.41 & $(0.92-2.15)$ \\
\hline
\end{tabular}

Bold figures indicate statistically significant associations.

OR: odds ratio; $\mathrm{Cl}$ : confidence interval.

ORs of continuous variables are expressed as change per standard deviation: higher scores on the scales of continuous variables indicate a higher age, higher levels of fatigue severity, a longer duration of complaints, a longer duration of absenteeism, higher levels of physical functioning, higher levels of psychological problems, higher levels of emotional exhaustion, higher levels of depression, and higher levels of psychological and somatic attributions compared to lower scores. 


\section{Multivariate analyses}

Table 4 shows the multivariate prediction models for outcome at the 4-year follow-up. Older age, female gender, and a lower level of physical functioning were strong predictors of work disability at follow-up. Predictors of fatigue were lower levels of physical functioning and lower levels of psychological attribution. Female gender and lower levels of physical functioning were predictors of CFS-like caseness at follow-up. A change towards a lower level of physical functioning between baseline and the 12-month follow-up was a significant predictor of work disability, fatigue and CFS-like caseness at the 4-year follow-up (table 4). A change score of psychological attribution could not be added to the regression model for fatigue, as this variable was not measured at the 12-month follow-up.

Table 4 Results of multiple regression analysis: associations between baseline predictors, change predictors and outcome measures at the 4-year follow-up

\begin{tabular}{|c|c|c|c|}
\hline \multicolumn{4}{|l|}{ Model including only baseline predictors } \\
\hline & Work disability & Fatigue & CFS-like caseness \\
\hline & OR $(95 \% \mathrm{Cl})$ & OR $(95 \% \mathrm{Cl})$ & OR $(95 \% \mathrm{Cl})$ \\
\hline Age & $2.72 \quad(1.56-4.75)$ & & \\
\hline Gender (male $=$ reference group) & $3.50 \quad(1.29-9.55)$ & & $3.15 \quad(1.15-8.63)$ \\
\hline Physical functioning & $0.46 \quad(0.29-0.73)$ & $0.51 \quad(0.33-0.77)$ & $0.27 \quad(0.15-0.49)$ \\
\hline Psychological attribution & & $0.56 \quad(0.37-0.86)$ & \\
\hline \multicolumn{4}{|c|}{ Model including baseline and change predictors } \\
\hline & Work disability & Fatigue & CFS-like caseness \\
\hline & $\mathrm{OR}(95 \% \mathrm{Cl})$ & $\mathrm{OR}(95 \% \mathrm{Cl})$ & $\mathrm{OR}(95 \% \mathrm{Cl})$ \\
\hline Age & $1.96 \quad(1.17-3.29)$ & & \\
\hline Gender (male =reference group) & & & $3.00 \quad(1.00-8.99)$ \\
\hline Physical functioning & $0.26 \quad(0.14-0.47)$ & $0.20 \quad(0.10-0.41)$ & $0.15 \quad(0.07-0.34)$ \\
\hline Psychological attribution & & $0.58 \quad(0.36-0.94)$ & \\
\hline Physical functioning change score to-t3 & $3.63 \quad(1.93-6.97)$ & $3.63 \quad(1.93-6.84)$ & $2.38 \quad(1.38-4.14)$ \\
\hline \multicolumn{4}{|c|}{$\begin{array}{l}\text { OR: odds ratio; } \mathrm{Cl} \text { : confidence interval. } \\
\text { ORs of continuous variables are expressed as change per standard deviation: higher scores on the scales of } \\
\text { continuous variables indicate a higher age, higher levels of physical functioning, higher levels psychological } \\
\text { attributions, and a change towards a lower level of physical functioning between to and t } 3 \text { compared to } \\
\text { lower scores. }\end{array}$} \\
\hline
\end{tabular}

\section{Physical functioning as a predictor of outcome}

Physical functioning appeared to be a strong predictor in all our models. We therefore analysed the relative contribution of physical functioning as a prognostic factor to outcome. Table 5 shows that lower levels of physical functioning remained associated with work disability and CFS-like-caseness after adjusting for potential confounders. The association between physical functioning and fatigue lost its significance after adjusting for confounders in the final step of the analysis. 
Table 5 Physical functioning at baseline as a risk factor for work disability, fatigue and CFSlike caseness at 4-year follow-up

\begin{tabular}{lll}
\hline $\begin{array}{l}\text { Work disability } \\
\text { OR }(95 \% \mathrm{Cl})\end{array}$ & $\begin{array}{l}\text { Fatigue } \\
\text { OR }(95 \% \mathrm{Cl})\end{array}$ & \multicolumn{2}{l}{$\begin{array}{l}\text { CFS-like caseness } \\
\text { OR }(95 \% \mathrm{Cl})\end{array}$} \\
\hline $0.52(0.34-0.81)^{\mathrm{a}}$ & $0.46(0.31-0.70)^{\mathrm{a}}$ & $0.29(0.17-0.51)^{\mathrm{a}}$ \\
$0.45(0.28-0.75)^{\mathrm{b}}$ & $0.54(0.35-0.83)^{\mathrm{b}}$ & $0.25(0.14-0.46)^{\mathrm{b}}$ \\
$0.43(0.26-0.73)^{\mathrm{c}}$ & $0.54(0.35-0.85)^{\mathrm{c}}$ & $0.26(0.14-0.50)^{\mathrm{c}}$ \\
$0.45(0.24-0.87)^{\mathrm{d}}$ & $0.70(0.40-1.24)^{\mathrm{d}}$ & $0.20(0.09-0.43)^{\mathrm{d}}$ \\
\hline
\end{tabular}

OR: odds ratio; $\mathrm{Cl}$ : confidence interval.

ORs are expressed as change per standard deviation on the physical functioning scale: higher scores on the physical functioning scale indicate higher levels of physical functioning.

a Crude association

${ }^{b}$ OR adjusted for age, gender and education

' OR adjusted for age, gender, education, fatigue severity and duration of fatigue complaints

' OR adjusted for age, gender, education fatigue severity, duration of fatigue complaints, psychological attributions, somatic attributions, psychological problems, duration of absenteeism, group allocation and follow-up period.

\section{Discussion}

\section{Summary of main findings}

We aimed to gain more insight into factors predicting outcome in a group of fatigued employees on sick leave following treatment for fatigue in the long term. The prognosis of fatigue in this sample was rather poor, with $57 \%$ of the participants meeting criteria for severe fatigue and $27 \%$ meeting the criteria for CFS-like caseness. Work disability was also high as, $26 \%$ of participants reported receiving full work disability benefits at follow-up.

We found work disability to be predicted by older age, lower levels of physical functioning and a decline in physical functioning between baseline and the 12-month follow-up. Fatigue caseness was found to be predicted by lower levels of physical functioning, lower levels of psychological attribution and a decline in physical functioning. Being a woman, having lower levels of physical functioning and a decline in physical functioning predicted CFS-like caseness.

We also focused on the role of physical functioning as a specific prognostic factor. After controlling for various confounders, we found that the association between physical functioning and work disability and CFS-like caseness remained significant, while the association between physical functioning and fatigue caseness did not. The magnitude of the associations found stands out in all of the analyses. In particular, the magnitude of the associations between physical functioning and the outcomes of this study are noteworthy. 


\section{Methodological considerations}

In two recent reviews it was concluded that occupational outcomes are rarely assessed in prognostic studies of chronic fatigue and CFS ${ }^{7,8}$. Besides examining predictors of fatigue and CFS-like caseness, we also focused on predictors of work disability. Furthermore, this was the first study to present long-term predictors of outcome in a group of fatigued employees on sick leave. A potential limitation is that CFS-like caseness was assessed as a composite variable made up of self-reported fatigue severity, duration of fatigue complaints, physical functioning and four or more CFS symptoms. CFS-like caseness is considered to be a good indicator of true CFS but only a physician can give a diagnosis of CFS ${ }^{25-27}$. None of the patients had received a diagnosis of CFS by physician at the start of this study. However, this may have improved the internal validity of this study as CFS-like caseness was not dependent on help-seeking behaviour and the variation between physicians in diagnosing CFS. Another aspect of the internal validity concerns selection bias during the inclusion of participants in this study and during follow-up. It is not very likely that selection bias occurred during the inclusion of participants, as participants were not selected based on prognostic variables in the study. Non-responders at follow-up differed significantly from the responders on baseline fatigue scores and physical functioning scores. As this difference was to the disadvantage of the non-responders, the results presented in this study could be an underestimation of the severity of health problems in the target population. The participants in this study originally took part in a randomised controlled trial with specific inclusion criteria, including being on sick leave for at least 6 weeks. It is questionable therefore, whether the findings of this study can be generalised to a wider range of fatigued patients who are not on sick leave. Moreover, fatigued individuals with a shorter duration of sick leave may have a different prognosis than the participants in this study.

\section{The role of illness attributions}

Previous studies have shown that illness attributions can play an important role in the course of fatigue conditions not meeting the criteria for CFS ${ }^{3,5,28,29}$. In this study, absence of a tendency towards psychological attributions was associated with fatigue caseness.

However, causal attributions were not related to CFS-like caseness in this sample, in contrast to several previous studies examining the role of illness attributions in diagnosed CFS patients ${ }^{15,30-32}$.

\section{Physical functioning as a predictor}

Physical functioning turned out to be a robust predictor of outcome in this study. Like physical functioning at baseline, deterioration of physical functioning between the baseline measurement and 12-month follow-up predicted work disability, fatigue caseness and CFSlike caseness at the 4-year follow-up. Fatigue has been shown to be related to work disability ${ }^{9,10}$, but in this study it seems it is not so much the fatigue but the diminished 
physical functioning associated with fatigue that is the most important factor in the course of fatigue in employees on sick leave. The finding that physical functioning is a predictor of CFS-like caseness after 4 years is consistent with the finding that physical functioning was a significant predictor of CFS-like caseness in a prospective study in this group at the 12 month follow-up ${ }^{5}$. A recent study also found functional impairment in combination with CFS status to be predictive of final fatigue following treatment for chronic fatigue in primary care ${ }^{33}$. Furthermore, it was found that functional impairment was a significant predictor of fatigue severity in CFS patients ${ }^{15}$. The results of this study underline the important role of physical functioning in the persistence of fatigue complaints and work disability. It also highlights the need to target the level of physical functioning in the treatment of fatigued patients.

\section{Conclusions}

The course of fatigue is a complex process with many factors contributing to its persistence or recovery. However, fatigue itself is not necessarily the main factor to focus on in the prognosis of fatigue conditions, as this study underlines. Factors such as physical functioning, work status and illness perceptions seem to become intertwined with fatigue at some time. This makes it difficult to treat fatigue conditions effectively because it is not known how and when these factors influence each other. To further our understanding of fatigue conditions these complex inter-relationships should be examined in future research. In this sense, exploring the temporal relationships between these factors could yield valuable information that can help us improve the care of fatigued patients.

\section{Acknowledgements}

This study was funded by the Health Research and Development Council (ZonMw), The Netherlands (grant no. 21000104). 


\section{References}

1 Afari N, Buchwald D. Chronic fatigue syndrome: A review. American Journal of Psychiatry 2003; 160: 221-36.

2 Joyce J, Hotopf $M$, Wessely S. The prognosis of chronic fatigue and chronic fatigue syndrome: a systematic review. Quarterly Journal of Medicine 1997; 90: 223-33.

3 Chalder T, Godfrey E, Ridsdale L, King M, Wessely S. Predictors of outcome in a fatigued population in primary care following a randomized controlled trial. Psychological Medicine 2003; 33: 283-7.

4 Schmaling KB, Fiedelak JI, Katon WJ, Bader JO, Buchwald DS. Prospective study of the prognosis of unexplained chronic fatigue in a clinic-based cohort. Psychosomatic Medicine 2003; 65: 1047-54.

5 Huibers MJ, Bleijenberg G, van Amelsvoort LG, Beurskens AJ, van Schayck CP, Bazelmans E, Knottnerus JA. Predictors of outcome in fatigued employees on sick leave: results from a randomised trial. Journal of Psychosomatic Research 2004; 57: 443-9.

6 Skapinakis $P$, Lewis $G$, Mavreas $V$. One-year outcome of unexplained fatigue syndromes in primary care: results from an international study. Psychological Medicine 2003; 33: 857-66.

7 Cairns R, Hotopf $M$. A systematic review describing the prognosis of chronic fatigue syndrome. Occupational Medicine 2005; 55: 20-31.

8 Ross SD, Estok RP, Frame D, Stone LR, Ludensky V, Levine CB. Disability and chronic fatigue syndrome: a focus on function. Archives of Internal Medicine 2004; 164: 1098-107.

9 Van Amelsvoort LG, Kant IJ, Beurskens AJ, Schroer CA, Swaen GM. Fatigue as a predictor of work disability. Occupational and Environmental Medicine 2002; 59: 712-3.

10 Janssen N, Kant IJ, Swaen GMH, Janssen PPM, Schroer CAP. Fatigue as a predictor of sickness absence: results from the Maastricht cohort study on fatigue at work. Occupational and Environmental Medicine 2003; 60 Suppl 1: i71-6.

11 Huibers MJ, Beurskens AJ, Van Schayck CP, Bazelmans E, Metsemakers JF, Knottnerus JA, Bleijenberg G. Efficacy of cognitive-behavioural therapy by general practitioners for unexplained fatigue among employees: Randomised controlled trial. British Journal of Psychiatry 2004; 184: 240-6.

12 Beurskens AJ, Bultmann U, Kant I, Vercoulen JH, Bleijenberg G, Swaen GM. Fatigue among working people: validity of a questionnaire measure. Occupational and Environmental Medicine 2000; 57: 353-7.

13 Vercoulen JHHM, Alberts M, Bleijenberg G. De Checklist individuele Spankracht (CIS) [The Checklist Individual Strength (CIS)]. Gedragstherapie 1999; 32: 131-6.

14 Prins JB, Bleijenberg G, Bazelmans E, Elving LD, de Boo TM, Severens $J L$, van der Wilt GJ, Spinhoven $P$, van der Meer JW. Cognitive behaviour therapy for chronic fatigue syndrome: a multicentre randomised controlled trial. Lancet 2001; 357: 841-7.

15 Vercoulen JH, Swanink CM, Fennis JF, Galama JM, van der Meer JW, Bleijenberg G. Prognosis in chronic fatigue syndrome: a prospective study on the natural course. Journal of Neurology, Neurosurgery and Psychiatry 1996; 60: 489-94.

16 Ware JE, Jr., Sherbourne CD. The MOS 36-item short-form health survey (SF-36). I. Conceptual framework and item selection. Medical Care 1992; 30: 473-83.

17 Aaronson NK, Muller M, Cohen PD, Essink-Bot ML, Fekkes M, Sanderman R, Sprangers MA, te Velde A, Verrips E. Translation, validation, and norming of the Dutch language version of 
the SF-36 Health Survey in community and chronic disease populations. Journal of Clinical Epidemiology 1998; 51: 1055-68.

18 Derogatis LR, Lipman RS, Covi L. SCL-90: an outpatient psychiatric rating scale--preliminary report. Psychopharmacological Bulletin 1973; 9: 13-28.

19 Arrindel WA, Ettema JHM. Symptom Checklist-90, SCL-90, een multidimensionele psychpathologie-indicator, handleiding [Symptom Checklist-90, a multidimensional psychopathology indicator, manual]. Lisse: Swets Test Services, 1986.

20 Beck AT, Steer RA, Garbin MG. Psychometric Properties of the Beck Depression Inventory 25 Years of Evaluation. Clinical Psychology Review 1988; 8: 77-100.

21 Bouman TK, Luteijn FA, Albersnagel FA, van der Ploeg FAE. Enige ervaringen met de Beck Depression Inventory (BDI). Gedrag 1985; 13: 13-24.

22 Schaufeli WB, Leiter MP, Maslach C, Jackson SE. The Maslach Burnout Inventory- General Survey. In: Maslach C, Jackson SE, Leiter MP, eds. Maslach Burnout Inventory manual: 3rd Edition. Palo Alto, CA: Consulting Psychologists Press, 1996; 19-26.

23 Schaufeli WB, Van Dierendonk D. UBOS, Utrechtse Burnout Schaal, Handleiding. Lisse: Swets Test Publishers, 2000.

24 Klingers C, Diepstraten LAM. 'Arbeidsongeschiktheid'; wat is er aan de hand? [What is the meaning of the concept "incapacity for work"? Nederlandse Tijdschrift voor Geneeskunde 1998; 142: 671-84.

25 Fukuda K, Straus SE, Hickie I, Sharpe MC, Dobbins JG, Komaroff A. The chronic fatigue syndrome: a comprehensive approach to its definition and study. International Chronic Fatigue Syndrome Study Group. Annals of Internal Medicine 1994; 121: 953-9.

26 Jason LA, Taylor RR. Applying cluster analysis to define a typology of chronic fatigue syndrome in a medically-evaluated, random community sample. Psychology \& Health 2002; 17: 323-37.

27 Taylor RR, Jason LA, Torres A. Fatigue rating scales: an empirical comparison. Psychological Medicine 2000; 30: 849-56.

28 Sharpe $M$, Hawton $K$, Seagroatt $V$, Pasvol G. Follow up of patients presenting with fatigue to an infectious diseases clinic. British Medical Journal 1992; 305: 147-52.

29 Clark MR, Katon W, Russo J, Kith P, Sintay M, Buchwald D. Chronic fatigue: risk factors for symptom persistence in a $21 / 2$-year follow-up study. American Journal of Medicine 1995; 98: $187-95$.

30 Van der Werf SP, de Vree B, Alberts M, van der Meer JW, Bleijenberg G. Natural course and predicting self-reported improvement in patients with chronic fatigue syndrome with a relatively short illness duration. Journal of Psychosomatic Research 2002; 53: 749-53.

31 Wilson A, Hickie I, Lloyd A, Hadzi-Pavlovic D, Boughton C, Dwyer J, Wakefield D. Longitudinal study of outcome of chronic fatigue syndrome. British Medical Journal 1994; 308: 756-9.

32 Cope H, Mann A, Pelosi A, David A. Psychosocial risk factors for chronic fatigue and chronic fatigue syndrome following presumed viral illness: a case-control study. Psychological Medicine 1996; 26: 1197-209.

33 Darbishire L, Seed P, Ridsdale L. Predictors of outcome following treatment for chronic fatigue. British Journal of Psychiatry 2005; 186: 350-1. 


\section{Long-term efficacy of cognitive- behavioural therapy by general practitioners for fatigue:

S.S. Leone $e^{1}$

M.J.H. Huibers ${ }^{2,3}$

IJ. Kant ${ }^{1}$

L.G.P.M. van Amelsvoort ${ }^{1}$

C.P. van Schayck ${ }^{3}$

G. Bleijenberg ${ }^{4}$

J.A. Knottnerus ${ }^{3}$

${ }^{1}$ Department of Epidemiology, Maastricht University, Maastricht, The Netherlands

${ }^{2}$ Department of Clinical Psychological Science, Maastricht University, Maastricht, The Netherlands

${ }^{3}$ Department of General Practice, Maastricht University, Maastricht, The Netherlands

${ }^{4}$ Expert Centre Chronic Fatigue, Radboud University Nijmegen Medical Centre, Nijmegen, The Netherlands 


\section{Abstract}

\section{Objective}

In an earlier study, we found that cognitive-behavioural therapy (CBT) delivered by general practitioners (GPs) for fatigue among employees on sick leave was not effective after 12 months. In this study, we aim to assess the long-term efficacy of CBT by GPs for fatigue. It was hypothesised that the intervention could prevent deterioration as well as relapse of fatigue complaints and relapse into absenteeism in the long term.

\section{Methods}

Patients who participated in the original randomised controlled trial were followed up 4 years later. Fatigue and absenteeism were the main outcomes.

\section{Results}

Fatigue and absenteeism were high in the intervention and control group at the 4-year follow-up. There was no significant difference between the intervention and control group on fatigue and absenteeism. The intervention group however, tended towards less favourable outcomes as compared with the control group.

\section{Conclusions}

Like that of chronic fatigue syndrome, the prognosis of less advanced fatigue is rather poor. CBT delivered by GPs is not effective in the long-term. 


\section{Introduction}

Without adequate treatment, the prognosis of severe medically unexplained fatigue is rather poor ${ }^{1}$. Several interventions for fatigue conditions such as chronic fatigue syndrome (CFS) and chronic fatigue have been studied, of which cognitive-behavioural therapy (CBT) seems to be one of the most promising approaches ${ }^{2}$. Despite the fact that general practitioners (GPs) are faced with the majority of fatigue cases, there has been little research focused on whether GPs are able to deliver CBT effectively. Two earlier studies examined $\mathrm{CBT}$ as an intervention for fatigued patients in primary care, but the therapy was not delivered by GPs ${ }^{3,4}$. A controlled trial in primary care aimed to determine if GPs were able to manage CFS by means of brief CBT ${ }^{5}$. The results suggested that GPs were not able to effectively treat CFS. However, the study suffered from serious flaws, such as a high dropout rate, making it difficult to interpret its findings.

The efficacy of CBT delivered by GPs for less advanced fatigue among employees on sick leave was assessed in a published randomised controlled trial (RCT) ${ }^{6}$. No significant or clinically relevant difference was found between patients in the intervention group, who received $\mathrm{CBT}$, and patients in the control group, who were merely followed up prospectively, at 4,8 , and 12 months.

We now report on the 4-year follow-up of the original study sample. As this was the first study of its kind, it is not known what the long-term efficacy of CBT by GPs for less advanced fatigue among employees is. Despite the results that were found at the previous measurements, we hypothesised that CBT could possibly prevent further deterioration and relapse of fatigue complaints as well as relapse into long-term sickness absence. In the current study, we assessed the long-term outcome of CBT delivered by GPs for less advanced fatigue cases.

\section{Methods}

\section{Design}

We conducted a randomised controlled trial in primary care using an adapted prerandomisation or randomised consent design ${ }^{7}$. Randomisation took place before detailed information about the study was provided, and patients allocated to one group were kept blinded to the randomisation procedure and thus to the existence of the other group. After randomisation, patients were informed only about the procedures in the condition to which they were allocated, and their informed consent was obtained. Patients were randomised to receive cognitive-behavioural therapy by a GP or to be followed up in a control group.

Clinical outcomes were initially assessed on four occasions: at baseline and at 4, 8, and 12 months. These measurements were fixed for each participant. A fifth measurement was 
conducted simultaneously for all participants, as a result of which, the mean follow-up period is 3.8 years (range 3.1-4.8 years). Patients were informed about the design and the results of the study after the fifth measurement. The medical ethics committee of Maastricht University approved the study protocol. More details on the design of this study are described elsewhere ${ }^{6,8}$.

\section{Patients}

In the original trial, 151 employees who met the inclusion criteria of (a) being severely fatigued (a score of 35 or higher on the subjective fatigue subscale of the Dutch Checklist Individual Strength $(\mathrm{CIS})^{9,10}$ ) for at least 4 months and (b) being on sick leave for 6 to 26 weeks were recruited from an occupational health service. Exclusion criteria for participation were as follows: having a medical condition that explained fatigue, receiving another intervention for fatigue, having a previously classified psychiatric disorder or receiving current psychological treatment, work incapacity, and absenteeism that was not health-related (e.g. work conflict).

\section{Intervention}

Patients were allocated to either the intervention group or the control group. Patients in the intervention group were offered five to seven 30-minute sessions of CBT over the course of 4 months. The primary goals of the intervention were to diminish fatigue complaints and to establish work resumption. Nine research GPs delivered all interventions aside their regular practice. The GPs received training in the delivery of the intervention and were supervised in monthly 2-hour sessions throughout the trial by two experienced behaviour therapists. No research intervention was offered to patients in the control group. Patients in both groups were free to visit their regular GP for usual care.

\section{Measures}

All study variables were assessed at the fifth measurement, except for causal attributions, which were assessed at baseline.

Fatigue severity was measured with the subjective fatigue subscale of the $\mathrm{CIS}^{9}{ }^{9}$. This subscale consists of eight items that are scored on a seven-point scale. Scores can range from 8 to 56 , with higher scores indicating higher levels of fatigue severity. A score of 35 or higher indicates severe fatigue and was used as the cut-off for defining fatigue cases.

Absenteeism was assessed by means of self-report and consisted of sickness absence, full work incapacity, partial work incapacity, partial work incapacity combined with partial unemployment, retirement, full unemployment, cessation of work, and other reasons for absenteeism (e.g. going back to school).

Psychological and somatic causal attributions were assessed with a modified version of the Causal Attribution List (CAL), which was used in previous studies of fatigue ${ }^{11,12}$. The psychological attribution subscale consists of seven questions with a total score range of 7 
to 28. The scale was divided into two equal groups (strong vs. weak attributions) where a score of 20 or higher indicated strong psychological attributions. The somatic attribution subscale consists of four questions with total scores ranging from 4 to 16 . This scale was also dichotomised, with a score of 10 or higher indicating strong somatic attributions.

Physical functioning was assessed with the physical functioning subscale of the Dutch version of the 36 -item Short Form Health Survey (SF-36) ${ }^{13,14}$, with high scores indicating high levels of physical functioning.

Psychological distress was measured with the Dutch version of the Symptom CheckList-90 (SCL-90, ${ }^{15,16}$ ), high scores indicate high distress.

Duration of fatigue complaints was assessed on a nine-point rating scale ranging from 'no complaints' to 'all my life'. The scale was divided into two categories: a year or less (scores 1-4) and 2 years or more (scores $5-9$ ).

Patients were classified as potential chronic fatigue syndrome cases (CFS-like cases) if they met the following research criteria, which were based on the CDC criteria for CFS ${ }^{17}$ : a subjective fatigue $\mathrm{ClS}$ score of 40 or higher, a self reported duration of fatigue complaints of 6 months or more, an SF-36 score on physical functioning of 60 or lower, and the selfreported presence of four or more CFS symptoms during the past 6 months.

\section{Statistical analysis}

Based on a clinical difference on the CIS, the original required sample size was calculated to require 75 patients per group ${ }^{6}$. Mixed linear regression models were used to analyse the development of fatigue over time (in months) in the CBT group versus the control group. This statistical method makes it possible to include a repeated number of outcome measurements in time per individual. We specified an unstructured covariance matrix. This means that no predefined structure was posed on the modelled correlation matrix. To test the effect of the intervention, we performed an analysis of covariance. This means that changes in fatigue from 4 months onward were modelled with adjustment for baseline levels of fatigue. Twisk and Proper ${ }^{18}$ advised this as the most appropriate way to analyse continuous outcomes in RCTs. Attributions were also modelled this way to account for the potential influence of the intervention. However, the results of the analysis testing the efficacy of the intervention also made it plausible to model fatigue using all measurements (including baseline). Therefore, the results of both analyses are presented. Psychological distress and physical functioning at baseline were controlled for in these analyses. Logistic regression analyses were conducted to examine the effect of treatment condition on absenteeism and full work incapacity. Physical functioning and psychological distress at baseline were controlled for in the logistic regression analyses. Absenteeism at the $12-$ month measurement was also controlled for in the logistic regression analyses to account for the differences that developed in absenteeism within the first year.

Age, gender, and education were controlled for in all the analyses but did not alter any of the findings and were therefore omitted from the final analyses. All of the analyses were 
conducted according to the intention-to-treat principle, using all available data at all consecutive time points, with the exception of the analysis of work incapacity, which used all patients who could have worked at the last measurement, effectively excluding all retirement cases. The mixed procedure of the statistical package SAS (version 8) was used to perform the covariance analysis (mixed linear regression analyses). All other analyses were performed using SPSS statistical package (version 11.0).

\section{Results}

\section{Recruitment of patients}

Of the original 151 patients, 127 (84\%) participated in this follow-up study. Eleven patients in the CBT group and thirteen patients in the control group were lost to follow-up (see figure 1). Non-responders at the 4-year follow-up were significantly more fatigued and had significantly lower levels of physical functioning at baseline compared to responders. However, when comparing the non-responders in the intervention group with the nonresponders in the control group there was no significant difference. There was no significant difference in the mean follow-up period between the intervention and the control group.

Table 1 shows the patient characteristics at the last measurement. In general, many patients in both groups were (still) severely fatigued and absent from work at the 4 year follow-up measurement. Age, gender, education, and duration of fatigue complaints were comparable in both groups. There was a small difference between the groups on fatigue scores and psychological distress scores. More patients in the CBT group were absent from work as compared with the control group. The number of patients claiming full work incapacity benefit or work incapacity benefit combined with an unemployment benefit was higher in the CBT group. There were more patients in the control group claiming partial work incapacity benefit, Finally, the degree of physical functioning was higher in the control group than in the CBT group. 


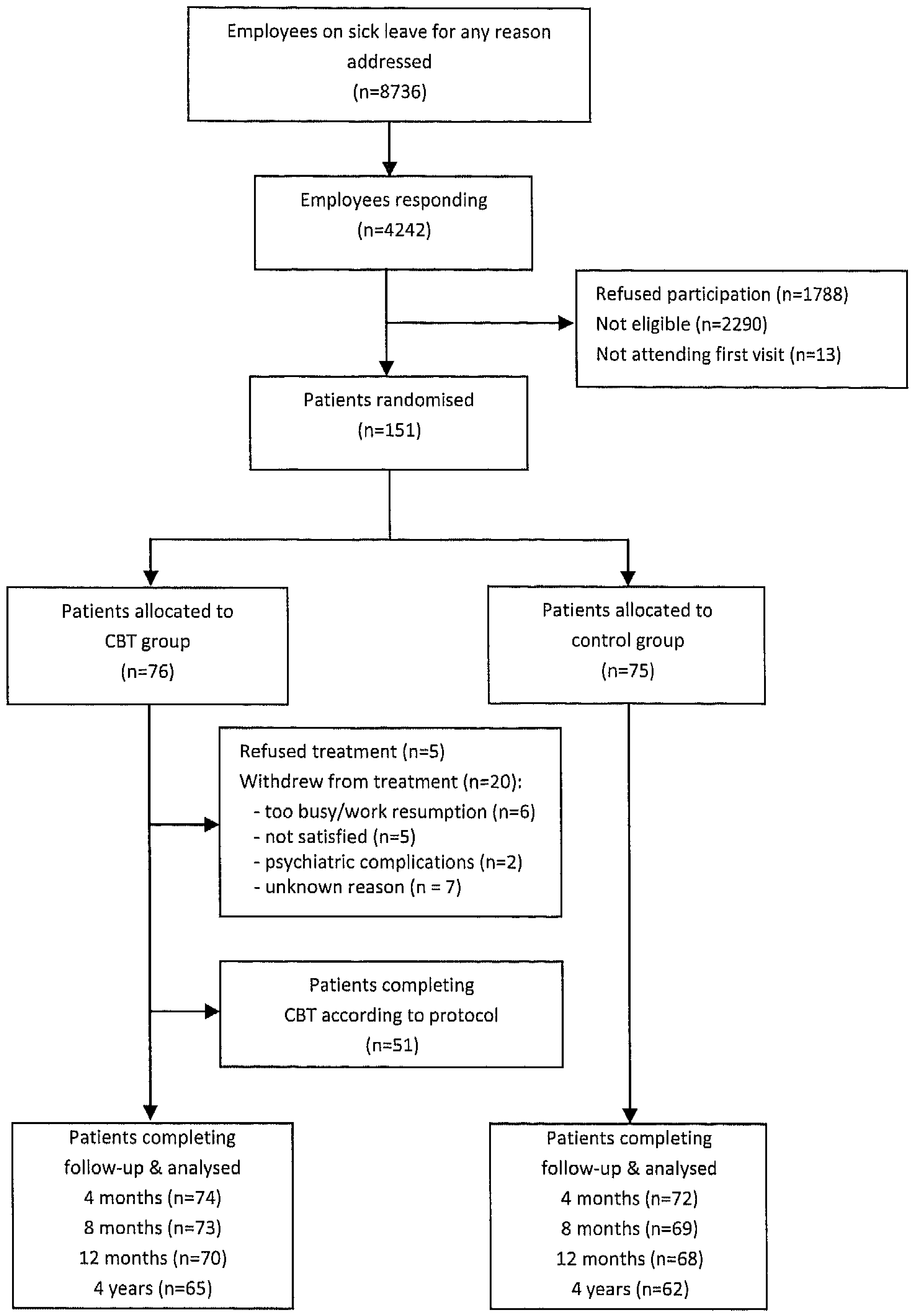

Figure 1 Flowchart of patient recruitment, treatment allocation and outcome assessments 
Table 1 Charatengtits of patients at long-term follow up (4 years)

\begin{tabular}{|c|c|c|}
\hline 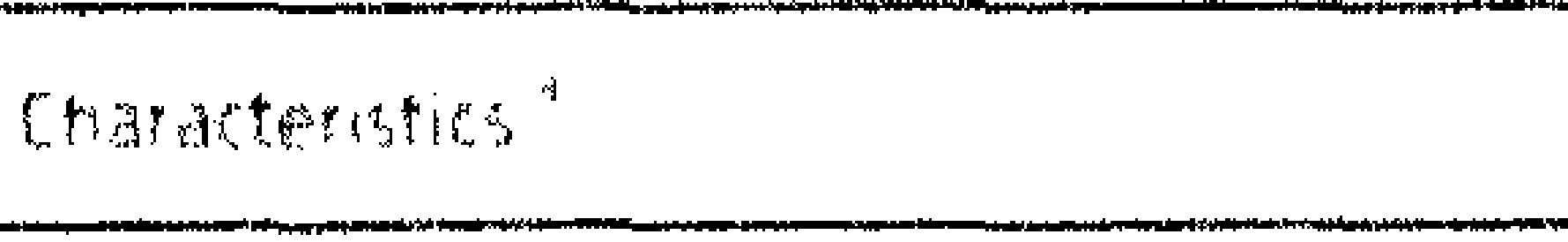 & $\begin{array}{c}\text { Cet group } \\
(n=65)\end{array}$ & $\begin{array}{l}\text { Sontrol group } \\
(n=62)\end{array}$ \\
\hline Agetyears & $486(9.2)$ & $48.0(7.3)$ \\
\hline Grander, $m / t / m, m$ & $31 / 34(48 \%)$ & $25 / 37(40 \%)$ \\
\hline Eduratton 11 - tow to 7 hishi & $3.8(1.7)$ & $3.8(1.6)$ \\
\hline F & 35.0114 .41 & $33.3(14.0)$ \\
\hline 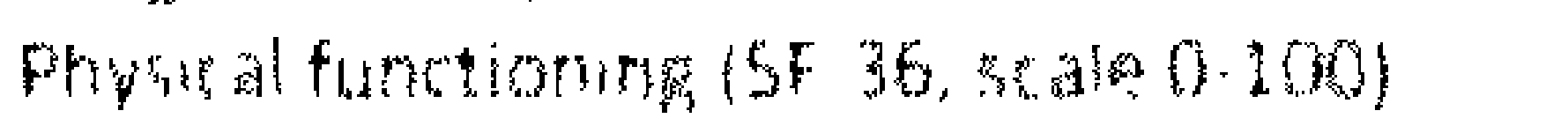 & 66112701 & $74.7(21.6)$ \\
\hline 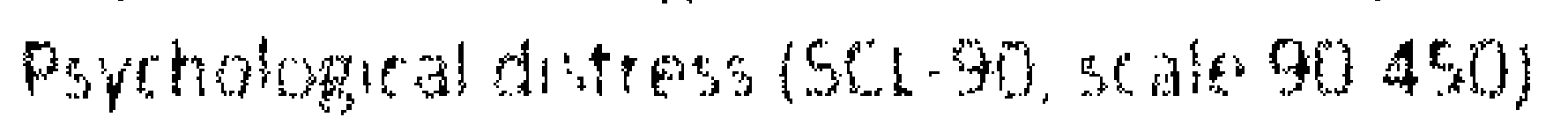 & $1472(42.1)$ & $149.4(47.0)$ \\
\hline \multicolumn{3}{|l|}{ Duration of tatigus comphants } \\
\hline 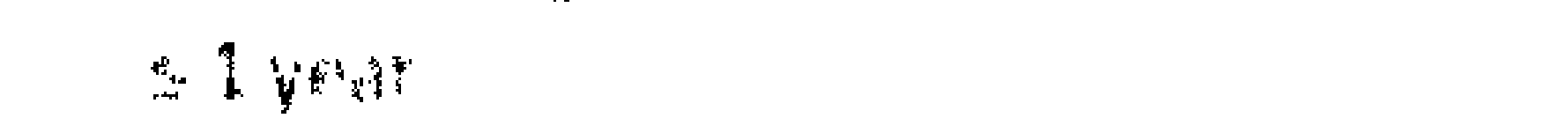 & $23(35 \%)$ & $20(32 \%)$ \\
\hline 22 ybets: & $42\left(65 x_{2}\right)$ & $42(67 \%)$ \\
\hline \multicolumn{3}{|l|}{ Absentengism } \\
\hline Total: & $29(45 \%)$ & $18(29 \%)$ \\
\hline $\operatorname{sicknax} \pi$ & $1(2)$ & $2(3 \%)$ \\
\hline Full work incapacity & $20(31 \mathrm{~m})$ & $13(21 \%)$ \\
\hline Partial work ircapakity & $1(2 \%)$ & $4(7 \%)$ \\
\hline Work incapacity and unemployment & $3(5 \%)$ & $0(0 \%)$ \\
\hline Fatigue cases & $42(65 \%)$ & $30(48 \%)$ \\
\hline CFS like cases: & $18(28 \%$ & $15(25 \%)$ \\
\hline
\end{tabular}

"Data are mean values (5.0.) orn (\%)

"Total absenteerm includes sick leave, full or partal work ncapacity, unemployment and retirement pension

\section{Fatigue as outcome}

The results of the covariance analysis for fatigue development over time are presented in table 2 . The difference between the groups in decrease of fatigue scores showed a trend toward significance ( $p=0.09$ for both the uncorrected and the corrected coefficient). The analysis of covariance revealed that there was a significant decrease in the fatigue score from 4 months to 4 years (corrected for baseline scores of fatigue, psychological distress, and physical functioning) in the control group but not in the CBT group. Figure 2 shows the mean $\mathrm{CIS}$ scores at each measurement.

The analysis of covariance controlling for baseline fatigue, psychological distress, and physical functioning showed that patients with a high psychological attribution at baseline had a significant reduction in fatigue scores from 4-month follow-up onward (table 2). This was not the case for the patients with a low psychological attribution. The difference between high and low psychological attributions on fatigue development was not significant. Patients with low somatic attributions had a significant decrease in fatigue scores, as opposed to patients with high somatic attributions. The difference between high and low somatic attributions on fatigue showed a trend towards significance $(p=0.09)$. 
Table 2 Effect of treatment condition (CBT versus control), psychological attribution, and somatic attribution on fatigue over time

\begin{tabular}{|c|c|c|c|c|}
\hline Variable & $\begin{array}{l}\text { Coefficient } \\
(95 \% \mathrm{Cl})\end{array}$ & p-value & $\begin{array}{l}\text { Coefficient } \\
(95 \% \mathrm{Cl})\end{array}$ & p-value \\
\hline Time $\times$ CBT group & $-0.04(-0.10$ to 0.03$)$ & 0.30 & $-0.03(-0.10$ to 0.05$)$ & 0.50 \\
\hline Time $x$ control group & $-0.10(-0.17$ to -0.03$)$ & 0.00 & $-0.12(-0.19$ to -0.04$)$ & 0.00 \\
\hline $\begin{array}{l}\text { Difference } \\
\text { Time } \times \text { CBT - time } x \text { control }\end{array}$ & $0.09(-0.01$ to 0.20$)$ & 0.09 & $0.09(-0.01$ to 0.19$)$ & 0.09 \\
\hline Time $x$ low psychological attribution & $-0.03(-0.10$ to 0.04$)$ & 0.42 & $-0.03(-0.10$ to 0.04$)$ & 0.41 \\
\hline $\begin{array}{l}\text { Time } x \text { high psychological attribution } \\
\text { Difference }\end{array}$ & $-0.11(-0.19$ to -0.04$)$ & 0.00 & $-0.11(-0.18$ to -0.03$)$ & 0.00 \\
\hline $\begin{array}{l}\text { Time } x \text { low psychological attribution } \\
\text { time } x \text { high psychological attribution }\end{array}$ & $0.08(-0.03$ to 0.18$\}$ & 0.12 & $0.08(-0.02$ to 0.18$)$ & 0.13 \\
\hline Time $x$ low somatic attribution & $-0.11(-0.18$ to -0.04$)$ & 0.00 & $-0.11(-0.18$ to -0.04$)$ & 0.00 \\
\hline $\begin{array}{l}\text { Time } x \text { high somatic attribution } \\
\text { Difference }\end{array}$ & $-0.02(-0.10$ to 0.05$)$ & 0.52 & $-0.02(-0.10$ to 0.05$)$ & 0.55 \\
\hline $\begin{array}{l}\text { Time } x \text { low somatic attribution - } \\
\text { time } x \text { high somatic attribution }\end{array}$ & $-0.09(-0.19$ to 0.02$)$ & 0.10 & $-0.09(-0.19$ to 0.01$)$ & 0.09 \\
\hline
\end{tabular}

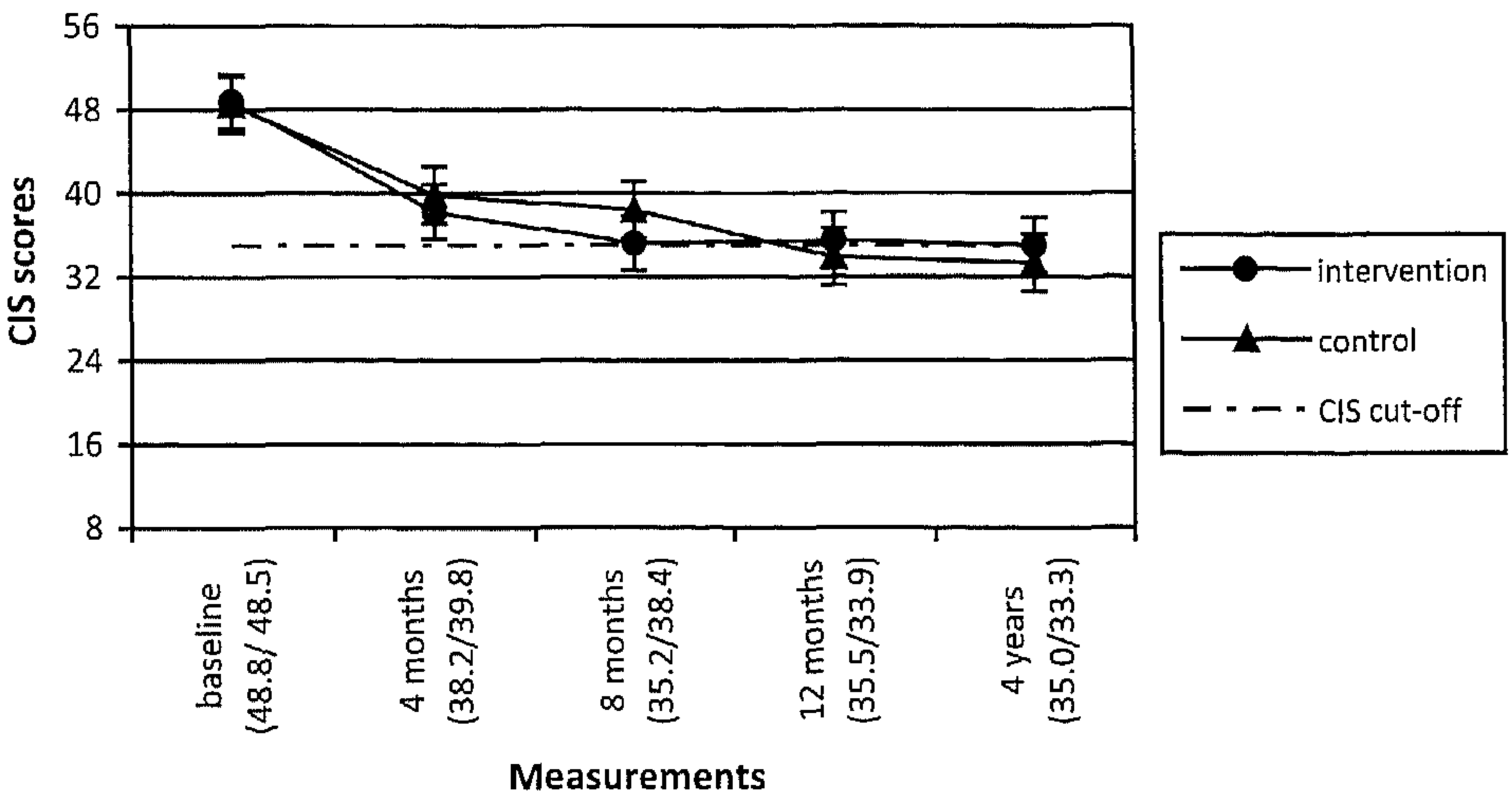

Figure 2 Mean CIS scores with confidence intervals at baseline, 4 months, 8 months, 12 months and 4 years [mean CIS values (intervention/control)]

When modelling from baseline onward, the results show a significant reduction in fatigue scores in both the high and low psychological attribution groups (coefficients corrected for psychological distress and physical functioning: $-0.24, p<0.0001$ and $-0.14, p<0.0001$, respectively). The difference in reduction of fatigue scores from baseline onward between 
the high and low psychological groups was significant (coefficient corrected for psychological distress and physical functioning: $0.10, p=0.049)$. A significant reduction in fatigue scores was also observed in both the high and low somatic attribution groups (coefficients corrected for psychological distress and physical functioning: $-0.13, p<0.0001$ and $-0.24, p=0.0002$, respectively). The difference between the high and low somatic groups was significant (coefficient corrected for psychological distress and physical functioning: $0.10, p=0.039)$.

\section{Absenteeism and work incapacity as outcome}

The patients in the CBT group showed a trend towards an increased risk of becoming absent as compared with those in the control group (table 3). Although the odds ratio (OR) is considerable, it failed to reach statistical significance. The OR decreased when controlling for physical functioning and psychological distress at baseline.

Similarly, patients in the CBT group tended toward an increased risk of full work incapacity as compared with those in the control group. This OR also failed to reach significance. Again, the $O R$ decreased after controlling for baseline physical functioning and psychological distress scores. However, the OR increased for both absenteeism and work incapacity when the work status at the 12 -month measurement was entered into the model.

Table 3 Effect of treatment condition (CBT versus control) on absenteeism and full work incapacity

\begin{tabular}{lllllll}
\hline & $\begin{array}{l}\mathrm{OR}^{3} \\
(95 \% \mathrm{Cl})\end{array}$ & $\mathrm{p}$-value & $\begin{array}{l}\mathrm{OR}^{\mathrm{b}} \\
(95 \% \mathrm{Cl})\end{array}$ & $\mathrm{p}$-value & $\begin{array}{l}\mathrm{OR}^{6} \\
(95 \% \mathrm{Cl})\end{array}$ & p-value \\
\hline Absenteeism & $1.76(0.87-3.59)$ & 0.12 & $1.39(0.65-3.01)$ & 0.40 & $1.48(0.59-3.75)$ & 0.41 \\
Full work incapacity & $1.72(0.76-3.86)$ & 0.19 & $1.33(0.56-3.15)$ & 0.52 & $1.40(0.49-4.03)$ & 0.53 \\
\hline
\end{tabular}

OR: odds ratio; $\mathrm{Cl}$ : confidence interval.

${ }^{\text {a }}$ Crude OR.

${ }^{b}$ OR adjusted for SF-36 scores and SCL-90 scores at baseline.

' $O R$ adjusted for SF-36 scores and SCL-90 scores at baseline and absenteeism at 12 months. 


\section{Discussion}

\section{Summary of main findings}

We found that patients with less advanced fatigue had a poor prognosis in the long term. In both the intervention and the control group, the mean CIS score at the 4-year follow-up was still around the cut-off score for severe fatigue, with $57 \%$ of the participants meeting criteria for severe fatigue. Absenteeism and full work incapacity were also high in both groups. These results are in line with previous studies on the course of CFS, which have shown a poor prognosis for patients with CFS ${ }^{1}$. This study shows that the prognosis in less advanced medically unexplained fatigue cases is unfavourable as well. Causal attributions were related to a decrease in fatigue scores in the long term. Specifically, strong psychological attributions and weak somatic attributions seem to be related to higher reductions in fatigue scores as compared with weak psychological attributions and strong somatic attributions. Various studies have shown that causal attributions affect the course of chronic fatigue and CFS ${ }^{11,19-21}$. Psychological attributions were also found to predict short-term recovery from fatigue in a previous analysis of this study sample ${ }^{22}$.

With respect to the RCT, it appears that our intervention is not effective for this sample in the long term. The results of the previous observations are sustained in this study, implying that there is no preventive effect on relapse of fatigue complaints and absenteeism. At the 12-month follow-up, it was not clear whether the nature of the intervention, the delivery of the intervention by GPs, the severity of fatigue among participants, or a combination of these three was responsible for the ineffectiveness of the intervention ${ }^{23}$. The present results indicate that the condition of the patients in this trial is more serious than previously thought. It could be that the delivery and intensity (five to seven 30-minute sessions) of the intervention by the GPs did not match the severity of the complaints.

\section{Strengths and weaknesses}

This is the first study to present long-term results of the efficacy of CBT for less advanced medically unexplained fatigue cases. Another strong point of this study is the high response rate $(84 \%)$. This study did have some limitations. As mentioned, non-responders in the total group at the last measurement differed significantly from the responders on baseline fatigue scores and physical functioning scores. This was not the case when comparing the non-responders in the intervention group with the non-responders in the control group. As this difference in the total group was to the disadvantage of the non-responders, the results presented in this study could be an underestimation of the severity of health problems among patients. The power of this study may not have been sufficient to uncover significant differences between the groups, especially with respect to the noteworthy differences in absenteeism and full work incapacity. 


\section{Adverse effects in the CBT group}

Although not significant, there were some noteworthy differences between the two groups on several outcome measures. Unexpectedly, it was the intervention group and not the control group that tended towards less favourable outcomes in the long-term. The difference in absenteeism and work incapacity is especially striking. Although the results do not permit drawing any definite conclusions, a possible explanation for this finding could be the occurrence of some form of labelling in the intervention group due to the design we chose. First, the patients were only informed about the research condition to which they were allocated and did not know of the existence of the other condition. Second, these patients had not received a diagnosis for their fatigue complaints at the start of the trial. The patients who went on to receive CBT, which came as a surprise to many of them, may have been affected by the intervention in a way that was not intended. The intervention may have defined and inadvertently labelled a condition that, up to that point, the patients were not aware of, encouraging or confirming perceptions of ill health. The patients in the control group, however, merely filled out questionnaires at the various measurements and were not placed in the same situation as the patients in the intervention group with respect to the defining and labelling of a fatigue condition. If this were the case, a serious difference could have been created between the research conditions other than the presence or absence of CBT.

Earlier, we hypothesised that labelling can affect the course of fatigue complaints ${ }^{24}$. Indeed, recent findings suggest that different labels for the same fatigue condition result in different prognoses of that fatigue condition ${ }^{25}$. More specifically, it was found that the label ME entailed a worse prognosis than the label CFS, although the condition these labels denote is one and the same. Because of these serious implications, we feel that further research is needed to investigate the issue of labelling.

\section{Acknowledgements}

This study was funded by the Health Research and Development Council (ZonMw), The Netherlands (grant no. 21000104). 


\section{References}

1 Afari N, Buchwald D. Chronic fatigue syndrome: A review. American Journal of Psychiatry 2003; 160: 221-36.

2 Whiting P, Bagnall AM, Sowden AJ, Cornell JE, Mulrow CD, Ramirez G. Interventions for the treatment and management of chronic fatigue syndrome: a systematic review. Journal of the American Medical Association 2001; 286: 1360-8.

3 Ridsdale L, Darbishire L, Seed PT. Is graded exercise better than cognitive behaviour therapy for fatigue? A UK randomized trial in primary care. Psychological Medicine 2004; 34: 37-49.

4 Ridsdale L, Godfrey E, Chalder T, Seed P, King M, Wallace P, Wessely S. Chronic fatigue in general practice: is counselling as good as cognitive behaviour therapy? A UK randomised trial. British Journal of General Practice 2001; 51: 19-24.

5 Whitehead L, Campion P. Can general practitioners manage chronic fatigue syndrome? A controlled trial. Journal of Chronic Fatigue Syndrome 2002; 10: 55-64.

6 Huibers MJ, Beurskens AJ, Van Schayck CP, Bazelmans E, Metsemakers JF, Knottnerus JA, Bleijenberg G. Efficacy of cognitive-behavioural therapy by general practitioners for unexplained fatigue among employees: Randomised controlled trial. British Journal of Psychiatry 2004; 184: 240-6.

7 Zelen M. Randomized consent designs for clinical trials: an update. Statistics in Medicine 1990; 9: 645-56.

8 Huibers MJ, Bleijenberg G, Beurskens AJ, Kant IJ, Knottnerus JA, van der Windt DA, Bazelmans $E$, van Schayck CP. An alternative trial design to overcome validity and recruitment problems in primary care research. Family Practice 2004; $21: 213-8$.

9 Beurskens AJ, Bultmann U, Kant I, Vercoulen JH, Bleijenberg G, Swaen GM. Fatigue among working people: validity of a questionnaire measure. Occupational and Environmental Medicine 2000; 57: 353-7.

10 Vercoulen JHHM, Alberts M, Bleijenberg G. De Checklist Individuele Spankracht (CIS) [The Checklist Individual Strength (CIS)]. Gedragstherapie 1999; 32: 131-6.

11 Vercoulen JH, Swanink CM, Fennis JF, Galama JM, van der Meer JW, Bleijenberg G. Prognosis in chronic fatigue syndrome: a prospective study on the natural course. Journal of Neurology, Neurosurgery and Psychiatry 1996; 60: 489-94.

12 Prins JB, Bleijenberg G, Bazelmans E, Elving LD, de Boo TM, Severens JL, van der Wilt GJ, Spinhoven $P$, van der Meer JW. Cognitive behaviour therapy for chronic fatigue syndrome: a multicentre randomised controlled trial. Lancet 2001; 357: 841-7.

13 Ware JE, Jr., Sherbourne CD. The MOS 36-item short-form health survey (SF-36). I. Conceptual framework and item selection. Medical Care 1992; 30: 473-83.

14 Aaronson NK, Muller M, Cohen PD, Essink-Bot ML, Fekkes M, Sanderman R, Sprangers MA, te Velde A, Verrips $E$. Translation, validation, and norming of the Dutch language version of the SF-36 Health Survey in community and chronic disease populations. Journal of Clinical Epidemiology 1998; 51: 1055-68.

15 Derogatis LR, Lipman RS, Covi L. SCL-90: an outpatient psychiatric rating scale--preliminary report. Psychopharmacological Bulletin 1973; 9: 13-28.

16 Arrindel WA, Ettema JHM. Symptom Checklist-90, SCL-90, een multidimensionele psychpathologie-indicator, handleiding [Symptom Checklist-90, a multidimensional psychopathology indicator, manual]. Lisse: Swets Test Services, 1986. 
17 Fukuda K, Straus SE, Hickie I, Sharpe MC, Dobbins JG, Komaroff A. The chronic fatigue syndrome: a comprehensive approach to its definition and study. International Chronic Fatigue Syndrome Study Group. Annals of Internal Medicine 1994; 121: 953-9.

18 Twisk J, Proper K. Evaluation of the results of a randomized controlled trial: how to define changes between baseline and follow-up. Journal of Clinical Epidemiology 2004; 57: 223-8.

19 Wilson A, Hickie I, Lloyd A, Hadzi-Pavlovic D, Boughton C, Dwyer J, Wakefield D. Longitudinal study of outcome of chronic fatigue syndrome. British Medical Journal 1994; 308: 756-9.

20 Chalder T, Power MJ, Wessely S. Chronic fatigue in the community: 'A question of attribution'. Psychological Medicine 1996; 26: 791-800.

21 Schmaling KB, Fiedelak JI, Katon WJ, Bader JO, Buchwald DS. Prospective study of the prognosis of unexplained chronic fatigue in a clinic-based cohort. Psychosomatic Medicine 2003; 65: 1047-54.

22 Huibers MJ, Bleijenberg G, van Amelsvoort LG, Beurskens AJ, van Schayck CP, Bazelmans E, Knottnerus JA. Predictors of outcome in fatigued employees on sick leave: results from a randomised trial. Journal of Psychosomatic Research 2004; 57: 443-9.

23 Bazelmans E, Huibers MJH, Bleijenberg G. A Qualitative Analysis of the Failure of CBT for Chronic Fatigue Conducted by General Practitioners. Behavioural \& Cognitive Psychotherapy 2005; 33: 225-35.

24 Huibers MJH, Beurskens AJHM, Prins JB, Kant IJ, Bazelmans E, van Schayck CP, Knottnerus $J A$, Bleijenberg $G$. Fatigue, burnout, and chronic fatigue syndrome among employees on sick leave: do attributions make the difference? Occupational and Environmental Medicine 2003; 60: 26-31.

25 Hamilton WT, Gallagher AM, Thomas JM, White PD. The prognosis of different fatigue diagnostic labels: a longitudinal survey. Family Practice 2005; 22: 383-8. 
Chronic fatigue syndrome-like caseness as a predictor of work status in fatigued employees on sick leave: A 4-year follow-up study

M.J.H. Huibers ${ }^{1}$

S.S. Leone ${ }^{2}$

IJ. Kant ${ }^{2}$

J.A. Knottnerus ${ }^{3}$

${ }^{1}$ Department of Clinical Psychological Science, Maastricht University, Maastricht, The Netherlands

${ }^{2}$ Department of Epidemiology, Maastricht University, Maastricht, The Netherlands

${ }^{3}$ Department of General Practice, Maastricht University, Maastricht, The Netherlands

Occupational and Environmental Medicine 2006; 63:570-572 


\section{Abstract}

\section{Objective}

To assess whether CFS-like caseness [meeting the criteria for chronic fatigue syndrome (CFS)] predicts work status in the long term.

\section{Methods}

A prospective study in a sample of fatigued employees absent from work. Data were collected at baseline and 4 years later, and included CFS-like caseness and work status (inactive work status and full work incapacity).

\section{Results}

CFS-like cases at baseline were three times more likely to be unable to work at follow-up than fatigued employees who did not meet CFS criteria at baseline (odds ratios (ORs) between 3 and 3.3). These associations grew even stronger when demographic and clinical confounders were controlled for (ORs 3.4 and 4.4).

\section{Conclusion}

A CFS-like status (compared to non-CFS fatigue) proved to be a strong predictor of an inactive work status and full work incapacity in the long term. Since little is known about effective interventions that prevent absenteeism and work incapacity or facilitate return to work in subjects with chronic fatigue, there is a great need for powerful early interventions that restore or preserve the ability to work, especially for workers who meet criteria for CFS. 


\section{Introduction}

Chronic fatigue syndrome (CFS) is characterised by persistent, unexplained fatigue that lasts at least 6 months, and impaired functional abilities ${ }^{1}$. Although alleviation of symptoms is not uncommon, full recovery from untreated CFS is rare ${ }^{2}$.

The prevalence of CFS among workers has been estimated to be $3.6 \%{ }^{3}$. The issue of CFS and work status has been addressed in two recent systematic reviews ${ }^{4,5}$. It was found that many CFS patients are unemployed or unable to work, and that the prognosis in terms of return to work is poor. However, it was also concluded in both reviews that most prognosis studies to date have failed to focus on occupational outcomes, despite the apparent economic and societal consequences of CFS. As a result, many questions remain unanswered: the association between functional impairment and work status is not well demonstrated, evidence on effective interventions restoring the ability to work is limited, and predictors of occupational outcomes in CFS have yet to be found ${ }^{4}$.

In the present report, we focus on CFS-like caseness as a predictor of work status in a sample of fatigued employees absent from work who were followed up approximately 4 years later. We believe we are the first to do so.

\section{Methods}

\section{Design}

We conducted a prospective study as part of a randomised trial described elsewhere ${ }^{6}$. Data used in the present analysis were collected at the baseline assessment and at the long-term follow-up. This additional follow-up measurement was conducted simultaneously for all participants, as a result of which the mean follow-up period was 3.8 years (range 3.1-4.8 years).

\section{Subjects}

Participants in the original trial were recruited in collaboration with a local occupational health service (OHS) that monitors a working population of 80,000 employees. The inclusion criterion was severe fatigue (a score of 35 or more on the subscale fatigue severity of the Checklist Individual Strength ${ }^{7}$ ) for 4 months or more as one of the main health problems in combination with complete absenteeism from work for 6 to 26 weeks (thereby excluding formal work incapacity). Participants were excluded from participation if they: had medical conditions that explained fatigue, received co-interventions for fatigue, had a previously classified psychiatric disorder, or received psychological treatment. In addition, absenteeism should not be caused by problems unrelated to health (e.g. a conflict at work). Of the 151 participants who entered the original study, 127 (84\%) responded to the long-term follow-up and were included in this analysis. Non-responders at follow-up 
were significantly more fatigued and had significantly lower levels of physical functioning at baseline than responders.

\section{Study variables}

Fatigue severity was measured with the subscale fatigue severity of the Dutch version of the Checklist Individual Strength $(\mathrm{CIS})^{7}$. Higher scores indicate a higher severity of fatigue; a score of 35 or higher is indicative of severe fatigue.

Physical functioning was measured with a subscale from the Dutch version of the Short Form Health Survey $(S F-36)^{8}$, with higher scores indicating higher levels of physical functioning.

Participants were identified as CFS-like cases at baseline if they met all of the following research criteria: a CIS score on the subscale fatigue severity of $40 \mathrm{or} \mathrm{higher}^{9}$, a selfreported duration of fatigue complaints of 6 months or more and a SF-36 score on the subscale physical functioning of 60 or lower. Except for the symptom criteria, these research criteria approximate the CDC criteria for CFS ${ }^{1}$. Without a proper medical examination, subjects who meet CFS criteria do not necessarily qualify as CFS patients, but a CFS-like status is widely regarded as a good proxy for medically diagnosed CFS ${ }^{10}$. None of the fatigued employees had a CFS diagnosis made by a physician at entry in the study.

Work status at follow-up was assessed in two ways: self-reported inactive work status (including sick leave, full or partial work incapacity, unemployment and retirement pension) and self-reported full work incapacity (including disability benefits) as specified in the Dutch Social Disability Act.

Other variables included psychological problems (SCL-90 ${ }^{11,12}$ ), self-rated health $\left(\mathrm{SF}-36^{8}\right.$ ), self-efficacy (sense of control in relation to complaints, SES ${ }^{6,9}$, psychological attributions (beliefs regarding the psychological cause of complaints, $\mathrm{CAL}^{6,9}$ ), somatic attributions (beliefs regarding the somatic cause of complaints, CAL ${ }^{6,9}$ ), self-reported duration of absenteeism and a self-reported CFS diagnosis at follow-up.

\section{Statistical analysis}

We used multiple logistic regression analysis to determine the association between a CFSlike status at baseline and work status at follow-up. In a first step, CFS-like caseness at baseline was entered in the model. Subsequently, we controlled for potential confounders at baseline. We also controlled for treatment received in the original study and variations in follow-up time, but these variables were later omitted from the analysis since adjustment did not alter our findings. Logistic regression analysis was performed using SPSS (version 11.5). 


\section{Results}

\section{Characteristics of the sample}

Table 1 presents the characteristics of the participants at baseline and at follow-up. What stands out is the high level of fatigue and absenteeism at follow-up in the entire sample. Fifty-seven percent of the participants (still) met criteria for severe fatigue 4 years later, while 54 participants $(43 \%)$ were not working at the time of follow-up. A substantial number of CFS-like employees at baseline went on to meet criteria for CFS four years later (40\%), in most cases without ever receiving a CFS diagnosis. Twelve participants $(16.9 \%)$ developed a CFS-like status during the 4 years.

\section{CFS as predictor of work status}

Table 2 presents odds ratios (ORs) for the association between CFS-like caseness at baseline and work status. In a univariate analysis, CFS-like cases were three times more likely to be unable to work at follow-up than fatigued employees who did not meet CFS criteria at baseline. These associations grew even stronger when we controlled for demographic and clinical confounders, with an adjusted odds ratio of 4.4 for inactive work status and 3.9 for full work incapacity.

In an ancillary analysis, we extended the model and controlled for CFS selection variables at baseline (data not shown). Controlling for fatigue severity and fatigue duration did not alter the strong association between CFS-like caseness and work status (OR inactive work status 4.2, 95\% confidence interval (Cl) 1.5-12.3; OR full work incapacity $4.5,95 \% \mathrm{Cl} 1.4-14.6$ ), but the odds ratios decreased and lost their significance when we controlled for physical functioning in a final step (OR inactive work status $2.2,95 \% \mathrm{Cl} 0.6-7.7$; OR full work incapacity $2.3,95 \% \mathrm{Cl} 0.6-8.4)$. 
Table 1 Characteristics of 127 participants at baseline and 4-year follow-up, according to CFS-like caseness at baseline

\begin{tabular}{|c|c|c|}
\hline Characteristics $^{\circ}$ & $\begin{array}{l}\text { CFS-like employees } \\
\qquad(n=52)\end{array}$ & $\begin{array}{l}\text { Fatigued employees } \\
\qquad(n=75)\end{array}$ \\
\hline \multicolumn{3}{|l|}{ Demographics at baseline } \\
\hline Age (years) & $43.9(8.4)$ & $44.2(8.1)$ \\
\hline Gender, female & $31(60 \%)$ & $40(53 \%)$ \\
\hline Education (1=low to $7=$ high) & $3.2(1.4)$ & $4.2(1.7)$ \\
\hline \multicolumn{3}{|l|}{ CFS selection variables } \\
\hline \multicolumn{3}{|l|}{ Fatigue severity (CIS, scale 8-56) } \\
\hline Baseline & $50.1(5.0)$ & $46.7(6.6)$ \\
\hline Follow-up & $39.0(13.8)$ & $30.8(13.5)$ \\
\hline Duration of fatigue complaints (months) at baseline & $35.0(31.0)$ & $22.8(26.6)$ \\
\hline \multicolumn{3}{|l|}{ Physical functioning (SF-36, scale $0-100)$} \\
\hline Baseline & $45.1(13.1)$ & $77.0(20.3)$ \\
\hline Follow-up & $58.0(25.1)$ & $78.8(20.8)$ \\
\hline CFS-like cases at follow-up & $21(40 \%)$ & $12(17 \%)$ \\
\hline CFS diagnoses at follow-up & $4(8 \%)$ & $3(4 \%)$ \\
\hline \multicolumn{3}{|l|}{ Work status at follow-up } \\
\hline Inactive work status & $31(60 \%)$ & $23(31 \%)$ \\
\hline Full work incapacity & $20(39 \%)$ & $13(17 \%)$ \\
\hline \multicolumn{3}{|l|}{ Possible confounders } \\
\hline Duration of absenteeism (weeks) at baseline & $11.8(3.5)$ & $12.4(5.3)$ \\
\hline \multicolumn{3}{|l|}{ Psychological problems (SCL-90, scale $90-450)$} \\
\hline Baseline & $177.9(50.2)$ & $181.0(49.1)$ \\
\hline Follow-up & $160.6(51.2)$ & $139.7(36.9)$ \\
\hline \multicolumn{3}{|l|}{ Self-rated health (SF-36, scale $0-100$ ) } \\
\hline Baseline & $45.9(16.5)$ & $59.0(17.1)$ \\
\hline Follow-up & $47.2(20.9)$ & $62.6(20.1)$ \\
\hline $\begin{array}{l}\text { Somatic attributions at baseline } \\
\text { (CAL, scale } 4-16 \text { ) }\end{array}$ & $10.5(2.1)$ & $8.1(2.4)$ \\
\hline $\begin{array}{l}\text { Psychological attributions at baseline } \\
\text { (CAL, scale 7-28) }\end{array}$ & $18.5(4.6)$ & $19.3(4.2)$ \\
\hline
\end{tabular}

Fatigued employees= participants who did not meet research criteria for CFS at baseline.

CFS-like employees= participants who met research criteria for CFS at baseline.

${ }^{a}$ Data are mean values (S.D.) or $n(\%)$.

${ }^{b}$ Including sick leave, full or partial work incapacity, unemployment and retirement pension.

Table 2 CFS-like caseness at baseline as a predictor of inactive work status and full work incapacity at 4-year follow-up

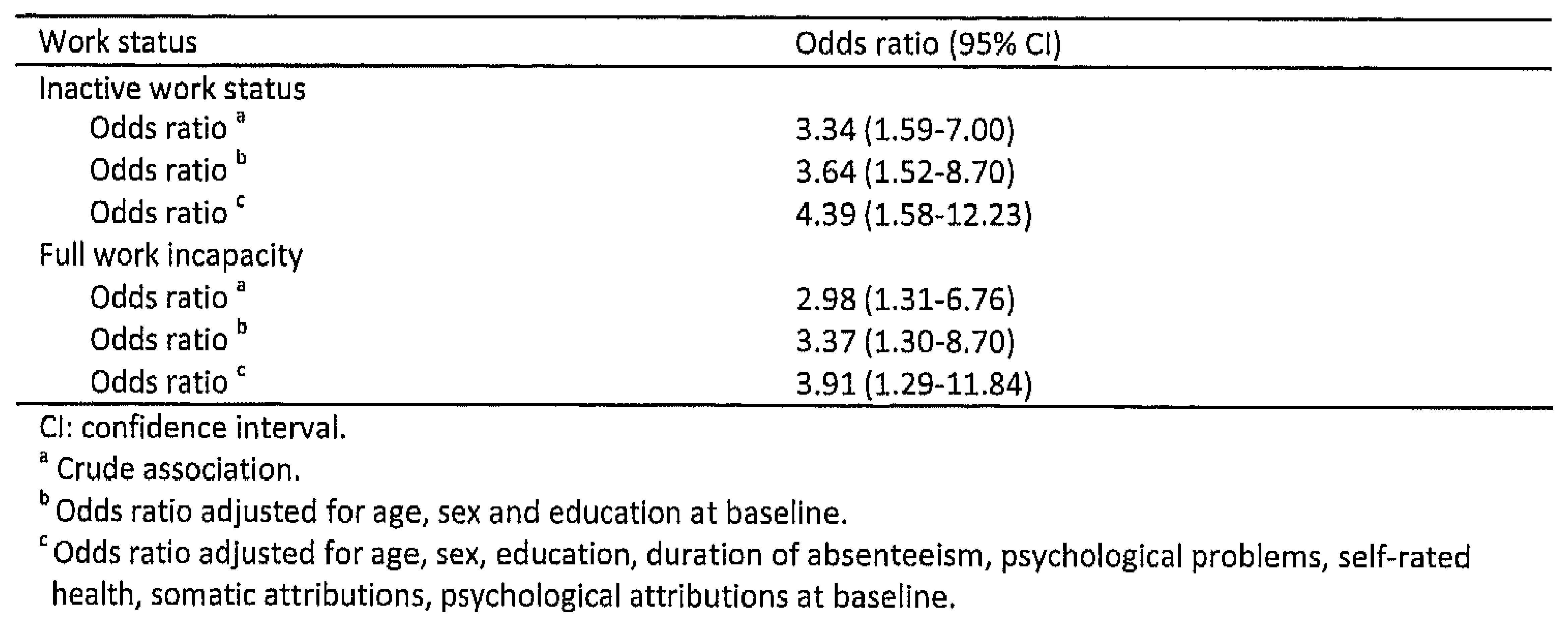




\section{Discussion}

We found that many fatigued employees were (still) unable to work 4 years later, in terms of inactive work status and full work incapacity. A CFS-like status at baseline proved to be a strong predictor of an inactive work status and full work incapacity in the long-term, despite the fact that fatigued employees without such a status showed a less than favourable prognosis as well.

Furthermore, controlling for CFS selection variables only had an impact when physical functioning was entered in the model. This ancillary analysis suggests that it is the component of physical dysfunctioning in CFS that leads to work incapacity, and not so much the component of fatigue, but these findings should be interpreted with some caution. Finally, a CFS-like status among the workers in our sample remained unrecognised in most cases, in line with findings from earlier studies ${ }^{3,13}$.

An obvious limitation of this study is that our CFS-like cases were not officially diagnosed with CFS, and may not represent CFS patients seen in clinical settings. Another limitation is that the use of research criteria for CFS and the fact that non-responders at follow-up displayed higher levels of fatigue and disability may have led to an underestimation of the association between CFS-like caseness and work status.

To date, little is known about effective interventions that prevent absenteeism and work incapacity or facilitate return to work in subjects with chronic fatigue ${ }^{4}$. In our own randomised trial, we compared brief cognitive-behavioural therapy by general practitioners with no treatment and found that our experimental intervention had no effect on fatigue or work status at any point in the course of 12 months ${ }^{6}$ and did not prevent work incapacity in the long term ${ }^{14}$. The findings in the present study seem to underline the need for powerful early interventions that restore or preserve the ability to work in chronic fatigue, especially for workers who meet criteria for CFS.

\section{Acknowledgements}

This study was funded by the Health Research and Development Council (ZonMw), The Netherlands (grant no. 21000104). 


\section{References}

1 Fukuda K, Straus SE, Hickie I, Sharpe MC, Dobbins JG, Komaroff A. The chronic fatigue syndrome: a comprehensive approach to its definition and study. International Chronic Fatigue Syndrome Study Group. Annals of Internal Medicine 1994; 121: 953-9.

2 Afari N, Buchwald D. Chronic fatigue syndrome: A review. American Journal of Psychiatry 2003; 160: 221-36.

3 Huibers MJ, Kant IJ, Swaen GM, KasI SV. Prevalence of chronic fatigue syndrome-like caseness in the working population: results from the Maastricht cohort study. Occupational and Environmental Medicine 2004; 61: 464-6.

4 Ross SD, Estok RP, Frame D, Stone LR, Ludensky V, Levine CB. Disability and chronic fatigue syndrome: a focus on function. Archives of Internal Medicine 2004; 164: 1098-107.

5 Cairns $R$, Hotopf $M$. A systematic review describing the prognosis of chronic fatigue syndrome. Occupational Medicine 2005; 55: 20-31.

6 Huibers MJ, Beurskens AJ, Van Schayck CP, Bazelmans E, Metsemakers JF, Knottnerus JA, Bleijenberg G. Efficacy of cognitive-behavioural therapy by general practitioners for unexplained fatigue among employees: Randomised controlled trial. British Journal of Psychiatry 2004; 184: 240-6.

7 Beurskens AJ, Bultmann U, Kant I, Vercoulen JH, Bleijenberg G, Swaen GM. Fatigue among working people: validity of a questionnaire measure. Occupational and Environmental Medicine 2000; 57: 353-7.

8 Ware JE, Jr., Sherbourne CD. The MOS 36-item short-form health survey (SF-36). I. Conceptual framework and item selection. Medical Care 1992; 30: 473-83.

9 Prins JB, Bleijenberg G, Bazelmans E, Elving LD, de Boo TM, Severens JL, van der Wilt GJ, Spinhoven P, van der Meer JW. Cognitive behaviour therapy for chronic fatigue syndrome: a multicentre randomised controlled trial. Lancet 2001; 357: 841-7.

10 Jason LA, Taylor RR. Applying cluster analysis to define a typology of chronic fatigue syndrome in a medically-evaluated, random community sample. Psychology \& Health 2002; 17: 323-37.

11 Derogatis LR, Lipman RS, Covi L. SCL-90: an outpatient psychiatric rating scale--preliminary report. Psychopharmacological Bulletin 1973; 9: 13-28.

12 Arrindel WA, Ettema JHM. Symptom Checklist-90, SCL-90, een multidimensionele psychpathologie-indicator, handleiding [Symptom Checklist-90, a multidimensional psychopathology indicator, manual]. Lisse: Swets Test Services, 1986.

13 Solomon L, Reeves WC. Factors influencing the diagnosis of chronic fatigue syndrome. Archives of Internal Medicine 2004; 164: 2241-5.

14 Leone SS, Huibers MJ, Kant I, van Amelsvoort LG, van Schayck CP, Bleijenberg G, Knottnerus JA. Long-term efficacy of cognitive-behavioral therapy by general practitioners for fatigue: a 4-year follow-up study. Journal of Psychosomatic Research 2006; 61: 601-7. 


\section{Two sides of the same coin? On the history and phenomenology of burnout and chronic fatigue}

5.S. Leone $e^{1}$

S. Wessely ${ }^{2}$

M.J.H. Huibers ${ }^{3}$

J.A. Knottnerus ${ }^{4}$

IJ. Kant ${ }^{1}$

${ }^{1}$ Department of Epidemiology, Maastricht University, Maastricht, The Netherlands

${ }^{2}$ Department of Psychological Medicine, Guy's, King's, and St Thomas' School of Medicine, Institute of Psychiatry, London, United Kingdom

${ }^{3}$ Department of Clinical Psychological Science, Maastricht University, Maastricht, The Netherlands

${ }^{4}$ Department of General Practice, Maastricht University, Maastricht, The Netherlands 


\section{Abstract}

\section{Background}

Burnout and chronic fatigue syndrome (CFS) are two fatigue syndromes which have developed largely independently from each other, yet whose similarities in symptoms can be a source of confusion. We aim to explore the phenomenology of burnout and CFS in a historical context as this may provide some insight into the links and relationship between these conditions.

\section{Methods}

A narrative review based on literature in the fields of history, social science and medicine.

\section{Results}

The origins of CFS lie within medicine, whereas burnout developed in a psychological setting. As well as symptoms, burnout and CFS also share similar themes such as an overload process triggering illness onset, the need for restoration of depleted energy, external causal attributions and the characteristics of people suffering from these illnesses. However, these themes are expressed in either psychological or medical terms according to the historical background.

\section{Conclusion}

Despite their similarities, there have been few direct comparisons of the two concepts. Culture, illness perceptions and accountability are important issues in both conditions and could contribute to their differences. Comparing burnout and CFS within one sample frame, thus looking beyond the psychology/ medicine divide, could be a useful first step towards understanding their relationship. 


\section{Introduction}

Burnout and chronic fatigue syndrome (CFS) are two syndromes that both have fatigue as a core component, and that are both associated with sickness absence and work disability ${ }^{1-3}$. Besides fatigue, there also seems to be an overlap in other symptoms such as depressed mood, muscle pains, nausea, headaches, and flu like symptoms ${ }^{2,4}$. In theory, these similarities ought to be a cause of diagnostic confusion, and hence to have stimulated empirical research. However, in practice the two appear to exist in very different spheres so that few are aware of the overlap either academically or empirically. The two constructs appear to have developed largely independently of each other. At best, the similarities have been noted en passant in an introduction of a paper or thesis ${ }^{5-7}$ or a paragraph in a book covering either burnout or CFS ${ }^{2,4}$ with few reflecting on the similarities and/or differences in more detail ${ }^{8,9}$. In one of the few empirical studies on the subject, it was found that burnout and CFS seem to overlap to some extent as employees identified as being fatigued or meeting research criteria for CFS could also fulfil criteria for burnout ${ }^{10}$. Comparing CFS and burnout is relevant due to the simple fact that these labels exist, that people suffer from these conditions and that their diagnosis is confusing due to the seemingly similar symptoms ${ }^{11}$.

The current essay is a narrative review on the phenomenology of CFS and burnout based on literature from the fields of history, social science and medicine. Exploring burnout and CFS in a historical context may provide some insight into the links and relationship between these conditions. Moreover, in a practical sense, it could provide a conceptual starting point to unravel these two fatigue syndromes. We will start with a brief history of the study and development of the concept of fatigue starting from the $19^{\text {th }}$ century when the modern interest in fatigue was sparked. The history of fatigue is an important and shared feature of both burnout and CFS but could, at the same time, also have been a source of the current difference.

\section{The discovery of fatigue: objective, subjective and abnormal}

Rabinbach has argued persuasively that the modern interest in the concept of fatigue was a product of the industrial revolution ${ }^{12}$. The change in work behaviour, longer hours and more monotonous tasks, triggered a sudden preoccupation with the problem of fatigue. At first, this centred largely around the problems of loss of productivity due to fatigue, a process that became further accelerated with the invention of the assembly line. The parallel expansion in education, especially once it started to encompass both the rising middle and then lower classes, and also women, along with the emergent themes of the overstrain and degeneration of society, also led to increasing concerns about mental fatigue or "surmenage" 9, 12,13.

One of the first issues at hand was to define and measure fatigue. The dramatic increase in understanding and measurement of the function of the peripheral nervous system, using 
such devices as Mosso's ergograph, promised much ${ }^{14}$. For a while it seemed as though physiology would provide a system for the measurement and, ultimately, the management of fatigue and hence to achieve the desired goal of increased productivity in either the factory or the class room ${ }^{12}$. But whilst the objective measurement of fatigue as in neuromuscular disorders did prove successful, the same did not happen with the subjective sense of fatigue - indeed by the end of the $19^{\text {th }}$ century it had become clear that these were two separate concepts ${ }^{15}$. The measurement of objective fatigue rarely coincided with the feeling of subjective fatigue.

The differences between the subjective and the objective became highlighted as fatigue also became of interest to doctors. This reached its apotheosis when the American neurologist George Beard introduced a new disease in 1869 which he labelled neurasthenia. Severe debilitating mental and physical fatigue arising after minimal effort was the hallmark of the new illness. With a deft blending of medical knowledge and social concern, Beard ascribed this new condition to a variety of social concerns, such as industrialisation, the rise of capitalism, the increase in working hours, and also the education of women, but couched it in the language of the new medicine and physiology, giving a spurious scientific authenticity that was accepted by many, but by no means all, of his contemporaries ${ }^{16}$. For Beard, neurasthenia was the result of both mental and physical overload, which might follow, for example, either a prolonged viral infection or, alternatively, an excessively demanding or pressured job. The result however, was an organic depletion of nervous energy ${ }^{17}$. Beard's neurasthenia combined features of both modern burnout and modern fatigue syndromes. With the arrival of neurasthenia, we see two notable changes. First, the inability of neurophysiologists to achieve the same understanding of fatigue in this new condition of nervous exhaustion as was being achieved elsewhere in neurology shifted the emphasis from seeing fatigue as purely objective and quantifiable to accepting the importance of the subjective feeling of fatigue. Second, neurasthenia signalled the interest of firstly medicine, and then later psychiatry, in fatigue, shifting away from being the concern solely of those dealing with productivity in the factory or the school. Fatigue had thus become abnormal rather than just an inconvenience or a hindrance to productivity.

\section{Neurasthenia, CFS and burnout}

Several scholars have drawn links between neurasthenia and its modern counter part of CFS ${ }^{18-20}$, but there are also striking similarities with burnout. Both burnout and neurasthenia are thought to be brought on by societal changes. Herbert Freudenberger, one of the first burnout researchers, noted that burnout was "a demon, born of the society and times we live in and our ongoing struggle to invest our lives with meaning" ${ }^{21}$ which could be applied directly to neurasthenia and Beard's time. Moreover, problematic work situations (e.g. overwork, monotonous work), which are thought to cause burnout ${ }^{22}$, have also always been associated with neurasthenia ${ }^{4,23-25}$. However, the process by which they 
influence neurasthenia is different from burnout and more similar to CFS. This is directly related to the presumed cause of the condition: psychological or somatic. This will be discussed in more detail later, but for now it is important to emphasise that at its outset neurasthenia was explicitly a somatic condition, even if its causes reflected social concerns. It was only later as it proved difficult to define and objectively measure fatigue that neurasthenia moved from the somatic to the psychological domain ${ }^{26,27}$. This shift from somatic to psychological along with the fact that neurasthenia came to encompass so many things, which made it not very useful or specific as a diagnosis, caused interest in neurasthenia to wane ${ }^{4}$. After this time, it has been noted that fatigue was studied in different areas according to its function or relevance ${ }^{9}$. Fatigue as relevant to work ended up in organisational or environmental medicine and psychology, whereas fatigue as relevant to a somatic process was assigned to medical fields such as virology or immunology ${ }^{9}$. Perhaps not surprisingly, these are the fields that correspond to the conditions of burnout and CFS, respectively.

\section{Cause of fatigue: somatic or psychological?}

The 1980's saw the emergence of two syndromes in which fatigue played an important role: burnout and CFS. The development of the concept of CFS followed a medical path. Immunology and virology played an important role in shaping perspectives on CFS. The first case definition of CFS and the first use of the word in the modern medical literature can be traced to the 1988 CDC meeting which was attended almost exclusively by virologists and immunologists ${ }^{28}$. The term CFS was introduced in order to replace one of the previous labels, namely chronic mononucleosis or chronic Epstein Barr virus infection ${ }^{28}$. Moreover, other synonyms that achieved prominence at about the same time, such as myalgic encephalomyelitis (originally introduced in the United Kingdom in 1956, but which remained largely unheard of until the 1980s) and chronic fatigue and immune dysfunction syndrome (CFIDS) ${ }^{4}$ also reflect the strong medical roots of this condition.

Burnout on the other hand, followed a more psychological path. Initial work on burnout suggested it affected mainly healthcare professionals due to chronic stress arising from strenuous interpersonal relationships at work ${ }^{29,30}$. This chronic stress depletes emotional and empathetic reserves leaving one to feel drained and weak or burned out. The work setting and factors related to it such as job demands, social support and occupational role ambiguity are considered to important causal factors ${ }^{22}$.

From the beginning then, there is a clear delineation between burnout and CFS in terms of their background and assumed cause: psychological and medical/somatic, respectively. Despite the difference in thinking about the cause and nature of both conditions, the initial symptoms associated with burnout and CFS were actually similar in their nature and magnitude: chronic fatigue, depressed mood, physical symptoms (e.g. muscle pains, nausea, headaches, flu like symptoms) and disability ${ }^{2,4}$. As both burnout and CFS developed further, the line between being a psychological condition or a medical condition 
began to blur. As with neurasthenia, it proved difficult to find solid somatic underpinnings for CFS and psychological factors such as psychological distress, illness perceptions and causal attributions became the focus of interest in studies on CFS ${ }^{31,32}$. Likewise, the focus of study in burnout did not remain solely on psychological and occupational factors but also turned to physiological factors such as cortisol levels and immunological factors ${ }^{8,33}$.

Despite the differences in background, several common themes can be identified in the phenomenology of burnout and CFS as we will now discuss. Perhaps the quintessential difference here is that these themes are expressed in either psychological (i.e. burnout) or somatic (i.e. CFS) terms. A central theme of both burnout and CFS is that there is a lack of energy that needs to be restored in some way. The defence mechanisms to preserve energy in burnout and CFS also reflect their respective perceived psychological and somatic nature. Burnout sufferers withdraw psychologically from stressful situations by acquiring a cynical attitude towards work ${ }^{34}$ whereas CFS sufferers withdraw physically and tend to reduce their activity out of fear it may cause more fatigue ${ }^{32}$.

Another theme is the type of people affected by these illnesses: hardworking, dedicated, active people. Even people in specific occupations, namely health care professionals, are assumed to be at an increased risk of both burnout and CFS ${ }^{34,35}$. One of the original and much derided sobriquets for CFS adopted by the media in the 1980s was "yuppie flu", reflecting the stereotype of the hard working young urban professional who had "burnt the candle at both ends" as it was often put, and then developed CFS in response. In burnout this increased risk is due to the stressful interpersonal relationships between the healthcare professional and the patient. In CFS however, it could also be due to an alleged increased exposure to certain infectious or viral agents in the work or school situation.

The theme of overload is present in both burnout and CFS either in psychological terms (i.e. psychological overstrain) or medical terms (overload of the immune system). The process seems to be similar: a history of stressful events leading to overload which triggers the breakdown, either in terms of burnout or CFS ${ }^{4,36}$. The theme of overload is especially important in popular or lay explanations of both burnout and CFS. Perhaps the single most common popular model for CFS is that of the body being overloaded by various insults, which might be infective, toxic or even stress related, which in turn depletes the body of "energy", almost invariably acting by "weakening the immune system", and which in turn leaves the person defenceless and exposed to new infections such as candida, or allergies and sensitivities ${ }^{37}$. The theme of overload is also an important lay explanation of burnout. In fact, the term "burnout" itself is a metaphor for the process of overload and the subsequent energy depletion, not unlike "a broken car battery that cannot be recharged and loses its power bit by bit" ${ }^{2}$. Burnout as a metaphorical term adequately reflected the experience of sufferers and became a popular and powerful term among the lay public before it became of interest to researchers ${ }^{2,34}$.

The shift of neurasthenia from the neurological to the psychological was accompanied by considerable opposition from the original exponents of neurasthenia in the medical 
profession, who became increasingly isolated and derided by their colleagues ${ }^{18}$. In the modern era a similar shift in the formulations of CFS, with increasing emphasis on psychological factors rather than physical factors in the study of CFS has been accompanied by fierce resistance from CFS patient organisations ${ }^{4}$. The problem is not so much the idea that psychological factors can play a part in the onset of CFS but rather that CFS itself is a psychological condition. Psychological factors such as stress can be considered as perhaps increasing vulnerability at the onset of CFS (a fact explicitly acknowledged in most self help literature), but are not seen to be the actual cause. Rather, stress sets physical responses in motion such as a weakening of the immune system (CFS) ${ }^{4}$ or previously the nervous system in neurasthenia ${ }^{38}$. It seems that experiencing stress is fine, but succumbing to it is not, as this would imply weakness and place the blame of the illness on the afflicted person. From the outset, burnout has been considered to be a psychological condition so there has been no real need to struggle for it to be recognised as a somatic condition. Furthermore, the conflation of psychological aetiologies with guilt and biame has never been an issue with respect to burnout. More than likely, this has not so much to do with the distinction between a physical or psychological origin of illness per se, but with how either the illness itself (CFS versus burnout) or psychological disorders in general are perceived by the sufferer and other stakeholders. More specifically, it depends on what the perceived cause is and the implied accountability.

\section{IIIness perceptions, labelling and attributions}

Although burnout and CFS have different backgrounds they do in a sense share the same attribution, namely an external one. As noted above, an important distinction between CFS and burnout is the avoidance of a psychological or psychiatric label. It has been argued that seeking a somatic illness label, as seen in functional somatic syndromes such as CFS, provides a guard against a psychiatric label for all sorts of reasons: the stigma attached to a psychiatric label, being perceived as a malingerer and the associated illness benefits (e.g. disability pensions) ${ }^{39}$. So perceiving the cause to be somatic, in effect, places the blame and the cause of the illness firmly outside the self. Despite the fact that burnout is perceived to be a psychological condition, the label does not seem to carry with it the negative connotations of a psychiatric label which is probably partly due to the fact that the cause of burnout is seen as outside the self. It can be argued that the "success" of burnout as a psychological illness depended on the blame being placed on the work situation and therefore outside the self ${ }^{9}$. In order for this to happen, work would have to be able to be blamed which historically has not necessarily always been the case. Up until approximately the 1980s, illnesses arising from stress at work were not thought to be caused by work but rather by the temperament or personality of the individual. A report from the Industrial Health Research Board on nervous temperament, for example, suggests that employees interpret their mental discomfort as being caused by work or their work conditions, instead of realising that their mental states are subjective experiences ${ }^{40}$. Neurasthenia was 
thought to arise due to the inability of an individual personality to adapt to prevailing work conditions ${ }^{38,41}$ and in military circles neurasthenia has been noted to indicate "unfitness or unwillingness for military service" ${ }^{42}$. The above implies that it is not the work that causes psychological illness but rather the employee's personal characteristics and their inability to adapt. Moreover, this inability to adapt has also, rather derogatorily, been termed constitutional inferiority ${ }^{43}, 44$. Thus in the first half of the last century all "neurotic disorders" were seen as reflecting largely inherited or constitutional factors with little importance being placed on the actual trigger for illness - predisposition or vulnerability was what mattered. The introduction of post-traumatic stress disorder (PTSD) in 1980 signalled a dramatic shift in psychiatric thinking specifically in relation to trauma and illness, but more generally across the field of the neuroses (a term that was then abandoned in the DSM). So there was a shift in placing the blame or responsibility on the individual to placing it on an external (work) stressor, made explicit in the new category of PTSD as it emerged in the DSM-III in $1980^{45}$.

Despite both conditions having an external attribution there is an important difference between burnout and CFS. The cause is "known" in burnout (i.e. work) and unknown in CFS which can lead to considerable uncertainty and the continued speculation regarding the cause. Moreover, perceptions about the cause of CFS have consistently been shown to influence the prognosis of this illness, especially, when patients attribute CFS to somatic causes the course can be negatively influenced ${ }^{32}$.

A related aspect of illness labels is the fight for an officially recognised label. In this respect, CFS and burnout also differ as this recognition is an important goal for CFS patients and patient organisations to achieve, whereas organised activism has not been an important issue in burnout. It has been noted that part of the reason the term burnout became so popular is that it was a socially acceptable and non-stigmatising label for being temporarily overworked. In other words burnout was not medicalised ${ }^{46,47}$. Even today, there are only a few countries in which burnout is considered and treated as a diagnostic entity with all its related benefits ${ }^{46}$.

This raises the important issue of the role society and culture play in shaping and forming illnesses. That is, the same set of symptoms may attract different labels in different eras, countries and cultures ${ }^{48}$. For example, although burnout is a widely accepted and recognised label in the Netherlands and Sweden this is true to a lesser extent for the UK where other labels for a similar set of symptoms may be used (e.g. work stress or depression). There are a number of possible reason for accepting or refuting a certain diagnosis including the prevailing welfare system, beliefs held by clinicians, beliefs held by patients, and the cultural acceptance of psychological or somatic labels ${ }^{4}$. Due to the uncertain nature of CFS and the psychological versus somatic debate, some CFS patients tend to feel that their illness and suffering is not legitimised and recognised by society ${ }^{49}$. The most important function of an illness label is that it provides a cause for symptoms and also recognition that something is wrong. However, in some instances the label given to a 
condition can cause more harm than good. In whiplash it has been noted that some patients can become more disabled by the diagnosis (or at least its implications) than by the injury ${ }^{50}$. The same phenomenon has been noted in CFS and indeed many other conditions $^{39,51}$.

\section{Specificity of a construct}

An ongoing discussion in both the CFS and the burnout literature is the conceptualisation of these constructs. A specific issue is whether burnout and CFS are distinct from other conditions, most notably depression ${ }^{32,52-54}$. Interestingly enough, the issue of whether burnout and CFS are different from each other has not received as much attention, as has been noted above. Distinguishing between burnout and CFS may be difficult because of the overlap in symptoms and course of illness ${ }^{11}$. Others emphasise the "somatic" nature of symptoms in CFS and the work-related nature of burnout ${ }^{2}$. Burnout and CFS have also had to fight for a place within their own respective territories with CFS having to be differentiated from other unexplained medical syndromes (e.g. irritable bowel syndrome and fibromyalgia) and burnout from other occupational health constructs (e.g. work stress and job satisfaction) ${ }^{2,32}$. Besides having to distinguish themselves from other conditions there has been considerable debate about the conceptualisation of the conditions themselves. In CFS this is, among others, reflected by different (cross-cultural) sets of diagnostic criteria for CFS and the difficulties in classification arising from the somatic/psychological debate surrounding CFS ${ }^{4,55}$. The confusion surrounding fatigue diagnoses is also reflected in their classification in various classification systems (table 1). Most clinicians consider ME and CFS to be synonymous, with the one being preferred in the media/vernacular but the other dominating the professional/scientific literature, but the ICD-10 uneasily classifies the former under neurology and the latter (with neurasthenia as a synonym) under psychiatry ${ }^{4,56}$, despite the clear and obvious similarities of the clinical descriptions. The Dutch classification for occupational health and social insurance physicians (CAS) classifies CFS as a central nervous system disorder and ME as a nervous system disorder implying a more specific cause or nature of CFS compared to $\mathrm{ME}$ (http://cba.uwv.nl/cba/opencms/CBA/module4/80/01.htm). Burnout is seen as a disorder in the CAS system, but it is seen as a life management problem in the ICD-10. The DSM-IV does not mention these conditions at all, but the concepts /descriptions imply that they belong within the somatoform disorder category, not least because nearly every patient will fulfil criteria for the unsatisfactory and largely ignored category of undifferentiated somatoform disorder.

The reader might be confused by the preceding paragraph, and rightly so. The classification of CFS, burnout and indeed other overlapping syndromes is a nosological and political minefield, and it is not for nothing that perhaps the central focus of CFS activism is around the issue of labels and classifications, an issue that has been largely ignored in the professional/scientific literature. 
Table 1 Classification of fatigue conditions in various classification systems

\begin{tabular}{|c|c|c|c|}
\hline & $1 \mathrm{CD}-10^{\mathrm{a}}$ & $\mathrm{CAS}^{\mathrm{b}}$ & $D S M-I V^{c}$ \\
\hline Burnout & $\begin{array}{l}\text { Problems related to life } \\
\text { management difficulty }\end{array}$ & Adjustment disorder & $\begin{array}{l}\text { No } \\
\text { classification }\end{array}$ \\
\hline CFS & $\begin{array}{l}\text { Psychiatry } \\
\text { (other neurotic disorders) }\end{array}$ & $\begin{array}{l}\text { Neurology } \\
\text { (other central nervous system } \\
\text { disorders) }\end{array}$ & $\begin{array}{l}\text { No } \\
\text { classification }\end{array}$ \\
\hline ME & $\begin{array}{l}\text { Neurology } \\
\text { (other disorders) }\end{array}$ & $\begin{array}{l}\text { Neurology } \\
\text { (other diseases of the nervous } \\
\text { system) }\end{array}$ & $\begin{array}{l}\text { No } \\
\text { classification }\end{array}$ \\
\hline Neurasthenia & $\begin{array}{l}\text { Psychiatry } \\
\text { (other neurotic disorders) }\end{array}$ & $\begin{array}{l}\text { Psychiatry } \\
\text { (other psychological disorders) }\end{array}$ & $\begin{array}{l}\text { No } \\
\text { classification }\end{array}$ \\
\hline
\end{tabular}

Regarding the conceptualisation of burnout, the main focus has been on two aspects: is it more than prolonged or chronic fatigue and is it solely work-related ${ }^{57,58,59}$ ? In CFS the principal arguments and fault lines, at least in the popular debate, concerns the vexed issue of "physical" versus "psychological" aetiology, in burnout the issue is more work versus non work. Whereas some see burnout as only a work-related condition, others feel it can be generalised to other areas of life as well ${ }^{2,57}$. Moreover, several researchers have argued that fatigue and exhaustion are the main elements of burnout and have defined burnout around this central feature alone instead of including the psychological withdrawal and professional efficacy components of burnout ${ }^{2,8}$. However, the usefulness of extending the concept of burnout beyond the work situation and reducing it to just the fatigue or exhaustion element has been questioned as it would become non-specific and coincide with the concept of fatigue which is not domain specific: "when burnout is identical to fatigue, the term is redundant..." ${ }^{58}$. An interesting fact in this respect, is that studies on burnout in clinical samples have actually used the ICD-10 criteria for neurasthenia to define burnout, provided that it was work-related ${ }^{60,61}$. If the work-relatedness was left out of the equation then burnout would indeed equate to CFS or fatigue, not least given the $96 \%$ overlap between CFS and neurasthenia, for example, reported from one CFS clinic ${ }^{62}$.

\section{Conclusion}

Burnout and CFS are two conditions which come from different backgrounds, are conceptualised differently and are generally thought to be separate conditions ${ }^{2,4}$. In this essay, we explored several themes related to the phenomenology of burnout and CFS and found that the similarities between these conditions occur at more than just the symptom level. Similarities exist on such themes as so called "overload" as a triggering factor, the 
need for restoration of depleted energy, external causal attributions, the characteristics of people suffering from these conditions, and the classification and distinction of these conditions. This causes the presumed differences to become a little unclear. It is striking that the main differences appear to be related to the perceived cause of the conditions (related to the historical development and background of burnout and CFS), in particular the somatic or psychological cause, and not so much to the phenomenology of the conditions themselves. Even though the main symptom(s) are so close, the perception of these symptoms is different and could consequently make the conditions different. Our findings suggest that culture, illness perceptions and accountability are important issues in both burnout and CFS as they give meaning to a certain set of symptoms and shape the diagnoses that were embraced by those suffering from these symptoms. This should be kept in mind when comparing these conditions. As was previously demonstrated for CFS ${ }^{19}$, 48, burnout too is also a compelling illustration of how illness is shaped by culture and society.

In a sense, the conclusion of this essay could be that, irrespective of "objective" findings, burnout and CFS are different simply because they are perceived to be different. It is important however, to realise that perceptions and even assumptions surrounding burnout and CFS may have actually hampered a comparison of these conditions. It can, for example, be assumed that they are different based on the somatic/ psychological divide or that they are the same due to the similar symptoms. However, the validity of such assumptions will never be known if burnout and CFS are not compared empirically. At this moment it is difficult to compare results from separate studies on burnout and CFS as the emphasis and approach to their study is, quite naturally, influenced by perceptions shaped by their respective backgrounds.

So does all this talk about perceptions mean that different labels are being given to the same set of symptoms? Although this issue deserves further research, it is not unlikely that the proposed differences between burnout and CFS may be more assumed than real. And paradoxically, some of the so called differences may actually be similarities, while similarities may also really be differences. One way of resolving the dilemma is to prospectively compare burnout and CFS in one sample in which both conditions have been measured along with factors that could influence both burnout and CFS, such as those noted in this essay (e.g. illness perceptions). This may provide the key to understanding the relationship between CFS and burnout. 


\section{References}

1 Borritz M, Rugulies R, Christensen KB, Villadsen E, Kristensen TS. Burnout as a predictor of self-reported sickness absence among human service workers: prospective findings from three year follow up of the PUMA study. Occupational and Environmental Medicine 2006; 63: 98-106.

2 Schaufeli WB, Enzman D. The burnout companion to study and practice: a critical analysis. London: Taylor \& Francis, 1998.

3 Huibers MJ, Leone SS, Kant IJ, Knottnerus JA. Chronic fatigue syndrome-like caseness as a predictor of work status in fatigued employees on sick leave: four year follow up study. Occupational and Environmental Medicine 2006; 63: 570-2.

4 Wessely $S$, Hotopf $M$, Sharpe $M$. Chronic fatigue and its syndromes. Oxford: Oxford University Press, 1998.

5 Mommersteeg P. The psychophysiology of burnout. Utrecht University: PhD thesis, 2006

6 Veldhuizen I. Acute fatigue and burnout. Tilburg University: PhD thesis, 2003

7 De Vente $W$, Olff $M$, Van Amsterdam JG, Kamphuis JH, Emmelkamp PM. Physiological differences between burnout patients and healthy controls: blood pressure, heart rate, and cortisol responses. Occupational and Environmental Medicine 2003; 60 Suppl 1: i54-61.

8 Shirom A, Melamed S, Toker S, Berliner S, Shapira I. Burnout and health: current knowledge and future research directions. In: Hodgkinson G, Kevin F, eds. International Review of Industrial and Organizational Psychology. New York: Wiley, 2005; 269-309.

9 Johannison K. Modern fatigue: A historical perspective. In: Arnetz B, Ekman R, eds. Stress in Health and Disease. Weinheim: Wiley-VCH, 2006; 3-19.

10 Huibers MJH, Beurskens AJHM, Prins JB, Kant IJ, Bazelmans E, van Schayck CP, Knottnerus $J A$, Bleijenberg $G$. Fatigue, burnout, and chronic fatigue syndrome among employees on sick leave: do attributions make the difference? Occupational and Environmental Medicine 2003; 60: 26-31.

11 Weber A, Jaekel-Reinhard A. Burnout syndrome: a disease of modern societies? Occupational Medicine 2000; 50: 512-7.

12 Rabinbach A. The human motor: energy, fatigue, and the origins of modernity. New York: Basic Books, Inc, 1990.

13 Nye RA. Degeneration, Neurasthenia and the Culture of Sport in Belle Epoque France. Journal of Contemporary History 1982; 17: 51-68.

14 Mosso A. Fatigue. London: Swan Sonnenschein and Co., 1904.

15 Berrios GE. Feelings of Fatigue and Psychopathology - a Conceptual History. Comprehensive Psychiatry 1990; 31: 140-51.

16 Wessely S. Neurasthenia and chronic fatigue. In: Porter R, Berrios G, eds. A History of Clinical Psychiatry. London: Athlone, 1996; 509-32.

17 Beard G. Neurasthenia or nervous exhaustion. Boston Medical and Surgical Journal 1869; 3: 217-21.

18 Wessely S. Old wine in new bottles: neurasthenia and 'ME'. Psychological Medicine 1990; 20: 35-53.

19 Abbey SE, Garfinkel PE. Neurasthenia and chronic fatigue syndrome: the role of culture in the making of a diagnosis. American Journal of Psychiatry 1991; 148: 1638-46. 
20 Greenberg DB. Neurasthenia in the 1980s: chronic mononucleosis, chronic fatigue syndrome, and anxiety and depressive disorders. Psychosomatics 1990; 31: 129-37.

21 Freudenberger HJ, Richelson G. Burn-out: The high cost of high achievement. New York; Bantam Books Inc., 1980.

22 Schaufeli W. Past performance and future perspectives of burnout research. South African Journal of Industrial Psychology 2003; 29: 1-15.

23 Johnson G. Nervous disorders that result from overwork and mental anxiety. The Lancet 1875; 106: 85-7.

24 Jewell J. Influence of our present civilization in the production of nervous and mental disease. Journal of Nervous and Mental Disease 1881; 8: 1-24.

25 Schwab SI. Neurasthenia among garment workers. American Economic Review 1911; 1: 265-70.

26 Taylor RE. Death of neurasthenia and its psychological reincarnation: a study of neurasthenia at the National Hospital for the Relief and Cure of the Paralysed and Epileptic, Queen Square, London, 1870-1932. British Journal of Psychiatry 2001; 179: 550-7.

27 Dana CL. The partial passing of neurasthenia. Boston Medical and Surgical Journal 1904; 60: 339-44.

28 Holmes GP, Kaplan JE, Gantz NM, Komaroff AL, Schonberger LB, Straus SE, Jones JF, Dubois $R E$, Cunningham-Rundles $C$, Pahwa $S$, et al. Chronic fatigue syndrome: a working case definition. Annals of Internal Medicine 1988; 108: 387-9.

29 Maslach C, Jackson SE. The measurement of experienced burnout. Journal of Occupational Behavior 1981; 2: 99-113.

30 Freudenberger H. Staff burn-out. Journal of Social issues 1974; 30: 159-65.

31 Prins JB, van der Meer JW, Bleijenberg G. Chronic fatigue syndrome. Lancet 2006; 367: 34655.

32 Afari N, Buchwald D. Chronic fatigue syndrome: A review. American Journal of Psychiatry $2003 ; 160: 221-36$

33 Mommersteeg PM, Heijnen CJ, Verbraak MJ, van Doornen LJ. A longitudinal study on cortisol and complaint reduction in burnout. Psychoneuroendocrinology 2006; 31: 793-804.

34 Maslach C, Schaufeli WB, Leiter MP. Job burnout. Annual Review of Psychology 2001; 52: 397-422.

35 Taylor RR, Jason LA, Richman JA, Torres-Harding SR, King C, Song S. Epidemiology. In: Jason LA, Fennell PA, Taylor RR, eds. Handbook of chronic fatigue syndrome. New Jersey: John Wiley \& Sons, 2003

36 Terluin B, Van der Klink JلL, Schaufeli WB. Stressgerelateerde klachten: spanningsklachten, overspanning en burnout. In: Van der Klink JJL, Terluin B, eds. Psychische problemen en de werk. Handboek voor een activerende begeleiding door huisarts en bedrijfsarts. Houten: Bohn Stafleu van Loghum, 2005; 259-90.

37 Wessely S. Neurasthenia and chronic fatigue: theory and practice in Britain and America. Transcultural Psychiatric Research Review 1994; 31: 173-209.

38 Gilbert JB. Work without salvation: America's intellectuals and industrial alienation, 18801910. Baltimore: John Hopkins University Press, 1977.

39 Huibers MJ, Wessely S. The act of diagnosis: pros and cons of labelling chronic fatigue syndrome. Psychological Medicine 2006; 36: 895-900.

40 Culpin M, Smith $M$. The nervous temperament. London: Industrial Health Research Board Report, Report 61, 1930 
41 White WA. The principles of mental hygiene. New York: The Macmillan Company, 1917.

42 Mott FW. War neuroses and shell shock. London: Henry Frowde, 1919.

43 Day LW. Study of the last one hundred cases diagnosed as neurasthenia discharged from United States veterans' hospital, Perry Point, MD. U.S. Veterans' Bureau Medical Bulletin 1927; 3: 559-73.

44 Wilbur DL. Clinical management of the patient with fatigue and nervousness. Journal of the American Medical Association 1949; 141: 1199-204.

45 Jones $E$, Wessely S. A paradigm shift in the conceptualization of psychological trauma in the 20th century. Journal of Anxiety Disorders 2007; 21: 164-75.

46 Schaufeli $W$. Burnout in discussie: Stand van zaken [Burnout discussed: Current state of affairs]. De Psycholoog 2007; 42: 534-40.

47 Maslach C, Schaufeli WB. Historical and conceptual development of burnout. In: Schaufeli WB, Maslach C, Marek T, eds. Professional burnout: recent developments in theory and research. New York: Taylor \& Francis, 1993

48 Barsky AJ, Borus JF. Functional somatic syndromes. Annals of Internal Medicine 1999; 130: 910-21.

49 Ware NC. Suffering and the social construction of illness - the delegitimation of illness experience in chronic fatigue syndrome. Medical Anthropology Quarterly 1992; 6: 347-361.

50 Malleson A. Whiplash and other useful illnesses. Montreal: McGill-Queenn's University Press, 2002.

51 Hamilton WT, Gallagher AM, Thomas JM, White PD. The prognosis of different fatigue diagnostic labels: a longitudinal survey. Family Practice 2005; 22: 383-8.

52 Glass DC, Mcknight JD. Perceived control, depressive symptomatology, and professional burnout: A review of the evidence. Psychology \& Health 1996; 11: 23-48.

53 lacovides A, Fountoulakis KN, Kaprinis S, Kaprinis G. The relationship between job stress, burnout and clinical depression. Journal of Affective Disorders 2003; 75: 209-21.

54 Moss Morris R, Petrie KJ. Discriminating between chronic fatigue syndrome and depression: a cognitive analysis. Psychological medicine 2001; 31: 469-79.

55 Health council of the Netherlands. Het chronische-vermoeidheidssyndroom [Chronic fatigue syndrome]. Den Haag: Health council of the Netherlands, 2005.

56 David A, Wessely S. Chronic fatigue, ME, and ICD-10. Lancet 1993; 342: 1247-8.

57 Kristensen TS, Borritz M, Villadsen E, Christensen KB. The Copenhagen Burnout Inventory: A new tool for the assessment of burnout. Work and Stress 2005; 19: 192-207.

58 Schaufeli WB, Taris TW. The conceptualization and measurement of burnout: Common ground and worlds apart. Work and Stress 2005; 19: 256-62.

59 Shirom A. Reflections on the study of burnout. Work and Stress 2005; 19: 263-70.

60 Sonnenschein M, Sorbi MJ, Doornen UPV, Schaufeli WB, Maas CJM. Electronic diary evidence on energy erosion in clinical burnout. Journal of Occupational Health Psychology 2007; 12: 402-13.

61 Schaufeli WB, Bakker AB, Hoogduin K, Schaap C, Kladler A. On the clinical validity of the Maslach Burnout Inventory and the Burnout Measure. Psychology \& Health 2001; 16: 56582.

62 Farmer A, Jones I, Hillier J, Llewelyn M, Borysiewicz L, Smith A. Neuraesthenia revisited: ICD10 and DSM-III-R psychiatric syndromes in chronic fatigue patients and comparison subjects. British Journal of Psychiatry 1995; 167: 503-6. 
Similarities, overlap and differences between burnout and prolonged fatigue in the working population

S.S. Leone ${ }^{1}$

M.J.H. Huibers ${ }^{2}$

J.A. Knottnerus ${ }^{3}$

IJ. Kant ${ }^{1}$

${ }^{1}$ Department of Epidemiology, Maastricht University, Maastricht, The Netherlands

${ }^{2}$ Department of Clinical Psychological Science, Maastricht University, Maastricht, The Netherlands

${ }^{3}$ Department of General Practice, Maastricht University, Maastricht, The Netherlands 


\section{Abstract}

\section{Background}

Burnout and prolonged fatigue are related but distinct concepts which have seldom been empirically compared.

\section{Aim}

To examine similarities, overlap and differences between burnout and prolonged fatigue.

\section{Design}

Observational study.

\section{Methods}

We analysed baseline data from the Maastricht Cohort Study on Fatigue at Work $(n=12,140)$. The discriminative ability of the Checklist Individual Strength (CIS) and the Maslach Burnout Inventory-General Survey (MBI-GS) was evaluated using principal component analysis. Overlap, similarities and differences regarding health, work and demographic factors between subgroups were assessed.

\section{Results}

The discriminative ability of the $\mathrm{CIS}$ and the MBI-GS appeared to be moderate. Prolonged fatigue and burnout cases overlapped considerably. The subgroup consisting of cases with concurrent fatigue and burnout tended to have poorer outcomes in terms of health and work factors than the subgroups with either prolonged fatigue or burnout. Similar patterns were found for subjective fatigue and exhaustion.

\section{Conclusion}

There appear to be some relevant differences between burnout and prolonged fatigue with respect to work and health factors. Furthermore, burnout and prolonged fatigue can occur both separately and simultaneously. Having both conditions simultaneously seems to be associated with worse outcomes than having either alone. 


\section{Introduction}

Burnout and prolonged fatigue are two conditions in which the symptom of fatigue plays a central role ${ }^{1}$. These two conditions come from different backgrounds: typically prolonged fatigue comes from a medical background ${ }^{2,3}$, while burnout comes from a psychological background ${ }^{1}$. Furthermore, they are also conceptualised differently: burnout is conceptualised as a work-related condition and prolonged fatigue as a general condition ${ }^{4}$. Despite these differences, it is likely that they share similarities in terms of complaints, course and consequences. Moreover, the distinction that is made between burnout and fatigue conditions could have consequences in terms of prognosis, treatment and work reintegration due to the assigned label, when they may be more similar than different. The concepts of burnout and prolonged fatigue have, however, hardly been compared in empirical research, so little is known about the differences or similarities between them.

Fatigue is a complex phenomenon. Besides occurring as a symptom alongside another primary medical or psychiatric condition, it can also be the main clinical complaint or condition ${ }^{5}$. However, in the majority of cases in which fatigue is the central complaint, no medical explanation can be found ${ }^{5,6}$ and therefore, the cause of fatigue remains medically unexplained. Moreover, whereas acute fatigue disappears after a period of rest, prolonged fatigue is not easily reversible in the short term ${ }^{7}$. Although the medical reason is unknown, prolonged fatigue can occur both within and outside the context of work. The complexity of fatigue is also evident from the many different definitions used to describe fatigue and the various accompanying measures of fatigue ${ }^{3,8}$. One such measure is the Checklist Individual Strength (CIS), which is a multidimensional measure of prolonged fatigue, and includes items on subjective fatigue, motivation, activity and concentration. It was originally developed to measure prolonged unexplained fatigue (lasting at least 2 weeks) in chronic fatigue syndrome patients, but has been validated in the working population ${ }^{9-11}$. Studies in the working population have shown that prolonged fatigue, can predict sickness absence and work disability ${ }^{12,13}$.

Burnout is a condition related to both fatigue and work. It was originally conceptualised as a syndrome consisting of emotional exhaustion, depersonalisation and reduced personal accomplishment among individuals in 'helping' professions ${ }^{14}$. The most widely used measure to examine the three dimensions of burnout is the Maslach Burnout inventory $(\mathrm{MBI})^{1}$. As the original $\mathrm{MBI}$ could not be applied to occupations outside the human services, a more general version of the $\mathrm{MBI}$ was developed: the MBI-General Survey (MBIGS) ${ }^{15}$. The MBI-GS measures the three dimensions of burnout in generic terms (as opposed to occupation-specific) terms ${ }^{16}$. Unlike prolonged fatigue, burnout is assumed to occur only inside the context of work, although this is an ongoing point of debate in the burnout literature ${ }^{4}$. Like prolonged fatigue, burnout can also predict sickness absence ${ }^{17,18}$.

Although the MBI-GS and the CIS are quite different, they have in common that they are both multidimensional measures with core complaints, exhaustion and subjective fatigue 
respectively, and that the core complaint of both measures is very similar. In studies examining the exhaustion component of burnout along with several other measures of fatigue, exhaustion appeared to measure the same concept ${ }^{8,19,20}$. Moreover, De Vries et al. ${ }^{8}$ and Michielsen et al. ${ }^{19}$ found correlations between exhaustion and subjective fatigue of 0.65 and 0.60 , respectively. However, it has been argued that burnout should not be reduced to merely exhaustion, even though exhaustion is the central component of burnout ${ }^{4,16}$

Various studies have shown that causal attributions have an effect on the course of chronic fatigue and CFS ${ }^{2122-24}$. In particular, those who attribute their fatigue complaints to a somatic cause rather than a psychological cause have a poorer prognosis. It is possible that the psychological background of burnout could influence these attributions. In one study comparing unexplained fatigue, chronic fatigue syndrome and burnout, it was found that although the conditions shared some important characteristics, a distinguishing feature between fatigue and burnout seemed to be the causal attributions made by patients ${ }^{25}$. We aimed to gain more insight into similarities, overlap and differences between burnout and prolonged fatigue as conceptualised by the MBI-GS and the CIS respectively, by addressing two issues. Firstly, we assessed the ability of the instruments that were developed to measure burnout (MBI-GS) and prolonged fatigue $(\mathrm{ClS})$ to discriminate between these conditions. This is a prerequisite to comparing burnout and prolonged fatigue. Secondly, we examined the overlap and the similarities and differences in terms of health, work and demographic factors between burnout and prolonged fatigue cases. This comparison allows us to gain some insight into whether a relevant distinction can be made between burnout and prolonged fatigue or if they are in fact more similar than different.

\section{Methods}

\section{Design}

Baseline data from the Maastricht Cohort Study on Fatigue at Work (MCS) were used for this study. The baseline data were gathered in May 1998 by means of a self-administered questionnaire. A total of 12,140 employees from 45 different companies and organisations participated at baseline (response rate $45 \%$ ). There were statistically significant differences at baseline between non-respondents and respondents: non-respondents reported fewer fatigue complaints, less sickness absence and less difficulty in work execution compared to respondents. Detailed information on the design of the MCS is provided elsewhere ${ }^{26}$

\section{Study population}

Participants at the baseline of the MCS were included in this study. Subgroups based on prolonged fatigue cases and burnout cases, and on exhaustion cases and subjective fatigue cases were examined. Participants were excluded from analysis if baseline data regarding 
their (multidimensional) burnout or fatigue status $(n=254)$ or their exhaustion or subjective fatigue status $(n=106)$ were missing. To ensure that fatigue among the participants was unexplained, participants were excluded if they had one of the following chronic conditions that might explain fatigue complaints: cerebrovascular accidents, liver dysfunction, diabetes mellitus, hyperthyroidism or cancer. In total, 11,597 participants were included in the analyses for subgroups based on burnout and fatigue, and 11,739 participants were included in the analyses for subgroups based on exhaustion and subjective fatigue.

\section{Measures}

\section{Fatigue}

The Checklist Individual Strength (CIS) was used to assess prolonged fatigue ${ }^{9,10}$. The CIS consists of four subscales: subjective fatigue ( 8 items, Cronbach's $\alpha$ : 0.93 ), motivation (4 items, Cronbach's $\alpha: 0.80$ ), activity (3 items, Cronbach's $\alpha: 0.75$ ) and concentration (5 items, Cronbach's $\alpha: 0.85)$. Items are scored on a seven-point Likert scale. Higher scores indicate higher levels of subjective fatigue, motivation, concentration or a reduced level of activity. Scores on the subscales can be added to produce a composite total score which ranges from 20 to 140 . The cut-off for classification as a fatigue case was a total score higher than $76^{27}$. Subjective fatigue cases were defined as having a score of 35 or higher on the subjective fatigue subscale ${ }^{9}$.

Participants were also asked to indicate whether they had fatigue complaints during the past 4 months and if so, what they thought the cause was of their fatigue complaints: a psychological cause (psychological attribution), a somatic cause (somatic attribution), or an unknown cause (unknown attribution).

\section{Burnout}

The Dutch version of the Maslach Burnout Inventory-General Survey (MBI-GS) was used to measure burnout ${ }^{15,28}$. The MBI-GS consists of three subscales: exhaustion (5 items, Cronbach's $\alpha: 0.88$ ), cynicism (4 items, Cronbach's $\alpha: 0.76$ ) and professional efficacy (6 items, Cronbach's $\alpha: 0.76$ ). Originally, the cynicism subscale consisted of five items, but one item did not fit well, and in line with other research it was omitted ${ }^{29}$. All scales have a range of 0 to 6 . Burnout cases were defined according to the definition in the Dutch MBI-GS manual as having a score higher than the $75^{\text {th }}$ percentile on exhaustion $(>2.40)$ as well as either a score higher than the $75^{\text {th }}$ percentile on cynicism $(>2.25)$ or a score lower than the $25^{\text {th }}$ percentile on professional efficacy $(<3.50)$.

\section{Health related factors}

Psychological distress was assessed using the 12-item General Health Questionnaire (GHQ12, Cronbach's $\alpha: 0.89)^{30,31}$. The GHQ-12 was developed as a screening instrument for detecting minor psychiatric disorders. The traditional binary scoring method $(0,0,1,1)$ was 
used to define probable cases of minor psychiatric disorder. This gives a range of scores of 0 to 12 . The cut-off for case classification was 4 or higher ${ }^{32}$.

Self-reported chronic conditions (somatic and psychological) were assessed by asking participants if they suffered from a chronic condition and if so, if they could indicate, by means of a list of 15 items, from which chronic condition they suffered ${ }^{33}$. Based on these responses participants were classified as having a somatic and/ or a psychological chronic condition.

Perceived general health was assessed with one item from the Dutch version of the Short Form Health Survey (SF-36) ${ }^{34,35}$. Participants indicated on a five-point scale whether they thought their perceived general health was excellent (1), very good (2), good (3), moderate (4), or bad (5). This variable was dichotomised into good perceived general health (1-3) and bad perceived general health (4-5).

\section{Work-related factors}

Working hours, work schedule, managerial position (yes/no) and absenteeism were all assessed by means of self-reports.

Working hours were assessed in five categories $(<16,16-25,26-35,36-40,>40)$ which were dichotomised into two categories: full-time work (more than 36 hours/week) and part-time work (less than 36 hours/week).

Work schedule was assessed by asking participants if their normal working hours were between $7 \mathrm{am}$ and $7 \mathrm{pm}$ (yes = day work, no = shift work / irregular working hours).

Self-reported sickness absenteeism was defined as being either completely or partially absent (working limited hours or able to do limited activities) in the past 4 months.

The psychosocial work characteristics psychological job demands ( 5 items, Cronbach's $\alpha$ : 0.70 ), skill discretion ( 6 items, Cronbach's $\alpha: 0.73$ ), decision authority ( 3 items, Cronbach's $\alpha: 0.73$ ), decision latitude (9 items, Cronbach's $\alpha: 0.82$ ), co-worker social support (4 items, Cronbach's $\alpha: 0.76$ ), and supervisor social support (4 items, Cronbach's $\alpha: 0.85$ ), were assessed with the validated Dutch version of the Job Content Questionnaire ${ }^{36,37}$. Higher scores indicate higher levels on these scales.

\section{Demographic factors}

Age, gender and education were all assessed by means of self reports.

\section{Definition of subgroups}

Four exclusive subgroups were formed based on the cut-off points for burnout and/ or prolonged fatigue caseness described in the measures section: pure fatigue cases (prolonged fatigue case but no burnout case), pure burnout cases (burnout case but no prolonged fatigue case), burnout \& fatigue cases (burnout and prolonged fatigue case simultaneously), and neither burnout nor fatigue cases. Similarly subgroups were also formed based on exhaustion and subjective fatigue status: pure subjective fatigue cases, 
pure exhaustion cases, subjective fatigue $\&$ exhaustion cases and neither subjective fatigue nor exhaustion cases.

\section{Statistical analysis}

Principal component analysis (PCA) was used to determine if the CIS and the MBI-GS were able to discriminate between burnout and prolonged fatigue. The CIS and the MBI-GS were analysed simultaneously by means of a forced two-factor solution to determine the discriminative ability on a construct level. The CIS and the MBI-GS were also analysed simultaneously with an unforced factor solution to refine these results and see whether and which domains can be distinguished within these constructs. An oblimin rotation was used, and the eigenvalue criterion greater-than-one was used to extract factors. Double loadings were defined as secondary factor loadings of 0.4 or higher. Factor loadings (including cross loadings) of at least 0.3 were interpreted (the highest is interpreted in the event of an item loading on two factors). Moreover, Pearson correlations were calculated between the scales of the measures.

Kruskal-Wallis tests were used to analyse differences between the subgroups on continuous variables. To analyse differences between the groups on dichotomous or categorical variables, chi-square tests were used. All analyses were performed using SPSS (version 12.0).

\section{Results}

\section{Pearson correlations}

Pearson correlation coefficients between the subscales of the CIS and the MBI-GS were calculated in order to gain some insight into their associations. The correlations between the subscales were moderate to strong, ranging from 0.26 to 0.72 . Notably, the strongest correlation (0.72) is between the CIS subscale subjective fatigue and the MBI-GS subscale exhaustion.

\section{Principal component analysis: Simultaneous analysis of CIS and MBI-GS}

\section{(forced two-factor solution)}

To examine the ability of the CIS and the MBI-GS to discriminate between two different constructs, the items of these two instruments were analysed with PCA using a forced twofactor solution (table 1). The first factor consisted of the five exhaustion items of the MBIGS, the eight subjective fatigue items of the CIS, the four motivation items of the CIS and four of the five concentration items of the CIS. The second factor consisted of the six professional efficacy items of the MBI-GS, the four cynicism items of the MBI-GS, one of the five items of the concentration subscale of the CIS and the three activity items of the CIS. 
Table 1 Results of simultaneous principal component analysis of the MBI-GS and the CIS for the forced two factor solution

\begin{tabular}{|c|c|c|}
\hline & Factor $1^{3}$ & Factor $2^{a}$ \\
\hline \multicolumn{3}{|c|}{ Maslach Burnout Inventory-General Survey (MBI-GS) } \\
\hline \multicolumn{3}{|c|}{ Exhaustion subscale } \\
\hline Item 1 & .69 & .05 \\
\hline Item 3 & .63 & -.02 \\
\hline Item 5 & .77 & .03 \\
\hline Item 11 & .81 & .10 \\
\hline Item 14 & .68 & -.06 \\
\hline \multicolumn{3}{|c|}{ Cynicism subscale } \\
\hline Item 2 & .06 & -.56 \\
\hline Item 7 & .06 & -.55 \\
\hline Item 8 & .08 & -.68 \\
\hline Item 15 & .22 & -.39 \\
\hline \multicolumn{3}{|c|}{ Professional efficacy subscale } \\
\hline Item 4 & .01 & .51 \\
\hline Item 6 & .11 & .74 \\
\hline Item 9 & .12 & .64 \\
\hline Item 10 & .04 & .59 \\
\hline Item 12 & .05 & .59 \\
\hline Item 16 & -.02 & .62 \\
\hline \multicolumn{3}{|c|}{ Checklist Individual Strength (CIS) } \\
\hline \multicolumn{3}{|c|}{ Subjective fatigue subscale } \\
\hline Item 1 & .85 & .02 \\
\hline Item 4 & .80 & .11 \\
\hline Item 6 & .86 & .13 \\
\hline Item 9 & .80 & .01 \\
\hline Item 12 & .83 & .03 \\
\hline Item 14 & .76 & .06 \\
\hline Item 16 & .81 & .02 \\
\hline Item 20 & .76 & .04 \\
\hline \multicolumn{3}{|c|}{ Motivation subscale } \\
\hline Item 2 & .70 & -.11 \\
\hline Item 5 & .51 & -.08 \\
\hline Item 15 & 31 & -.24 \\
\hline Item 18 & .61 & -.17 \\
\hline \multicolumn{3}{|c|}{ Concentration subscale } \\
\hline Item 3 & .43 & -.21 \\
\hline Item 8 & .36 & -.40 \\
\hline Item 11 & .41 & -.39 \\
\hline Item 13 & .47 & -.26 \\
\hline Item 19 & .39 & -.35 \\
\hline \multicolumn{3}{|c|}{ Activity subscale } \\
\hline Item 7 & -.03 & -.47 \\
\hline Item 10 & .16 & -.44 \\
\hline Item 17 & .34 & -.39 \\
\hline
\end{tabular}

Bold factor loadings indicate to which factor the item was assigned.

For copyright reasons, full items are not listed. Item numbers correspond to the items of the questionnaires (CIS and MBI-GS) ${ }^{10,11,28}$.

'Explained variance: factor $1,36 \%$; factor 2, $8 \%$. 
The items of the cynicism and professional efficacy subscales of the MBI-GS loaded on the second factor whereas, the exhaustion items of the MBI-GS loaded on the first factor along with the subjective fatigue, concentration, and motivation subscales of the CIS (table 1). Moreover, the CIS activity items loaded on the second factor, although the majority of the items of the other three subscales of the CIS loaded on the first factor.

\section{Principal component analysis: Simultaneous analysis of CIS and MBI-GS}

\section{(unforced factor solution)}

PCA of the CIS and the MBI-GS with an unforced factor solution yielded six factors (table 2). The first factor consisted of the eight subjective fatigue items of the CIS, one motivation item of the CIS and one exhaustion item of the MBI-GS. The second factor captured the six professional efficacy items of the MBI-GS. The third factor captured the three activity items of the CIS. The fourth factor consisted of the five concentration items of the CIS. The fifth factor consisted of four of the five exhaustion items of the MBI-GS as well as the four cynicism items of the MBI-GS. The final component consisted of three of the four motivation items of the CIS. The results of this PCA show double loadings of one cynicism item (MBI-GS, factor 2 and 5) and one motivation item (ClS, factor 1 and 6) (table 2). The items of the exhaustion subscale and the cynicism subscale of the MBI-GS were clustered together on one factor.

Table 2 Results of simultaneous principal component analysis of the MBI-GS and the CIS for the unforced factor solution

\begin{tabular}{lrrrrrr}
\hline & Factor & Factor & Factor & Factor & Factor & Factor \\
& $1^{\mathrm{a}}$ & $2^{\mathrm{a}}$ & $3^{\mathrm{a}}$ & $4^{\mathrm{a}}$ & $5^{\mathrm{a}}$ & \\
\hline Maslach Burnout Inventory-General Survey (MBI-GS) & & & & & & \\
\hline Exhaustion sub5cale & & & & & & \\
Item 1 & .18 & .16 & -.31 & .26 & .41 & .18 \\
Item 3 & .23 & .06 & -.28 & .16 & .40 & .18 \\
Item 5 & .32 & .13 & -.28 & .16 & .45 & .19 \\
Item 11 & .36 & .17 & -.28 & .15 & .40 & .20 \\
Item 14 & .48 & .01 & -.11 & .07 & .36 & .03 \\
Cynicism subscale & & & & & & \\
Item 2 & -.06 & -.15 & .14 & .05 & .66 & -.05 \\
Item 7 & -.09 & -.14 & .13 & .06 & .68 & -.03 \\
Item 8 & .04 & -.47 & .02 & -.02 & .49 & .06 \\
Item 15 & .03 & -.03 & .05 & .01 & .72 & -.03 \\
Professional efficacy subscale & & & & & & \\
Item 4 & -.07 & .64 & .13 & -.17 & .13 & -.01 \\
Item 6 & -.04 & .64 & -.07 & .01 & -.23 & .03 \\
Item 9 & .04 & .53 & -.13 & -.25 & .03 & .03 \\
Item 10 & -.04 & .60 & .03 & .14 & -.18 & -.15 \\
Item 12 & -.12 & .59 & -.02 & .19 & -.19 & -.03 \\
Item 16 & -.03 & .60 & .03 & -.24 & .04 & -.06 \\
\hline
\end{tabular}


Table 2 continued

\begin{tabular}{|c|c|c|c|c|c|c|}
\hline & $\begin{array}{r}\text { Factor } \\
1^{\mathrm{a}} \\
\end{array}$ & $\begin{array}{r}\text { Factor } \\
2^{a} \\
\end{array}$ & $\begin{array}{r}\text { Factor } \\
3^{a} \\
\end{array}$ & $\begin{array}{r}\text { Factor } \\
4^{a} \\
\end{array}$ & $\begin{array}{r}\text { Factor } \\
5^{a} \\
\end{array}$ & $\begin{array}{r}\text { Factor } \\
6^{a} \\
\end{array}$ \\
\hline \multicolumn{7}{|c|}{ Checklist Individual Strength (CIS) } \\
\hline \multicolumn{7}{|c|}{ Subjective fatigue subscale } \\
\hline Item 1 & .75 & -.04 & .02 & .02 & .01 & .15 \\
\hline Item 4 & .77 &.,- 01 & -.08 & .07 & .00 & -.05 \\
\hline Item 6 & .80 & -.03 & -.12 & .06 & -.01 & -.01 \\
\hline Item 9 & .76 & -.01 & .05 & .11 & .05 & -.03 \\
\hline Item 12 & .69 & -.03 & -.06 & .10 & .02 & .13 \\
\hline Item 14 & .89 & -.02 & .15 & -.06 & -.04 & -.08 \\
\hline Item 16 & .76 & -.03 & .05 & .09 & -.02 & .03 \\
\hline Item 20 & .85 & -.08 & .10 & -.09 & -.08 & .03 \\
\hline \multicolumn{7}{|c|}{ Motivation subscale } \\
\hline Item 2 & .50 & -.07 & .11 & .00 & -.02 & .42 \\
\hline Item 5 & .05 & .02 & .02 & -.00 & -.03 & .81 \\
\hline Item 15 & -.13 & -.12 & .07 & .02 & -.09 & .86 \\
\hline Item 18 & .27 & .01 & .14 & .16 & .06 & .46 \\
\hline \multicolumn{7}{|c|}{ Concentration subscale } \\
\hline Item 3 & .09 & -.05 & -.07 & .65 & -.00 & .01 \\
\hline Item 8 & -.07 & -.04 & .12 & .75 & .05 & .12 \\
\hline Item 11 & -.01 & -.07 & .08 & .77 & .01 & .11 \\
\hline Item 13 & .10 & -.01 & .02 & .76 & .01 & -.03 \\
\hline Item 19 & .06 & -.06 & .07 & .70 & .07 & -.04 \\
\hline \multicolumn{7}{|c|}{ Activity subscale } \\
\hline Item 7 & .04 & .02 & .75 & .03 & .07 & .16 \\
\hline Item 10 & .17 & .08 & .72 & .18 & .16 & .03 \\
\hline Item 17 & .21 & .03 & .48 & .28 & .13 & .12 \\
\hline
\end{tabular}

Bold factor loadings indicate to which factor the item was assigned.

For copyright reasons, full items are not listed. Item numbers correspond to the items of the questionnaires (CIS and MBI-GS) ${ }^{10,11,28}$.

${ }^{a}$ Explained variance: factor $1,36 \%$; factor $2,8 \%$; factor $3,6 \%$; factor $4,4 \%$; factor $5,4 \%$; factor $6,3 \%$.

\section{Overlap in constructs and complaints}

We looked at the extent to which the constructs of burnout and prolonged fatigue as well as exhaustion and subjective fatigue overlapped. We found that $63 \%$ of the burnout cases were also prolonged fatigue cases, whereas $51 \%$ of the prolonged fatigue cases were also burnout cases (specific data not shown). Moreover, $61 \%$ of the exhaustion cases were also subjective fatigue cases, and $68 \%$ of the subjective fatigue cases were also exhaustion cases (specific data not shown). There was a considerable overlap between burnout and prolonged fatigue on the one hand, and their respective main complaints exhaustion and subjective fatigue on the other (table 3 ).

\section{Characteristics of subgroups based on prolonged fatigue and burnout status}

Table 4 shows characteristics of pure fatigue cases, pure burnout cases, burnout $\&$ fatigue cases and neither burnout nor fatigue cases. Due to the large number of participants most of the comparisons between the groups (even small differences) on the presented variables were statistically significant. 
Table 3 Overlap in conditions (burnout and prolonged fatigue) and main complaints (exhaustion and subjective fatigue)

\begin{tabular}{lll}
\hline & $\begin{array}{l}\text { Prolonged fatigue } \\
(\mathrm{n}=2497)\end{array}$ & $\begin{array}{l}\text { Burnout } \\
(\mathrm{n}=2034)\end{array}$ \\
\hline $\begin{array}{l}\text { Subjective fatigue } \\
\text { Exhaustion }\end{array}$ & $\begin{array}{l}2075(83 \%)^{\mathrm{a}} \\
1724(69 \%)\end{array}$ & $\begin{array}{l}1339(66 \%) \\
2034(100 \%)\end{array}$ \\
\hline & $\begin{array}{l}\text { Subjective fatigue } \\
(\mathrm{n}=2993)\end{array}$ & $\begin{array}{l}\text { Exhaustion } \\
(\mathrm{n}=3308)\end{array}$ \\
\hline Prolonged fatigue & $2076(70 \%)$ & $1726(53 \%)$ \\
Burnout & $1364(46 \%)$ & $2068(63 \%)$ \\
\hline
\end{tabular}

Data are presented as $n(\%)$.

${ }^{a}$ Valid percentages are presented.

There were no notable differences between the subgroups in demographic factors, except for a slightly lower percentage of men in the pure fatigue group compared to the other subgroups. The most notable differences between the subgroups were in perceived general health and GHQ-caseness. The proportion of GHQ-cases was highest in the burnout \& fatigue group. Moreover, the proportion of GHQ-cases in the pure fatigue group was higher than in the pure burnout group. The same pattern was also observed for a perceived bad general health. The pure fatigue, pure burnout and burnout \& fatigue groups were quite comparable with respect to self-reported chronic conditions. Mean CIS and MBI-GS scores were higher in the burnout \& fatigue group than in the pure fatigue group or the pure burnout group, respectively. Pure fatigue cases and the neither burnout nor fatigue cases reported doing day-work slightly more often than pure burnout cases and the burnout $\&$ fatigue cases. The pure burnout group and the burnout \& fatigue group tended to have more unfavourable scores than the other two groups in terms of demands, skill discretion, decision authority, decision latitude and supervisor social support. Those who were both burned out and fatigued reported a higher percentage of absenteeism than any of the other groups.

\section{Characteristics of subgroups based on subjective fatigue and exhaustion status}

In general, the same patterns emerged as with the burnout and prolonged fatigue subgroups analysis (table 5). However there were a few differences. There was a lower percentage of men in the pure subjective fatigue group than in the other subgroups. The difference between pure subjective fatigue and pure exhaustion in GHQ-caseness frequency was smaller than between pure fatigue and pure burnout cases. Differences emerged with respect to attributions: the pure exhaustion subgroup and the subjective fatigue \& exhaustion group reported a psychological attribution for their fatigue complaints more often than in the other two subgroups. Moreover, pure exhaustion cases reported less somatic attributions for their fatigue complaints than the other subgroups. Finally, only the neither subjective fatigue nor exhaustion subgroup differed from the other subgroups with respect to shift work. 
Table 4 Characteristics of pure fatigue cases, pure burnout cases, burnout \& fatigue cases and neither fatigue nor burnout cases

\begin{tabular}{|c|c|c|c|c|}
\hline Characteristics $^{a}$ & $\begin{array}{c}\text { Pure } \\
\text { fatigue } \\
\text { cases }^{b} \\
(n=1225)\end{array}$ & $\begin{array}{l}\text { Pure } \\
\text { burnout } \\
\text { cases }^{\text {b }} \\
(n=762)\end{array}$ & $\begin{array}{l}\text { Burnout } \& \\
\text { fatigue } \\
\text { cases }^{\text {b }} \\
(n=1272)\end{array}$ & $\begin{array}{c}\text { Neither fatigue } \\
\text { nor burnout } \\
\text { cases }^{\text {b }} \\
(n=8338)\end{array}$ \\
\hline Age (years) & $41.4(8.6)$ & $40.2(9.3)$ & $41.2(9.0)$ & $40.7(8.9)$ \\
\hline Gender $\mathrm{m} / \mathrm{f}(\% \mathrm{~m})$ & $847 / 377(69 \%)$ & $579 / 182(76 \%)$ & $968 / 304(76 \%)$ & $6121 / 2216(73 \%)$ \\
\hline \multicolumn{5}{|l|}{ Highest educational level } \\
\hline Primary school & $59(5 \%)$ & $35(5 \%)$ & $89(7 \%)$ & $296(4 \%)$ \\
\hline Lower vocational education & $194(16 \%)$ & $163(22 \%)$ & $255(21 \%)$ & $1125(14 \%)$ \\
\hline Lower secondary school & $158(13 \%)$ & $80(11 \%)$ & $180(15 \%)$ & $1016(13 \%)$ \\
\hline Intermediate vocational education & $271(23 \%)$ & $162(22 \%)$ & $261(21 \%)$ & $2004(25 \%)$ \\
\hline Upper secondary school & $102(9 \%)$ & $67(9 \%)$ & $92(8 \%)$ & $701(9 \%)$ \\
\hline Upper vocational education & $297(25 \%)$ & $149(20 \%)$ & $243(20 \%)$ & $1941(24 \%)$ \\
\hline University & $112(9 \%)$ & $80(11 \%)$ & $110(9 \%)$ & $1003(12 \%)$ \\
\hline Prolonged fatigue $(20-140)^{c}$ & $88.1(10.6)$ & $62.7(11.2)$ & $95.0(13.6)$ & $46.0(15.2)$ \\
\hline Subjective fatigue $(8-56)^{c}$ & $40.4(7.2)$ & $30.3(7.9)$ & $43.6(7.4)$ & $20.4(9.1)$ \\
\hline Exhaustion $(0-6)^{c}$ & $2.4(1.0)$ & $3.1(0.7)$ & $3.7(1.0)$ & $1.4(0.8)$ \\
\hline Cynicism $(0-6)^{c}$ & $1.6(0.9)$ & $2.7(0.9)$ & $3.0(1.0)$ & $1.2(0.9)$ \\
\hline Professional efficacy $(0-6)^{c}$ & $3.9(0.9)$ & $3.4(0.8)$ & $3.1(97 \%)$ & $4.3(0.9)$ \\
\hline Fatigue symptoms in last 4 months & $1090(90 \%)$ & $616(82 \%)$ & $1223(97 \%)$ & $3328(40 \%)$ \\
\hline Psychological attribution & $564(52 \%)$ & $359(58 \%)$ & $720(59 \%)$ & $1509(45 \%)$ \\
\hline Somatic attribution & $425(39 \%)$ & $226(37 \%)$ & $502(41 \%)$ & $1393(42 \%)$ \\
\hline Unknown attribution & $246(23 \%)$ & $105(17 \%)$ & $215(18 \%)$ & $692(21 \%)$ \\
\hline GHQ cases & $586(48 \%)$ & $284(37 \%)$ & $829(65 \%)$ & $903(11 \%)$ \\
\hline Perceived general health, bad & $431(36 \%)$ & $116(15 \%)$ & $600(48 \%)$ & $467(6 \%)$ \\
\hline Self-reported chronic somatic condition & $331(27 \%)$ & $181(24 \%)$ & $374(29 \%)$ & $1505(18 \%)$ \\
\hline Self-reported chronic psychological condition & $49(4 \%)$ & $31(4 \%)$ & $110(9 \%)$ & $67(1 \%)$ \\
\hline $\begin{array}{l}\text { Self-reported chronic somatic and } \\
\text { psychological condition }\end{array}$ & $72(6 \%)$ & $24(3 \%)$ & $138(11 \%)$ & $38(1 \%)$ \\
\hline Psychological task demands $(12-48)^{c}$ & $33.4(5.9)$ & $35.8(5.5)$ & $35.8(6.0)$ & $32.6(5.5)$ \\
\hline Skill discretion $(12-48)^{c}$ & $36.2(5.4)$ & $34.3(5.9)$ & $33.5(6.4)$ & $37.1(5.2)$ \\
\hline Decision authority $(12-48)^{\mathrm{c}}$ & $35.0(6.7)$ & $31.9(7.2)$ & $30.2(7.7)$ & $36.4(6.7)$ \\
\hline Decision latitude $(24-96)^{c}$ & $71.2(10.7)$ & $66.2(11.4)$ & $63.7(12.6)$ & $73.5(10.6)$ \\
\hline Supervisor social support $(4-16)^{\mathfrak{C}}$ & $10.3(2.2)$ & $9.2(2.4)$ & $9.0(2.6)$ & $10.8(2.2)$ \\
\hline Co-worker social support $(4-16)^{c}$ & $11.7(1.6)$ & $11.51 .7)$ & $11.3(1.9)$ & $12.0(1.5)$ \\
\hline Managerial position & $289(24 \%)$ & $158(21 \%)$ & $232(18 \%)$ & $2125(26 \%)$ \\
\hline \multicolumn{5}{|l|}{ Work schedule } \\
\hline Day work & $862(71 \%)$ & $463(62 \%)$ & $762(61 \%)$ & $5977(72 \%)$ \\
\hline Shift work & $357(29 \%)$ & $287(38 \%)$ & $498(40 \%)$ & $2297(28 \%)$ \\
\hline \multicolumn{5}{|l|}{ Working hours } \\
\hline Fulltime work & $878(72 \%)$ & $576(77 \%)$ & $939(74 \%)$ & $6126(74 \%)$ \\
\hline Part-time work & $338(28 \%)$ & $176(23 \%)$ & $323(26 \%)$ & $2150(26 \%)$ \\
\hline Absenteeism & $167(14 \%)$ & $75(10 \%)$ & $270(22 \%)$ & $441(5 \%)$ \\
\hline
\end{tabular}

${ }^{a}$ Data are mean values (S.D.) or $n$ (\%)

${ }^{b}$ The groups differed significantly at the $p<0.001$ level on all characteristics except:

working hours ( $p>0.05$, n.s.); somatic attribution ( $p>0.05$, n.s.); age $(p<0.05)$; unknown attribution $(p<0.01)$

'Range of scale 
Table 5 Characteristics of pure subjective fatigue cases, pure exhaustion cases, subjective fatigue \& exhaustion cases and neither subjective fatigue nor exhaustion cases

\begin{tabular}{|c|c|c|c|c|}
\hline Characteristics $^{\circ}$ & $\begin{array}{c}\text { Pure } \\
\text { subjective fatigue } \\
\text { cases }^{b} \\
(n=968)\end{array}$ & $\begin{array}{c}\begin{array}{c}\text { Pure } \\
\text { exhaustion } \\
\text { cases }^{\mathrm{b}}\end{array} \\
(n=1283)\end{array}$ & $\begin{array}{c}\text { Subjective fatigue } \\
\text { \& exhaustion } \\
\text { cases }^{\mathrm{b}} \\
(n=2025)\end{array}$ & $\begin{array}{l}\text { Neither subjective } \\
\text { fatigue nor } \\
\text { exhaustion } \\
\text { cases }^{b} \\
(n=7463)\end{array}$ \\
\hline$\overline{\text { Age (years) }}$ & $39.8(8.6)$ & $41.1(8.9)$ & $40.7(9.0)$ & $41.0(8.9)$ \\
\hline Gender $\mathrm{m} / \mathrm{f}(\% \mathrm{~m})$ & $602 / 365(62 \%)$ & $1018 / 264(79 \%)$ & $1492 / 533(74 \%)$ & $5486 / 1976(74 \%)$ \\
\hline \multicolumn{5}{|l|}{ Highest educational level } \\
\hline Primary school & $41(4 \%)$ & $59(5 \%)$ & $123(6 \%)$ & $568(4 \%)$ \\
\hline Lower vocational education & $132(14 \%)$ & $234(19 \%)$ & $389(20 \%)$ & $1013(14 \%)$ \\
\hline Lower secondary school & $136(14 \%)$ & $148(12 \%)$ & $277(14 \%)$ & $897(12 \%)$ \\
\hline Intermediate vocational education & $235(25 \%)$ & $292(23 \%)$ & $416(21 \%)$ & $1783(25 \%)$ \\
\hline Upper secondary school & $74(8 \%)$ & $90(7 \%)$ & $162(8 \%)$ & $646(9 \%)$ \\
\hline Upper vocational education & $213(23 \%)$ & $287(23 \%)$ & $411(21 \%)$ & $1736(24 \%)$ \\
\hline University & $112(12 \%)$ & $135(11 \%)$ & $175(9 \%)$ & $895(12 \%)$ \\
\hline Prolonged fatigue $(20-140)^{\mathrm{C}}$ & $79.9(13.7)$ & $61.7(14.5)$ & $88.9(16.4)$ & $44.5(15.4)$ \\
\hline Subjective fatigue $(8-56)^{c}$ & $40.3(4.8)$ & $27.1(5.9)$ & $44.0(6.2)$ & $18.7(7.6)$ \\
\hline Exhaustion $(0-6)^{c}$ & $1.7(0.4)$ & $3.0(0.6)$ & $3.6(0.9)$ & $1.2(0.6)$ \\
\hline Cynicism $(0-6)^{\mathrm{c}}$ & $1.5(1.0)$ & $2.0(1.1)$ & $2.4(1.2)$ & $1.2(0.9)$ \\
\hline Professional efficacy $(0-6)^{c}$ & $3.9(0.9)$ & $3.9(0.9)$ & $3.6(1.0)$ & $4.3(0.9)$ \\
\hline Fatigue symptoms in last 4 months & $853(89 \%)$ & $993(79 \%)$ & $1940(97 \%)$ & $2556(35 \%)$ \\
\hline Psychological attribution & $376(44 \%)$ & $626(63 \%)$ & $1103(57 \%)$ & $1087(43 \%)$ \\
\hline Somatic attribution & $383(45 \%)$ & $326(33 \%)$ & $809(42 \%)$ & $1070(42 \%)$ \\
\hline Unknown attribution & $185(22 \%)$ & $163(16 \%)$ & $354(18 \%)$ & $570(22 \%)$ \\
\hline GHQ cases & $364(38 \%)$ & $400(32 \%)$ & $1148(57 \%)$ & $723(10 \%)$ \\
\hline Perceived general health, bad & $299(31 \%)$ & $140(11 \%)$ & $900(45 \%)$ & $298(4 \%)$ \\
\hline $\begin{array}{l}\text { Self-reported chronic } \\
\text { somatic condition }\end{array}$ & $280(29 \%)$ & $286(22 \%)$ & $616(30 \%)$ & $1252(17 \%)$ \\
\hline $\begin{array}{l}\text { Self-reported chronic } \\
\text { psychological condition }\end{array}$ & $29(3 \%)$ & $40(3 \%)$ & $124(6 \%)$ & $67(1 \%)$ \\
\hline $\begin{array}{l}\text { Self-reported chronic } \\
\text { somatic and psychological condition }\end{array}$ & $45(5 \%)$ & $34(3 \%)$ & $177(9 \%)$ & $24(0.3 \%)$ \\
\hline Psychological task demands $(12-48)^{c}$ & $32.7(5.2)$ & $35.8(5.4)$ & $36.1(6.0)$ & $32.1(5.3)$ \\
\hline Skill discretion $(12-48)^{c}$ & $36.0(5.4)$ & $36.0(5.7)$ & $34.9(6.4)$ & $37.0(5.2)$ \\
\hline Decision authority $(12-48)^{c}$ & $34.9(6.8)$ & $33.9(7.2)$ & $32.2(8.2)$ & $36.4(6.6)$ \\
\hline Decision latitude $(24-96)^{c}$ & $70.9(10.9)$ & 69.9 (11.6) & $67.1(13.2)$ & $73.3(10.5)$ \\
\hline Supervisor social support $(4-16)^{c}$ & $10.3(2.2)$ & $9.8(2.4)$ & $9.4(2.6)$ & $10.8(2.2)$ \\
\hline Co-worker social support $(4-16)^{c}$ & $11.8(1.6)$ & $11.7(1.6)$ & 11.5 (1.9) & $12.0(1.5)$ \\
\hline Managerial position & $213(22 \%)$ & $325(26 \%)$ & $440(22 \%)$ & $1855(25 \%)$ \\
\hline \multicolumn{5}{|l|}{ Work schedule } \\
\hline Day work & $666(69 \%)$ & $842(67 \%)$ & $1273(64 \%)$ & $5375(73 \%)$ \\
\hline Shift work & $294(31 \%)$ & $425(34 \%)$ & $733(37 \%)$ & $2031(27 \%)$ \\
\hline \multicolumn{5}{|l|}{ Working hours } \\
\hline Fulltime work & $676(70 \%)$ & $988(78 \%)$ & $1526(76 \%)$ & $5421(73 \%)$ \\
\hline Part-time work & $287(30 \%)$ & $280(22 \%)$ & $482(14 \%)$ & $1987(27 \%)$ \\
\hline Absenteeism & $117(12 \%)$ & $113(9 \%)$ & $347(17 \%)$ & $387(5 \%)$ \\
\hline
\end{tabular}




\section{Discussion}

\section{Principal Component Analysis}

The forced two-factor PCA indicates that the discriminative ability of the CIS and the MBIGS with respect to discriminating between burnout and prolonged fatigue on a construct level is moderate. The discriminative ability could be described as good if the CIS items and the MBI-GS items loaded on two separate factors in a forced two-factor solution as for example has been shown for the $\mathrm{GHQ}$ and the $\mathrm{CIS}{ }^{38}$. However, in our results the exhaustion items of the MBI-GS cannot be adequately discriminated from the CIS items which measure prolonged fatigue. This is not an unexpected finding as exhaustion is strongly related to, especially, the subjective fatigue component of the CIS. This finding is also in line with other research that found that the exhaustion component of burnout along with several measures of fatigue (among which the CIS) measured the same concept ${ }^{8,19,20}$. As the CIS has four subscales and the MBI-GS has three subscales, we would have expected to find seven separate factors in the unforced PCA. However, we found six factors, as the exhaustion and cynicism items of the MBI-GS loaded on one factor. In contrast to the forced two-factor analysis, we saw that the exhaustion subscale loaded on a separate factor than the subjective fatigue subscale which could indicate that there is a subtle distinction in subjective fatigue and exhaustion items. Taking the results together, in general the MBI-GS and the CIS can discriminate between burnout and prolonged fatigue. Although exhaustion (MBI-GS) measures the construct of fatigue it seems to be slightly different than the subjective fatigue subscale of the CIS.

\section{Overlap}

There was a considerable overlap between burnout and fatigue cases as well as between exhaustion and subjective fatigue cases. However, the conditions did not overlap completely, meaning that burnout and prolonged fatigue, and exhaustion and subjective fatigue can evidently occur as separate conditions. This is a surprising finding since exhaustion is regarded as a specific (work-related) form of non-specific general fatigue.

\section{Pure fatigue and pure burnout}

Pure fatigue and pure burnout cases in this study were quite similar with respect to demographic factors and attributions. The latter finding is somewhat unexpected. Although there is a small difference, one might expect burnout cases to report a psychological attribution for fatigue complaints more often than fatigue cases as it is thought to be a psychological condition. There were differences between the pure fatigue and pure burnout groups on several health and work-related factors. With respect to the healthrelated factors (i.e. GHQ cases and perceived bad general health) the pure fatigue group tended to do worse than the pure burnout group. The pure burnout group however, tended toward more negative work conditions such as a higher percentage of shift workers, 
higher demands, less control and less supervisor support than the pure fatigue group. This finding could support the notion that burnout is not merely fatigue but rather a specific work-related syndrome ${ }^{4}$. Alternatively, employees might evaluate their work more negatively if their complaints are labelled as 'burnout'.

\section{Concurrent fatigue and pure burnout}

Being concurrently fatigued and burned out seemed to be associated with worse outcomes than having only one of these conditions. This finding seems to be more pronounced for the health-related outcomes than for the work-related outcomes (absenteeism however, was higher in the burnout $\&$ fatigue group compared to the other three subgroups). Mean scores on the MBI-GS and CIS dimensions indicate that the level of both prolonged fatigue and burnout is more severe in this group than in the other groups. Moreover, a high percentage $(65 \%)$ of the group meeting criteria for both prolonged fatigue and burnout also met criteria for GHQ-caseness (minor psychiatric cases). These results are in line with other research findings. One study reported that $70 \%$ of a group of severe burnout cases could be classified as psychiatric cases based on the GHQ-12 ${ }^{1,39}$. A study that aimed to examine the relationship between burnout and depressive disorders found that $53 \%$ of those with severe burnout also had a depressive disorder ${ }^{40}$. Studies on fatigue have also found considerable associations between fatigue and psychological distress ${ }^{38,41}$. Moreover, it was found that the association increased as the severity of fatigue increased ${ }^{41}$. Several explanations can be given for the tendency of more severe complaints to be associated with co-occurrence of other conditions. One is the possibility of a synergistic effect, causing higher scores on the CIS and the MBI-GS as well as more health complaints in this group compared to the single condition groups. Another possibility could be that those who develop or have both conditions concurrently are from the outset the more severe or prone cases and thus also tend to have higher scores on other clinical symptoms.

\section{Subjective fatigue and exhaustion}

After comparing subgroups based on subjective fatigue and exhaustion status, the same pattern emerged as with the comparison of burnout and prolonged fatigue status. However, causal attributions did differ between these groups in the expected direction. Specifically, the pure exhaustion group and the subjective fatigue \& exhaustion group reported a psychological attribution for fatigue more often than the other subgroups. Moreover, the pure exhaustion group reported fewer somatic attributions for their fatigue complaints than the other subgroups. This suggests that attributions might play a role in the distinction of prolonged fatigue and burnout, as previously found by Huibers et al. ${ }^{25}$. However, in this study attributions seem to play a role at the level of the main complaints of burnout and prolonged fatigue. 


\section{Methodological considerations}

A methodological consideration when using continuous measures to examine the prevalence and overlap in burnout and prolonged fatigue caseness is the use of cut-off points. The prevalence of caseness and the degree of overlap is partly dependent on the cut-off and can therefore vary according to the chosen cut-off point. Another issue with respect to prevalence and overlap is the instrument (and its underlying construct definition) used to operationalise fatigue or burnout. Using another measure for fatigue for example (with other cut-off criteria) would probably lead to a different prevalence and overlap. Non-responders at baseline were less likely to report fatigue complaints, absenteeism and difficulty in work execution. This could have led to a slight overestimation of the prevalence with respect to fatigue cases and possibly burnout cases. Overestimation of the observed associations due to the influence of common method variance (owing to the sole use of questionnaires in this study) and stable third variables such as negative affectivity cannot be ruled out.

\section{Conclusion}

Our study suggests there are some relevant differences between burnout and fatigue with respect to work and health factors, and that burnout and fatigue can occur both separately as well as simultaneously. Having both conditions simultaneously seems to be associated with worse outcomes than having either prolonged fatigue or burnout separately, particularly in terms of health-related factors such as psychological distress and selfreported general health. Pure fatigue seems to be more associated with health-related factors whereas pure burnout seems to be more associated with work-related factors. A longitudinal study of prolonged fatigue and burnout may provide valuable information as to whether and how these differences influence their respective courses.

\section{Acknowledgements}

This study was funded by the Occupational Health Epidemiology programme of the Research Institute Caphri, Maastricht University, The Netherlands. The authors wish to thank W. Schaufeli for his valuable comments on the manuscript. 


\section{References}

1 Schaufeli WB, Enzman D. The burnout companion to study and practice: a critical analysis. London: Taylor \& Francis, 1998.

2 Lewis $G$, Wessely 5 . The epidemiology of fatigue: more questions than answers. Journal of Epidemiology and Community Health 1992; 46: 92-7.

3 Wessely S. Chronic fatigue: symptom and syndrome. Annals of Internal Medicine 2001; 134: 838-43.

4 Schaufeli WB, Taris TW. The conceptualization and measurement of burnout: Common ground and worlds apart. Work and Stress 2005; 19: 256-62.

5 Sharpe M, Wilks D. Fatigue. British Medical Journal 2002; 325: 480-3.

6 Swain MG. Fatigue in chronic disease. Clinical Science 2000; 99: 1-8.

7 Meijman T, Schaufeli W. Psychische vermoeidheid en arbeid; Ontwikkelingen in de A\&Opsychologie/ Psychological fatigue and work; developments in occupational and organisational psychology. Psycholoog 1996: 236-41.

8 De Vries J, Michielsen HJ, Van Heck GL. Assessment of fatigue among working people: a comparison of six questionnaires. Occupational and Environmental Medicine 2003; 60 Suppl 1: i10-5.

9 Vercoulen JHHM, Alberts M, Bleijenberg G. De Checklist Individuele Spankracht (CIS) [The Checklist Individual Strength (CIS)]. Gedragstherapie 1999; 32: 131-6.

10 Vercoulen JH, Swanink CM, Fennis JF, Galama JM, van der Meer JW, Bleijenberg G. Dimensional assessment of chronic fatigue syndrome. Journal of Psychosomatic Research 1994; 38: 383-92.

11 Beurskens AJ, Bultmann U, Kant I, Vercoulen JH, Bleijenberg G, Swaen GM. Fatigue among working people: validity of a questionnaire measure. Occupational and Environmental Medicine 2000; 57: 353-7.

12 Van Amelsvoort LG, Kant IJ, Beurskens AJ, Schroer CA, Swaen GM. Fatigue as a predictor of work disability. Occupational and Environmental Medicine 2002; 59: 712-3.

13 Janssen N, Kant IJ, Swaen GMH, Janssen PPM, Schroer CAP. Fatigue as a predictor of sickness absence: results from the Maastricht cohort study on fatigue at work. Occupational and Environmental Medicine 2003; 60 Suppl 1: i71-6.

14 Maslach C, Jackson SE. The measurement of experienced burnout. Journal of Occupational Behavior 1981; 2: 99-113.

15 Schaufeli WB, Leiter MP, Maslach C, Jackson SE. The Maslach Burnout inventory- General Survey. In: Maslach C, Jackson SE, Leiter MP, eds. Maslach Burnout Inventory manual: 3rd Edition. Palo Alto, CA: Consulting Psychologists Press, 1996; 19-26.

16 Maslach C, Schaufeli WB, Leiter MP. Job burnout. Annual Review of Psychology 2001; 52: 397-422.

17 Borritz $M$, Rugulies R, Christensen KB, Villadsen E, Kristensen TS. Burnout as a predictor of self-reported sickness absence among human service workers: prospective findings from three year follow up of the PUMA study. Occupational and Environmental Medicine 2006; 63: 98-106.

18 Toppinen-Tanner S, Ojajarvi A, Vaananen A, Kalimo R, Jappinen P. Burnout as a predictor of medically certified sick-leave absences and their diagnosed causes. Behavioral Medicine 2005; 31: 18-27. 
19 Michielsen HJ, De Vries J, Van Heck GL, Van de Vijver FJR, Sijtsma K. Examination of the dimensionality of fatigue - The Construction of the Fatigue Assessment Scale (FAS). European Journal of Psychological Assessment 2004; 20: 39-48.

20 Michielsen HJ, Willemsen TM, Croon MA, de Vries J, Van Heck GL. Determinants of general fatigue and emotional exhaustion: A prospective study. Psychology \& Health 2004; 19: 22335.

21 Prins JB, van der Meer JW, Bleijenberg G. Chronic fatigue syndrome. Lancet 2006; 367: 34655.

22 Cairns R, Hotopf $M$. A systematic review describing the prognosis of chronic fatigue syndrome. Occupational Medicine 2005; 55: 20-31.

23 Afari N, Buchwald D. Chronic fatigue syndrome: A review. American Journal of Psychiatry 2003; 160: 221-36.

24 Joyce J, Hotopf $M$, Wessely $S$. The prognosis of chronic fatigue and chronic fatigue syndrome: a systematic review. Quarterly Journal of Medicine 1997; 90: 223-33.

25 Huibers MJH, Beurskens AJHM, Prins JB, Kant IJ, Bazelmans E, van Schayck CP, Knottnerus JA, Bleijenberg G. Fatigue, burnout, and chronic fatigue syndrome among employees on sick leave: do attributions make the difference? Occupational and Environmental Medicine 2003; 60: 26-31.

26 Kant IJ, Bultmann U, Schroer KA, Beurskens AJ, Van Amelsvoort LG, Swaen GM. An epidemiological approach to study fatigue in the working population: the Maastricht Cohort Study. Occupational and Environmental Medicine 2003; 60 Suppl 1: i32-9.

27 Bultmann $U$, de Vries M, Beurskens AJ, Bleijenberg G, Vercoulen JH, Kant I. Measurement of prolonged fatigue in the working population: determination of a cutoff point for the checklist individual strength. Journal of Occupational Health Psychology 2000; 5: 411-6.

28 Schaufeli WB, Van Dierendonk D. UBOS, Utrechtse Burnout Schaal, Handleiding. Lisse: Swets Test Publishers, 2000.

29 Schutte N, Toppinen S, Kalimo R, Schaufeli W. The factorial validity of the Maslach Burnout Inventory-General Survey (MBI-GS) across occupational groups and nations. Journal of Occupational and Organizational Psychology 2000; 73: 53-66.

30 Koeter MWJ, Ormel J. General Health Questionnaire, Handleiding Nederlandse bewerking [General Health Questionnaire, Manual Dutch version]. Lisse: Swets \& Zeitlinger, 1991.

31 Goldberg DP, Williams P. A users guide to the General Health Questionnaire. Windsor: Nfer Nelson, 1988.

32 Hardy GE, Shapiro DA, Borrill CS. Fatigue in the workforce of National Health Service Trusts: levels of symptomatology and links with minor psychiatric disorder, demographic, occupational and work role factors. Journal of Psychosomatic Research 1997; 43: 83-92.

33 Franssen PM, Bultmann U, Kant I, van Amelsvoort LG. The association between chronic diseases and fatigue in the working population. Journal of Psychosomatic Research 2003; 54: 339-44.

34 Aaronson NK, Muller M, Cohen PD, Essink-Bot ML, Fekkes M, Sanderman R, Sprangers MA, te Velde $A$, Verrips $E$. Translation, validation, and norming of the Dutch language version of the SF-36 Health Survey in community and chronic disease populations. Journal of Clinical Epidemiology 1998; 51: 1055-68.

35 Ware JE, Jr., Sherbourne CD. The MOS 36-item short-form health survey (SF-36). I. Conceptual framework and item selection. Medical Care 1992; 30: 473-83. 
36 Houtman I. Reliability and validity of the Dutch version of the Karasek Job Content Questionnaire. NIOSH/APA conference on Stress, Work, and Health. Washington, DC, 1995

37 Karasek RA. The Job Content Questionnaire and User's Guide (version 1.1). Los Angeles: Department of Industrial and Systems Engineering, University of Southern California, 1985

38 Bultmann U, Kant I, Kasl SV, Beurskens AJ, van den Brandt PA. Fatigue and psychological distress in the working population: psychometrics, prevalence, and correlates. Journal of Psychosomatic Research 2002; 52: 445-52.

39 Schaufeli W, Van Dierendonck D. Burnout, een begrip gemeten. De Nederlandse versie van de Maslach Burnout Inventory (MBI-NL). / Burnout--The measurement of a concept: The Dutch version of the Maslach Burnout Inventory (MBI--NL). Gedrag and Gezondheid Tijdschrift voor Psychologie en Gezondheid 1994; 22: 153-72

40 Ahola K, Honkonen T, Isometsa E, Kalimo R, Nykyri E, Aromaa A, Lonnqvist J. The relationship between job-related burnout and depressive disorders-results from the Finnish Health 2000 Study. Journal of Affective Disorders 2005; 88: 55-62.

41 Pawlikowska T, Chalder T, Hirsch SR, Wallace P, Wright DJ, Wessely SC. Population based study of fatigue and psychological distress. British Medical Journal 1994; 308: 763-6. 


\section{A comparison of the course of burnout and prolonged fatigue:}

\section{A 4-year prospective cohort study}

5.S. Leone ${ }^{1}$

M.J.H. Huibers ${ }^{2}$

J.A. Knottnerus ${ }^{3}$

IJ. Kant ${ }^{1}$

${ }^{1}$ Department of Epidemiology, Maastricht University, Maastricht, The Netherlands

${ }^{2}$ Department of Clinical Psychological Science, Maastricht University, Maastricht, The Netherlands

${ }^{3}$ Department of General Practice, Maastricht University, Maastricht, The Netherlands 


\section{Abstract}

\section{Objective}

Outcomes in burnout and prolonged fatigue have hardly been compared in longitudinal research, despite several similarities such as the importance of fatigue symptoms in both conditions. This study aims to assess and compare the course of burnout and prolonged fatigue in the working population.

\section{Methods}

Prospective data from the Maastricht Cohort Study on Fatigue at work were used. The course was determined in terms of complaints and absenteeism. Participants who completed questionnaires at baseline and the 12-, 24-, and 48-month follow-ups were divided into three subgroups: "pure fatigue" ( $n=485)$, "pure burnout" $(n=296)$ and "burnout \& fatigue" $(n=426)$.

\section{Results}

The "burnout \& fatigue" group had the highest proportion (29\%) of the chronic course type compared to the "pure burnout" (2\%) and "pure fatigue" (9\%) groups in addition to more absenteeism over time compared to the "pure fatigue" group. Recovery from all conditions was highest in the "pure burnout" group (40\%). The course of burnout and prolonged fatigue is characterised by its dynamic nature.

\section{Discussion}

Differences emerged in the course of burnout and prolonged fatigue. The differential diagnosis of employees presenting with fatigue complaints could be important in estimating the outcome of complaints and need for therapy. 


\section{Introduction}

Although burnout and prolonged fatigue differ in background, context, and conceptualisation, a major similarity between burnout and prolonged fatigue is that the symptom of fatigue plays a central role in both conditions ${ }^{1}$. From a medical point of view, fatigue is termed unexplained when a medical condition cannot account for its presence ${ }^{2}$, which prolonged fatigue refers to in this study. Despite an ongoing discussion in the burnout literature about whether burnout is actually more than just (work-related) fatigue ${ }^{3}$, prolonged fatigue and burnout have hardly been compared empirically. In contrast to burnout, a considerable amount of studies have examined the clinical course of fatigue, especially with respect to chronic fatigue and chronic fatigue syndrome ${ }^{4,5}$. Both burnout and prolonged fatigue are assumed to be persistent, yet this has been substantiated more widely for prolonged fatigue than for burnout ${ }^{4-9}$. Employees presenting with fatigue complaints could be misdiagnosed due to the similarities between burnout and prolonged fatigue, which may result in less efficient treatment. However, to date, it is unknown whether the differential diagnosis of burnout and prolonged fatigue is truly relevant, as the differential clinical course of burnout and prolonged fatigue in the working population is not known.

In a previous study, we found differences between burnout and prolonged fatigue on work and health factors. Moreover, we found that having both burnout and prolonged fatigue simultaneously was associated with the most severe symptoms and the most unfavourable work and health outcomes ${ }^{10}$. It is likely that this group is characterised by a poorer course compared to having either burnout or prolonged fatigue separately. This study aims to assess and compare the clinical course of burnout and prolonged fatigue in a 4-year prospective cohort study in the working population.

\section{Methods}

\section{Design}

This study uses prospective data from the Maastricht Cohort Study on Fatigue at Work (MCS) gathered between 1998 and 2001 by means of self-administered questionnaires. Employees from 45 different companies and organisations participated in this study. Over the course of 3 years participants received an extensive questionnaire containing questions on health factors (e.g. fatigue, burnout), work factors, non work factors, and demographic factors once a year. In addition, they received a brief questionnaire on outcome measures (e.g. fatigue and sickness absence) twice a year. An additional (extensive) follow-up was carried out at 48 months after baseline. The response rate at baseline was $45 \%$ and a total of 12,140 employees were included. A non-response analysis among a sample of nonrespondents to the baseline questionnaire showed that non-respondents reported less 
fatigue complaints, less sickness absence and less difficulty in work execution ${ }^{11}$. Detailed information on the design of the MCS is provided elsewhere ${ }^{12}$. For this study the baseline measurement and the 12-, 24- and 48-month follow-up measurements were used (i.e. extensive measurements) as burnout was only assessed at these four measurements.

\section{Study population}

Participants who had data on burnout and prolonged fatigue at all four measurements were included in this study. This was necessary to determine the course type. To ensure fatigue complaints were medically unexplained, participants who were known to have one of the following chronic conditions that might explain burnout or fatigue complaints were excluded: cerebrovascular accidents, liver dysfunction, diabetes mellitus, hyperthyroidism or cancer. This left us with a study population of $N=1207$ (see figure 1 ).

\section{Measures}

Prolonged fatigue was measured with the Checklist Individual Strength (CIS) which includes items (scored on a seven-point Likert scale) on subjective fatigue ( 8 items), motivation (4 items), activity ( 3 items), and concentration ( 5 items) ${ }^{13,14}$. Higher scores indicate higher levels of subjective fatigue, motivation, concentration, or a reduced level of activity. A composite total score can be attained by adding the scores of the subscales (range 20-140). Participants were classified as a prolonged fatigue case if they had a total score of higher than $76^{15}$.

Burnout was assessed with the three subscales of the Dutch version of the Maslach Burnout Inventory-General Survey (MBI-GS): exhaustion (5 items), cynicism (4 items) and professional efficacy ( 6 items) ${ }^{16,17}$. Higher scores (range 0-6) indicate higher levels on these scales. Burnout cases were defined according to the definition in the manual of the Dutch version of the MBI-GS as having a score higher than the $75^{\text {th }}$ percentile on exhaustion and a score higher than the $75^{\text {th }}$ percentile on cynicism, or a score lower than the $25^{\text {th }}$ percentile on professional efficacy. In our study population, this resulted in the following cut-off points: exhaustion $>2.40$, cynicism $>2.25$ and professional efficacy $<3.50$.

Absenteeism was defined in broad terms as being completely absent or partially absent (working limited hours or able to do limited activities due to sickness). Participants indicated at each measurement whether they had reported themselves sick at any time during the four months prior to the measurement.

Age, gender and educational level (low, medium, and high) were assessed by means of selfreport at baseline.

\section{Definition of subgroups}

Subgroups at baseline were formed based on prolonged fatigue and burnout status: pure fatigue cases, pure burnout cases and burnout \& fatigue cases. We applied the idea of course types, which is common in research of psychiatric conditions such as depression, to 
this study ${ }^{18-20}$. Four course types were defined in each subgroup: chronic, recovery, recurrence, and double recovery. We defined these course types in two different ways to reflect the stability of a condition and the clinical course of a condition, respectively. First, we defined the course types in terms of recovery from the subgroup definition: chronic la pure fatigue, pure burnout or burnout \& fatigue case at all measurements), recovery (recovery from the subgroup definition, i.e. from pure fatigue, pure burnout or burnout $\&$ fatigue, at any measurement lasting the rest of the study), recurrence (becoming a pure fatigue, pure burnout or burnout $\&$ fatigue case after recovery from the subgroup definition) and double recovery (recovery the subgroup definition after a recurrence). Secondly, we defined the course types in terms of recovery from all (three) conditions under study: chronic (a pure fatigue, pure burnout or burnout \& fatigue case at all measurements), recovery (recovery from all conditions at any measurement lasting the rest of the study), recurrence (becoming a pure fatigue, pure burnout or burnout $\&$ fatigue case after recovery from all conditions) and double recovery (recovery from all conditions after a recurrence).

\section{Statistical analysis}

A non-response analysis, using independent $t$ tests and chi-square tests, was performed to determine if there was selective non-response in the course of follow-up as a result of our selection. Differences between subgroups at baseline were analysed using chi-square tests and Kruskal-Wallis tests. Logistic regression analysis was used to examine the relationship between subgroups and course types, adjusting for age, gender, education and absenteeism at baseline. The standard error of measurement (SEM) was calculated as a measure used to compare the magnitude of change scores between measurements with. As we only use questionnaires to assess burnout and /or fatigue status, this gives us some insight into the magnitude and relevance of a change in score for participants shifting from case to non-case (i.e. recovery from all conditions) and vice versa, in a similar vein to Beekman et al. ${ }^{18}$. A logistic generalised estimating equations (GEE) analysis was performed to determine the relationship between the subgroups and absenteeism in the course of follow-up. All statistical tests were two-tailed. Data were analysed using SPSS version 13 and intercooled STATA version 9.

\section{Results}

\section{Baseline characteristics and attrition}

Attrition was quite high and highest in the burnout \& fatigue group (figure 1: $66 \%$ vs. $60 \%$ and $61 \%$ in the pure fatigue and the pure burnout groups, respectively; $\chi^{2}=10.92 ; p=$ 0.004). Compared to participants who completed the four measurements, the participants who dropped out in the course of follow-up were younger ( $t=-5.07, p=0.000)$, scored 
lower on professional efficacy $(t=-2.35, p=0.019)$, and scored higher on exhaustion $(t=$ $3.89, p=0.000)$, cynicism $(t=2.92, p=0.004)$, prolonged fatigue $(t=1.98, p=0.048)$, and subjective fatigue $(t=3.26, p=0.001)$. Furthermore, they were absent from work more often $\left(\chi^{2}=17.63, p=0.000\right)$ and also had a low educational level more often and a high educational level less often $\left(\chi^{2}=53.72, p=0.000\right)$. In the specific subgroups it was found that, compared to participants, dropouts in the pure fatigue group scored higher on subjective fatigue $(t=2.43, p=0.015)$, had a low educational level more often and a high educational level less often $\left(\chi^{2}=12.52, p=0.002\right)$. Dropouts in the pure burnout group scored higher on exhaustion ( $t=2.50, p=0.013)$, were younger $(t=-3.75, p=0.000)$ and had a low educational level more often and a high educational level less often $\left(\chi^{2}=29.67, p\right.$ $=0.000)$. Dropouts in the burnout $\&$ fatigue group were found to have a higher score on subjective fatigue $(t=2.19, p=0.029)$, exhaustion $(t=2.16, p=0.031)$ and cynicism $(t=$ $2.02, p=0.046)$, to be younger $(t=-3.77, p=0.000)$, to be absent more often $\left(x^{2}=8.33, p=\right.$ $0.004)$, and to have had a low educational level more often and a high educational less often $\left(\chi^{2}=20.21, p=0.000\right)$. Table 1 summarises baseline characteristics of our selected study sample.

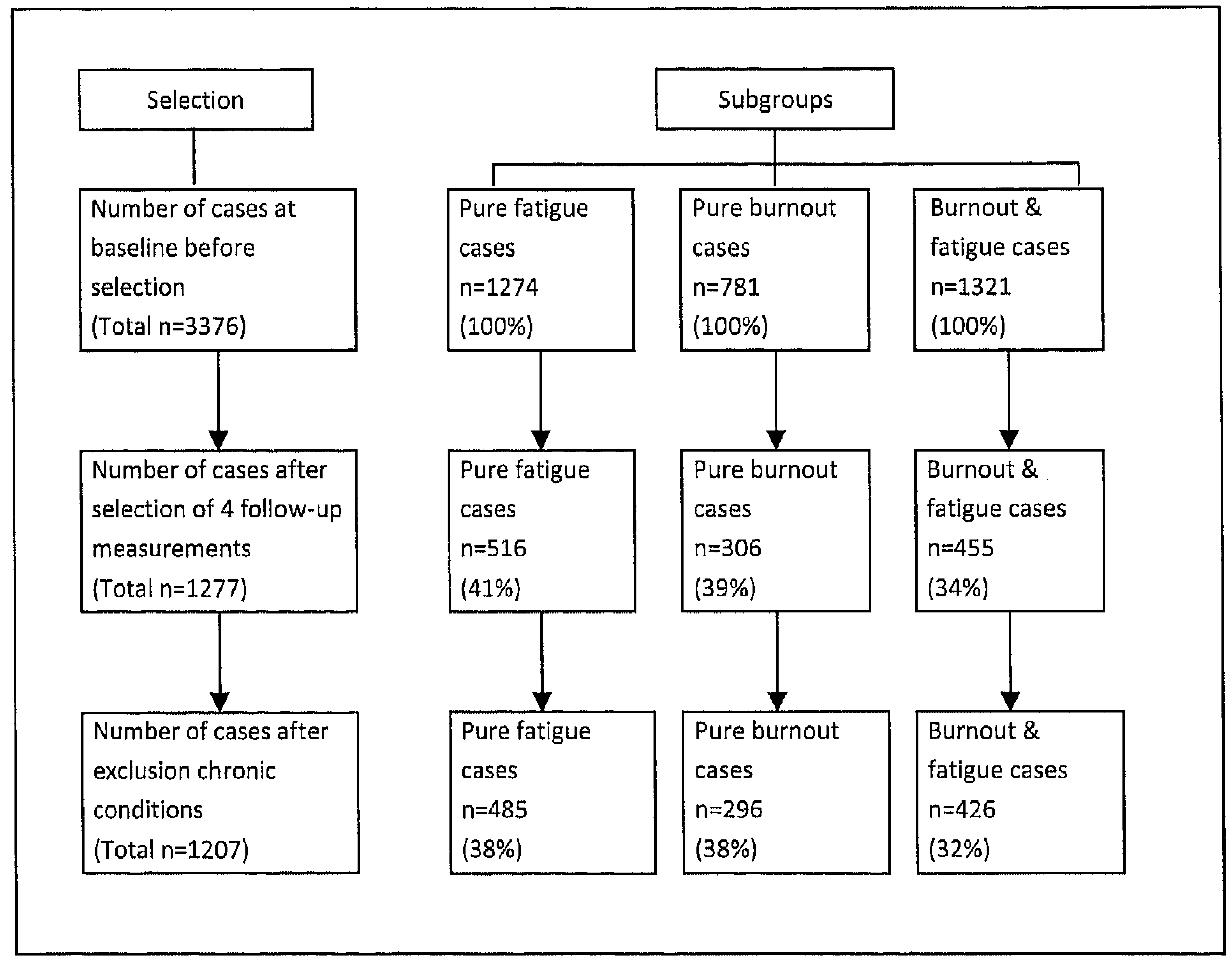

Figure 1 Flowchart of case selection 
Table 1 Baseline characteristics of subgroups

\begin{tabular}{|c|c|c|c|c|}
\hline Characteristics $^{a}$ & $\begin{array}{l}\text { Pure fatigue } \\
\qquad(n=485)\end{array}$ & $\begin{array}{l}\text { Pure burnout } \\
\qquad(\mathrm{n}=296)\end{array}$ & $\begin{array}{l}\text { Burnout } \\
\text { \& fatigue } \\
(n=426)\end{array}$ & $\begin{array}{c}\text { Neither burnout nor } \\
\text { fatigue } \\
(n=3596)\end{array}$ \\
\hline Age (years) & $41.7(7.6)$ & $41.7(7.6)$ & $42.4(7.8)$ & $41.4(8.2)$ \\
\hline Gender $\mathrm{m} / \mathrm{f}(\% \mathrm{~m})^{\mathrm{b}}$ & $336 / 149(69 \%)$ & $220 / 76(75 \%)$ & $338 / 88(79 \%)$ & $2637 / 965(73 \%)$ \\
\hline \multicolumn{5}{|l|}{ Education $^{c}$} \\
\hline High & $186(39 \%)$ & $119(41 \%)$ & $155(37 \%)$ & $1429(41 \%)$ \\
\hline Medium & $210(44 \%)$ & $119(41 \%)$ & $160(38 \%)$ & $1584(45 \%)$ \\
\hline Low & $80(17 \%)$ & $52(18 \%)$ & $105(25 \%)$ & $500(14 \%)$ \\
\hline $\begin{array}{l}\text { Prolonged fatigue }^{c} \\
\text { (CIS, scale 20-140) }\end{array}$ & $87.8(9.9)$ & $62.8(11.2)$ & $94.8(13.0)$ & $45.6(14.9)$ \\
\hline $\begin{array}{l}\text { Subjective fatigue }{ }^{c} \\
\text { (CIS, scale 8-56) }\end{array}$ & $39.9(7.2)$ & $30.3(7.9)$ & $43.1(7.2)$ & $20.1(8.9)$ \\
\hline $\begin{array}{l}\text { Exhaustion }{ }^{\mathrm{C}} \\
\text { (MBI-GS, scale 0-6) }\end{array}$ & $2.4(1.0)$ & $3.0(0.7)$ & $3.6(0.9)$ & $1.3(0.8)$ \\
\hline $\begin{array}{l}\text { Cynicism }{ }^{\mathrm{C}} \\
\text { (MBI-GS, scale 0-6) }\end{array}$ & $1.6(0.9)$ & $2.7(0.9)$ & $2.9(0.9)$ & $1.2(0.9)$ \\
\hline $\begin{array}{l}\text { Professional efficacy } \\
\text { (MBI-GS, scale 0-6) }\end{array}$ & $4.0(0.8)$ & $3.4(0.8)$ & $3.1(0.8)$ & $4.3(0.8)$ \\
\hline Absenteeism ${ }^{c}$ & $57(12 \%)$ & $24(8 \%)$ & $72(17 \%)$ & $164(5 \%)$ \\
\hline
\end{tabular}

Data are mean values (S.D.) or $n(\%)$

${ }^{b}$ Statistically significant differences between the subgroups at the $p<.01$ level

${ }^{c}$ Statistically significant differences between the subgroups at the $p<.001$ level

\section{Number of cases at each measurement}

Of the pure fatigue cases, $31 \%$ is a pure fatigue case at the 12 -month follow-up, $36 \%$ after the 24 -month follow-up and $28 \%$ after the 48 -month follow-up. Of the pure burnout cases, $27 \%$ is a pure burnout case at the12-month follow-up, $19 \%$ after the 24 -month follow-up and $14 \%$ after the 48 -month follow-up. Looking at these numbers, there seems to be a more marked decline in the number of pure burnout cases than in the number of pure fatigue cases. A high number of the burnout \& fatigue cases is a burnout $\&$ fatigue case 12 months after baseline (56\%). This number stays more or less stable throughout the rest of the study: $57 \%$ at the 24 -month follow-up and $50 \%$ at the 48 -month follow-up.

\section{Course types}

Table 2 shows the different course types within the subgroups. The top half of the table gives an indication of the stability of the subgroup conditions over time. The pure burnout and pure fatigue groups do not have a high percentage of the chronic course type, meaning that they tend to change in the course of time, whereas having both conditions concurrently (burnout \& fatigue group) seems to be fairly stable and chronic as indicated by the high percentage (29\%) of this course type. The high rates of recovery from the subgroup definition in especially the pure burnout group $(78 \% !)$ indicates that the subgroup condition does not persist and remain the same over time, but rather changes into full recovery or into one of the other subgroup conditions. Pure fatigue and burnout $\&$ fatigue tend to reoccur slightly more often than pure burnout after a change has taken 
place. Moreover, the percentages of double recovery show that pure fatigue tends to switch more often after a recurrence compared to the other subgroups.

The bottom half of the table shows the course types defined by recovery from all (three) conditions under study. The percentages are considerably lower using this strict definition of recovery and a high percentage must be classified as an "other" course type due to the dynamic nature of these conditions. The relationship of the percentages between the subgroups in the bottom half of the table is quite similar to that in the top half, with one exception. In the top half, recurrence in the burnout \& fatigue is higher compared to the other subgroups whereas in the bottom half recurrence in the burnout \& fatigue group is lower than the other subgroups. The results show that the pure burnout group has the highest rate of recovery from all conditions, followed by the pure fatigue group. The percentage of recurrence after recovery from all conditions and double recovery is highest in the pure fatigue group, but this percentage is quite comparable to the other subgroups. Logistic regression analysis within each course type underlined these findings, even after adjustment for several confounders (table 3).

Table 2 Number (\%) of participants with each course type within each subgroup defined by different criteria for recovery

\begin{tabular}{|c|c|c|c|}
\hline & $\begin{array}{l}\text { Pure fatigue } \\
(n=485)\end{array}$ & $\begin{array}{c}\text { Pure burnout } \\
(n=296)\end{array}$ & $\begin{array}{l}\text { Burnout \& fatigue } \\
(n=426)\end{array}$ \\
\hline \multicolumn{4}{|l|}{ Recovery from subgroup definition } \\
\hline Chronic & $42(9 \%)$ & $6(2 \%)$ & $122(29 \%)$ \\
\hline $\begin{array}{l}\text { Recovery } \\
\text { from subgroup definition }\end{array}$ & $285(59 \%)$ & $231(78 \%)$ & $184(43 \%)$ \\
\hline $\begin{array}{l}\text { Recurrence } \\
\text { after recovery from subgroup definition }\end{array}$ & $92(19 \%)$ & $36(12 \%)$ & $91(21 \%)$ \\
\hline $\begin{array}{l}\text { Double recovery } \\
\text { from subgroup definition }\end{array}$ & $66(14 \%)$ & $23(8 \%)$ & $29(7 \%)$ \\
\hline \multicolumn{4}{|l|}{ Recovery from all conditions } \\
\hline Chronic & $42(9 \%)$ & $6(2 \%)$ & $122(29 \%)$ \\
\hline $\begin{array}{l}\text { Recovery } \\
\text { from all conditions }\end{array}$ & $139(29 \%)$ & $118(40 \%)$ & $55(13 \%)$ \\
\hline $\begin{array}{l}\text { Recurrence } \\
\text { after recovery from all conditions }\end{array}$ & $49(10 \%)$ & $20(7 \%)$ & $18(4 \%)$ \\
\hline $\begin{array}{l}\text { Double recovery } \\
\text { from all conditions }\end{array}$ & $25(5 \%)$ & $9(3 \%)$ & $7(2 \%)$ \\
\hline Other course & $230(47 \%)$ & $143(48 \%)$ & $224(53 \%)$ \\
\hline
\end{tabular}


Table 3 Results of logistic regression analysis: associations, expressed as odds ratios, between course types and subgroups

\begin{tabular}{|c|c|c|c|c|c|}
\hline Course types & & $\begin{array}{c}\text { Pure } \\
\text { burnout }\end{array}$ & & $\begin{array}{l}\text { Pure } \\
\text { fatigue }\end{array}$ & $\begin{array}{c}\text { Burnout \& } \\
\text { fatigue }\end{array}$ \\
\hline Chronic & $\begin{array}{l}O R^{b} \\
(95 \% \mathrm{Cl})\end{array}$ & 1 & 4.51 & $(1.89-10.78)$ & $17.89(7.73-41.36)$ \\
\hline $\begin{array}{l}\text { Recovery } \\
\text { from subgroup definition }\end{array}$ & $\begin{array}{l}\mathrm{OR}^{6} \\
(95 \% \mathrm{Cl})\end{array}$ & 1 & 0.39 & $(0.28-0.54)$ & $0.22(0.16-0.31)$ \\
\hline $\begin{array}{l}\text { Recovery } \\
\text { from all conditions }\end{array}$ & $\begin{array}{l}\mathrm{OR}^{\mathrm{b}} \\
(95 \% \mathrm{Cl})\end{array}$ & 1 & 0.60 & $(0.44-0.83)$ & $0.23(0.16-0.33)$ \\
\hline $\begin{array}{l}\text { Recurrence } \\
\text { after recovery from subgroup definition }\end{array}$ & $\begin{array}{l}O R^{b} \\
(95 \% \mathrm{Cl})\end{array}$ & 1 & 1.77 & $(1.16-2.69)$ & $2.04(1.33-3.12)$ \\
\hline $\begin{array}{l}\text { Recurrence } \\
\text { after recovery from all conditions }\end{array}$ & $\begin{array}{l}\mathrm{OR}^{\mathrm{b}} \\
(95 \% \mathrm{Cl})\end{array}$ & 1 & 1.53 & $(0.89-2.63)$ & $0.59(0.31-1.15)$ \\
\hline $\begin{array}{l}\text { Double recovery } \\
\text { from subgroup definition }\end{array}$ & $\begin{array}{l}O R^{b} \\
(95 \% \mathrm{Cl})\end{array}$ & 1 & 1.89 & $(1.14-3.12)$ & $0.83(0.47-1.48)$ \\
\hline $\begin{array}{l}\text { Double recovery } \\
\text { From all conditions }\end{array}$ & $\begin{array}{l}\mathrm{OR}^{\mathrm{b}} \\
(95 \% \mathrm{Cl})\end{array}$ & 1 & 1.76 & $(0.81-3.82)$ & $0.54(0.20-1.47)$ \\
\hline
\end{tabular}

Bold figures indicate statistically significant associations. OR: odds ratio; $\mathrm{Cl}$ : confidence interval.

a Reference group

${ }^{b}$ OR adjusted for age, gender, education and absenteeism at baseline

\section{Distribution and change of scores}

From a clinical point of view, it is important to know whether the change in score from above the cut-off for caseness to below the cut-off for caseness represents a real change. Table 4 gives some insight into the distribution of the mean scores and the mean change scores of the MBI-GS and the CIS over time. For example, as one would expect, the CIS and/or MBI-GS scores of the chronic subgroups remain stable and high throughout the course of follow-up. The CIS and/or MBI-GS scores of the double recovery subgroups however, change considerably in the course of time. The magnitude of the change scores seems to be sufficient to represent a real change, especially when compared to the standard error of measurement (SEM) of the CIS ( 4.5 points) and the MBI-GS (0.4 points) in this population. 
Table 4 Distribution of mean scores (S.D.) and mean change scores (S.D.) of the CIS and the $\mathrm{MBI}-\mathrm{GS}$ among the course types defined with recovery from all conditions

\begin{tabular}{|c|c|c|c|c|c|c|c|c|}
\hline & & $\begin{array}{c}0 \\
\text { months }\end{array}$ & $\begin{array}{c}12 \\
\text { months }\end{array}$ & $\begin{array}{c}24 \\
\text { months }\end{array}$ & $\begin{array}{c}48 \\
\text { months }\end{array}$ & $\begin{array}{c}\text { Change } \\
0-12 \\
\text { months }\end{array}$ & $\begin{array}{c}\text { Change } \\
12-24 \\
\text { months }\end{array}$ & $\begin{array}{c}\text { Change } \\
24-48 \\
\text { months }\end{array}$ \\
\hline \multicolumn{9}{|l|}{ Pure fatigue } \\
\hline Chronic & \multirow[t]{4}{*}{ CIS total } & $\begin{array}{l}87.6 \\
(8.9)\end{array}$ & $\begin{array}{l}86.7 \\
(7.5)\end{array}$ & $\begin{array}{l}89.6 \\
(8.4)\end{array}$ & $\begin{array}{l}89.7 \\
(11.0)\end{array}$ & $\begin{array}{l}0.9 \\
(10.8)\end{array}$ & $\begin{array}{l}-2.9 \\
(9.6)\end{array}$ & $\begin{array}{l}-0.1 \\
(10.9)\end{array}$ \\
\hline Recurrence & & $\begin{array}{l}89.3 \\
(10.2)\end{array}$ & $\begin{array}{l}68.7 \\
(13.8)\end{array}$ & $\begin{array}{l}71.5 \\
(13.2)\end{array}$ & $\begin{array}{l}89.5 \\
(11.9)\end{array}$ & $\begin{array}{l}20.6 \\
(17.3)\end{array}$ & $\begin{array}{l}-2.9 \\
(19.2)\end{array}$ & $\begin{array}{l}-18.0 \\
(17.8)\end{array}$ \\
\hline Recovery & & $\begin{array}{l}89.9 \\
(9.6)\end{array}$ & $\begin{array}{l}60.9 \\
(19.3)\end{array}$ & $\begin{array}{l}59.3 \\
(19.0)\end{array}$ & $\begin{array}{l}55.1 \\
(13.2)\end{array}$ & $\begin{array}{l}26.0 \\
(19.6)\end{array}$ & $\begin{array}{l}1.6 \\
(18.1)\end{array}$ & $\begin{array}{l}4.2 \\
(18.7)\end{array}$ \\
\hline $\begin{array}{l}\text { Double } \\
\text { recovery }\end{array}$ & & $\begin{array}{l}85.8 \\
(8.2) \\
\end{array}$ & $\begin{array}{l}62.6 \\
(12.7) \\
\end{array}$ & $\begin{array}{l}86.4 \\
(8.0) \\
\end{array}$ & $\begin{array}{l}61.2 \\
(12.9) \\
\end{array}$ & $\begin{array}{l}23.2 \\
(17.1) \\
\end{array}$ & $\begin{array}{l}-23.8 \\
(14.4) \\
\end{array}$ & $\begin{array}{l}25.3 \\
(16.2) \\
\end{array}$ \\
\hline \multicolumn{9}{|l|}{ Pure burnout } \\
\hline Chronic & Exhaustion & $\begin{array}{l}3.4 \\
(1.3)\end{array}$ & $\begin{array}{l}3.3 \\
(1.2)\end{array}$ & $\begin{array}{l}3.3 \\
(1.3)\end{array}$ & $\begin{array}{l}3.8 \\
(1.2)\end{array}$ & $\begin{array}{l}0.1 \\
(0.5)\end{array}$ & $\begin{array}{l}0.1 \\
(0.4)\end{array}$ & $\begin{array}{l}-0.5 \\
(0.7)\end{array}$ \\
\hline \multicolumn{2}{|l|}{ Recurrence } & $\begin{array}{l}3.0 \\
(0.6)\end{array}$ & $\begin{array}{l}2.5 \\
(0.6)\end{array}$ & $\begin{array}{l}2.8 \\
(1.1)\end{array}$ & $\begin{array}{l}3.2 \\
(0.5)\end{array}$ & $\begin{array}{l}0.5 \\
(0.6)\end{array}$ & $\begin{array}{l}-0.3 \\
(1.5)\end{array}$ & $\begin{array}{l}-0.4 \\
(1.0)\end{array}$ \\
\hline \multicolumn{2}{|l|}{ Recovery } & $\begin{array}{l}2.8 \\
(0.5)\end{array}$ & $\begin{array}{l}2.1 \\
(0.8)\end{array}$ & $\begin{array}{l}1.8 \\
(0.7)\end{array}$ & $\begin{array}{l}1.7 \\
(1.0)\end{array}$ & $\begin{array}{l}0.7 \\
(0.8)\end{array}$ & $\begin{array}{l}0.3 \\
(0.8)\end{array}$ & $\begin{array}{l}0.1 \\
(0.9)\end{array}$ \\
\hline \multicolumn{2}{|l|}{$\begin{array}{l}\text { Double } \\
\text { recovery }\end{array}$} & $\begin{array}{l}3.0 \\
(0.5) \\
\end{array}$ & $\begin{array}{l}2.3 \\
(0.8) \\
\end{array}$ & $\begin{array}{l}2.8 \\
(0.6) \\
\end{array}$ & $\begin{array}{l}1.4 \\
(0.8) \\
\end{array}$ & $\begin{array}{l}0.7 \\
(1.0) \\
\end{array}$ & $\begin{array}{l}-0.5 \\
(1.2) \\
\end{array}$ & $\begin{array}{l}1.4 \\
(1.2) \\
\end{array}$ \\
\hline \multicolumn{9}{|c|}{ Burnout \& fatigue } \\
\hline \multirow{2}{*}{ Chronic } & CIS total & $\begin{array}{l}99.9 \\
(14.3)\end{array}$ & $\begin{array}{l}99.5 \\
(14.8)\end{array}$ & $\begin{array}{l}101.5 \\
(13.9)\end{array}$ & $\begin{array}{l}100.1 \\
(12.6)\end{array}$ & $\begin{array}{l}-0.5 \\
(13.3)\end{array}$ & $\begin{array}{l}-2.0 \\
(13.7)\end{array}$ & $\begin{array}{l}1.4 \\
(13.1)\end{array}$ \\
\hline & Exhaustion & $\begin{array}{l}3.9 \\
(0.9)\end{array}$ & $\begin{array}{l}3.8 \\
(0.9)\end{array}$ & $\begin{array}{l}4.0 \\
(0.9)\end{array}$ & $\begin{array}{l}4.0 \\
(1.0)\end{array}$ & $\begin{array}{l}0.03 \\
(0.8)\end{array}$ & $\begin{array}{l}-0.1 \\
(0.7)\end{array}$ & $\begin{array}{l}-0.02 \\
(1.0)\end{array}$ \\
\hline \multirow{2}{*}{ Recurrence } & CIS total & $\begin{array}{l}90.5 \\
(9.5)\end{array}$ & $\begin{array}{l}71.8 \\
(14.2)\end{array}$ & $\begin{array}{l}79.1 \\
(25.7)\end{array}$ & $\begin{array}{l}99.7 \\
(11.6)\end{array}$ & $\begin{array}{l}18.6 \\
(17.6)\end{array}$ & $\begin{array}{l}-7.3 \\
(31.3)\end{array}$ & $\begin{array}{l}-20.6 \\
(23.6)\end{array}$ \\
\hline & Exhaustion & $\begin{array}{l}3.3 \\
(0.8)\end{array}$ & $\begin{array}{l}2.4 \\
(0.6)\end{array}$ & $\begin{array}{l}2.9 \\
(1.4)\end{array}$ & $\begin{array}{l}3.7 \\
(1.0)\end{array}$ & $\begin{array}{l}0.9 \\
(1.2)\end{array}$ & $\begin{array}{l}-0.5 \\
(1.2)\end{array}$ & $\begin{array}{l}-0.8 \\
(1.0)\end{array}$ \\
\hline \multirow{2}{*}{ Recovery } & CIS total & $\begin{array}{l}91.0 \\
(12.1)\end{array}$ & $\begin{array}{l}73.8 \\
(26.3)\end{array}$ & $\begin{array}{l}69.1 \\
(27.1)\end{array}$ & $\begin{array}{l}53.1 \\
(13.0)\end{array}$ & $\begin{array}{l}17.2 \\
(25.4)\end{array}$ & $\begin{array}{l}4.7 \\
(21.1)\end{array}$ & $\begin{array}{l}15.9 \\
(24.8)\end{array}$ \\
\hline & Exhaustion & $\begin{array}{l}3.5 \\
(0.9)\end{array}$ & $\begin{array}{l}2.8 \\
(1.4)\end{array}$ & $\begin{array}{l}2.4 \\
(1.4)\end{array}$ & $\begin{array}{l}1.5 \\
(0.7)\end{array}$ & $\begin{array}{l}0.7 \\
(1.2)\end{array}$ & $\begin{array}{l}0.5 \\
(1.1)\end{array}$ & $\begin{array}{l}0.9 \\
(1.3)\end{array}$ \\
\hline \multirow{2}{*}{$\begin{array}{l}\text { Double } \\
\text { recovery }\end{array}$} & CIS total & $\begin{array}{l}95.4 \\
(18.0)\end{array}$ & $\begin{array}{l}52.7 \\
(17.4)\end{array}$ & $\begin{array}{l}90.3 \\
(11.7)\end{array}$ & $\begin{array}{l}51.1 \\
(12.0)\end{array}$ & $\begin{array}{l}42.7 \\
(32.4)\end{array}$ & $\begin{array}{l}-37.6 \\
(22.9)\end{array}$ & $\begin{array}{l}39.1 \\
(20.6)\end{array}$ \\
\hline & Exhaustion & $\begin{array}{l}3.9 \\
(1.1)\end{array}$ & $\begin{array}{l}2.4 \\
(1.7) \\
\end{array}$ & $\begin{array}{l}3.5 \\
(1.0)\end{array}$ & $\begin{array}{l}2.2 \\
(1.3) \\
\end{array}$ & $\begin{array}{l}1.5 \\
(1.2) \\
\end{array}$ & $\begin{array}{l}-1.1 \\
(1.3)\end{array}$ & $\begin{array}{l}1.3 \\
(1.1) \\
\end{array}$ \\
\hline
\end{tabular}

\section{Absenteeism}

The burnout \& fatigue group seems to have a higher percentage of absenteeism compared to either the pure fatigue group or the pure burnout group (table 5). Logistic GEE analysis revealed that, in the course of time, absenteeism is higher in the burnout $\&$ fatigue group compared to the pure fatigue group (crude odds ratio (OR) 1.65, 95\% confidence interval (Cl) 1.33-2.05; adjusted OR 1.53, 95\% Cl 1.26-1.86, adjusted for age, gender, education and absenteeism at baseline) and to the pure burnout group (crude $O R 1.63,95 \% \mathrm{Cl} 1.27-2.09$; adjusted $\mathrm{OR}=1.26,95 \% \mathrm{Cl} 1.00-1.58$ adjusted for age, gender, education and absenteeism at baseline), although this relationship reached a borderline (non) significance level after 
adjustment. No significant differences were found between the pure fatigue group and the pure burnout group in the course of absenteeism. Contrasting the percentages of absenteeism found across the subgroups with the baseline percentage of absenteeism in the total cohort, which is $8.3 \%$ (after exclusion of chronic conditions, see methods), shows that especially the burnout $\&$ fatigue group have a very high percentage of absenteeism.

Table 5 Absenteeism within each subgroup in the course of follow-up

\begin{tabular}{|c|c|c|c|c|c|}
\hline & & Baseline & 12 months & 24 months & 48 months \\
\hline Pure burnout group & $(n=296)$ & $23(8 \%)$ & $24(8 \%)$ & $30 \quad(10 \%)$ & $52(18 \%)$ \\
\hline Pure fatigue group & $(n=485)$ & $57(12 \%)$ & $44(9 \%)$ & $55(11 \%)$ & $54 \quad(11 \%)$ \\
\hline Burnout \& fatigue group & $(n=426)$ & $71 \quad(17 \%)$ & $66(16 \%)$ & $70 \quad(17 \%)$ & $76 \quad(18 \%)$ \\
\hline
\end{tabular}
Data are n (\%).

\section{Discussion}

This is, to the best of our knowledge, the first study that aimed to asses and compare the course of burnout and fatigue in a prospective cohort study among employees. The results indicate that there are differences in the course of the pure burnout, pure fatigue and burnout \& fatigue groups. Compared to the pure fatigue and pure burnout groups, the burnout \& fatigue group has the highest percentage of the chronic course type indicating the fairly chronic and stable nature of this condition. This large difference remained after correction for potential confounders in logistic regression analysis. The results concerning the course types defined by recovery from the subgroup definition show that the pure burnout group has the highest rate of recovery $(78 \%)$, indicating that this condition, more than the other subgroup conditions, does not tend to persist or remain unchanged throughout time. Recurrence is more likely in the burnout \& fatigue group and the pure fatigue group. The pure fatigue group has the highest percentage of double recovery from the subgroup definition.

The results concerning the course types defined by recovery from all conditions underlines the dynamic nature of these conditions, as this strict definition of recovery leads to the classification of a considerable percentage in the "other" course type. The highest rate of recovery was in the pure burnout group. Recurrence and double recovery were highest in the pure fatigue group, although the difference with the other subgroups was not statistically significant after correction in a logistic regression analysis. In terms of absenteeism, the burnout $\&$ fatigue group had the highest percentage over time compared to both the pure fatigue and pure burnout groups. However, after adjustment the difference in absenteeism between the burnout $\&$ fatigue group and the pure burnout group reached a borderline (non-) significance level. There was no significant difference in absenteeism between pure fatigue and pure burnout. 
In summary, the burnout \& fatigue group seems to have the most unfavourable course in terms of persistence of symptoms and absenteeism. Looking at the rate of recovery from all conditions, pure burnout seems to have the most favourable course. The course of pure fatigue in terms of persistence and recovery from symptoms is better than the burnout \& fatigue group, but seems to be slightly worse than the pure burnout group. In terms of absenteeism, the pure fatigue group has a more favourable outcome than the burnout $\&$ fatigue group, but there was no difference compared to the pure burnout group.

\section{Methodological considerations}

The baseline of this cohort study does not necessarily correspond to the onset of prolonged fatigue and/or burnout in our participants. It is unknown how long symptoms were present prior to our baseline. Therefore, the participants at baseline are highly likely to have been captured in the middle of an ongoing process of their condition(s). A solution could have been to use "incident" cases by selecting those who did not fulfil criteria for burnout or prolonged fatigue at baseline but who did fulfil these criteria at 1-year follow-up. However, as our results show, the course of these conditions can fluctuate as well as be persistent. For this reason, including "incident" cases will probably not differ from the method used in this study (i.e. including participants at baseline). It must be noted that the measurements during the follow-up period were not linear as the last measurement (48-months) took place 2 years after the previous measurement, instead of 1 year, as was the case with the 12- and 24- month follow-up. The classification of prolonged fatigue and burnout cases was based on self-report data and not on clinical interviews or investigations. However, for the CIS, a validated cut-off point was used ${ }^{15}$. For burnout, validated statistically derived cut-off points were used. Cut-off points derived from the 75th percentiles for exhaustion and cynicism and the $25^{\text {th }}$ percentile for professional efficacy were quite similar to those of the general working population described in the Dutch MBI manual ${ }^{17}$. Moreover, the magnitude of change in scores from case to non-case and vice versa seems to be large enough to indicate a relevant change. Using course types, as in depression research, has also proved useful in studying the course of burnout and prolonged fatigue ${ }^{18-20}$. It should be noted that, burnout is frequently measured cross-culturally in the same way using the validated $\mathrm{MBl}$, but there are cultural differences in the "labelling" of burnout symptoms. In the Netherlands, where this study was performed, burnout can be seen as a diagnosis or condition whereas this is not necessarily the case across different countries ${ }^{21}$.

Although there was a high dropout rate, analysis revealed that selection bias was limited. Most of the differences that were found between participants and dropouts were small, but statistically significant nonetheless. This was probably due to the large sample size. Any differences that were found were in the direction of an underestimation of the effects we found, as those who dropped out tended to have more unfavourable characteristics (e.g. higher levels of exhaustion and higher levels of fatigue). With respect to absenteeism it 
must be noted that a broad definition of absenteeism was chosen which could lead to an overestimation in this study.

\section{Different definitions for recovery}

The course of a condition can follow many different paths. By using two definitions for recovery in order to define the course types, we aimed to highlight and evaluate the dynamic nature of these conditions. In general, the relation of the course type percentages between the subgroups remained intact, but the magnitude of the percentages declined when using recovery from all conditions as the definition of recovery, as opposed to recovery from the subgroup definition. For example, the percentage of recovery was highest in the pure burnout group compared to the other subgroups, irrespective of the definition of recovery. However, the magnitude of this percentage was higher when recovery was defined as recovery from the subgroup definition (78\%), as opposed to recovery from all conditions $(40 \%)$. This discrepancy tells us that a large number fluctuate between the categories (pure fatigue, burnout $\&$ fatigue and no condition) during the course of follow-up, as they do not meet the criteria for pure burnout but also do not consistently meet the criteria for full recovery. An exception to the above is the percentage of recurrence in the burnout \& fatigue group which was highest (although not statistically significant) compared to the other subgroups when recovery was defined in terms of the subgroup definition, but was lowest when recovery was defined as recovery from all conditions. This indicates that, after recovery from all conditions, the recurrence of concurrent burnout and prolonged fatigue is not as likely as another route to recurrence, (e.g. recovery from either burnout or fatigue and then relapse back into both burnout and fatigue). Finally, the percentage of "other" course types seems to be similarly high in the subgroups, indicating the complex and dynamic nature in which these conditions are related in time. This is an issue that goes beyond the scope of this study but definitely requires further examination as it may help clarify the interrelatedness of burnout and prolonged fatigue in time.

\section{Can we explain why symptoms persist?}

Previous studies suggest that the persistence of burnout and/ or fatigue will partly depend on the severity of the symptoms. One study among Dutch teachers found that $68 \%$ of teachers who were clinically burned out at baseline were still burned out one year later indicating the chronic nature of clinical severe burnout ${ }^{6}$. Moreover, several fatigue studies have shown that the severity of fatigue complaints is associated with the course of complaints ${ }^{5,22}$. This is one explanation for the chronic nature of the burnout \& fatigue group as this group can be characterised by severe burnout and fatigue symptoms. However, it also apparent that severe burnout and fatigue symptoms become intertwined, with each other and with other psychological and/ or somatic complaints ${ }^{23-26}$, which can also account for a more chronic course. Thus, when fatigue and burnout symptoms become 
more advanced they can generalise into other areas of well-being and start to overlap, which, more than likely, will not be favourable for the course.

\section{The role of context and causal attributions in the course of fatigue and burnout symptoms}

The symptoms in both the pure burnout group and the pure fatigue group are milder than those of the burnout \& fatigue group and are not complicated by co-occurrence. However, we do see that the course of the pure fatigue group is slightly more unfavourable than the pure burnout group. In terms of their course, (pure) prolonged fatigue symptoms and (pure) burriout symptoms seem to exist in different contexts that our previous study also implicated ${ }^{10}$. This could pertain to the fact that prolonged fatigue can be seen as a more general condition and that burnout can be seen as a work-related condition ${ }^{3}$ : mild burnout complaints may still be relatively contained in the work domain, whereas prolonged fatigue complaints encompass more life domains from the outset. Alternatively, the fact that the diagnosis "burnout" implies a cause (namely, work) and that the diagnosis prolonged fatigue does less so, could also affect the course. Causal attributions have been found to play a role in the course of unexplained fatigue syndromes ${ }^{5}$ and in the distinction of burnout and prolonged fatigue ${ }^{27}$ and their main complaints subjective fatigue and exhaustion ${ }^{10}$. Possibly, they could also play a role in the differential course types of prolonged fatigue and burnout, specifically with respect to pure fatigue and pure burnout.

\section{Conclusion}

This study shows that the course of the burnout \& fatigue group is rather poor compared to the pure burnout and pure fatigue groups, in terms of both the persistence of burnout and fatigue symptoms and the prevalence of absenteeism in the course of time. Moreover, the course of pure burnout seems to be slightly more favourable than that of pure fatigue due to the high percentage of recovery in the former group. These results suggest that the differential diagnosis of employees presenting with fatigue complaints could be important in estimating the outcome of the complaints and the need for therapy. Examining factors that influence the course of prolonged fatigue and burnout will provide valuable information for intervention possibilities.

\section{Acknowledgements}

This study was funded by the Occupational Health Epidemiology programme of the Research Institute Caphri, Maastricht University, The Netherlands. 


\section{References}

1 Schaufeli WB, Enzman D. The burnout companion to study and practice: a critical analysis. London: Taylor \& Francis, 1998.

2 Sharpe M, Wilks D. Fatigue. British Medical Journal 2002; 325: 480-3.

3 Schaufeli WB, Taris TW. The conceptualization and measurement of burnout: Common ground and worlds apart. Work and Stress 2005; 19: 256-62.

4 Prins JB, van der Meer JW, Bleijenberg G. Chronic fatigue syndrome. Lancet 2006; 367: 34655.

5 Cairns $R$, Hotopf $M$. A systematic review describing the prognosis of chronic fatigue syndrome. Occupational Medicine 2005; 55: 20-31.

6 Taris T, Schaufeli W, Schreurs PJ, Caljé D. Opgebrand in het onderwijs: stress, psychische vermoeidheid en ziekteverzuim onder leraren [Burnout in education: stress, psychological fatigue and sickness absence among teachers]. In: Houtman I, Schaufeli WB, Taris TW, eds. Psychische vermoeidheid en werk: cijfers, trends en analyses. Alphen aan den Rijn: NWO/Samson, 2000; 97-106.

7 Schaufeli W. Past performance and future perspectives of burnout research. South African Journal of Industrial Psychology 2003; 29: 1-15.

8 Huibers MJ, Bultmann U, Kasl SV, Kant I, van Amelsvoort LG, van Schayck CP, Swaen GM. Predicting the two-year course of unexplained fatigue and the onset of long-term sickness absence in fatigued employees: results from the Maastricht Cohort Study. Journal of Occupational and Environmental Medicine 2004; 46: 1041-7.

9 Joyce J, Hotopf $M$, Wessely 5 . The prognosis of chronic fatigue and chronic fatigue syndrome: a systematic review. Quarterly Journal of Medicine 1997; 90: 223-33.

10 Leone SS, Huibers MJ, Knottnerus JA, Kant IJ. Similarities, overlap and differences between burnout and prolonged fatigue in the working population. Quarterly Journal of Medicine 2007; 100: 617-27.

11 Janssen $\mathrm{N}$. The natural course of fatigue in a working population. Maastricht: Maastricht University Press, 2004.

12 Kant IJ, Bultmann U, Schroer KA, Beurskens AJ, Van Amelsvoort LG, Swaen GM. An epidemiological approach to study fatigue in the working population: the Maastricht Cohort Study. Occupational and Environmental Medicine 2003; 60 Suppl 1: i32-9.

13 Vercoulen JHHM, Alberts M, Bleijenberg G. De Checklist Individuele Spankracht (CIS) [The Checklist Individual Strength (CIS)]. Gedragstherapie 1999; 32: 131-6.

14 Vercoulen JH, Swanink CM, Fennis JF, Galama JM, van der Meer JW, Bleijenberg G. Dimensional assessment of chronic fatigue syndrome. Journal of Psychosomatic Research 1994; 38: 383-92.

15 Bultmann $U$, de Vries $M$, Beurskens AJ, Bleijenberg G, Vercoulen JH, Kant I. Measurement of prolonged fatigue in the working population: determination of a cutoff point for the checklist individual strength. Journal of Occupational Health Psychology 2000; 5; 411-6.

16 Schaufeli WB, Leiter MP, Maslach C, Jackson SE. The Maslach Burnout Inventory- General Survey, In: Maslach C, Jackson SE, Leiter MP, eds. Maslach Burnout Inventory manual: 3rd Edition. Palo Alto, CA: Consulting Psychologists Press, 1996; 19-26.

17 Schaufeli WB, Van Dierendonk D. UBOS, Utrechtse Burnout Schaal, Handleiding. Lisse: Swets Test Publishers, 2000. 
18 Beekman AT, Geerlings SW, Deeg DJ, Smit JH, Schoevers RS, de Beurs E, Braam AW, Penninx $B W$, van Tilburg W. The natural history of late-life depression: a 6-year prospective study in the community. Archives of General Psychiatry 2002; 59: 605-11.

19 Klein DN, Shankman SA, Rose S. Ten-year prospective follow-up study of the naturalistic course of dysthymic disorder and double depression. American Journal of Psychiatry 2006; 163: $872-80$.

20 Mueller TI, Leon AC, Keller MB, Solomon DA, Endicott J, Coryell W, Warshaw M, Maser JD. Recurrence after recovery from major depressive disorder during 15 years of observational follow-up. American Journal of Psychiatry 1999; 156: 1000-6.

21 Schaufeli $W$. Burnout in discussie: Stand van zaken [Burnout discussed: Current state of affairs]. De Psycholoog 2007; 42: 534-40.

22 Skapinakis $P$, Lewis $G$, Mavreas $V$. One-year outcome of unexplained fatigue syndromes in primary care: results from an international study. Psychological Medicine 2003; 33: 857-66.

23 Schaufeli W, Van Dierendonck D. Burnout, een begrip gemeten. De Nederlandse versie van de Maslach Burnout Inventory (MBI-NL). / Burnout--The measurement of a concept: The Dutch version of the Maslach Burnout Inventory (MBI--NL). Gedrag and Gezondheid Tijdschrift voor Psychologie en Gezondheid 1994; 22: 153-72

24 Ahola K, Honkonen T, Isometsa E, Kalimo R, Nykyri E, Aromaa A, Lonnqvist J. The relationship between job-related burnout and depressive disorders-results from the Finnish Health 2000 Study. Journal of Affective Disorders 2005; 88: 55-62.

25 Pawlikowska T, Chalder T, Hirsch SR, Wallace P, Wright DJ, Wessely SC. Population based study of fatigue and psychological distress. British Medical Journal 1994; 308: 763-6.

26 Bultmann U, Kant I, Kasl SV, Beurskens AJ, van den Brandt PA. Fatigue and psychological distress in the working population: psychometrics, prevalence, and correlates. Journal of Psychosomatic Research 2002; 52: 445-52.

27 Huibers MJH, Beurskens AJHM, Prins JB, Kant IJ, Bazelmans E, van Schayck CP, Knottnerus JA, Bleijenberg $G$. Fatigue, burnout, and chronic fatigue syndrome among employees on sick leave: do attributions make the difference? Occupational and Environmental Medicine 2003; 60: 26-31. 


\section{The prognosis of burnout and prolonged}

fatigue in the working population:

\section{A comparison}

S.S. Leone ${ }^{1}$

M.J.H. Huibers ${ }^{2}$

J.A. Knottnerus ${ }^{3}$

IJ. Kant ${ }^{1}$

${ }^{1}$ Department of Epidemiology, Maastricht University, Maastricht, The Netherlands

${ }^{2}$ Department of Clinical Psychological Science, Maastricht University, Maastricht, The Netherlands

${ }^{3}$ Department of General Practice, Maastricht University, Maastricht, The Netherlands 


\section{Abstract}

\section{Objective}

To assess and compare prognostic factors for recovery in burnout and prolonged fatigue.

\section{Methods}

Baseline, 12-, 24- and 48-month follow-up data from the Maastricht Cohort Study were used. Prolonged fatigue or burnout cases or both at baseline $(n=2356)$ were divided into three subgroups: "pure fatigue", "pure burnout" and "burnout \& fatigue". Using logistic generalised estimating equation analysis, baseline predictors of recovery, including (mental) health, work and demographic factors, were determined.

\section{Results}

Selection variables predicted recovery across the subgroups. Health factors predicted recovery in the pure fatigue and burnout \& fatigue subgroups. Differences in work factors emerged between the subgroups. Work factors especially predicted recovery in the pure burnout group.

\section{Conclusion}

Differences emerged with respect to work and health factors which suggest the importance of differentiating between burnout and prolonged fatigue. This could provide valuable leads for intervention possibilities. 


\section{Introduction}

Prolonged fatigue and burnout are two conditions which affect employees quite often with estimated prevalences of $22 \%$ and $14 \%$, respectively ${ }^{1}$. In order to develop interventions for these conditions, an understanding of prognostic factors is important, especially considering the prevalence and burden of fatigue and burnout complaints as well as their associations with such negative outcomes as (mental) health and absenteeism ${ }^{2 \cdot 6}$.

Although burnout and prolonged fatigue differ with respect to background, context and conceptualisation, a common feature of these conditions is the symptom of fatigue 7,8 . The issue of whether burnout is actually more than just work-related fatigue is a point of debate in the burnout literature ${ }^{8}$. Despite this, a comparison of burnout and prolonged fatigue has hardly been the topic of empirical research. Previous studies have shown differences between burnout and prolonged fatigue with respect to attributions and various work and health factors ${ }^{9,10}$. Due to the lack of empirical studies the relationship between burnout and prolonged fatigue remains largely unclear. Effective treatment of burnout and prolonged fatigue could be hampered by this unclear relationship, especially if burnout and prolonged fatigue have different prognostic factors. Different predictors of outcome suggest that a different approach is required to alter outcome, in prevention and in treatment. Also, different prognostic factors might reflect the differences in nature of both conditions. Nevertheless, as yet, it is unknown whether burnout and prolonged fatigue have similar prognostic factors or not. Causal attributions and psychological health problems have been found to be consistent predictors of outcome in fatigue (ranging in severity) ${ }^{11}$. Predictors of outcome in burnout have however, received far less attention. Studies in a clinical burnout sample have found that cortisol levels were hardly related to levels of burnout over time ${ }^{12}$ and that various factors including exhaustion, recovery through sleep and sleep duration predicted a decline in symptom severity ${ }^{13}$. In an aetiological sense, work factors such as work overload and role problems have been found to be important in predicting burnout ${ }^{5}$. However, it is unknown which role these factors play in the course of burnout as this has hardly been examined. Due to the work-related nature of burnout, work factors could be important prognostic factors and also important distinguishing factors in the prognosis of burnout and prolonged fatigue. In this study we aim to asses prognostic factors for recovery in burnout and prolonged fatigue and examine whether they differ in their prognostic factors.

\section{Methods}

\section{Design}

Prospective data from the Maastricht Cohort Study on Fatigue at Work (MCS) were used for this study. Starting in May 1998, 12,140 employees from 45 different companies and 
organisations participated in this cohort study by completing self-administered questionnaires (response rate $45 \%$ ). For 3 years participants were followed every 4 months as well as an additional follow-up at 48 months after baseline. Non-respondents at baseline reported less fatigue complaints, less sickness absence and less difficulty in work execution. Detailed information on the design of the MCS is provided elsewhere ${ }^{1}$. The baseline, 12-, 24- and 48-month follow-up measurements were used in this study as burnout was only assessed at these four measurements.

\section{Study population}

As the prognosis of subgroups of prolonged fatigue cases and burnout cases at baseline will be examined, participants were excluded if they did not meet the criteria for burnout or prolonged fatigue caseness or both at baseline and if a prolonged fatigue and burnout score could not be obtained due to missing data at baseline. Participants were also excluded if they did not have at least one follow-up measurement after baseline. Furthermore, participants who had more than one contract and who indicated having one of the following chronic conditions that might explain burnout or fatigue complaints were excluded: cerebrovascular accidents, liver dysfunction, diabetes mellitus, hyperthyroidism or cancer. After exclusion, 2356 participants were included in the analyses. Participants were divided into three subgroups: pure fatigue cases (fatigue case and no burnout case), pure burnout cases (burnout case and no fatigue case) and burnout \& fatigue cases (both a burnout and a fatigue case). Selective withdrawal within the subgroups was analysed by comparing those who responded at all four measurements to those who responded at only two or three measurements (baseline and at least one follow-up) on the following baseline variables: exhaustion, cynicism, professional efficacy, prolonged fatigue, age, gender, education and absenteeism. The analyses revealed that in the pure fatigue group, participants who did not respond to all measurements had a low educational level ( $23 \%$ vs. $17 \%)$ more often and a high educational level less often ( $32 \%$ vs. $39 \%$ ). In the pure burnout group participants not responding to all measurements had significantly higher scores on exhaustion [mean (standard deviation, S.D.): 3.2 (0.7) vs. $3.0(0.7)$ ], had a low education more often ( $34 \%$ vs.19\%), a high education less often ( $25 \%$ vs. $41 \%$ ) and were women less often ( $18 \%$ vs. $26 \%$ ). Finally, participants not responding to all measurements in the burnout \& fatigue group had significantly higher levels of cynicism [mean (S.D.): 3.0 (1.1) vs. $2.9(0.9)]$, had a higher educational level less often $(28 \%$ vs. $36 \%)$, had a medium educational level more often ( $46 \%$ vs. $38 \%$ ) and were absent more often ( $23 \%$ vs. $17 \%$ ).

\section{Predictor variables}

\section{Burnout}

Burnout was assessed with the Dutch version of the Maslach Burnout Inventory-General Survey (MBI-GS) which consists of three subscales: exhaustion (5 items), cynicism (4 items) and professional efficacy ( 6 items) ${ }^{14,15}$. Higher scores on these scales indicate higher levels 
(range 0-6). In line with the definition in the manual of the Dutch version of the MBI-GS, burnout cases were defined as having a score higher than the $75^{\text {th }}$ percentile on exhaustion and a score higher than the $75^{\text {th }}$ percentile on cynicism or a score lower than the $25^{\text {th }}$ percentile on professional efficacy. In our cohort at baseline $(n=12,140)$, this resulted in the following cut-off points: exhaustion $>2.40$, cynicism $>2.25$ and professional efficacy $<3.50$ which were used in this study.

\section{Prolonged fatigue}

Prolonged fatigue was assessed with the Checklist Individual Strength (CIS) which consists of four subscales: subjective fatigue ( 8 items), concentration ( 5 items), motivation (4 items) and activity ( 3 items) ${ }^{16,17}$. Adding the scores on the subscales produces a composite total score (range 20-140) with higher scores indicating higher levels of prolonged fatigue. Participants were classified as a prolonged fatigue case if they had a total score higher than $76^{18}$.

\section{Health factors}

Psychological distress was assessed with the 12-item General Health Questionnaire (GHQ12) ${ }^{19,20}$. Probable minor psychiatric disorder cases were defined by using the traditional binary scoring method $(0,0,1,1)$. This gives a score range of 0 to 12 with a score of 4 or higher used as the cut-off for case classification ${ }^{21}$.

Depressed mood (yes/no) was assessed with one item ("Did you feel down almost every day for the past 2 weeks?").

Participants indicated whether they had suffered from fatigue complaints during the past 4 months (yes/no). Causal attributions were assessed by asking participants whether they attributed their fatigue complaints to a psychological cause (psychological attribution), a somatic cause (somatic attribution), a psychological and a somatic cause (psychological and somatic attribution) or an unknown cause (unknown attribution).

Perceived general health was assessed with one five-point scale item ("In general, how would you rate your health?" 1: excellent, 2: very good, 3: good, 4: moderate or 5: bad) from the Dutch version of the Short Form Health Survey ${ }^{22,}{ }^{23}$. This variable was dichotomised into good perceived general health (1-3) and bad perceived general health (45).

Participants were further asked to indicate whether they suffered from a chronic condition (yes/no) and whether they visited a general practitioner (yes/no) or an occupational physician (yes/no) in the past 4 months due to work-related problems.

\section{Work factors}

Psychological job demands, skill discretion, decision authority, co-worker support and supervisor support were assessed with the Dutch version of the Job Content Questionnaire 24,25 . Higher scores on each scale indicate higher levels. 
Working hours per week were assessed by a five-category item $(<16,16-25,26-35,36-40$, $>40$ ). This item was dichotomised to produce a two-category factor: full-time work (more than 36 hours/week) and part-time work (less than 36 hours/week).

Work schedule was assessed with an item asking whether the normal working hours were between 7 am and $7 \mathrm{pm}$ (yes = day work and no = shift work /irregular working hours).

Self-reported sickness absenteeism in the past 4 months was defined as being either completely or partially absent (working limited hours or able to do limited activities).

Career opportunities were assessed by three items: two from the Dutch Questionnaire on the Experience and Evaluation of Work (possibilities to take extra courses or training and possibilities for personal growth and development) ${ }^{26}$ and one from a survey on living conditions in the Netherlands (sufficiency of career opportunities) ${ }^{27}$. A total score was produced by adding the item scores (range 0-3) with higher scores indicating fewer career opportunities.

Job insecurity was assessed by two items (one item from the Dutch Questionnaire on the Experience and Evaluation of Work: "Do you fear losing your job on short notice?" ${ }^{26}$ and one item from the Dutch Questionnaire on Work and Health: "Does this work environment offer you enough security?" ${ }^{28}$ ) which were summed to produce a total score (range 0-2). Higher scores indicate more job insecurity.

Role ambiguity was assessed with two items from the Dutch Questionnaire on the Experience and Evaluation of Work ("Do you know exactly what you are and are not responsible for in your job?" and "Is it clear to you what your specific tasks are in your job?" ${ }^{26}$ ). Item scores were added to produce a total score (range 0-2) with higher scores indicating more role ambiguity.

Emotional job demands were assessed with three items from the Dutch Questionnaire on the Experience and Evaluation of Work ("Are you often confronted with things that affect you personally?", "Do you often feel personally attacked or threatened at work?" and "Are you often faced with distressing situations?") ${ }^{26}$, one item from the Dutch Questionnaire on Work and Health ("Are you often annoyed by others at work?") ${ }^{28}$ and one self-formulated item ("Have you experienced one or more shocking events in the past year at work?"). The scores on these items were added to produce a total score ranging from 0 to 5 . Higher scores indicate higher emotional demands.

Managerial position (yes/no), conflicts with co-worker (yes/no), conflicts with supervisor (yes/no), working overtime regularly (yes/no) were each assessed with separate self report items.

\section{Demographic factors}

Age, gender and education (low, medium, high) were all assessed by self-report. 
Other

Living alone (yes/no), care of children (yes/no), work-home conflict (yes/no) and enough leisure time (yes/no) were each assessed with separate self-report items.

\section{Statistical analysis}

Baseline predictors of recovery in the course of follow-up (12, 24 and 48 months) in the three subgroups (pure fatigue, pure burnout and burnout \& fatigue) were examined using logistic generalised estimating equation analysis (GEE). GEE is a longitudinal analysis technique which allows all data across time to be analysed simultaneously by taking the dependency of measurements within subjects into account. We modelled the amount of recovery over time in the subgroups and the factors contributing to this recovery. Four prognostic models were determined: recovery from fatigue caseness (see definition above) in the pure fatigue group, recovery from burnout caseness (see definition above) in the pure burnout group, recovery from at least one condition (burnout or fatigue) in the burnout \& fatigue group and finally, recovery from both conditions (burnout and fatigue) in the burnout \& fatigue group. Recovery was defined as 1 and no recovery was defined as 0 at all measurements in the models. Factors which were significantly bivariately associated $(p<0.05)$ with the outcome were entered into a multivariate model and non-significant predictors were removed from the model using a backward stepwise procedure until only significant predictors $(p<0.05)$ remained. Age, gender, education and time of measurement were adjusted for in all models.

\section{Results}

\section{Characteristics of study sample}

The baseline characteristics of the subgroups in terms of demographic and selection variables are described in table 1 . Figure 1 shows the percentage of recovery in the subgroups at each measurement. In addition to figure 1 , recovery from at least one condition in the burnout $\&$ fatigue group at each measurement can be broken down into recovery from only burnout (12 months: $32 \%, 24$ months: $33 \%$ and 48 months: $34 \%$ ), only fatigue ( 12 months: $21 \%, 24$ months: $22 \%$ and 48 months: $16 \%$ ) and recovery from both conditions ( 12 months: $47 \%, 24$ months: $45 \%$ and 48 months: $50 \%$ ). 
Table 1 Baseline characteristics of participants in each subgroup

\begin{tabular}{lccc}
\hline Characteristics ${ }^{\text {a }}$ & Pure fatigue & $\begin{array}{c}\text { Pure burnout } \\
(n=912)\end{array}$ & $\begin{array}{c}\text { Burnout \& } \\
\text { fatigue } \\
(\mathrm{n}=897)\end{array}$ \\
\hline Age (years) & $41.6(8.5)$ & $40.9(8.8)$ & $\begin{array}{c}41.9(8.6) \\
\text { Gender } \mathrm{m} / \mathrm{f}(\% \mathrm{~m})\end{array}$ \\
Education & $281 / 631(69 \%)$ & $120 / 427(78 \%)$ & $202 / 695(78 \%)$ \\
$\quad$ Low & $175(20 \%)$ & $139(26 \%)$ & $228(26 \%)$ \\
$\quad$ Medium & $395(45 \%)$ & $216(41 \%)$ & $369(42 \%)$ \\
$\quad$ High & $316(36 \%)$ & $178(33 \%)$ & $277(32 \%)$ \\
Prolonged fatigue (CIS, scale 20-140) & $87.8(10.3)$ & $62.9(11.1)$ & $95.0(13.4)$ \\
Exhaustion (MBI-GS, scale 0-6) & $2.4(1.0)$ & $3.1(0.7)$ & $3.6(0.9)$ \\
Cynicism (MBI-GS, scale 0-6) & $1.6(0.9)$ & $2.7(0.9)$ & $3.0(1.0)$ \\
Professional efficacy (MBI-GS, Scale 0-6) & $3.9(0.8)$ & $3.4(0.8)$ & $3.1(0.8)$ \\
Absenteeism & $121(13 \%)$ & $51(9 \%)$ & $179(20 \%)$ \\
\hline a Data are mean values (S.D.) or $n(\%)$. & & &
\end{tabular}

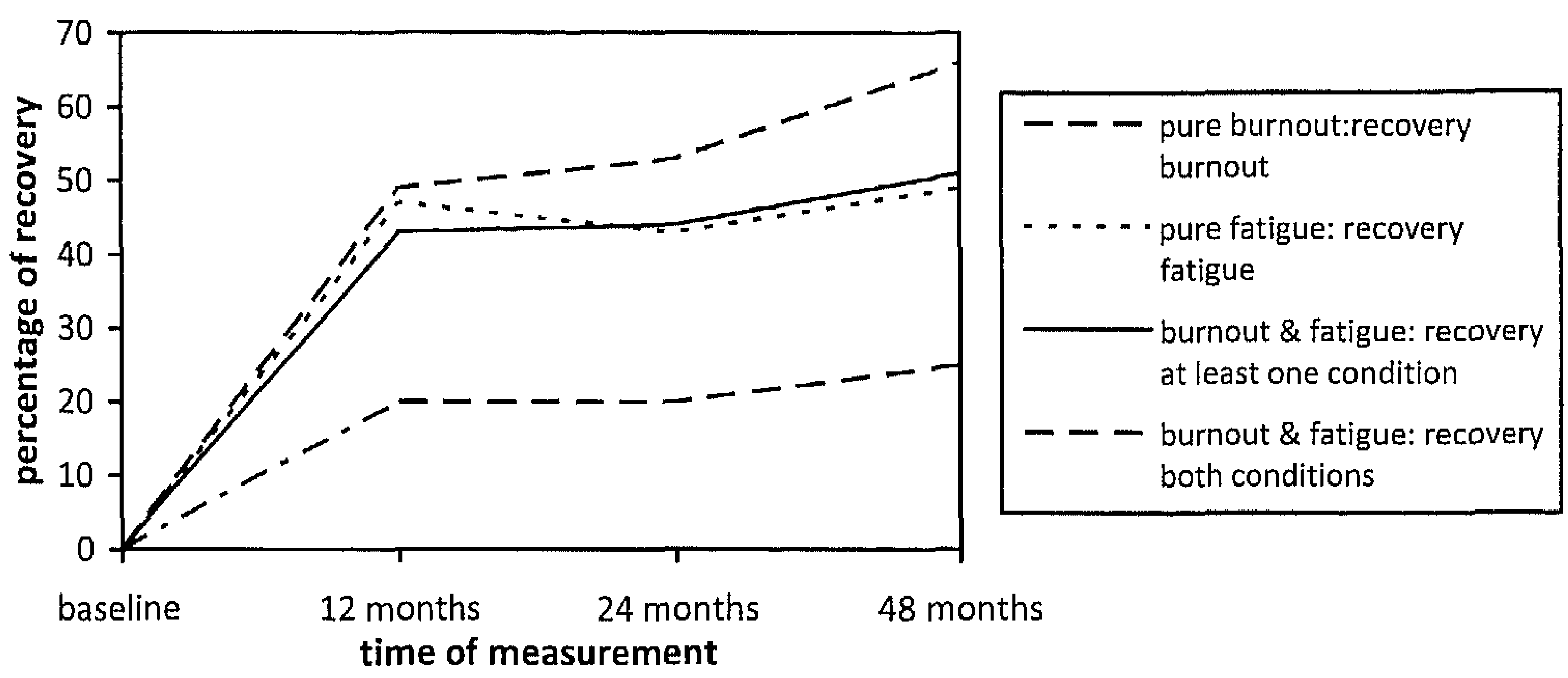

Figure 1 Percentage of recovery in subgroups at each measurement

\section{Pure fatigue: recovery from fatigue}

In the univariate analyses, the following baseline factors had a significant univariate association with recovery from fatigue in the pure fatigue group (data not shown): prolonged fatigue, exhaustion, co-worker support, emotional job demands, role ambiguity, an unknown attribution, perceived general health, enough leisure time and work-home conflict. Table 2 shows the results of the multivariate analysis for the prediction of recovery from fatigue in the pure fatigue group.

A lower level of prolonged fatigue, a lower level of exhaustion, more co-worker support and the absence of an unknown attribution for fatigue best predicted recovery from fatigue. 
Table 2 Results of the multivariate analysis for the prediction of recovery from fatigue in the pure fatigue group $(n=912)$

\begin{tabular}{|c|c|c|}
\hline Baseline predictors & $\begin{array}{l}\text { Recovery from fatigue at follow-up: } \\
\text { OR }(95 \% \mathrm{Cl})^{\text {a }}\end{array}$ & p-value \\
\hline Prolonged fatigue (scale $20-140$ ) & $0.81 \quad(0.72-0.92)$ & 0.001 \\
\hline Exhaustion (scale 0-6) & $0.73 \quad(0.64-0.82)$ & 0.000 \\
\hline Co-worker support (scale 4-16) & $1.16 \quad(1.03-1.32)$ & 0.014 \\
\hline Unknown attribution ( $1=y e s$ ) & $0.72(0.54-0.96)$ & 0.025 \\
\hline
\end{tabular}

OR: odds ratio; $\mathrm{Cl}$ : confidence interval.

ORs of continuous variables are expressed as change per S.D.

${ }^{a}$ OR adjusted for: age, gender, education and time of measurement.

\section{Pure burnout: recovery from burnout}

The baseline factors in the univariate analyses that had a significant univariate association with recovery from burnout in the pure burnout group were (data not shown): exhaustion, cynicism, professional efficacy, prolonged fatigue, psychological job demands, decision authority, supervisor social support, career opportunities, work schedule, emotional job demands, a psychological and somatic attribution, perceived general health, enough leisure time, work-home conflict, visit to a general practitioner, visit to an occupational physician, conflict with supervisor and conflict with co-worker. The results of the multivariate analysis for the prediction of recovery from burnout in the pure burnout group are shown in table 3. A lower level of exhaustion, more professional efficacy, the absence of conflicts with coworkers, doing day work and having enough leisure time best predict recovery from burnout.

\section{Burnout \& fatigue: recovery from at least one condition (burnout or fatigue)}

Prolonged fatigue, exhaustion, cynicism, professional efficacy, decision authority, coworker support, visit to a general practitioner, visit to an occupational physician, perceived general health, chronic condition, depressed mood, psychological distress, work-home conflict, working hours and career opportunities had significant univariate associations (data not shown) with recovery from at least one condition in the burnout \& fatigue group.

Table 3 Results of the multivariate analysis for the prediction of recovery from burnout in the pure burnout group $(n=547)$

\begin{tabular}{|c|c|c|}
\hline Baseline predictors & $\begin{array}{l}\text { Recovery from burnout at follow-up: } \\
\text { OR }(95 \% \mathrm{Cl})^{\mathrm{a}}\end{array}$ & $p$-value \\
\hline Exhaustion (scale 0-6) & $0.60 \quad(0.51-0.71)$ & 0.000 \\
\hline Professional efficacy (scale $0-6$ ) & $1.27 \quad(1.09-1.49)$ & 0.002 \\
\hline Conflict colleagues (1=yes) & $0.45 \quad(0.28-0.73)$ & 0.001 \\
\hline Work schedule ( $0=$ shift work, $1=$ day work) & $1.57 \quad(1.10-2.27)$ & 0.014 \\
\hline Enough leisure time (1=yes) & $1.67 \quad(1.24-2.25)$ & 0.001 \\
\hline
\end{tabular}

$\mathrm{OR}$ : odds ratio; $\mathrm{Cl}$ : confidence interval.

ORs of continuous variables are expressed as change per S.D.

a OR adjusted for: age, gender, education and time of measurement. 
The results of the multivariate analysis for the prediction of recovery from at least one condition in the burnout \& fatigue group are shown in table 4. A lower level of prolonged fatigue, a lower level of exhaustion, more professional efficacy, and a good perceived general health best predicted recovery from at least one condition (burnout or fatigue).

Table 4 Results of the multivariate analysis for the prediction of recovery from at least one condition (burnout or fatigue) and both conditions (burnout and fatigue) in the burnout \& fatigue group ( $n=897$ )

\begin{tabular}{|c|c|c|c|c|}
\hline Baseline predictors & $\begin{array}{l}\text { Recovery from at } \\
\text { least one } \\
\text { condition at } \\
\text { follow-up: } \\
\text { OR }(95 \% \mathrm{Cl})^{\text {a }}\end{array}$ & p-value & $\begin{array}{l}\text { Recovery from } \\
\text { both burnout and } \\
\text { fatigue at } \\
\text { follow-up: } \\
\text { OR }(95 \% \mathrm{CI})^{\text {a }}\end{array}$ & p-value \\
\hline Prolonged fatigue (scale 20-140) & $0.81(0.71-0.92)$ & 0.002 & $0.77(0.63-0.93)$ & 0.006 \\
\hline Exhaustion (scale 0-6) & $0.80(0.70-0.90)$ & 0.000 & $0.82(0.69-0.98)$ & 0.033 \\
\hline Professional efficacy (scale 0-6) & $1.17(1.04-1.32)$ & 0.010 & & \\
\hline Career opportunities (scale 0-3) & & & $0.82(0.76-0.95)$ & 0.007 \\
\hline Perceived general health ( $1=$ good) & $1.58(1.25-2.00)$ & 0.000 & $1.57(1.16-2.13)$ & 0.003 \\
\hline
\end{tabular}

OR: odds ratio; $\mathrm{Cl}$ : confidence interval.

ORs of continuous variables are expressed as change per S.D.

a OR adjusted for: age, gender, education and time of measurement.

\section{Burnout \& fatigue: recovery from both conditions (burnout and fatigue)}

In the univariate analyses, the following baseline factors had a significant univariate association with recovery from both burnout and fatigue in the burnout $\&$ fatigue group (data not shown): prolonged fatigue, exhaustion, cynicism, professional efficacy, co-worker support, career opportunities, chronic condition and perceived general health. Table 4 shows that recovery from both burnout and fatigue in the burnout \& fatigue group was best predicted by a lower level of prolonged fatigue, a lower level of exhaustion, more career opportunities and a good perceived general health in the multivariate analysis.

\section{Discussion}

The aim of this study was to assess and compare prognostic factors for recovery in burnout and prolonged fatigue. The results showed that recovery from fatigue in the pure fatigue group was predicted by low fatigue, low exhaustion, high co-worker support and lack of an unknown fatigue attribution. Recovery from burnout in the pure burnout group was predicted by low exhaustion, high professional efficacy, absence of conflicts with colleagues, doing day work, and having enough leisure time. Recovery from at least one condition (burnout or fatigue) in the burnout \& fatigue group was predicted by low fatigue, low exhaustion, high professional efficacy and a good perceived general health whereas 
recovery from both burnout and prolonged fatigue (i.e. both conditions) was predicted by low fatigue, low exhaustion, more career opportunities and a good perceived general health.

\section{Methodological considerations}

Analysis revealed that there was selective withdrawal but its effects were probably limited. The statistically significant differences that were found in the subgroups between participants who responded to all measurements and those who did not were quite small (see methods section). Moreover, participants who did not complete every measurement tended to have more unfavourable characteristics and were probably less likely to recover. Therefore, an underestimation of the associations that we found in this study due to this dropout cannot be ruled out. On the other hand, an overestimation of the observed associations due to the influence of common method variance (owing to the sole use of questionnaires in this study) and stable third variables such as negative affectivity cannot be ruled out.

Absenteeism is an important factor when studying burnout due to its work-related nature, and indeed when studying prolonged fatigue in the working population. Absenteeism was not a predictor of recovery in any of the subgroups either in univariate or multivariate analyses. However, one can imagine that absenteeism and burnout as well as possibly prolonged fatigue are entwined. The aim of our study was to gain more insight into the relationship between burnout and prolonged fatigue by studying their prognosis. Nevertheless, in future research a next step would be to disentangle this relationship further by exploring their relationship with absenteeism. With respect to prognosis, an important limitation of our study is that we did not have information on some potentially very important prognostic factors such as the duration of fatigue and/or burnout complaints prior to baseline and whether participants had received a diagnostic label for their complaints which is suggested to be an important prognostic factor ${ }^{29,30}$. We did however, have information on help seeking behaviour (visiting the general practitioner or occupational physician) which could be seen as a proxy for labelling and therefore as a partial solution for the lack of information on labelling.

\section{Similarities: selection variables}

The selection variables prolonged fatigue and exhaustion were important predictors in (nearly) all of the models as one would expect. Notably, the level of prolonged fatigue at baseline was not a predictor of recovery in the pure burnout group whereas the level of exhaustion at baseline was a predictor of recovery in the pure fatigue group. In a similar vein, Michielsen et al. ${ }^{31}$ found that general fatigue at baseline did not predict exhaustion 2 years later and that exhaustion at baseline did predict general fatigue two years later. Although studies have found exhaustion as measured by the $M B I$ and prolonged fatigue as measured by the CIS to measure the same construct ${ }^{32,33}$ other studies have suggested that 
exhaustion and (components of) prolonged fatigue contain different information ${ }^{9,12,34}$. In terms of fatigue experience it seems exhaustion has an added value over and above prolonged fatigue. This could be due to the work-related nature of the exhaustion scale or possibly due to the proposed more severe nature of exhaustion ${ }^{34}$.

\section{Differences: work factors and health-related factors}

Differences emerged with respect to several work factors. Work factors were especially important in predicting recovery in the pure burnout group compared to the other groups. Work factors are known to play an important role in the aetiology of burnout ${ }^{7}$. Within the pure burnout subgroup they also seem important in predicting recovery, in contrast to the other groups. It has been noted that work factors may not play such an important role in the course of fatigue as they do in the aetiology ${ }^{35}$, which this study seems to underline. An explanation for the difference in the importance of work factors in predicting recovery in the pure burnout group as compared to the burnout \& fatigue group could be that the complaints in the pure burnout group are not as advanced as in the burnout \& fatigue group and seem to be still predominantly work-related. Work factors still have an important impact on the course in the relatively uncomplicated symptoms in the pure burnout group whereas when symptoms become more advanced and start to merge with other health complaints as in the burnout \& fatigue group ${ }^{9}$, work factors are of less importance in predicting recovery. Co-worker social support was a predictor of recovery in the pure fatigue group which is in line with a study examining work characteristics in relation to changes in fatigue ${ }^{35}$ which found that more co-worker support was related to a reduction in subjective fatigue. Although co-worker support is work-related in nature, the items of this scale (e.g. "My co-workers are interested in me" and "My co-workers are friendly" 24, 25) reflect a more personal or emotional component to this type of support which seems to be important in the pure fatigue group. Finally, we defined two forms of recovery in the burnout \& fatigue group as the prognostic factors could depend on the definition of outcome. Although the prognostic factors for both definitions of recovery were very similar there was a difference in the work factors: more professional efficacy was a predictor of recovery from at least one condition whereas having more career opportunities was a predictor of recovery from both conditions.

Health-related factors such as a lack of an unknown attribution for fatigue complaints and a good perceived general health were important predictors of recovery in the pure fatigue group and burnout \& fatigue group, but not in the pure burnout group. These results underline findings from other research that these factors play an important role in the course of fatigue ${ }^{11,36,37}$. Notably, perceived general health was not a predictor of recovery in the pure fatigue group but only in the burnout \& fatigue group. With respect to causal attributions in fatigue research, the focus is usually on psychological or somatic attributions $11,38-40$. Our study indicates that not knowing or having no attribution can also have a 
negative impact on the course of fatigue (in the pure fatigue group). This may be an issue that requires further research.

\section{Clinical implications}

The primary goal of this study was not directly focused on intervention. However, a review of the findings could provide leads for future intervention possibilities. As one would expect the results show that the main difference in prognosis between burnout and prolonged fatigue lies in work factors. This implies that interventions aimed at burnout need to take the work situation into account whether it be by modifying these factors directly when possible or indirectly when this is not possible by, for example, providing tools to the affected employee to deal with the work situation. However, an important consideration seems to be timing, as work factors seem to be more important in predicting recovery from less advanced burnout symptoms (i.e. the pure burnout group) than more advanced burnout symptoms (i.e. the burnout \& fatigue group). In the latter case as well as in the case of the pure fatigue group, health-related factors such as causal attributions and perceived general health play a more prominent role in the prognosis and these factors should receive attention in interventions aimed at prolonged fatigue.

\section{Conclusion}

Although prolonged fatigue and exhaustion at baseline were important predictors of recovery in nearly all of the subgroups there were also differences in prognostic factors between the subgroups. Differences emerged with respect to work and health factors. Moreover, although different work factors predicted recovery in the different subgroups, they were especially important in predicting recovery in the pure burnout group. The results suggest that differentiating between burnout and prolonged fatigue is useful as the focus of intervention for these conditions should be different. Specifically, work factors seem to be more important in the prognosis of burnout (depending on timing) whereas health-related factors seem to be more important in the prognosis of prolonged fatigue.

\section{Acknowledgements}

This study was funded by the Occupational Health Epidemiology programme of the Research Institute Caphri, Maastricht University, The Netherlands. 


\section{References}

1 Kant I. J., Bultmann U., Schroer K. A., Beurskens A. J., Van Amelsvoort L. G., Swaen G. M. An epidemiological approach to study fatigue in the working population: the Maastricht Cohort Study. Occupational and Environmental Medicine 2003; 60 Suppl 1: i32-9.

2 Janssen N., Kant I. J., Swaen G. M. H., Janssen P. P. M., Schroer C. A. P. Fatigue as a predictor of sickness absence: results from the Maastricht cohort study on fatigue at work. Occupational and Environmental Medicine 2003; 60 Suppl 1: i71-6.

3 Borritz M., Rugulies R., Christensen K. B., Villadsen E., Kristensen T. S. Burnout as a predictor of self-reported sickness absence among human service workers: prospective findings from three year follow up of the PUMA study. Occupational and Environmental Medicine 2006; 63: 98-106.

4 Skapinakis P., Lewis G., Mavreas V. Temporal relations between unexplained fatigue and depression: longitudinal data from an international study in primary care. Psychosomatic Medicine 2004; 66: 330-5.

5 Schaufeli W. Past performance and future perspectives of burnout research. South African Journal of Industrial Psychology 2003; 29: 1-15.

6 Bultmann U., Kant I., Kasl S. V., Beurskens A. J., van den Brandt P. A. Fatigue and psychological distress in the working population: psychometrics, prevalence, and correlates. Journal of Psychosomatic Research 2002; 52: 445-52.

7 Schaufeli W.B. , Enzman D. The burnout companion to study and practice: a critical analysis. London: Taylor \& Francis, 1998.

8 Schaufeli W. B., Taris T. W. The conceptualization and measurement of burnout: Common ground and worlds apart. Work and Stress 2005; 19: 256-62.

9 Leone S. S., Huibers M. J., Knottnerus J. A., Kant I. J. Similarities, overlap and differences between burnout and prolonged fatigue in the working population. Quarterly Journal of Medicine 2007; 100: 617-27.

10 Huibers M. J. H., Beurskens A. J. H. M., Prins J. B., Kant I. J., Bazelmans E., van Schayck C. P., Knottnerus J. A., Bleijenberg G. Fatigue, burnout, and chronic fatigue syndrome among employees on sick leave: do attributions make the difference? Occupational and Environmental Medicine 2003; 60: 26-31.

11 Cairns R., Hotopf M. A systematic review describing the prognosis of chronic fatigue syndrome. Occupational Medicine 2005; 55: 20-31.

12 Mommersteeg P. M., Heijnen C. J., Verbraak M. J., van Doornen L. J. A longitudinal study on cortisol and complaint reduction in burnout. Psychoneuroendocrinology 2006; 31: 793-804.

13 Sonnenschein M. Sick with burnout clarified through electronic diaries. Utrecht University: PhD thesis, 2007

14 Schaufeli W.B., Leiter M.P., Maslach C., Jackson S.E. The Maslach Burnout InventoryGeneral Survey. In: Maslach C, Jackson SE, Leiter MP, eds. Maslach Burnout Inventory manual: 3rd Edition. Palo Alto, CA: Consulting Psychologists Press, 1996; 19-26.

15 Schaufeli W.B., Van Dierendonk D. UBOS, Utrechtse Burnout Schaal, Handleiding. Lisse: Swets Test Publishers, 2000.

16 Vercoulen J. H. H. M., Alberts M., Bleijenberg G. De Checklist Individuele Spankracht (CIS) [The Checklist Individual Strength (CIS)]. Gedragstherapie 1999; 32: 131-6. 
17 Vercoulen J. H., Swanink C. M., Fennis J. F., Galama J. M., van der Meer J. W., Bleijenberg G. Dimensional assessment of chronic fatigue syndrome. Journal of Psychosomatic Research 1994; 38: 383-92.

18 Bultmann U., de Vries M., Beurskens A. J., Bleijenberg G., Vercoulen J. H., Kant I. Measurement of prolonged fatigue in the working population: determination of a cutoff point for the checklist individual strength. Journal of Occupational Health Psychology 2000; 5: 411-6.

19 Goldberg D.P., Williams P. A users guide to the General Health Questionnaire. Windsor: Nfer Nelson, 1988.

20 Koeter M.W.J., Ormel J. General Health Questionnaire, Handleiding Nederlandse bewerking [General Health Questionnaire, Manual Dutch version]. Lisse: Swets \& Zeitlinger, 1991.

21 Hardy G. E., Shapiro D. A., Borrill C. S. Fatigue in the workforce of National Health Service Trusts: levels of symptomatology and links with minor psychiatric disorder, demographic, occupational and work role factors. Journal of Psychosomatic Research 1997; 43: 83-92.

22 Aaronson N. K., Muller M., Cohen P. D., Essink-Bot M. L., Fekkes M., Sanderman R., Sprangers M. A., te Velde A., Verrips E. Translation, validation, and norming of the Dutch language version of the SF-36 Health Survey in community and chronic disease populations. Journal of Clinical Epidemiology 1998; 51: 1055-68.

23 Ware J. E., Jr., Sherbourne C. D. The MOS 36-item short-form health survey (SF-36). I. Conceptual framework and item selection. Medical Care 1992; 30: 473-83.

24 Karasek R.A. The Job Content Questionnaire and User's Guide (version 1.1). Los Angeles: Department of Industrial and Systems Engineering, University of Southern California, 1985

25 Houtman I. Reliability and validity of the Dutch version of the Karasek Job Content Questionnaire. NIOSH/APA conference on Stress, Work, and Health. Washington, DC, 1995

26 Veldhoven van M., Meijman T. Het meten van psychosociale arbeidsbelasting met een vragenlijst: de Vragenlijst Beleving en Beoordeling van de Arbeid (VBBA) [Questionnaire on psychosocial job demands and job stress]. Amsterdam: NIA, 1994.

27 Central Bureau of Statistics. Doorlopend Leefsituatie Onderzoek [Ongoing Survey on Living Conditions]. Voorburg/Heerlen: Central Bureau of Statistics 1996

28 Gründemann R.W.M., Smulders P.W.G., De Winter C.R. Handleiding Vragenlijst Arbeid en Gezondheid [Manual, Questionnaire on work and health]. Lisse: Swets \& Zeitlinger, 1993.

29 Hamilton W. T., Gallagher A. M., Thomas J. M., White P. D. The prognosis of different fatigue diagnostic labels: a longitudinal survey. Family Practice $2005 ; 22: 383-8$.

30 Huibers M. J., Wessely S. The act of diagnosis: pros and cons of labelling chronic fatigue syndrome. Psychological Medicine 2006; 36: 895-900.

31 Michielsen H. J., Willemsen T. M., Croon M. A., de Vries J., Van Heck G. L. Determinants of general fatigue and emotional exhaustion: A prospective study. Psychology \& Health 2004; 19: 223-35.

32 De Vries J., Michielsen H. J., Van Heck G. L. Assessment of fatigue among working people: a comparison of six questionnaires. Occupational and Environmental Medicine 2003; 60 Suppl 1: i10-5.

33 Michielsen H. J., De Vries J., Van Heck G. L., Van de Vijver F. J. R., Sijtsma K. Examination of the dimensionality of fatigue - The Construction of the Fatigue Assessment Scale (FAS). European Journal of Psychological Assessment 2004; 20: 39-48. 
34 Sonnenschein M., Sorbi M. J., Doornen L. J. P. V., Schaufeli W. B., Maas C. J. M. Electronic diary evidence on energy erosion in clinical burnout. Journal of Occupational Health Psychology 2007; 12: 402-13.

35 Janssen $\mathrm{N}$. The natural course of fatigue in a working population. Maastricht: Maastricht University Press, 2004.

36 Huibers M. J., Kant I. J., Knottnerus J. A., Bleijenberg G., Swaen G. M., Kasl S. V. Development of the chronic fatigue syndrome in severely fatigued employees: predictors of outcome in the Maastricht cohort study. Journal of Epidemiology and Community Health 2004; 58: 877-82.

37 Huibers M. J., Bultmann U., Kasl S. V., Kant I., van Amelsvoort L. G., van Schayck C. P., Swaen G. M. Predicting the two-year course of unexplained fatigue and the onset of long-term sickness absence in fatigued employees: results from the Maastricht Cohort Study. Journal of Occupational and Environmental Medicine 2004; 46: 1041-7.

38 Schmaling K. B., Fiedelak J. I., Katon W. J., Bader J. O., Buchwald D. S. Prospective study of the prognosis of unexplained chronic fatigue in a clinic-based cohort. Psychosomatic Medicine 2003; 65: 1047-54.

39 Chalder T., Godfrey E., Ridsdale L., King M., Wessely S. Predictors of outcome in a fatigued population in primary care following a randomized controlled trial. Psychological Medicine $2003 ; 33: 283-7$.

40 Afari N., Buchwald D. Chronic fatigue syndrome: A review. American Journal of Psychiatry 2003; 160: 221-36. 
The temporal relationship between

burnout and prolonged fatigue:

A 4-year prospective cohort study

S.S. Leone ${ }^{1}$

M.J.H. Huibers ${ }^{2}$

J.A. Knottnerus ${ }^{3}$

IJ. Kant ${ }^{1}$

${ }^{1}$ Department of Epidemiology, Maastricht University, Maastricht, The Netherlands

${ }^{2}$ Department of Clinical Psychological Science, Maastricht University, Maastricht, The Netherlands

${ }^{3}$ Department of General Practice, Maastricht University, Maastricht, The Netherlands 


\begin{abstract}

\section{Objective}

Burnout and prolonged fatigue have hardly been compared empirically despite similarities. Knowledge on how these conditions influence each other in time is limited, although this could have implications for (the timing of) intervention. This study aims to examine the temporal relationship between burnout and prolonged fatigue by examining 1) if they predict each other in time, 2) if there is a dose-response relationship and 3 ) if they tend to alternate or merge together in time.
\end{abstract}

\title{
Methods
}

Four-year prospective follow-up data from the Maastricht Cohort Study were used for this study. After selection, 11,710 participants could be included. Burnout and prolonged fatigue were measured with the Maslach Burnout inventory-General Survey and the Checklist Individual Strength, respectively. Data were analysed using Cox regression analysis, generalised estimating equation analysis and multinomial regression analysis.

\section{Results}

Burnout at baseline was associated with an increased risk of subsequent prolonged fatigue (hazard ratio (HR) 1.33, 95\% confidence interval (CI) 1.16-1.53) and prolonged fatigue was associated with an increased risk of subsequent burnout (HR 1.65, 95\% $\mathrm{Cl} 1.44-1.89$ ). There seems to be evidence of a dose-response relationship. When burnout and prolonged fatigue influence each other, they tend to merge rather than replace each other.

\section{Conclusions}

Burnout and prolonged fatigue seem to influence each other in the manner of a downward spiral. Recognising and correctly identifying fatigue complaints at an early stage seems important, as early intervention could prevent the conditions from co-occurring and avert a worsening of outcome. 


\section{Introduction}

Although prolonged fatigue and burnout are similar they are not necessarily one and the same. For instance, burnout is seen as a work-related condition whereas prolonged fatigue is a more general condition which is not necessarily related to work. The shared importance of the symptom of fatigue in both burnout and prolonged fatigue is the most striking similarity, which could cause confusion in the working population when employees present with fatigue complaints. The issue of the similarity of burnout and (prolonged) fatigue has long been debated ${ }^{1}$. However, there has been relatively little empirical research into this matter. In a previous study we found that burnout and prolonged fatigue could occur separately from each other despite a large overlap ${ }^{2}$. Moreover, differences between burnout and prolonged fatigue were found in work and health factors. However, from an empirical point of view, it is not really known if and how burnout and prolonged fatigue influence each other in time. Two issues which could be relevant to the relationship between burnout and prolonged fatigue have been mentioned in the literature: the context of the condition ${ }^{1,3}$ and the severity of the symptom of fatigue ${ }^{4}$. In the former case, a specific work-related fatigue condition (i.e. burnout) could induce a more general fatigue condition (i.e. prolonged fatigue) in a similar vein to the proposed relationship between burnout and depression ${ }^{5}$. In the latter case, prolonged fatigue could induce burnout when relatively mild fatigue symptoms gradually become more severe and develop into burnout, with exhaustion as a severe form of fatigue at its heart, similar to prolonged fatigue and chronic fatigue syndrome ${ }^{6}$. Alternatively, another possibility could be that burnout and prolonged fatigue influence each other in the manner of a vicious cycle or a downward spiral as has been suggested, for example, in the relationship between fatigue and depression ${ }^{7,8}$.

The importance of studying their temporal relationship lies in the implications for intervening in and thereby possibly preventing the onset of the other condition or indeed in the merging of both conditions which tends to have a worse outcome if a temporal relationship exists ${ }^{2,9}$. This also implies that studying the temporal relationship is important with regard to the issue of the timing of an intervention.

In this study, we aim to examine and unravel the temporal relationship between burnout and prolonged fatigue. To this end, we will examine whether burnout and prolonged fatigue predict each other, adjusting for, among others, prior symptom levels. Moreover, the possibility of a dose-response relationship between burnout and prolonged fatigue will be examined. Finally, we will try to determine whether burnout and prolonged fatigue tend to alternate with each other or merge together. 


\section{Methods}

\section{Design}

The Maastricht Cohort Study on Fatigue at Work (MCS) provided the data for this study. Self-administered questionnaires were completed by 12,140 employees from 45 different companies and organisations who participated in this prospective cohort study (response rate $45 \%$ ). Informed consent was obtained from all participants. Starting in May 1998, participants were followed every four months for three years as well as an additional follow-up 4 years after baseline. Non-respondents at baseline reported less fatigue complaints, less sickness absence and less difficulty in work execution. Detailed information on the design of the MCS is provided elsewhere ${ }^{10}$. The baseline, 12-, 24- and 48-month follow-up measurements were used in this study as burnout was only assessed at these four measurements.

\section{Study population}

Participants were excluded if they indicated having one of the following chronic conditions that might explain fatigue complaints: cerebrovascular accidents, liver dysfunction, diabetes mellitus, hyperthyroidism or cancer. After exclusion, 11,710 participants could be included in the analyses.

\section{Predictor variables}

Burnout

Burnout was assessed with the Dutch version of the Maslach Burnout Inventory-General Survey (MBI-GS) which consists of three subscales: exhaustion (5 items), cynicism (4 items) and professional efficacy $(6 \text { items })^{11,12}$. Higher scores on these scales indicate higher levels (range 0-6). In line with the definition in the manual of the Dutch version of the MBI-GS, burnout cases were defined as having a score higher than the $75^{\text {th }}$ percentile on exhaustion and a score higher than the $75^{\text {th }}$ percentile on cynicism or a score lower than the $25^{\text {th }}$ percentile on professional efficacy. In our cohort at baseline $(n=12,140)$, this resulted in the following cut-off points: exhaustion $>2.40$, cynicism $>2.25$ and professional efficacy $<3.50$ which were used in this study.

\section{Prolonged fatigue}

Prolonged fatigue was assessed with the Checklist Individual Strength (CIS) which consists of four subscales: subjective fatigue ( 8 items), concentration ( 5 items), motivation ( 4 items) and activity ( 3 items) ${ }^{13,14}$. Adding the scores on the subscales produces a composite total score (range 20-140) with higher scores indicating higher levels of prolonged fatigue. Participants were classified as a prolonged fatigue case if they had a total score higher than $76^{15}$. 


\section{Other factors}

Age, gender, education (low, medium and high) and sickness absenteeism (partial and full) were all assessed by self-report.

\section{Statistical analysis}

The temporal relationship between burnout and prolonged fatigue was analysed using Cox regression analysis and generalised estimating equation analysis (GEE). In the Cox regression analyses of burnout $(0=$ no, $1=y e s)$ as a predictor of prolonged fatigue $(0=$ no, $1=y e s)$, we excluded prolonged fatigue cases at baseline and examined whether burnout at baseline was associated with the onset of prolonged fatigue at 12-, 24- or 48-months follow-up ( $n=9025$ ). Adjustments were made for the continuous prolonged fatigue score, age, gender, education and absenteeism at baseline. Similarly, in the analysis of prolonged fatigue as a predictor of burnout, the burnout cases at baseline were excluded and it was examined whether prolonged fatigue at baseline was associated with the onset of burnout

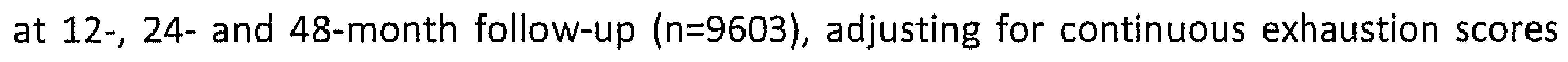
(as there is no total burnout score and exhaustion is the most important symptom), age, gender, education and absenteeism at baseline. GEE is a longitudinal analysis technique in which all available data at the different measurements are analysed simultaneously and which takes the dependency of measurements within subjects into account. Moreover, we used a time lag approach which allows prolonged fatigue ( $0=$ no, $1=y e s)$ measured one year prior, to be associated with burnout $(0=n o, 1=y e s)$ measured one year later (time lag of one year) and vice versa. The same adjustments were made as in the Cox regression with the addition of time of measurement. We also calculated the attributive proportion in the exposed group, based on the adjusted hazard ratios, to indicate the relative importance of prolonged fatigue or burnout with respect to the onset of the other condition. To analyse the dose-response relationship between burnout and prolonged fatigue, we also used Cox regression analysis and GEE time lag analysis. We divided the exhaustion score and the subjective fatigue scores into categories and associated these with prolonged fatigue and burnout, respectively, at follow-up. Depending on the direction of the relationship being investigated, burnout cases (fatigue $\rightarrow$ burnout) or prolonged fatigue cases (burnout $\rightarrow$ fatigue) at baseline were excluded. In addition, adjustments were made for prior prolonged fatigue scores or exhaustion scores, age, gender, education and absenteeism at baseline. Finally, to examine whether burnout or prolonged fatigue cases at baseline were more likely to replace each other or merge together at the three separate follow-up measurements, we used a multinomial regression analysis. In this analysis, the association between prolonged fatigue or burnout cases at baseline was examined with the outcome variable ( 4 categories): neither burnout nor fatigue (0), pure fatigue (prolonged fatigue case, not a burnout case; 1 ), pure burnout (burnout case, not a prolonged fatigue case; 2 ) and burnout \& fatigue (a burnout and a prolonged fatigue case; 3 ). The Cox regression 
analyses and the multinomial regression analyses were performed using SPSS (version 12.0) and the GEE analyses were performed using Stata (version 9).

\section{Results}

\section{Sample characteristics}

Table 1 shows the number of valid cases at each measurement in addition to several baseline characteristics for each group.

Table 1 Number of valid cases and baseline characteristics at each measurement in several subgroups

\begin{tabular}{|c|c|c|c|c|c|c|}
\hline & Total group & $\begin{array}{c}\text { Prolonged } \\
\text { fatigue } \\
\text { cases }\end{array}$ & $\begin{array}{c}\text { Burnout } \\
\text { cases }\end{array}$ & $\begin{array}{c}\text { Pure } \\
\text { fatigue } \\
\text { cases }\end{array}$ & $\begin{array}{c}\text { Pure } \\
\text { burnout } \\
\text { cases }\end{array}$ & $\begin{array}{c}\text { Burnout } \\
\& \text { fatigue } \\
\text { cases }\end{array}$ \\
\hline \multicolumn{7}{|l|}{ Valid cases, $n(\%)$} \\
\hline Baseline & $11710(100 \%)$ & $2456(21 \%)$ & $2048(17 \%)$ & $1200(11 \%)$ & $755(6 \%)$ & $1250(11 \%)$ \\
\hline 12 months & $9296(100 \%)$ & $2018(22 \%)$ & $1673(18 \%)$ & $904(10 \%)$ & $552(6 \%)$ & $1086(12 \%)$ \\
\hline 24 months & $7758(100 \%)$ & $1908(25 \%)$ & $1414(18 \%)$ & $861(11 \%)$ & $397(5 \%)$ & $1002(13 \%)$ \\
\hline 48 months & $5328(100 \%)$ & $1210(23 \%)$ & $847(16 \%)$ & $566(11 \%)$ & $228(4 \%)$ & $607(11 \%)$ \\
\hline \multicolumn{7}{|l|}{ Baseline characteristics ${ }^{a}$} \\
\hline Age (years) & $40.8(8.9)$ & $41.2(8.8)$ & $40.8(9.2)$ & $41.3(8.6)$ & $40.2(9.3)$ & $41.1(9.0)$ \\
\hline $\begin{array}{l}\text { Gender } \mathrm{m} / \mathrm{f} \\
(\% \mathrm{~m})\end{array}$ & $\begin{array}{c}3133 / 8574 \\
(73 \%)\end{array}$ & $\begin{array}{c}668 / 1787 \\
(73 \%)\end{array}$ & $\begin{array}{c}494 / 1553 \\
(76 \%)\end{array}$ & $\begin{array}{c}368 / 831 \\
(69 \%)\end{array}$ & $\begin{array}{c}181 / 573 \\
(76 \%)\end{array}$ & $\begin{array}{c}296 / 954 \\
(76 \%)\end{array}$ \\
\hline \multicolumn{7}{|l|}{ Education } \\
\hline Low & $2250 \quad(20 \%)$ & $588(25 \%)$ & $547(28 \%)$ & $245(21 \%)$ & $195(27 \%)$ & $340 \quad(28$ \\
\hline Medium & $5147 \quad(45 \%)$ & $1044(44 \%)$ & $847(43 \%)$ & $520(45 \%)$ & $306(42 \%)$ & $521 \quad(43$ \\
\hline High & $3952 \quad(35 \%)$ & $751(32 \%)$ & $582(30 \%)$ & $404(35 \%)$ & $228(31 \%)$ & $347 \quad 29$ \\
\hline $\begin{array}{l}\text { Prolonged fatigue } \\
\text { (CIS, scale 20-140) }\end{array}$ & $56.9(23.6)$ & $91.6(12.8)$ & $82.8(20.2)$ & $88.1(10.6)$ & $62.7(11.2)$ & $95.0(13.6)$ \\
\hline $\begin{array}{l}\text { Exhaustion } \\
\langle\text { MBI-GS, scale 0-6 }\end{array}$ & $1.8(1.2)$ & $3.0(1.2)$ & $3.5(0.9)$ & $2.4(1.0)$ & $3.1(0.7)$ & $3.7\langle 1.0\rangle$ \\
\hline $\begin{array}{l}\text { Cynicism } \\
\text { (MBI-GS, scale 0-6) }\end{array}$ & 1.5 (1.1) & $2.3(1.2)$ & $2.9(1.0)$ & $1.6(0.9)$ & $2.7(0.9)$ & $3.0(1.0)$ \\
\hline $\begin{array}{l}\text { Professional efficacy } \\
\text { (MBI-GS, scale 0-6) }\end{array}$ & $4.1(1.0)$ & $3.5(0.9)$ & $3.2(0.8)$ & $3.9(0.9)$ & $3.4(0.8)$ & $3.1(0.8)$ \\
\hline
\end{tabular}

\section{Temporal relationship}

Cox regression analysis shows that, after adjustment, burnout at baseline was related to an increased risk of a subsequent onset of prolonged fatigue (table 2). Moreover, prolonged fatigue at baseline was related to an increased risk of a subsequent onset of burnout. The results also show that the relationship between prolonged fatigue at baseline and subsequent burnout is slightly stronger than vice versa. The results of the GEE time lag analysis (table 2) show a similar picture: burnout was related to an increased odds of future prolonged fatigue and prolonged fatigue was related to an increased odds of future 
burnout. Again the relationship was stronger for prolonged fatigue as a predictor of future burnout than vice versa. In both sets of analyses, there is a large difference between the crude and the adjusted hazard ratios (HRs)/odds ratios (ORs). This indicates a large amount of confounding by especially the criterion variables, as we see hardly any difference in the magnitude of the HRs/ORs between adjustment steps 2 and 3. The magnitude of the $\mathrm{HRs/ORs}$ is quite large which will be considered in the following paragraph.

Table 2 Temporal relationship between burnout and prolonged fatigue: results of Cox regression analysis and GEE time lag analysis

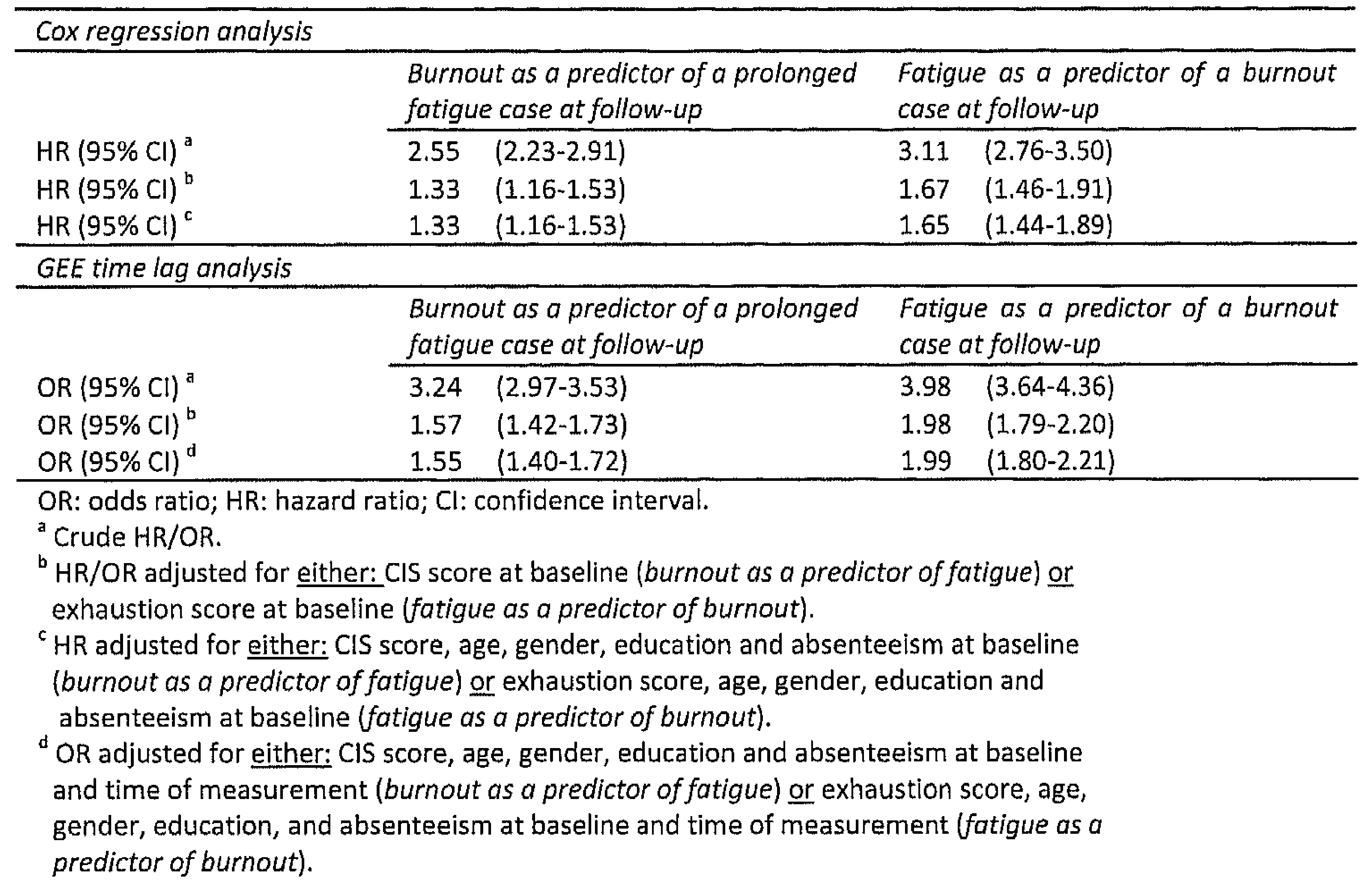

\section{Attributive proportion}

The magnitude of the HRs/ORs in the temporal relationship analysis is quite large, also when considering the prevalence of burnout and prolonged fatigue and the incidence of these conditions in the other group. To explore this further the attributive proportion in the exposed group was calculated for both groups.

The attributive proportion among burnout cases for burnout as a predictor prolonged fatigue is $25 \%$ which indicates that within the group of burnout cases at baseline, $25 \%$ of the subsequent prolonged fatigue cases can be attributed to being a burnout case at baseline. Alternatively, for the attributive proportion among prolonged fatigue cases for prolonged fatigue as a predictor of subsequent burnout is $39 \%$. This indicates that within the group of prolonged fatigue cases at baseline, $39 \%$ of the subsequent burnout cases can 
be attributed to being a prolonged fatigue case at baseline. These figures are put in some perspective in box 1 by using some figures from the analysis.

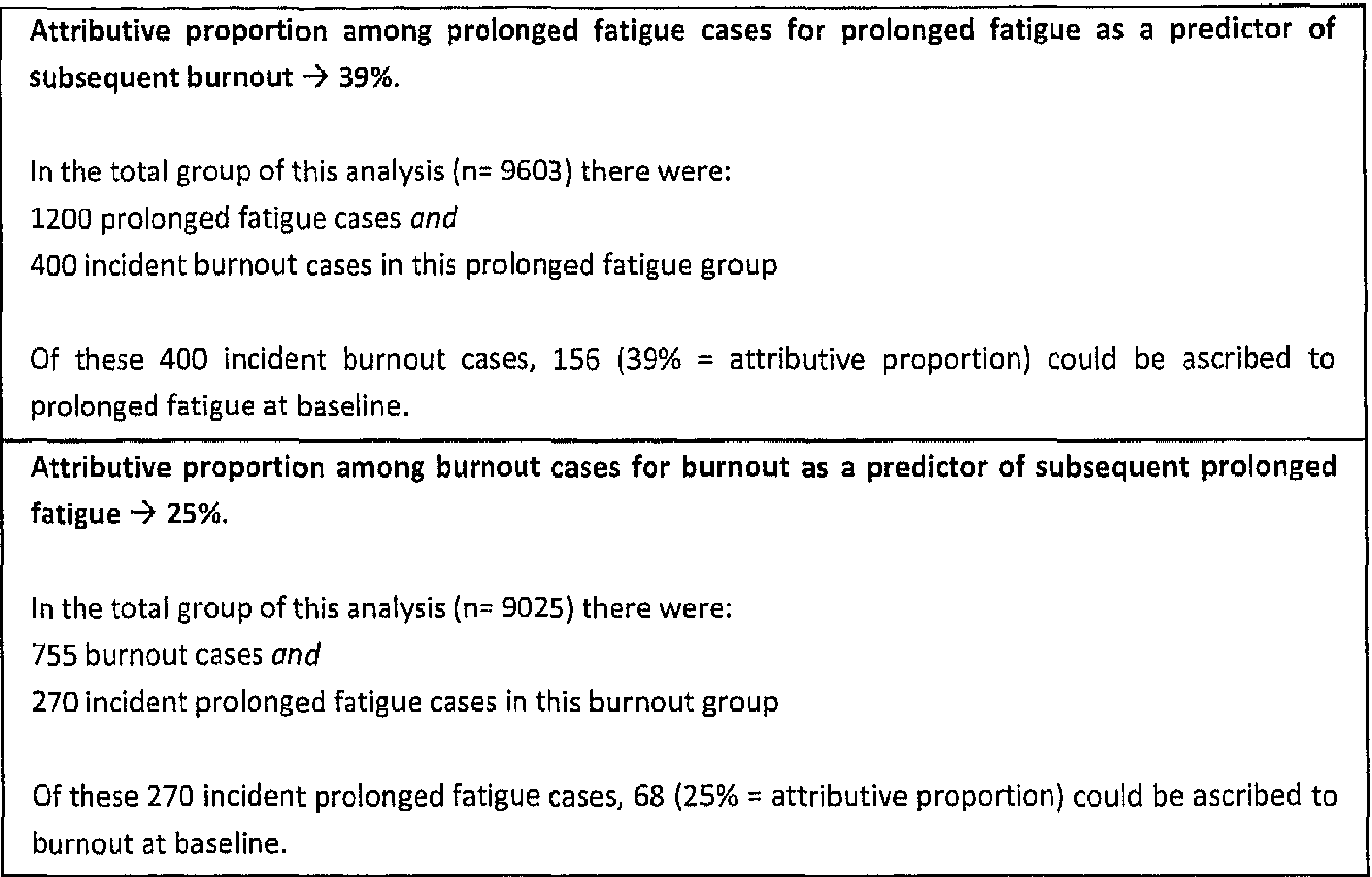

Box 1 Calculation of number of cases related to the attributive proportions in the exposed groups

\section{Dose-response relationship}

Table 3 shows that there does seem to be a dose-response relationship between exhaustion and prolonged fatigue as well as between subjective fatigue and burnout. After adjusting for potential confounders, the risk for developing burnout still increased as baseline scores of subjective fatigue increased and the risk for developing prolonged fatigue increased as baseline scores of exhaustion increased. The results of the GEE time lag analysis (not shown) showed the same pattern.

\section{Alternation/merging of conditions}

The results of the multinomial regression analysis (table 4) show that when burnout and prolonged fatigue influence each other, they do not tend to alternate with each but rather merge together. For example, we see that the OR for a burnout case at baseline as a predictor of the various categories at 12-month follow-up is smallest and non-significant for the pure fatigue category (meaning that the odds for being a pure fatigue case compared to being neither a burnout nor prolonged fatigue case at 12-month follow-up is about equal 
for a burnout case at baseline compared to a non-burnout case at baseline). This shows that burnout at baseline tends not to switch and be replaced by prolonged fatigue.

Table 3 Results of Cox regression in which the dose-response relationship between exhaustion and prolonged fatigue and subjective fatigue and burnout was modelled

\begin{tabular}{|c|c|c|c|c|c|}
\hline \multicolumn{6}{|c|}{ Exhaustion score categories as predictors of prolonged fatigue cases at follow-up } \\
\hline & $0^{a}$ & $>0-1.5$ & $1.6-3$ & $3.1-4.5$ & $4.6-6$ \\
\hline$H R^{b}$ & 1 & 3.20 & 7.28 & 12.47 & 15.65 \\
\hline$(95 \% \mathrm{Cl})$ & & $(1.76-5.82)$ & $(4.02-13.19)$ & $(6.78-22.94)$ & $(7.76-31.54)$ \\
\hline$H R^{c}$ & 1 & 1.87 & 2.50 & 3.17 & 3.37 \\
\hline$(95 \% \mathrm{Cl})$ & & $(1.03-3.41)$ & $(1.37-4.57)$ & $(1.70-5.91)$ & $(1.65-6.88)$ \\
\hline $\begin{array}{l}\mathrm{HR}^{d} \\
(95 \% \mathrm{Cl})\end{array}$ & 1 & $\begin{array}{l}1.91 \\
(1.05-3.49)\end{array}$ & $\begin{array}{l}2.58 \\
(1.41-4.71)\end{array}$ & $\begin{array}{l}3.26 \\
(1.75-6.09)\end{array}$ & $\begin{array}{l}3.39 \\
(1.66-6.93)\end{array}$ \\
\hline \multicolumn{6}{|c|}{ Subjective fatigue score categories as predictors of burnout cases at follow-up } \\
\hline & $8^{a}$ & $9-20$ & $21-32$ & $33-44$ & $45-56$ \\
\hline $\begin{array}{l}\mathrm{HR}^{6} \\
(95 \% \mathrm{Cl})\end{array}$ & 1 & $\begin{array}{l}2.80 \\
(1.76-4.45)\end{array}$ & $\begin{array}{l}6.69 \\
(4.23-10.59)\end{array}$ & $\begin{array}{l}11.39 \\
(7.19-18.03)\end{array}$ & $\begin{array}{l}13.98 \\
(8.63-22.65)\end{array}$ \\
\hline$H R^{c}$ & 1 & 2.18 & 3.86 & 5.12 & 4.22 \\
\hline$(95 \% \mathrm{Cl})$ & & $(1.37-3.46)$ & $(2.43-6.13)$ & $(3.20-8.22)$ & $(2.53-7.03)$ \\
\hline $\begin{array}{l}\mathrm{HR}^{\mathrm{d}} \\
(95 \% \mathrm{Cl})\end{array}$ & 1 & $\begin{array}{l}2.24 \\
(1.40-3.56)\end{array}$ & $\begin{array}{l}3.96 \\
(2.49-6.30)\end{array}$ & $\begin{array}{l}5.22 \\
(3.26-8.38)\end{array}$ & $\begin{array}{l}4.22 \\
(2.53-7.05)\end{array}$ \\
\hline
\end{tabular}

HR: hazard ratio; $\mathrm{Cl}$ : confidence interval.

${ }^{a}$ Reference category (lowest possible score).

${ }^{\text {b }}$ Crude HR

${ }^{c} \mathrm{HR}$ adjusted for either: CIS score at baseline (burnout as a predictor of fatigue) or exhaustion score at baseline (fatigue as a predictor of burnout)

${ }^{d} \mathrm{HR}$ adjusted for either: CIS score, age, gender, education and absenteeism at baseline (burnout as a predictor of fatigue) or exhaustion score, age, gender, education and absenteeism at baseline (fatigue as a predictor of burnout).

Moreover, the highest $O R$ at 12 months is the one between burnout and pure burnout at 12 months. Keeping in mind that fatigue cases at baseline were excluded in the analysis of burnout as a predictor of fatigue (effectively making burnout at baseline pure burnout) this result demonstrates that a burnout status at baseline is likely to persist and not remit at 12month follow-up compared to not being burned out at baseline. Finally, the OR for burnout at baseline and burnout \& prolonged fatigue at 12 months is quite high, showing that over time burnout and prolonged fatigue tend to merge together. This pattern can also be seen in the reverse relationship (fatigue $\rightarrow$ burnout). 
Table 4 Results of multinomial regression analysis: burnout and prolonged fatigue at baseline as predictors of pure fatigue, pure burnout, burnout $\&$ fatigue at 12-, 24and 48-months follow-up

\begin{tabular}{|c|c|c|c|c|}
\hline \multicolumn{5}{|c|}{ Burnout at baseline as a predictor } \\
\hline & Neither condition & Pure fatigue & Pure burnout & Burnout \& fatigue \\
\hline & $\mathrm{OR}^{\mathrm{a}}$ & $\mathrm{OR}^{\mathrm{b}}$ & $\mathrm{OR}^{\mathrm{b}}$ & $\mathrm{OR}^{\mathrm{b}}$ \\
\hline & $(95 \% \mathrm{Cl})$ & $(95 \% \mathrm{Cl})$ & $(95 \% \mathrm{Cl})$ & $(95 \% \mathrm{Cl})$ \\
\hline \multirow[t]{2}{*}{12 months } & 1 & 0.90 & 7.36 & 5.64 \\
\hline & & $(0.61-1.32)$ & $(5.67-9.55)$ & $(4.29-7.42)$ \\
\hline \multirow[t]{2}{*}{24 months } & 1 & 0.79 & 5.61 & 3.73 \\
\hline & & $(0.54-1.16)$ & $(4.11-7.66)$ & $(2.82-4.94)$ \\
\hline \multirow[t]{2}{*}{48 months } & 1 & 0.89 & 3.39 & 2.80 \\
\hline & & $(0.58-1.34)$ & $(2.23-5.14)$ & $(1.96-3.99)$ \\
\hline \multicolumn{5}{|c|}{ Prolonged fatigue at baseline as a predictor } \\
\hline & Neither condition & Pure fatigue & Pure burnout & Burnout \& fatigue \\
\hline & $O^{a}$ & $\mathrm{OR}^{\mathrm{c}}$ & $\mathrm{OR}^{\mathrm{c}}$ & $\mathrm{OR}^{\mathrm{c}}$ \\
\hline & $(95 \% \mathrm{Cl})$ & $(95 \% \mathrm{Cl})$ & $(95 \% \mathrm{Cl})$ & $(95 \% \mathrm{CI})$ \\
\hline \multirow[t]{2}{*}{12 months } & 1 & 5.89 & 0.92 & 5.27 \\
\hline & & $(4.83-7.17)$ & $(0.63-1.34)$ & $(4.13-6.72)$ \\
\hline \multirow[t]{2}{*}{24 months } & 1 & 5.06 & 1.14 & 4.76 \\
\hline & & $(4.09-6.27)$ & $(0.75-1.74)$ & $(3.72-6.11)$ \\
\hline \multirow[t]{2}{*}{48 months } & 1 & 4.09 & 1.12 & 4.64 \\
\hline & & $(3.13-5.35)$ & $(0.73-1.97)$ & $(3.44-6.25)$ \\
\hline
\end{tabular}

OR: odds ratio; Cl: confidence interval.

a Reference group

${ }^{b}$ OR adjusted for: CIS score, age, gender, education and absenteeism at baseline.

${ }^{c}$ OR adjusted for: exhaustion score, age, gender, education and absenteeism at baseline.

\section{Discussion}

\section{Main findings}

The results of the temporal relation analyses show that even after a rather conservative correction, burnout and prolonged fatigue significantly and substantially predict each other. Moreover, the association of prolonged fatigue as a predictor of burnout is a little stronger than vice versa. The attributive proportion of both prolonged fatigue as a predictor of burnout and burnout as a predictor of prolonged fatigue were noteworthy, although the former was higher than the latter. The results suggest that a dose response relationship exists between both the categories of subjective fatigue as a predictor of subsequent burnout and the categories of exhaustion as a predictor of subsequent prolonged fatigue. Finally, it was also found that compared to not being a prolonged fatigue case or burnout case at baseline, prolonged fatigue cases and burnout cases at baseline do not tend to switch and replace each other in time but rather they persist independently or merge together. 


\section{Considerations}

The Maastricht Cohort Study offers a unique sample frame to study the temporal relationship between burnout and prolonged fatigue due to the prospective design of the cohort and multiple repeated measurements. Moreover, burnout and prolonged fatigue were measured concurrently in the same participants, in addition to several factors which could be adjusted for in the analyses. However, the results should be interpreted in light of the following issues. Although this study deals with the temporal relationship between burnout and prolonged fatigue, caution is required in interpreting the results in terms of causality. Issues that should be considered in this respect are the time lag in this study and the unknown history of participants. The measurements that were used in this study had a minimum time lag of a year. Unfortunately, it is not known how burnout and prolonged fatigue affected each other during this time. Furthermore, although we speak of the onset of a prolonged fatigue or burnout case it is not exactly known if the onset is new (i.e. first ever episode) or if there have been many episodes preceding the start of the MCS. Despite this, we tried to be as strict as possible in the analyses by excluding cases at baseline and adjusting for baseline scores of the relevant clinical factors (i.e. exhaustion score and CIS total score). In the analyses, we adjusted for either the CIS total score or the MBI-GS exhaustion score depending on the direction of the relationship being investigated. We realise that in one case we adjust for the total construct (i.e. CIS total score) and in the other case for part of the construct (i.e. MBI-GS exhaustion score). However, as there is no total burnout score, as the three subscales cannot be added, we decided that the best alternative would be to adjust for the most central factor and the most conceptually similar factor to prolonged fatigue (which is part of the reason for adjusting) of the burnout construct (i.e. exhaustion).

\section{How do burnout and prolonged fatigue influence each other?}

As noted in the introduction, several mechanisms can be put forward on how burnout and prolonged fatigue could influence each other. It is evident from the results that the relationship is not one-directional, as burnout was found to predict prolonged fatigue and prolonged fatigue was found to predict burnout, although the hazard ratios and odds ratios of fatigue as a predictor of burnout were consistently a little stronger than vice versa. Moreover, the attributive proportions suggest that the influence that the conditions have on each other is considerable. It has been suggested that prolonged fatigue may be an early warning sign for burnout ${ }^{16}$, and although this may be true our results suggest that the reverse is also true.

Rather than a one-directional relationship, the results show a mutual influence between burnout and prolonged fatigue and tend to support the idea of a downward spiral. The mutual influence of burnout and prolonged fatigue increases as the core symptoms exhaustion and subjective fatigue increase. Moreover, it seems that the relationship 
between burnout and prolonged fatigue cannot be described as a vicious circle in the sense that they alternate and switch in time but rather that they become intertwined and merge together in the manner of a downward spiral. The fact that conditions tend to merge rather than alternate is seen in other studies on fatigue ${ }^{17,18}$. Moreover, previous studies found that the outcome and course of concurrent burnout and prolonged fatigue is worse than when prolonged fatigue and burnout occur separately ${ }^{2,9}$. As burnout and prolonged fatigue are similar with respect to fatigue symptoms, part of the overlap or co-occurrence between these conditions could be due to this similarity. However, the temporal relations remained after adjusting for exhaustion and the CIS total score with exhaustion being the main overlapping factor with the prolonged fatigue construct. Furthermore, previous studies suggest that, although there is of course a similarity, the fatigue symptoms in prolonged fatigue and burnout can be distinguished as separate entities ${ }^{2,4}$.

\section{Conclusion and implications}

Taken together the results show that burnout and prolonged fatigue influence each other in time and that they tend to merge together in time rather than replace each other. Cooccurrence tends to worsen outcome ${ }^{2,9}$, facilitating a downward spiral. These findings suggest the importance of recognising and correctly identifying fatigue complaints (burnout or prolonged fatigue) at an early stage, especially among employees, as, in theory, they run the risk of developing both burnout and prolonged fatigue. Moreover, intervening at this stage may help prevent burnout and prolonged fatigue from co-occurring which in turn may avert a worsening of outcome. It is important not to lose sight of the (work) context in this respect, as interventions could be aimed at both the individual and the work situation. In light of the above, some issues that require further research could be: determining the optimal time to intervene, finding a way to detect (mild) symptoms in employees, determining the nature and development of interventions aimed at burnout and prolonged fatigue occurring separately or simultaneously, and if the nature of the intervention for burnout and prolonged fatigue should be different, it is relevant to determine whether both conditions should be taken into account when intervening in only one condition.

\section{Acknowledgements}

This study was funded by the Occupational Health Epidemiology programme of the Research Institute Caphri, Maastricht University, The Netherlands. 


\section{References}

1 Schaufeli WB, Taris TW. The conceptualization and measurement of burnout: Common ground and worlds apart. Work and Stress 2005; 19: 256-62.

2 Leone SS, Huibers MJ, Knottnerus JA, Kant IJ. Similarities, overlap and differences between burnout and prolonged fatigue in the working population. Quarterly Journal of Medicine 2007; 100: 617-27.

3 Schaufeli WB, Enzman D. The burnout companion to study and practice: a critical analysis. London: Taylor \& Francis, 1998.

4 Sonnenschein M, Sorbi MJ, Doornen UPV, Schaufeli WB, Maas CJM. Electronic diary evidence on energy erosion in clinical burnout. Journal of Occupational Health Psychology 2007; 12: 402-13.

5 Glass DC, Mcknight JD. Perceived control, depressive symptomatology, and professional burnout: A review of the evidence. Psychology \& Health 1996; 11: 23-48.

6 Huibers MJ, Kant IJ, Knottnerus JA, Bleijenberg G, Swaen GM, KasI SV. Development of the chronic fatigue syndrome in severely fatigued employees: predictors of outcome in the Maastricht cohort study. Journal of Epidemiology and Community Health 2004; 58: 877-82.

7 Skapinakis $P$, Lewis $G$, Mavreas $V$. Temporal relations between unexplained fatigue and depression: longitudinal data from an international study in primary care. Psychosomatic Medicine 2004; 66: 330-5.

8 Huibers MJ, Leone SS, van Amelsvoort LG, Kant I, Knottnerus JA. Associations of fatigue and depression among fatigued employees over time: a 4-year follow-up study. Journal of Psychosomatic Research 2007; 63: 137-42.

9 Leone SS, Huibers MJ, Knottnerus JA, Kant I. A comparison of the course of burnout and prolonged fatigue: a 4-year prospective cohort study. Journal of Psychosomatic Research 2008; 65: 31-8.

10 Kant IJ, Bultmann U, Schroer KA, Beurskens AJ, Van Amelsvoort LG, Swaen GM. An epidemiological approach to study fatigue in the working population: the Maastricht Cohort Study. Occupational and Environmental Medicine 2003; 60 Suppl 1: i32-9.

11 Schaufeli WB, Leiter MP, Maslach C, Jackson SE. The Maslach Burnout Inventory- General Survey. In: Maslach C, Jackson SE, Leiter MP, eds. Maslach Burnout Inventory manual: 3rd Edition. Palo Alto, CA: Consulting Psychologists Press, 1996; 19-26.

12 Schaufeli WB, Van Dierendonk D. UBOS, Utrechtse Burnout Schaal, Handleiding. Lisse: Swets Test Publishers, 2000.

13 Vercoulen JHHM, Alberts M, Bleijenberg G. De Checklist Individuele Spankracht (CIS) [The Checklist Individual Strength (CIS)]. Gedragstherapie 1999; 32: 131-6.

14 Vercoulen JH, Swanink CM, Fennis JF, Galama JM, van der Meer JW, Bleijenberg G. Dimensional assessment of chronic fatigue syndrome. Journal of Psychosomatic Research 1994; 38: 383-92.

15 Bultmann $U$, de Vries M, Beurskens AJ, Bleijenberg G, Vercoulen JH, Kant I. Measurement of prolonged fatigue in the working population: determination of a cutoff point for the checklist individual strength. Journal of Occupational Health Psychology 2000; 5: 411-6.

16 Goldsmith E. Stress, fatigue, and social support in the work and family context. Journal of Loss \& Trauma 2007; 12: 155-69.

17 Van der Linden G, Chalder T, Hickie I, Koschera A, Sham P, Wessely S. Fatigue and psychiatric disorder: different or the same? Psychological Medicine 1999; 29: 863-8. 
18 Hickie I, Koschera A, Hadzi-Pavlovic D, Bennett B, Lloyd A. The temporal stability and comorbidity of prolonged fatigue: a longitudinal study in primary care. Psychological Medicine 1999; 29: 855-61. 
Discussion

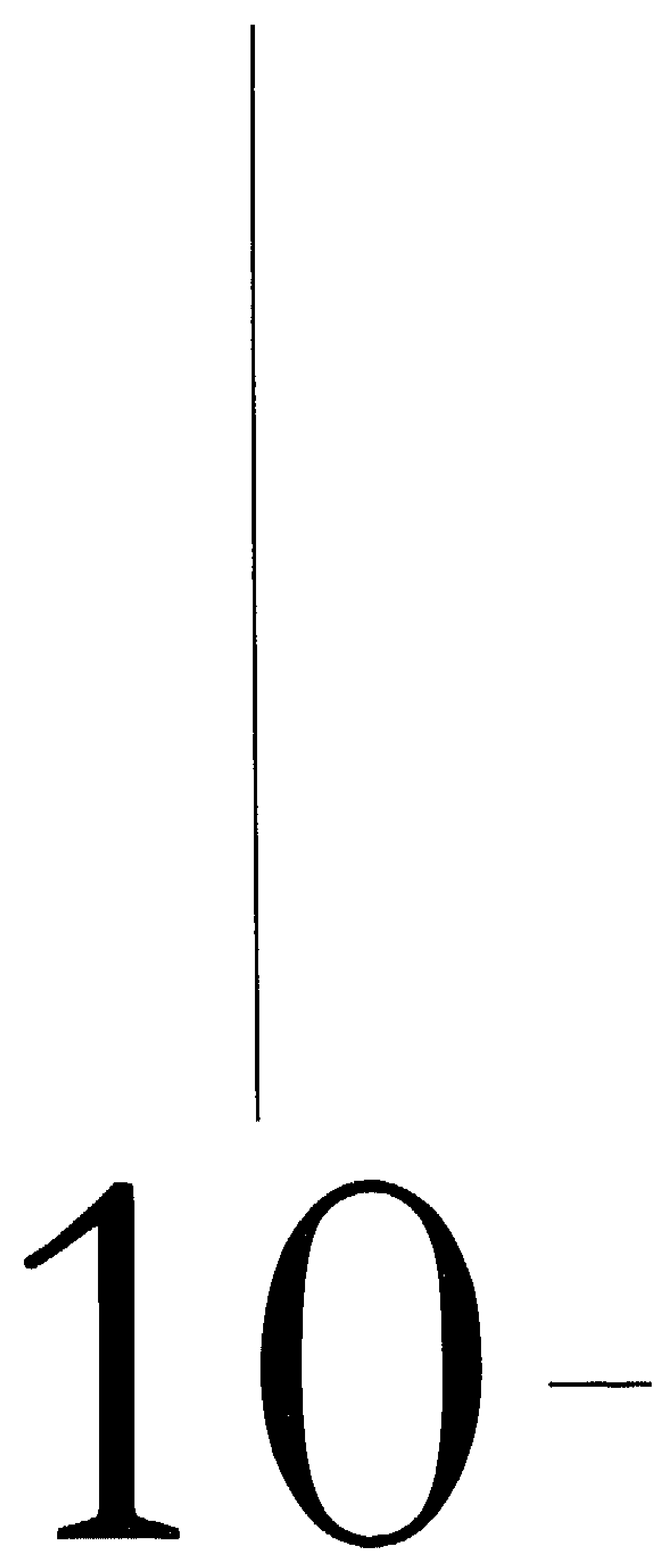




\section{Discussion}

The two main aims of this thesis were to gain insight into the course of fatigue in the working population and to compare and unravel different manifestations of fatigue in the working population. The aim of this chapter is to summarise and integrate the main findings of this thesis and to reflect on several methodological issues and the implications for practice and future research.

\section{Main findings}

The prognosis of fatigue among severely fatigued employees on sick leave was shown to be very poor as many employees were still severely fatigued after 4 years and many fulfilled criteria for CFS-like caseness (chapters 2 and 3). Physical functioning, or lack thereof, proved to be an important predictor of the persistence of fatigue complaints (chapter 2). Explanatory analyses showed that the relationship between physical functioning on the one hand, and work disability and CFS-like caseness on the other, was especially strong. The psychological intervention of the RCT did not prove to be effective in the long term, replicating earlier findings in the short term (chapter 3). Fulfilling criteria for CFS-like caseness also proved to be related to subsequently receiving a work disability benefit (chapter 4).

A historical and phenomenological comparison illustrated that the relationship between the fatigue conditions CFS and burnout is far from clear (chapter 5). Cultural factors, contextual factors, illness perceptions and accountability could be of importance to their relationship. A comparison of the measures of burnout and prolonged fatigue showed that they have a moderate discriminative ability (chapter 6 ). Notably, burnout and prolonged fatigue could occur separate from each other. Pure burnout cases (fulfilling criteria for burnout and not for prolonged fatigue) and pure fatigue cases (fulfilling criteria for prolonged fatigue and not for burnout) were identified. Burnout and prolonged fatigue also occurred simultaneously (burnout \& fatigue cases). Pure burnout was mainly characterised by unfavourable work factors, pure fatigue was mainly characterised by unfavourable health factors and burnout \& fatigue was characterised by both unfavourable work and health factors. Differences were found in the course of burnout and prolonged fatigue (chapter 7). Pure burnout seemed to have the most favourable course, whereas burnout $\&$ fatigue had the most unfavourable course. The course of burnout and prolonged fatigue was found to be very dynamic. Differences also emerged in the prognosis of burnout and prolonged fatigue with respect to work and health factors (chapter 8 ). Work factors were especially important in predicting recovery in the pure burnout group whereas health factors were more important in predicting recovery in the pure fatigue and burnout \& fatigue groups. The final study showed that burnout and prolonged fatigue could influence 
each other in time (chapter 9). Moreover, when they do influence each other, they tend to merge together in time rather than replace each other.

\section{Methodological considerations}

Prolonged fatigue and burnout: measurement, operationalisation and use.

Prolonged fatigue and burnout were measured with the Dutch versions of the $\mathrm{CIS}^{1}$ and the $\mathrm{MBI}-\mathrm{GS}^{2}$, which reflect a specific conceptualisation of prolonged fatigue and burnout. This needs to be considered when interpreting the results. Difficulties surrounding the conceptualisation and operationalisation of fatigue and burnout still remain, which is reflected in different definitions and measures for these constructs ${ }^{3,4}$. For example, the CIS operationalises fatigue as a multidimensional construct whereas others conceive fatigue to be a one-dimensional construct ${ }^{4}$. A specific conceptual issue with respect to burnout is the presumed work-related nature of this condition which remains a topic of debate ${ }^{3}$.

Although we used the CIS to measure fatigue across the studies in this thesis, it was used differently in studies using the trial sample and studies using the cohort sample. In the trial sample, the focus of study was specifically on the subjective fatigue component of the CIS (subjective fatigue) whereas the complete CIS (prolonged fatigue) was used in the cohort sample. When comparing these studies, it must be kept in mind that fatigue as measured in the cohort sample contains some different and additional information than the trial sample. However, from our own study (chapter 6 ) it became clear that employees classified as subjective fatigue cases or prolonged fatigue cases overlapped to a large extent, thus indicating that they are quite comparable.

Another measurement issue concerns the fact that burnout and prolonged fatigue scores were dichotomised, based on cut-off points, into cases (scoring above the cut-off) or non cases (scoring below the cut-off). Despite being fully aware that reality is much more complex than this and that continuous scores contain much more information, dichotomising was deemed to be an appropriate and useful (research) approach to the study aims which were to compare fatigue conditions (implying that a criterion must be chosen to define the condition) and to say something about the course of the conditions in terms of recovery, persistence and recurrence (implying that at some point the condition is thought to be present or absent).

\section{Sample selection and selective withdrawal}

The (initial) main aims of the RCT and the MCS differed, although they were both related to gaining insight into fatigue in the working population. The RCT aimed to assess the efficacy of a psychological intervention for severely fatigued employees on sick leave. It follows that a highly specific group of employees was selected to participate in this study. Although this selection was necessary and appropriate to the aim of the RCT, it has implications for the 
external validity of the trial sample findings of this thesis as the sample selection restricted the range of fatigue severity to quite severe fatigue in addition to including only employees on sick leave. The aim of the MCS was to examine various aspects of fatigue (e.g. aetiology, associations with other constructs, course etc.) in the general working population. The aim of the sample selection was therefore to include the broadest range of employees as possible which was also established in the MCS sample. Despite not achieving a fully representative sample, the MCS sample does cover most of the sectors of the Dutch workforce ${ }^{5}$.

Sample selection can also have implications for the internal validity, especially if there is selection bias at baseline. Unfortunately, this was not able to be discerned in the trial sample. In the cohort sample however, a non-response analysis at baseline revealed that responders to the baseline MCS questionnaire reported more fatigue complaints, more sickness absenteeism and more difficulty in work execution than non-responders ${ }^{6}$. This indicates the possibility of an overestimation of health problems at baseline ${ }^{7}$. A related issue and possible threat to the internal validity concerns selective withdrawal. The response rate of the trial sample at the long-term 4-year follow-up (which was the main focus of the studies in this thesis) was quite high at $84 \%$. A comparison between responders and non-responders at the 4-year follow-up revealed that responders were less fatigued and had higher levels of physical functioning at baseline which could have led to a underestimation of the health problems ${ }^{8}$. The same trend was found in the cohort sample as respondents at the different measurements tended to have more favourable characteristics at baseline than non-respondents which also could have led to a slight underestimation of health problems ${ }^{7,9}$.

In summary, the extent of the external validity differs between the two samples used in this study due to their original study aims. Moreover, aspects concerning the internal validity (i.e. selection bias and selective withdrawal) were examined and their effects seem to be reasonably under control. All in all, the samples were deemed suitable and relevant to use for the research aims of this thesis.

\section{Integration of research findings}

The focus will now turn to an integration of the research findings. The findings will be interpreted from three different, albeit related, perspectives. First, the results will be interpreted from the perspective of unravelling different fatigue conditions, and focuses in particular on the differences and similarities that were found between prolonged fatigue and burnout. Second, the results will be interpreted and integrated from the perspective of the course and (stages of) severity of fatigue complaints in the working population. And finally, the results will be interpreted from the perspective of work status. 


\section{Burnout and prolonged fatigue}

We started the journey of unravelling different fatigue conditions by considering the history and phenomenology of burnout and chronic fatigue syndrome (chapter 5). From this chapter it became apparent that little is known about differences and similarities between these conditions despite their similar history in fatigue. Moreover, it was found that cultural factors, illness perceptions and contextual factors may have an important role to play in the development and differentiation of these fatigue conditions.

From that point, we embarked on a more empirical journey to examine whether it is possible to distinguish between burnout and prolonged fatigue. Starting with principal component analysis (PCA) of the items of the Dutch versions of the CIS (prolonged fatigue) and the MBI-GS (burnout), it was found that these questionnaires were able to discriminate between burnout and prolonged fatigue (chapter 6). However, the PCA findings also showed that burnout and prolonged fatigue were related, especially with respect to their central symptoms exhaustion and subjective fatigue. The findings showed that exhaustion and subjective fatigue were quite similar which is in line with other research that found that they were highly correlated ${ }^{10,11}$. However, the PCA results also suggest that while very much related, subjective fatigue and exhaustion contain slightly different information which is in line with a recent study showing that exhaustion and (prolonged) fatigue contain different information possibly owing to the proposed more severe nature of exhaustion as compared to fatigue ${ }^{12}$. This slight difference could, however, also be an indication that context or possibly causal attributions may play a differential role in these conditions, as the primary difference in these items seems to be their reference to the work situation [e.g. I feel tired (CIS) and I feel tired when I get up in the morning and have to face another day on the job (MBI-GS)]. On the other hand, the CIS items tend to refer to the "physical" quite a lot (e.g. physically I feel exhausted) whereas this is not the case for the MBI-GS items.

A considerable amount of overlap was found between prolonged fatigue cases and burnout cases. More interestingly however, they could also occur separately from each other. What made this finding even more interesting is that it became clear that characteristics (chapter 6) and course (chapter 7) tended to be more favourable when burnout and prolonged fatigue occurred separately (i.e. pure burnout and pure fatigue, respectively) than when they occurred simultaneously (i.e. burnout \& fatigue). For example, the CIS score was much lower in the pure fatigue group (only fulfilling criteria for fatigue) as compared to the burnout \& fatigue group (fulfilling criteria for both conditions). Moreover, in the course of time, recovery was higher when burnout and prolonged fatigue occurred separately than when they co-occurred. For practical purposes, this indicates that preventing the cooccurrence of burnout and prolonged fatigue seems to be important. This implies, of course, that at some point in time burnout and prolonged fatigue can be distinguished and separated. This does seem to be the case, as there was a difference in the course of pure burnout and pure fatigue and different factors seemed to be associated with burnout and 
prolonged fatigue when they occurred separately. Examples of these findings are that the course of pure burnout was characterised by more recovery than pure fatigue (chapter 7). Moreover, work-related factors seemed to be particularly associated with pure burnout, and health-related factors with pure fatigue (chapters 6 and 8). Naturally, this could reflect a difference in the nature of these conditions, but it could also reflect a difference in the (contextual) attribution of (the same) fatigue complaints. As noted above, this attribution component is more or less embedded within the questions of the respective measures for burnout and prolonged fatigue (work-related fatigue versus physical/ health-related). Recently, Kristensen et al. suggested that the attribution of fatigue or exhaustion complaints to specific life domains is the key feature in distinguishing burnout (fatigue complaints attributed to work) from general fatigue (fatigue complaints that are present irrespective of the occupational status) ${ }^{13}$. The issue of attributing fatigue complaints to a specific psychological or somatic cause has received a lot of attention in the fatigue literature and attributions have been found to greatly influence the course of fatigue complaints ${ }^{14-17}$. However, the issue of "contextual" causal attribution as a distinguishing feature of different fatigue conditions is an interesting issue that deserves further research. The differential finding of work-related and health-related factors could prove to be a relevant practical lead to favourably influence the course of burnout and prolonged fatigue and also to prevent them from co-occurring. This practical implication becomes even more relevant considering the results of the final study of this thesis (chapter 9) which showed that burnout and prolonged fatigue can influence each other in time and when they do influence each other, they do not tend to switch and alternate in time but rather they tend to become intertwined and co-occur. Taking these findings together, it seems that burnout and prolonged fatigue can be separated at some point in time in terms of their characteristics, course and prognostic factors which suggests the importance of correctly identifying burnout and prolonged fatigue symptoms (i.e. differential diagnosis). Cooccurrence is associated with worse outcomes, thus underlining the relevance of not only correctly identifying burnout and prolonged fatigue symptoms, but also of recognising them at an early stage before they co-occur and focusing on factors that could influence the course of the prevailing condition. In this instance, "early stage" refers to the severity of fatigue complaints. In the introduction it was noted that the severity of complaints is an important factor to consider when studying the course of a condition which also became clear in this thesis as will now be discussed in further detail.

\section{Severity of complaints}

In this paragraph, the results will be interpreted and integrated from the perspective of the other aim of this thesis which was to examine the course and (stages of) severity of fatigue complaints in the working population.

If anything, the results of this thesis show that the course and prognosis of fatigued employees is particularly poor when the fatigue complaints have become severe. Across 
the studies in this thesis, it became evident that severe complaints tend to persist (chapters 2, 3 and 7), become difficult to treat (chapter 3) and become (more) associated with sickness absenteeism (chapters 6 and 7) or even predictive of work disability (chapter 4).

Perhaps not surprisingly, when symptoms tended towards the severe end of the continuum, they were associated with an unfavourable course. This is in line with other research on burnout and fatigue symptoms which suggest that more severe symptoms are associated with a more unfavourable, persistent course ${ }^{15,18,19}$.

A complicating factor in the course of severe complaints is that they tend to become inextricably linked with the co-occurrence of other (fatigue) conditions. For example, when burnout and prolonged fatigue co-occurred, the symptoms of the individual conditions were much more severe than when they occurred separately (chapters 6, 7 and 8). Moreover, most of the health and work-related factors were more unfavourable when burnout and prolonged fatigue co-occurred compared to when they occurred separately (chapter 6). The finding that burnout and prolonged fatigue co-occur when symptoms become more severe is consistent with research that found that severe burnout and/ or fatigue complaints become intertwined with other complaints such as psychological distress and depression ${ }^{20-23}$. This finding underlined the rationale, as outlined in the introduction of this thesis, for comparing (mild) burnout and prolonged fatigue as opposed to severe clinical burnout and CFS. In contrast to mild symptoms, severe burnout and prolonged fatigue symptoms are complicated by co-occurrence which makes it difficult to distinguish and examine them. This temporal issue in severity and co-occurrence of burnout and prolonged fatigue symptoms is an interesting and relevant finding of our studies, with possible implications for treatment and intervention, which probably would not have been found if we had focused on severe clinical burnout and CFS.

An interesting finding with respect to the severity of burnout symptoms is that the context, which is an important feature of burnout (i.e. work-related) ${ }^{3,24}$, seems to take a backseat when symptoms become severe. In chapter 6, for example, the pure burnout group distinguishes itself from the pure fatigue group with respect to mainly the work factors, but when burnout co-occurs with prolonged fatigue it is primarily the health factors that become notably more unfavourable. Moreover, in chapter 8 work-related factors were important prognostic factors when burnout was relatively mild and occurred alone whereas they were not very important prognostic factors when burnout symptoms were relatively severe and co-occurred with prolonged fatigue. These findings could imply that the context or work-related nature of burnout is especially important when symptoms are relatively mild and uncomplicated. At this point in the course of burnout, the complaints are still (perceived to be) work-related and therefore targeting work-related factors could help alleviate symptoms. However, when burnout becomes more severe, it seems that the complaints are not necessarily confined to the work domain, become complicated by cooccurrence, and affect general wellbeing. In other words, the specific work-related fatigue symptoms of burnout move into the realm of non-specific general fatigue symptoms. At 
this stage in the course of burnout, it does not seem useful to target work-related factors as the results suggest that they become less important than health (perception)-related factors such as perceived general health.

\section{Work status}

Work status is an important factor when studying fatigue complaints among employees. Across our studies work status has been defined in different ways (i.e. sickness absenteeism, work disability and active work status) and has been used in different capacities (i.e. as a confounder, prognostic factor or an outcome). The results showed that work status as an outcome (both in terms of sickness absenteeism and work disability) was a big problem with respect to, especially, severe fatigue complaints. Work disability was very high in the trial sample after 4 years of follow-up. Moreover, the association between CFS-like caseness at baseline and work disability 4 years later was very high. In the cohort it was found that in the course of time, absenteeism was highest in the group with the most severe fatigue complaints (i.e. the burnout \& fatigue group). It has been noted that return to work is more difficult for employees who are absent due to psychological complaints ${ }^{25}$ such as burnout and prolonged fatigue. On the hand, work resumption is generaliy deemed to be beneficial to the recovery of so-called "overstrain" complaints including burnout ${ }^{26}$. When symptoms are severe, tackling the complex issue of absenteeism and return to work becomes even more complicated by the points raised in the previous paragraph (i.e. cooccurrence and worse outcomes). Moreover, in conditions such as burnout, work resumption could also be complicated by the fact that work is thought to be the cause of the condition ${ }^{27}$. Preventing absenteeism therefore seems to be crucial. One possibility to accomplish this may be to intervene at an early stage in the development of fatigue complaints, as absenteeism is not as high when complaints are mild as compared to when complaints are severe (chapters 6 and 7).

Although work status was not the main focus of this thesis, the role of sickness absenteeism in the prognosis of fatigue complaints did receive attention. Unfortunately, it was not possible to examine work status as a prognostic factor in the trial sample as all participants were on sick leave at baseline. In the cohort sample, sickness absenteeism did not prove to be a specific prognostic factor for recovery from or persistence of (different) fatigue complaints (chapter 8). Despite this (lack of a) finding, the role of work status in the course of (different) fatigue complaints remains an interesting and relevant topic which needs to be looked at in more detail in future research.

\section{Conclusions}

It can be concluded from the interpretation of the results from the perspective of unravelling different fatigue conditions that burnout and prolonged fatigue can be separated at some point in time in terms of characteristics, course and prognosis which implies that correct identification of the fatigue conditions is relevant. For example, health- 
related factors were particularly associated with (mild) prolonged fatigue whereas workrelated factors were particularly associated with (mild) burnout. In addition, it was concluded that the co-occurrence of burnout and prolonged fatigue was associated with more unfavourable outcomes which points to the importance of the stage or severity of the conditions when studying the course of fatigue.

Interpreting the findings from the perspective of the severity complaints adds to these conclusions that severe complaints have a poor prognosis and are very persistent. Severe complaints also tend to become inextricably linked to co-occurrence, especially with respect to burnout and prolonged fatigue which could make intervention difficult and complicated. Moreover, the focus of intervention may have to be different for different stages of severity of the same condition as the results showed that work factors were important in the prognosis of mild burnout complaints, but as burnout became severe and co-occurred, work-factors did not seem to be as important.

Finally, from the point of view of work status, the results indicate that severe complaints are associated with more absenteeism and work disability. As absenteeism was not as prevalent when complaints were mild, preventing mild complaints from becoming severe may also have a beneficial influence on work status. Moreover, sickness absenteeism was not found to be a specific prognostic factor in the course of fatigue complaints, but further research may help to shed some more light on this relationship.

\section{Looking towards the future}

\section{Practical leads}

The severity of symptoms is an important issue to focus on as burnout and prolonged fatigue tended to occur separately when symptoms were mild and co-occurred when symptoms became severe. As noted above, the finding that burnout and prolonged fatigue can occur separately suggests the practical implication that a differential diagnosis may be relevant, especially as the prognostic factors associated with (mild) burnout and (mild) prolonged fatigue differ. This in turn implies that a different approach or perspective is needed for each diagnosis. In this respect, research is needed to examine intervention possibilities in terms of their nature (e.g. individual, group, organisational, behavioural, cognitive or physical) and focus (e.g. health-related or work-related) for mild burnout and prolonged fatigue in addition to determining their efficacy.

The timing of intervention is a particularly relevant issue when considering the finding that co-occurrence is associated with severe symptoms and with a worse outcome. Thus, preventing mild symptoms from progressing to severe symptoms by means of intervention is important. Besides influencing the actual symptoms or complaints, this approach may also influence sickness absenteeism which was found to be more prevalent as symptoms became more severe. Examining how to screen and detect mild symptoms within, for example, an organisation and determining the most optimal time to intervene may provide 
valuable information to achieve this goal. Moreover, gaining insight into which factors actually determine whether mild symptoms progress to severe symptoms is also relevant in this respect. Finally, due to the poor outcomes associated with severe (fatigue) complaints, interventions aimed at these symptoms may need to be more rigorous as compared to mild complaints and focus on unravelling and targeting different sets of symptoms as severity and co-occurrence seem to go hand in hand.

\section{Culture, labelling and illness perceptions}

The findings of chapter 5 of this thesis offer an interesting path to follow in future research. The findings imply that cultural factors along with labelling and illness attributions could be important in shaping the differences between CFS and burnout. The current thesis provides a first step in unravelling different fatigue conditions as prolonged fatigue and burnout were measured in one and the same sample along with various factors that could be associated with them. An important finding was that context played a differential role in the relationship between burnout and prolonged fatigue. However, in this thesis "context" was limited to work-relatedness. Context can also be seen in broader terms and include the impact that a culture or country has on illness. As the studies of this thesis were all conducted within one country and thus one context, it is nearly impossible to examine the role of culture as there is no contrast in this factor. In this respect, a cross-national comparison may provide the solution. Attention could be paid to questions such as: How do different occupational health care systems influence the development, acknowledgement and treatment of symptoms? How acceptable are psychological or somatic labels in a particular culture? Do the same symptoms get labelled differentiy across countries?

With respect to the role of labelling and illness perceptions in differentiating between fatigue conditions, it would be interesting to examine the effect of labelling fatigue symptoms as "burnout" or "CFS" by healthcare professionals or by the employees themselves (do they believe they have burnout or CFS? Does this correspond to the professional's opinion?).

Focusing on these issues in future research could provide valuable information and further our understanding of the relationship between seemingly different fatigue conditions.

\section{A final note}

Since modern interest in fatigue began in the 19th century, many researchers have explored and tried to explain the complex phenomenon of fatigue. As this discussion has shown, there are still many roads left to explore and many questions that need answering, but hopefully our results contribute a little to our understanding of fatigue. 


\section{References}

1 Vercoulen JHHM, Alberts M, Bleijenberg G. De Checklist Individuele Spankracht (CIS) [The Checklist Individual Strength (CIS)]. Gedragstherapie 1999; 32: 131-6.

2 Schaufeli WB, Van Dierendonk D. UBOS, Utrechtse Burnout Schaal, Handleiding. Lisse: Swets Test Publishers, 2000.

3 Schaufeli WB, Taris TW. The conceptualization and measurement of burnout: Common ground and worlds apart. Work and Stress 2005; 19: 256-62.

4 Dittner AJ, Wessely SC, Brown RG. The assessment of fatigue: a practical guide for clinicians and researchers. Journal of Psychosomatic Research 2004; 56: 157-70.

5 Kant IJ, Bultmann U, Schroer KA, Beurskens AJ, Van Amelsvoort LG, Swaen GM. An epidemiological approach to study fatigue in the working population: the Maastricht Cohort Study. Occupational and Environmental Medicine 2003; 60 Suppl 1: i32-9.

6 Janssen $N$. The natural course of fatigue in a working population. Maastricht: Maastricht University Press, 2004.

7 Mohren D, Jansen N, Van Amelsvoort L, Kant I. An epidemiological approach of fatigue and work. Experiences from the Maastricht Cohort Study. Maastricht: Programma Epidemiologie van Arbeid en Gezondheid, 2007.

8 Leone SS, Huibers MJ, Kant I, van Amelsvoort LG, van Schayck CP, Bleijenberg G, Knottnerus JA. Long-term efficacy of cognitive-behavioral therapy by general practitioners for fatigue: a 4-year follow-up study. Journal of Psychosomatic Research 2006; 61: 601-7.

9 Leone S5, Huibers MJ, Knottnerus JA, Kant I. A comparison of the course of burnout and prolonged fatigue: a 4-year prospective cohort study. Journal of Psychosomatic Research 2008; 65: 31-8.

10 Michielsen HJ, De Vries J, Van Heck GL, Van de Vijver FJR, Sijtsma K. Examination of the dimensionality of fatigue - The Construction of the Fatigue Assessment Scale (FAS). European Journal of Psychological Assessment 2004; 20: 39-48.

11 De Vries J, Michielsen HJ, Van Heck GL. Assessment of fatigue among working people: a comparison of six questionnaires. Occupational and Environmental Medicine 2003; 60 Suppl 1: i10-5.

12 Sonnenschein $M$, Sorbi MJ, Doornen LPV, Schaufeli WB, Maas CJM. Electronic diary evidence on energy erosion in clinical burnout. Journal of Occupational Health Psychology 2007; 12: 402-13.

13 Kristensen TS, Borritz M, Villadsen E, Christensen KB. The Copenhagen Burnout Inventory: A new tool for the assessment of burnout. Work and Stress 2005; 19: 192-207.

14 Prins JB, van der Meer JW, Bleijenberg G. Chronic fatigue syndrome. Lancet 2006; 367: 34655.

15 Cairns $R$, Hotopf $M$. A systematic review describing the prognosis of chronic fatigue syndrome. Occupational Medicine 2005; 55: 20-31.

16 Afari N, Buchwald D. Chronic fatigue syndrome: A review. American Journal of Psychiatry 2003; 160: 221-36.

17 Joyce J, Hotopf $M$, Wessely $S$. The prognosis of chronic fatigue and chronic fatigue syndrome: a systematic review. Quarterly Journal of Medicine 1997; 90: 223-33.

18 Taris T, Schaufeli W, Schreurs PJ, Caljé D. Opgebrand in het onderwijs: stress, psychische vermoeidheid en ziekteverzuim onder leraren [Burnout in education: stress, psychological fatigue and sickness absence among teachers]. In: Houtman I, Schaufeli WB, Taris TW, eds. 
Psychische vermoeidheid en werk: cijfers, trends en analyses. Alphen aan den Rijn: NWo/Samson, 2000; 97-106.

19 Skapinakis $P$, Lewis $G$, Mavreas V. One-year outcome of unexplained fatigue syndromes in primary care: results from an international study. Psychological Medicine 2003; 33: 857-66.

20 Schaufeli WB, Van Dierendonck D. Burnout, een begrip gemeten. De Nederlandse versie van de Maslach Burnout Inventory (MBI-NL). / Burnout--The measurement of a concept: The Dutch version of the Maslach Burnout Inventory (MBI--NL). Gedrag and Gezondheid Tijdschrift voor Psychologie en Gezondheid 1994; 22: 153-72

21 Ahola K, Honkonen T, Isometsa E, Kalimo R, Nykyri E, Aromaa A, Lonnqvist J. The relationship between job-related burnout and depressive disorders-results from the Finnish Health 2000 Study. Journal of Affective Disorders 2005; 88: 55-62.

22 Pawlikowska T, Chalder T, Hirsch SR, Wallace P, Wright DJ, Wessely SC. Population based study of fatigue and psychological distress. British Medical Journal 1994; 308: 763-6.

23 Bultmann U, Kant I, Kasl SV, Beurskens AJ, van den Brandt PA. Fatigue and psychological distress in the working population: psychometrics, prevalence, and correlates. Journal of Psychosomatic Research 2002; 52: 445-52.

24 Schaufeli WB, Enzman D. The burnout companion to study and practice: a critical analysis. London: Taylor \& Francis, 1998.

25 Zijlstra F, De Vries J. Burnout en de bijdrage van socio-demografische en werkgebonden variabelen [burnout and the contribution of socio-demograpic and work-related factors]. In: Houtman I, Schaufeli WB, Taris TW, eds. Psychische vermoeidheid en werk: cijfers, trends en analyses. Alphen aan den Rijn: NWO/Samson, 2000; 83-95.

26 Health council of the Netherlands. Verzekeringsgeneeskundige protocollen: algemene inleiding, overspanning, depressieve stoornis [Protocols for social insurance physicians: general introduction, adjustment disorder, depressive disorder]. Den Haag: Health council of the Netherlands, 2006.

27 Schaufeli W. Past performance and future perspectives of burnout research. South African Journal of Industrial Psychology 2003; 29: 1-15. 


\section{Summary}

Fatigue is an important health problem in the working population and has been linked to sickness absence and work disability. Moreover, fatigue is a complex phenomenon which can manifest itself in different ways. Relatively little is known about the course of (different manifestations of) fatigue in the working population, despite the implications this information may have for intervention and prevention. This thesis consists of several studies which examine the course of fatigue and the relationship between different manifestations of fatigue.

The introduction (chapter 1) describes the rationale, the aims, and the studies of this thesis. Moreover, a short description was given of the two study samples that will be used in the studies of the thesis. The first sample, the RCT sample, consist of 151 fatigued employees on sick leave who took part in a randomised controlled trial which aimed to examine the efficacy of a psychological intervention, delivered by general practitioners, for fatigue. The second sample, the cohort sample, consist of 12,140 employees (who were not necessarily fatigued) from 45 different companies and organisations who took part in a prospective cohort study which aimed to examine fatigue in the working population.

To treat fatigue effectively, insight into factors associated with outcome is necessary. Moreover, relatively little attention has been paid to occupational outcomes in prognostic studies on fatigue, despite persistent fatigue being strongly associated with functional status and being able to lead to absenteeism and work disability. In light of this, chapter 2 describes the results of a study examining long-term predictors of fatigue status, chronic fatigue syndrome-like caseness (meeting research criteria for chronic fatigue syndrome; CFS-like caseness) and work disability in the RCT sample. The participants were followed-up at approximately 4 years after baseline and 127 of the original 151 participants took part in this long-term follow-up (response rate $84 \%$ ). After 4 years, $57 \%$ of the participants still were severely fatigued, $27 \%$ met criteria for CFS-like caseness, and $26 \%$ reported they received work disability benefits. Using logistic regression model, baseline predictors of outcome at 4 years' follow-up were determined. Predictors of fatigue at the 4-year followup were: a lower level of physical functioning at baseline, lower levels of psychological attribution at baseline and a change towards a lower level of physical functioning between baseline and the 12-month follow-up. Predictors of CFS-like caseness were: female gender, a lower level of physical functioning at baseline, and a change towards a lower level of physical functioning between baseline and the 12-month follow-up. Predictors of work disability were: an older age at baseline, a lower level of physical functioning at baseline, and a change towards a lower level of physical functioning between baseline and the 12month follow-up. Physical (dys-)functioning proved to be an important and consistent predictor. Additional explanatory analyses showed that the relationship between physical 
functioning on the one hand, and work disability and CFS-like caseness on the other, was especially strong. This study suggests that physical functioning is an important prognostic factor in the course of fatigue complaints and work disability in severely fatigued employees on sick leave. It is concluded that exploring temporal relationships between fatigue, functional status and work status in future research could provide valuable information for the improvement of fatigue management.

The long-term efficacy of cognitive-behavioural therapy (CBT) delivered by general practitioners (GPs) for fatigue is examined in chapter 3. We hypothesised that the intervention can possibly prevent further deterioration and relapse of fatigue complaints as well as relapse into long-term sickness absence. At the 4-year follow-up, the CBT group consisted of 65 patients (11 patients lost-to-follow-up) and the control group consisted of 62 patients (13 patients lost-to-follow-up). Fatigue complaints were still quite severe in both groups at the 4-year follow-up. Moreover, sickness absence and work incapacity was high. Mixed linear regression models showed that there was no significant difference in the decrease of fatigue scores between the groups. Causal attributions, specifically weak somatic attributions and strong psychological attributions seem to be related to a reduction in fatigue complaints. Notably there was more sickness absenteeism and work incapacity in the CBT group compared to the control group although this difference failed to reach statistical significance. The results show that the condition of the patients in this trial is more serious than previously thought. A possible explanation for the inefficacy of the CBT in this trial could be that the delivery and intensity (five to seven 30-minute sessions) of the intervention by the GPs did not match the severity of the complaints.

Chapter 4 elaborates on the theme of fatigue and occupational outcome by addressing whether CFS-like caseness predicts future work status. Using the RCT sample and logistic regression analysis, it was found that a CFS-like status at baseline is predictive of an inactive work status (including sick leave, work incapacity, unemployment and retirement) and of full work incapacity at the 4-year follow-up (after adjustment of confounders). However, after adjusting for physical functioning in the regression models, the associations lost their statistical significance. CFS-like caseness was found to be an important predictor of work status, but it seems that the physical (dys) functioning component is an important factor to focus on in this relationship. In line with the findings of chapter 3 , this study underlines the need for powerful (early) interventions that restore or preserve the ability to work in chronic fatigue, especially for employees who meet criteria for CFS.

In chapter 5 the relationship between two fatigue syndromes, burnout and chronic fatigue syndrome (CFS), is explored by examining their history and phenomenology by means of a narrative review based on literature from the fields of history, social science and medicine was. Burnout and CFS appear to have developed largely independently of each other, 
despite their symptoms being similar. The origins of CFS lie within medicine, whereas burnout developed in a psychological setting. As well as symptoms, burnout and CFS also share similar themes such as an overload process triggering illness onset, the need for restoration of depleted energy, external causal attributions and the characteristics of people suffering from these illnesses. However, these themes were found to be expressed in either psychological or medical terms according to their respective historical backgrounds. The findings of this study showed that the two concepts have hardly been directly compared despite their similarities. Culture, illness perceptions and accountability are important issues in both conditions and could contribute to their differences. Comparing burnout and CFS within one sample frame in future research could be a useful first step towards further understanding their relationship.

The main focus of chapters $6,7,8$, and 9 is to try to empirically unravel the relationship between burnout and prolonged fatigue, using the Maastricht Cohort Study on Fatigue at Work (MCS), as they have hardly been compared empirically, despite several similarities such as the importance of fatigue symptoms in both conditions.

The aim of the study presented in chapter 6 is twofold: 1) to assess the ability of the Checklist Individual Strength (CIS) as a measure of fatigue and the Maslach Burnout Inventory-General survey (MBI-GS) as measure of burnout to discriminate between these conditions, and 2) to examine the overlap, similarities and differences between burnout and prolonged fatigue cases in terms of health, work and demographic factors. All analyses were performed on the baseline data of the MCS.

A comparison of the measures of burnout and prolonged fatigue, using principal component analysis, showed that they have a moderate discriminative ability. Prolonged fatigue and burnout cases overlapped considerably, $63 \%$ of the burnout cases could also be classified as prolonged fatigue cases, and $51 \%$ of the prolonged fatigue cases could also be classified as burnout cases. Furthermore, the overlap between burnout and prolonged fatigue on the one hand and their main symptoms exhaustion and subjective fatigue was also quite considerable.

However, the results also showed that burnout and prolonged fatigue could occur separate from each other. Subgroups were then formed based on burnout and prolonged fatigue status at baseline: pure burnout (fulfilling criteria for burnout and not for prolonged fatigue), pure fatigue (fulfilling criteria for prolonged fatigue and not for burnout), burnout \& fatigue (fulfilling criteria for both prolonged fatigue and burnout), and neither burnout nor fatigue (fulfilling criteria for neither prolonged fatigue nor burnout). The results showed that having both conditions simultaneously seems to be associated with worse outcomes than having either prolonged fatigue or burnout separately, particularly in terms of healthrelated factors such as psychological distress and self-reported general health. Pure fatigue seems to be more associated with health-related factors whereas pure burnout seems to 
be more associated with work-related factors. This study suggests there are some relevant differences between burnout and fatigue with respect to work and health factors, and that burnout and fatigue can occur both separately as well as simultaneously.

The course of burnout and prolonged fatigue in terms of complaints and absenteeism is examined in chapter 7. For this study the baseline measurement and the 12-, 24- and 48month follow-up measurements of the MCS were used as burnout was only assessed at these four measurements. Participants who had data on burnout and prolonged fatigue at all four measurements were included in this study. This was necessary to determine the course type. Participants were divided into three subgroups: "pure fatigue" ( $n=485)$, "pure burnout" ( $n=296)$ and "burnout \& fatigue" ( $n=426$ ). Moreover, four course types were defined in each subgroup: chronic, recovery, recurrence, and double recovery. The results indicate that the burnout \& fatigue group had the highest proportion $(29 \%)$ of the chronic course type compared to the pure burnout $(2 \%)$ and pure fatigue $(9 \%)$ groups in addition to more absenteeism over time compared to the pure fatigue group. Recovery from all conditions was highest in the pure burnout group (40\%) compared to the pure fatigue group $(29 \%)$ and the burnout \& fatigue group (13\%). The findings also indicate that the course of burnout and prolonged fatigue is characterised by its dynamic nature. This study shows that the course of the burnout \& fatigue group is rather poor compared to the pure burnout and pure fatigue groups, in terms of both the persistence of burnout and fatigue symptoms and the prevalence of absenteeism in the course of time. Moreover, the course of pure burnout seems to be slightly more favourable than that of pure fatigue due to the high percentage of recovery in the former group. These results suggest that the differential diagnosis of employees presenting with fatigue complaints could be important in estimating the outcome of the complaints and the need for therapy.

In chapter 8, prognostic factors for recovery from burnout and prolonged fatigue are examined. Baseline, 12-, 24- and 48-month follow-up data from the Maastricht Cohort Study were used and 2356 employees fulfilling criteria for prolonged fatigue and/or burnout at baseline could be included in this study. They were divided into three subgroups: "pure fatigue", "pure burnout" and "burnout \& fatigue". Using logistic generalised estimating equation analysis, baseline predictors of recovery, including (mental) health, work and demographic factors were determined. Four prognostic models were determined: recovery from fatigue caseness in the pure fatigue group, recovery from burnout caseness in the pure burnout group, recovery from at least one condition ( burnout or fatigue) in the burnout \& fatigue group and finally, recovery from both conditions (burnout and fatigue) in the burnout \& fatigue group. The results showed that recovery from fatigue in the pure fatigue group was predicted by: low fatigue, low exhaustion, high co-worker support and lack of an unknown fatigue attribution. Recovery from burnout in the pure burnout group was predicted by: low exhaustion, high 
professional efficacy, absence of conflicts with colleagues, doing day work, and having enough leisure time. Recovery from at least one condition (burnout or fatigue) in the burnout \& fatigue group was predicted by: low fatigue, low exhaustion, high professional efficacy and a good perceived general health whereas recovery from both burnout and prolonged fatigue (i.e. both conditions) was predicted by: low fatigue, low exhaustion, more career opportunities and a good perceived general health. The results suggest that differentiating between burnout and prolonged fatigue is useful as the focus of intervention for these conditions should be different. Specifically, work factors seem to be more important in the prognosis of burnout (depending on timing as work factors were more important in the pure burnout group, when symptom are less severe, than in the burnout \& fatigue group, when symptoms are more severe) whereas health-related factors seem to be more important in the prognosis of prolonged fatigue.

If and how burnout and prolonged fatigue influence each other in time (i.e. their temporal relationship), is examined in chapter 9 . This study has three aims: to examine if 1) burnout and prolonged fatigue predict each other in time, 2) if there is a dose-response relationship and 3 ) if they tend to alternate or merge together in time. Four-year prospective follow-up data from the MCS were used for this study. After selection, 11,710 participants could be included. Burnout at baseline was shown to be associated with an increased risk of subsequent prolonged fatigue (hazard ratio (HR) 1.33, 95\% confidence interval (Cl) 1.16 1.53) and prolonged fatigue was shown to be associated with an increased risk of subsequent burnout (HR 1.65, 95\% Cl 1.44-1.89). There also seemed to be evidence of a (bidirectional) dose-response relationship as the risk for developing burnout increased as baseline levels of subjective fatigue (main symptom of prolonged fatigue) increased, and the risk for developing prolonged fatigue increased as baseline levels of exhaustion (main symptom of burnout) increased. Finally, it was found that when burnout and prolonged fatigue influence each other, they tend to merge rather than replace each other. The findings seem to indicate that burnout and prolonged fatigue influence each other in the manner of a downward spiral. Therefore, recognising and correctly identifying fatigue complaints at an early stage seems important, as early intervention could prevent the conditions from co-occurring and avert a worsening of outcome.

In chapter 10, the discussion, the main aims are to summarise and integrate the main findings of this thesis and to reflect on several methodological issues and the implications for practice and future research. The findings are interpreted from three different, albeit related, perspectives. It can be concluded from the interpretation of the results from the perspective of unravelling different fatigue conditions that burnout and prolonged fatigue can be separated at some point in time in terms of characteristics, course and prognosis, which implies that correct identification of the fatigue conditions is relevant. For example, health-related factors were particularly associated with (mild) prolonged fatigue whereas 
work-related factors were particularly associated with (mild) burnout. In addition, it can be concluded that the co-occurrence of burnout and prolonged fatigue was associated with more unfavourable outcomes which points to the importance of the stage or severity of the conditions when studying the course of fatigue. Interpreting the findings from the perspective of the severity complaints adds to these conclusions that severe complaints have a poor prognosis and are very persistent. Severe complaints also tend to become inextricably linked to co-occurrence, especially with respect to burnout and prolonged fatigue which could make intervention difficult and complicated. Moreover, the focus of intervention may have to be different for different stages of severity of the same condition as the results showed that work factors were important in the prognosis of mild burnout complaints, but as burnout became severe and co-occurred, work-factors did not seem to be as important. Finally, from the point of view of work status, the results indicate that severe complaints are associated with more absenteeism and work disability. As absenteeism was not as prevalent when complaints were mild, preventing mild complaints from becoming severe may also have a beneficial influence on work status. Moreover, sickness absenteeism was not found to be a specific prognostic factor in the course of fatigue complaints, but further research may help to shed some more light on this relationship. Chapter 10 concludes with some practical implications and propositions for future research. For example, the findings suggest that the nature of interventions should be different for different subgroups of burnout and prolonged fatigue, and that the timing of intervention is a particularly relevant issue when considering the finding that cooccurrence is associated with severe symptoms and with a worse outcome. It also argued that the findings of chapter 5 of this thesis, on the history and phenomenology of burnout and CFS, offer an interesting path to follow in future research, especially as culture cultural factors along with labelling and illness attributions could be important in shaping the differences between CFS and burnout. This raises questions such as: How do different occupational health care systems influence the development, acknowledgement and treatment of symptoms? How acceptable are psychological or somatic labels in a particular culture? Do the same symptoms get labelled differently across countries?

In the final note, we conclude that there are still many roads left to explore and many questions that need answering, but hopefully our results contribute a little to our understanding of fatigue. 


\section{Samenvatting}

Vermoeidheid is een belangrijk gezondheidsprobleem in de werkende populatie en is geassocieerd met verzuim en arbeidsongeschiktheid. Bovendien is vermoeidheid een complex fenomeen dat zich op verschillende manieren kan uiten. Er is relatief weinig bekend over het beloop van (verschillende uitingen van) vermoeidheid in de werkende populatie, ondanks de implicaties die deze informatie kan hebben voor interventie en preventie. Dit proefschrift bestaat uit een aantal studies die het beloop van vermoeidheid en de relatie tussen verschillende uitingen van vermoeidheid bestuderen.

De introductie (hoofdstuk 1) beschrijft de rationale, de doelstellingen en de studies van dit proefschrift. Bovendien wordt er een korte omschrijving gegeven van de twee studiepopulaties die gebruikt zullen worden in de studies van dit proefschrift. De eerste studiepopulatie, de RCT populatie, bestaat uit 151 vermoeide en verzuimende werknemers die deelnamen aan een gerandomiseerd experiment (een RCT). Dit experiment had als doel de effectiviteit van een psychologische interventie voor vermoeidheid, gegeven door huisartsen, te onderzoeken. De tweede populatie, de cohort populatie, bestaat uit 12,140 werknemers (die niet per se vermoeid waren) afkomstig van 45 verschillende bedrijven en organisaties die deelnamen aan een prospectieve cohort onderzoek dat tot doel had vermoeidheid in de werkende populatie te bestuderen.

Om vermoeidheid effectief te kunnen behandelen, is het noodzakelijk om inzicht te krijgen in prognostische factoren. In de bestaande studies is bovendien relatief weinig aandacht besteed aan werkgerelateerde uitkomsten in prognostische studies naar vermoeidheid, ondanks de sterke associatie tussen aanhoudende vermoeidheid en fysiek functioneren en het feit dat vermoeidheid kan leiden tot ziekteverzuim en arbeidsongeschiktheid. In het licht van het voorgaande beschrijft hoofdstuk 2 de resultaten van een studie waarin lange termijn voorspellers van vermoeidheidsstatus, een chronisch vermoeidheid syndroomgelijkende status (voldoen aan onderzoekscriteria voor het chronische vermoeidheidssyndroom: CVS-gelijkende status) en arbeidsongeschiktheid. Hierbij wordt gebruik gemaakt van de RCT populatie. De deelnemers zijn ongeveer 4 jaar na het beginpunt van de studie (baseline) opgevolgd en 127 van de oorspronkelijke 151 deelnemers participeerden in deze lange termijn follow-up (respons $84 \%$ ). Na 4 jaar hadden $57 \%$ van de deelnemers nog steeds last van ernstige vermoeidheid, $27 \%$ voldeden aan de onderzoekscriteria voor CVS en $26 \%$ rapporteerden dat ze in de WAO zaten. Met logistische regressieanalyse werden baseline voorspellers van de verschillende uitkomsten 4 jaar later onderzocht. Voorspellers van vermoeidheid na 4 jaar follow-up waren: verminderde fysiek functioneren op baseline, het hebben van minder psychologische attributies op baseline en een vermindering van fysiek functioneren tussen baseline en 12 maanden follow-up. Voorspellers van een op CVS-gelijkende status waren: vrouwelijke geslacht, verminderde 
fysiek functioneren op baseline en een vermindering van fysiek functioneren tussen baseline en 12 maanden follow-up. Voorspellers van arbeidsongeschiktheid waren: een hogere leeftijd op baseline, verminderde fysiek functioneren op baseline en een vermindering van fysiek functioneren tussen baseline en 12 maanden follow-up. Fysiek (dis)functioneren bleek een belangrijke en consistente voorspeller te zijn. Aanvullende verklarende analyses toonden aan dat de relatie tussen fysiek functioneren aan de ene kant en arbeidsongeschiktheid en een op CVS-gelijkende status aan de andere kant, bijzonder sterk is. Deze studie wijst erop dat fysiek functioneren een belangrijke prognostische factor is in het beloop van vermoeidheidsklachten en arbeidsongeschiktheid onder ernstige vermoeide werknemers die verzuimen. Het analyseren van de temporele relaties tussen vermoeidheid, functionele status en werk status in toekomstig onderzoek zou waardevolle informatie kunnen opleveren om de behandeling van vermoeidheid te verbeteren.

De lange termijn effectiviteit van cognitieve gedragstherapie (CGT) gegeven door huisartsen voor vermoeidheidsklachten wordt onderzocht in hoofdstuk 3. Onze hypothese was dat de interventie mogelijk een verdere verslechtering en terugkeer van vermoeidheidsklachten kan voorkomen alsook een terugval in langdurige ziekteverzuim. $\mathrm{Na}$ 4 jaar follow-up bestond de CGT-groep uit 65 patiënten (11 patiënten vielen uit) en bestond de controlegroep uit 62 patiënten (13 patiënten vielen uit). In beide groepen waren de vermoeidheidsklachten 4 jaar na baseline nog steeds redelijk ernstig. Bovendien was het percentage verzuim en arbeidsongeschiktheid hoog. Longitudinale lineaire regressiemodellen (c.q. "mixed models") toonden aan dat er geen statistisch significante verschil was tussen de groepen met betrekking tot de daling van de vermoeidheidsscore. Causale attributies, met name zwakke somatische attributies en sterke psychologische attributies, lijken geassocieerd te zijn met een afname van vermoeidheidsklachten. Het was opmerkelijk dat er meer verzuim en arbeidsongeschiktheid was onder de patiënten in de CGT-groep dan in de controlegroep, hoewel dit verschil niet statistisch significant bleek. De resultaten lieten zien dat de gesteldheid van de patiënten die deelnamen aan deze studie slechter was dan eerder gedacht. Een mogelijke verklaring voor het niet effectief zijn van de CGT in deze studie zou kunnen zijn dat de uitvoering en intensiteit (vijf tot zeven sessies van 30 minuten) van de interventie door de huisartsen niet overeenkwam met de ernst van de klachten.

Hoofdstuk 4 gaat verder in op de thema van vermoeidheid en werkgerelateerde uitkomsten door zich te richten op de vraag of een op CVS-gelijkende status de toekomstige werkstatus kan voorspellen. Deze studie maakte gebruik van de RCT-populatie en logistische regressieanalyse en vond dat een op CVS-gelijkende status op baseline voorspellend is (na correctie voor verstorende variabelen, c.q. confounders) voor een niet actieve werkstatus (bestaande uit ziekteverzuim, arbeidsongeschiktheid, werkeloosheid en pensioen) en voor volledige arbeidsongeschiktheid, 4 jaar later. Echter, deze associaties waren niet statistisch 
significant na correctie voor fysiek functioneren in de regressiemodellen. Een op CVSgelijkende status bleek een belangrijke voorpeller te zijn van werkstatus, maar het lijkt alsof de component van fysiek (dis)functioneren in deze relatie een belangrijke factor is om ons op te richten. In lijn met de bevindingen van hoofdstuk 3 , onderstreept deze studie de noodzaak van krachtige (vroege) interventies die het vermogen om te werken herstelt of beschermt, met name onder werknemers die voldoen aan criteria voor CVS.

In hoofdstuk 5 wordt de relatie tussen twee vermoeidheidssyndromen, burnout en het chronische vermoeidheidssyndroom (CVS), onderzocht door hun geschiedenis en fenomenologie te onderzoeken door middel van een beschrijvend literatuuronderzoek gebaseerd op literatuur op het gebied van geschiedenis, de sociale wetenschappen en geneeskunde. Burnout en CVS lijken zich grotendeels onafhankelijk van elkaar ontwikkeld te hebben ondanks hun vergelijkbare symptomen. De oorsprong van CVS ligt in de geneeskunde terwijl burnout zich ontwikkelde binnen de psychologie. Naast hun symptomen, delen burnout en CVS ook vergelijkbare thema's zoals een proces van overbelasting dat ziekte teweegbrengt, de behoefte om uitgeputte energiereserves te herstellen, externe attributies en de kenmerken van mensen die deze aandoeningen krijgen. Er werd echter gevonden dat deze thema's geuit worden in óf psychologische óf medische termen, overeenkomend met de respectievelijke achtergronden van burnout en CVS.

De bevindingen van deze studie lieten zien dat de twee concepten nauwelijks rechtstreeks met elkaar vergeleken zijn ondanks hun overeenkomsten. Cultuur, ziektepercepties en verantwoordelijkheid zijn belangrijke kwesties in beide aandoeningen en zouden kunnen bijdragen aan hun verschillen. Het vergelijken van burnout en CVS in een studie in toekomstig onderzoek zou een nuttige eerste stap kunnen zijn om hun relatie beter te begrijpen.

De hoofdstukken 6, 7, 8 en 9 richten zich voornamelijk op het empirisch ontrafelen van de relatie tussen burnout en langdurige vermoeidheid, omdat deze aandoeningen nauwelijks empirisch vergeleken zijn ondanks een aantal overeenkomsten, zoals het belang van vermoeidheidsklachten in beide aandoeningen. In deze studies wordt gebruik gemaakt van de data van de Maastricht Cohort Studie naar Vermoeidheid in de Werksituatie (MCS).

De studie dat gepresenteerd wordt in hoofdstuk 6 had twee doelen: 1) om het discriminerend vermogen van de Checklist Individual Strength (CIS) als een maat voor vermoeidheid en de Maslach Burnout Inventory-General survey (MBI-GS) als een maat voor burnout te onderzoeken en 2) om de overlap en de overeenkomsten en verschillen tussen burnout en langdurige vermoeidheid cases te onderzoeken in termen van gezondheidsfactoren, werkfactoren en demografische factoren. Alle analyses werden uitgevoed op de baseline data van de MCS. 
Een vergelijking van de meetinstrumenten voor burnout en langdurige vermoeidheid, door middel van principale componentenanalyse, liet zien dat ze een redelijk discriminerend vermogen hebben. Langdurige vermoeidheidscases en burnout cases hadden een behoorlijke overlap, $63 \%$ van de burnout cases kon ook geclassificeerd worden als een langdurige vermoeidheidscase en $51 \%$ van de langdurige vermoeidheidscases kon ook geclassificeerd worden als een burnout case. Bovendien was de overlap tussen burnout en langdurige vermoeidheid aan de ene kant en hun voornaamste symptomen uitputting en subjectieve vermoeidheid aan de andere kant ook behoorlijk groot.

De resultaten lieten echter ook zien dat burnout en langdurige vermoeidheid zich ook apart konden voordoen. Subgroepen werden gecreëerd op basis van de burnout status en de langdurige vermoeidheidsstatus op baseline: pure burnout (voldoen aan criteria voor burnout maar niet voor langdurige vermoeidheid), pure vermoeidheid (voldoen aan criteria voor langdurige vermoeidheid maar niet voor burnout), burnout \& vermoeidheid (voldoen aan criteria voor zowel burnout als langdurige vermoeidheid) en geen burnout of vermoeidheid (niet voldoen aan de criteria van zowel burnout als langdurige vermoeidheid). De resultaten toonden aan dat het hebben van beide aandoeningen tegelijkertijd geassocieerd lijkt te zijn met slechtere uitkomsten dan het hebben van alleen langdurige vermoeidheid of alleen burnout, vooral in termen van gezondheidsgerelateerde factoren zoals psychisch onwelbevinden en zelfgerapporteerde algemene gezondheid. Pure vermoeidheid lijkt meer geassocieerd te zijn met gezondheidsgerelateerde factoren terwijl pure burnout meer geassocieerd lijkt te zijn met werkgerelateerde factoren. Deze studie suggereert dat er een aantal relevante verschillen tussen burnout en vermoeidheid met betrekking tot werk en gezondheidsfactoren zijn en dat burnout en vermoeidheid zich zowel tegelijkertijd als apart van elkaar kunnen voordoen.

Het beloop van burnout en langdurige vermoeidheid in termen van klachten en verzuim wordt onderzocht in hoofdstuk 7. Deze studie maakte gebruik van de MCS data die verzameld zijn op baseline en 12, 24 en 48 maanden na baseline. Deze vier metingen waren gebruikt, omdat burnout alleen op deze momenten is gemeten. Deelnemers van wie er informatie was met betrekking tot burnout en langdurige vermoeidheid op alle vier de metingen werden ge ncludeerd. Dit was nodig om het belooptype te kunnen bepalen. Deelnemers werden geclassificeerd in drie subgroepen: "pure vermoeidheid" ( $n=485)$, "pure burnout" $(n=296)$ en "burnout \& vermoeidheid" $(n=426)$. Bovendien werden er binnen de subgroepen vier belooptypes gedefinieerd: chronisch, herstel, terugval en dubbel herstel. De resultaten toonden aan dat de burnout \& vermoeidheidgroep de hoogste proportie (29\%) van het chronische belooptype heeft vergeleken met de pure burnoutgroep (2\%) en de pure vermoeidheidgroep (9\%). Hiernaast had de burnout \& vermoeidheidgroep ook meer verzuim in de loop van de tijd vergeleken met de pure vermoeidheidgroep. Herstel van alle aandoeningen was het hoogst in de pure burnoutgroep (40\%) vergeleken met de pure vermoeidheidgroep (29\%) en de burnout \& 
vermoeidheidgroep (13\%). De bevindingen gaven ook aan dat het beloop van burnout en langdurige vermoeidheid erg dynamisch is. Deze studie toont aan dat het beloop van de burnout \& vermoeidheidgroep behoorlijk slecht is vergeleken met de pure vermoeidheidgroep en de pure burnoutgroep, zowel in termen van aanhoudende burnout en langdurige vermoeidheidsklachten als de prevalentie van verzuim in de loop van de tijd. Bovendien lijkt het beloop van de pure burnoutgroep iets gunstiger te zijn dan die van de pure vermoeidheidgroep vanwege het hoge herstel percentage in de pure burnoutgroep. Deze resultaten suggereren dat de differentiaal diagnose van werknemers met vermoeidheidsklachten belangrijk kan zijn om het beloop van klachten en de noodzaak tot interventie in te schatten.

In hoofdstuk 8 worden prognostische factoren voor het herstel van burnout en langdurige vermoeidheid onderzocht. Data van de baseline, 12, 24 en 48 maanden metingen van de MCS werden gebruikt en 2356 werknemers die voldeden aan de criteria voor burnout en/of langdurige vermoeidheid konden ge n̈cludeerd worden in deze studie. Zij werden verdeeld in drie subgroepen: "pure vermoeidheid", "pure burnout" en "burnout \& vermoeidheid". Logistische "generalised estimating equation" analyse werd gebruikt om baseline voorspellers van herstel, waaronder gezondheidsfactoren, werkfactoren en demografische factoren, te bepalen. Vier prognostische modellen werden bepaald: herstel van vermoeidheid in de pure vermoeidheidgroep, herstel van burnout in de pure burnoutgroep, herstel van ten minste één aandoening (burnout of vermoeidheid) in de burnout \& vermoeidheidgroep en tot slot, herstel van beide aandoeningen (burnout en vermoeidheid) in de burnout \& vermoeidheidgroep. De resultaten lieten zien dat herstel van vermoeidheid in de pure vermoeidheidgroep voorspeld werd door: een lage mate van vermoeidheid, een lage mate van uitputting, een hoge mate van steun door collega's en de afwezigheid van een onbekende vermoeidheidsattributie. Herstel van burnout in de pure burnoutgroep werd voorspeld door: een lage mate van uitputting, een hoge mate van professionele bekwaamheid, de afwezigheid van conflicten met collega's, overdag werken en het hebben van genoeg vrije tijd. Herstel van ten minste één aandoening (burnout of vermoeidheid) in de burnout $\&$ vermoeidheid groep werd voorspeld door: een lage mate van vermoeidheid, een lage mate van uitputting, een hoge mate van professionele bekwaamheid en een goede waargenomen algemene gezondheid. Herstel van zowel burnout als langdurige vermoeidheid (c.q. beide aandoeningen) werd voorspeld door: een lage mate van vermoeidheid, een lage mate van uitputting, het hebben van meer toekomstperspectieven en een goede waargenomen algemene gezondheid. De resultaten doen vermoeden dat het nuttig is om een onderscheid te maken tussen burnout en langdurige vermoeidheid, omdat de focus van interventies voor deze aandoeningen verschillende moet zijn. In het bijzonder lijken werkfactoren belangrijker te zijn voor de prognose van burnout (hoewel het tijdstip van interventie hierbij van belang is, omdat werkfactoren belangrijker waren in de pure burnoutgroep, wanneer symptomen minder ernstig zijn, dan in de burnout \& 
vermoeidheidgroep, wanneer symptomen ernstiger zijn), terwijl gezondheidsfactoren belangrijker lijken te zijn voor de prognose van langdurige vermoeidheid.

Of burnout en langdurige vermoeidheid elkaar in de tijd be n̈vloeden en zo ja, hoe zij elkaar be invloeden (c.q. hun temporele relatie), wordt onderzocht in hoofdstuk 9. Deze studie had drie doelen: om na te gaan of 1) burnout en langdurige vermoeidheid elkaar in de tijd voorspellen, 2) er een dosis-respons relatie is en 3) ze elkaar afwisselen of samengaan in de tijd. Prospectieve data van de MCS die verzameld zijn in de loop van vier jaar werden gebruikt voor deze studie. Na selectie konden 11,710 deelnemers ge ncludeerd worden. Burnout op baseline was gerelateerd aan een verhoogd risico op toekomstige langdurige vermoeidheid (hazard ratio (HR) 1.33, 95\% betrouwbaarheidsinterval 1.16-1.53) en langdurige vermoeidheid op baseline was geassocieerd met een verhoogd risico op toekomstige burnout (HR 1.65, 95\% betrouwbaarheidsinterval 1.44-1.89). Er leek ook sprake te zijn van een (wederkerige) dosis-respons relatie, want het risico op het ontwikkelen van burnout nam toe naarmate het baseline niveau van subjectieve vermoeidheid (kernsymptoom van langdurige vermoeidheid) toenam en het risico op het ontwikkelen van langdurige vermoeidheid nam toe naar mate het baseline niveau van uitputting (kernsymptoom van burnout) toenam. Tot slot werd er gevonden dat wanneer burnout en langdurige vermoeidheid elkaar be nuvloeden, zij geneigd zijn om samen te gaan in plaats van elkaar af te wisselen. De bevindingen lijken erop te wijzen dat burnout en langdurige vermoeidheid elkaar be n̈vloeden bij wijze van een neerwaartse spiraal. Hierdoor lijkt het belangrijk om vermoeidheidsklachten in een vroeg stadium te herkennen en correct te identificeren, omdat vroegtijdige interventie mogelijk kan voorkómen dat deze aandoeningen tegelijk optreden, hetgeen een slechtere uitkomst kan afwenden.

In hoofdstuk 10, de discussie, zijn de belangrijkste doelen om de bevindingen van het proefschrift samen te vatten en te integreren, om een aantal methodologische aspecten te overwegen en om suggesties te doen voor klinische implicaties en toekomstig onderzoek. De bevindingen worden ge nterpreteerd vanuit drie verschillende, maar gerelateerde, invalshoeken.

Vanuit het perspectief van het ontwarren van verschillende uitingsvormen van vermoeidheid, kan geconcludeerd worden dat burnout en langdurige vermoeidheid op een bepaald moment onderscheiden kunnen worden in termen van hun kenmerken, hun beloop en hun prognose. Dit impliceert dat het correct identificeren van vermoeidheidsklachten belangrijk is. Gezondheidsfactoren waren bijvoorbeeld vooral geassocieerd met (milde) langdurige vermoeidheid terwijl werkgerelateerde factoren vooral geassocieerd waren met (milde) burnout. Bovendien kan geconcludeerd worden dat het samen voorkomen van burnout en langdurige vermoeidheid geassocieerd is met ongunstigere uikomsten. Dit onderstreept het belang van het stadium of de ernst van de aandoeningen bij het bestuderen van het beloop van vermoeidheid. Het interpreteren van 
de bevindingen vanuit het perspectief van de ernst van de klachten voegt aan deze conclusies toe dat ernstige klachten een slechte prognose hebben en erg hardnekkig zijn. Ernstige klachten zijn ook geneigd om onlosmakelijk verbonden te zijn aan comorbiditeit, vooral met betrekking tot burnout en langdurige vermoeidheid en dit kan interveniëren lastig en gecompliceerd maken. Bovendien moet de focus van de interventie mogelijk anders zijn voor verschillende stadia van ernst binnen dezelfde aandoeningen, aangezien de resultaten lieten zien dat werkfactoren belangrijk waren voor de prognose van milde burnout klachten. Wanneer burnout ernstiger werd en er comorbiditeit optrad, waren werkfactoren niet meer zo belangrijk. Ten slotte, vanuit het perspectief van werkstatus, geven de resultaten aan dat ernstige klachten geassocieerd zijn met meer verzuim en arbeidsongeschiktheid. Vanwege het feit dat verzuim niet zo prevalent was bij milde klachten, kan het zijn dat het voorkomen dat milde klachten ernstig worden ook een positieve invloed heeft op werkstatus. Tevens, bleek ziekteverzuim niet een specifieke prognostische factor te zijn in het beloop van vermoeidheidsklachten, maar verder onderzoek hiernaar kan mogelijk wat meer licht werpen op deze relatie. Hoofdstuk 10 eindigt met een aantal praktische implicaties en voorstellen voor toekomstig onderzoek. De bevindingen suggereren bijvoorbeeld dat de aard van de interventies anders moet zijn voor de verschillende subgroepen van burnout en langdurige vermoeidheid en dat de timing van de interventie bijzonder belangrijk is, zeker met het oog op de bevinding dat het tegelijk optreden van aandoeningen geassocieerd is met slechtere uitkomsten. Er wordt ook betoogd dat de bevindingen van hoofdstuk 5, over de geschiedenis en fenomenologie van burnout en CVS, een interessante perspectief biedt voor toekomstig onderzoek, vooral omdat culturele factoren samen met labelling en ziekteattributies belangrijk zouden kunnen zijn in het onderscheid tussen CVS en burnout. Dit roept vragen op als: Hoe be hvloeden verschillende arbeidsgerelateerde gezondheidszorgsystemen de ontwikkeling, erkenning en behandeling van symptomen? Hoe acceptabel zijn psychologische of somatische labels in een bepaalde cultuur? Worden dezelfde symptomen anders gelabeld in verschillende landen? Tot slot concluderen we dat er nog steeds vele vragen zijn die beantwoord moeten worden, maar dat onze resultaten hopelijk een kleine bijdrage leveren aan onze kennis van vermoeidheid. 


\section{Dankwoord}

Op deze plek wil ik graag alle mensen bedanken die op de een of andere manier hebben bijgedragen aan dit proefschrift, want hoe cliché het ook klinkt, ik heb het zeker niet in mijn eentje gedaan! Een aantal mensen wil ik in het bijzonder noemen.

Op de eerste plaats wil ik mijn projectgroep bedanken voor de fijne begeleiding en samenwerking. Ik heb de totstandkoming van dit proefschrift echt als een "team effort" ervaren en vind het eigenlijk toch wel een beetje vreemd dat het nu gelabeld wordt als "mijn proefschrift".

IJmert, je deur stond letterlijk altijd open en ik kon altijd binnenvallen met wat dan ook. Ik ben je erg dankbaar voor alle (ontwikkelings)mogelijkheden die je hebt gecreëerd en je betrokkenheid en steun op zowel werk-als privégebied (zoals je weet zijn ze soms onlosmakelijk met elkaar verbonden!). Ik heb ontzettend veel van je geleerd en vond het heel fijn om met je samen te mogen werken, IJmert, bedankt voor alles dat je voor me hebt gedaan en eigenlijk (nu via de telefoon) nog steeds doet!

Marcus, met jouw boekje in de hand ("de bijbel") ben ik begonnen aan dit onderzoeksavontuur. Stiekem werd het toch mijn streven om net zo'n mooi boekje te schrijven. Gelukkig heb ik dan ook van dichtbij jouw gedrevenheid, expertise en talent voor onderzoek (en schrijven!) mogen meemaken en heb ik daar een graantje van mee kunnen pikken om dat doel enigszins te kunnen nastreven. Ik heb je begeleiding, kritische blik en (snelle!) feedback als zeer waardevol ervaren en heb enorm veel van je geleerd. Thanks!

André, met je overkoepelende blik op het project bracht je de soms nodige rust en structuur aan. Ik wil je bedanken voor de fijne begeleiding, de voortgangsbewaking van het project, je kritische blik en de waardevolle feedback op de artikelen.

Mijn collega's van arbeidsepi: Nicole, Danielle, Ludo, Jos, Nathalie, Renee, Petra en Karin, wil ik bedanken voor al hun hulp, steun en interesse. Ik heb het heel erg gewaardeerd dat de deur altijd openstond en dat ik altijd bij jullie terecht kon als ik een vraag had. Bedankt! Natuurlijk wil ik ook de arbeidsepi aio's bedanken: Saskia, Lore, Monique en Karolien. Sas, jij was een van de eerste mensen met wie ik in contact kwam toen ik begon bij epidemiologie en ik vond het fijn dat we altijd bij elkaar neer konden ploffen in "de stoel". Het leuke is dat we dat nog steeds gewoon doen, maar dan in "het westen" (of is het nou "het noorden"?). Bedankt dat je mijn paranimf wilt zijn! Lore, mijn kamergenootje, bedankt voor al je hulp, steun, geduld en vooral bedankt voor je luisterend oor! We hebben samen veel gelachen, een beetje gehuild, veel gekletst en, nu ik er op terugkijk, eigenlijk ook best veel thee samen gedronken getuige de grote selectie theezakjes die we altijd op de kamer hadden! Net zoals jij ben ik ook blij dat we samen onze "Everest" konden beklimmen (hoewel....jij geniet nu van het uitzicht, maar ik kom eraan!). Ik heb nu een kamer helemaal voor mij alleen, maar ik zou het zo weer met je delen! Monique en Karolien, bedankt voor 
de steun, interesse en vooral de gezelligheid. Ik kijk er naar uit om jullie boekjes te mogen ontvangen!

Al mijn collega's en mede aio's bij de afdeling epidemiologie wil ik ontzettend graag bedanken voor hun hulp, betrokkenheid en interesse. Ik heb een fijne tijd gehad en zal alle gezellige uitjes en borrels zeker missen! Een speciaal woord van dank gaat uit naar Yvonne Leenders voor al haar hulp bij de lay-out van dit proefschrift. Ook wil ik graag Jos Bruystens bedanken voor al zijn hulp bij het drukklaar maken van het proefschrift.

De deelnemers aan de RCT wil ik graag bedanken voor de moeite die zij hebben genomen om (weer) een vragenlijst in te vullen zo lang na de interventieperiode. Math Reintjens wil ik bedanken voor het invoeren van de gegevens van deze vragenlijsten en ik wil Karin Aretz bedanken voor haar hulp bij het opschonen van deze gegevens.

I would like to thank everyone I met during my stay at the Institute of Psychiatry. In particular, I would like to thank Simon Wessely for sharing his time and expertise on fatigue and its history. I learned a lot from our meetings and I thank you for your valuable contribution to the paper that we worked on. I would also like to thank Matthew Hotopf and "Team Hotopf", especially Max Henderson, Sam Harvey, and of course Maria Verdecchia and Stephani Hatch ("the chicks") for all their help, hospitality, enthusiasm and willingness to share their ideas and knowledge.

Mijn familie, schoonfamilie en vrienden wil ik bedanken voor al hun steun, betrokkenheid en interesse. It means the world to me. Carla, bedankt dat je mijn paranimf wilt zijn!

Milad, bedankt dat je altijd voor me klaarstaat en bedankt voor alle steun, geduld en begrip (en natuurlijk ook voor de kaft en de tabellen ;-)), num nu!

Nogmaals, iedereen bedankt!

Lots of love,

Stephanie 


\section{About the author}

Stephanie Leone was born on June 25, 1980 in Stone (Great Britain). In 1999, she started a course in Psychology at Leiden University which she completed in 2004, resulting in a master's degree in Psychology (specialisation Clinical and Health Psychology). From June 2004 until August 2008 she worked as a PhD student at the Department of Epidemiology of Maastricht University, on a project that aimed to examine the course and different manifestations of fatigue in the working population which resulted in the present thesis. During her period as a PhD student she completed a master's degree in epidemiology.

Stephanie currently works as a researcher at a mental healthcare organisation in The Hague, The Netherlands. 


\section{List of publications}

Leone SS, Huibers MJH, Kant IJ, Van Amelsvoort LGPM, Van Schayck CP, Bleijenberg G, Knottnerus JA. Long-term efficacy of cognitive-behavioural therapy by general practitioners for fatigue: A 4-year follow-up study. Journal of Psychosomatic Research 2006; 61: 601-7.

Leone SS, Huibers MJH, Kant IJ, Van Schayck CP, Bleijenberg G, Knottnerus JA. Long-term predictors of outcome in fatigued employees on sick leave: A 4-year follow-up study. Psychological Medicine 2006; 36: 1293-1300.

Huibers MJH, Leone SS, Kant IJ, Knottnerus JA. Chronic fatigue syndrome-like caseness as a predictor of work status in fatigued employees on sick leave:

A 4-year follow-up study. Occupational and Environmental Medicine 2006;63: 570-72.

Huibers MJH, Leone SS, Van Amelsvoort LGPM, Kant IJ, Knottnerus JA. Associations of fatigue and depression among fatigued employees over time: A 4-year follow-up study. Journal of Psychosomatic Research 2007; 63:137-42.

Leone SS, Huibers MJH, Knottnerus, JA, Kant IJ. Similarities, overlap and differences between burnout and prolonged fatigue in the working population. Quarterly Journal of Medicine 2007; 100:617-27.

Leone SS, Huibers MJH, Knottnerus, JA, Kant IJ. A comparison of the course of burnout and prolonged fatigue: A 4-year prospective cohort study. Journal of Psychosomatic Research 2008; 65: 31-8.

Leone SS, Huibers MJH, Knottnerus, JA, Kant IJ. The prognosis of burnout and prolonged fatigue in the working population: A comparison. Journal of Occupational and Environmental Medicine 2008; 50:1195-202.

\section{Submitted manuscripts}

Leone SS, Wessely S, Huibers MJH, Knottnerus JA, Kant IJ. Two sides of the same coin? On the history and phenomenology of burnout and chronic fatigue. Submitted

Leone SS, Huibers MJH, Knottnerus, JA, Kant IJ. The temporal relationship between burnout and prolonged fatigue: A 4-year prospective cohort study. Submitted. 